This document was prepared in conjunction with work accomplished under Contract No. DE-AC09-96SR18500 with the U. S. Department of Energy.

\title{
DISCLAIMER
}

This report was prepared as an account of work sponsored by an agency of the United States Government. Neither the United States Government nor any agency thereof, nor any of their employees, nor any of their contractors, subcontractors or their employees, makes any warranty, express or implied, or assumes any legal liability or responsibility for the accuracy, completeness, or any third party's use or the results of such use of any information, apparatus, product, or process disclosed, or represents that its use would not infringe privately owned rights. Reference herein to any specific commercial product, process, or service by trade name, trademark, manufacturer, or otherwise, does not necessarily constitute or imply its endorsement, recommendation, or favoring by the United States Government or any agency thereof or its contractors or subcontractors. The views and opinions of authors expressed herein do not necessarily state or reflect those of the United States Government or any agency thereof. 
Key Words:

Monitored Natural Attenuation Availability, D-Area, Arsenic, Beryllium, Nickel, Uranium, Distribution Coefficient

Retention:

Permanent

\section{MONITORED NATURAL ATTENUATION OF INORGANIC CONTAMINANTS TREATABILITY STUDY FINAL REPORT}

Waste Treatment Technology

Kimberly Powell Crapse, Steven M. Serkiz, and Adrian Pishko

Environmental Sciences and Technology

Pamela C. McKinsey, Robin L. Brigmon, Eugene P. Shine, Carl Fliermans, and Anna S. Knox

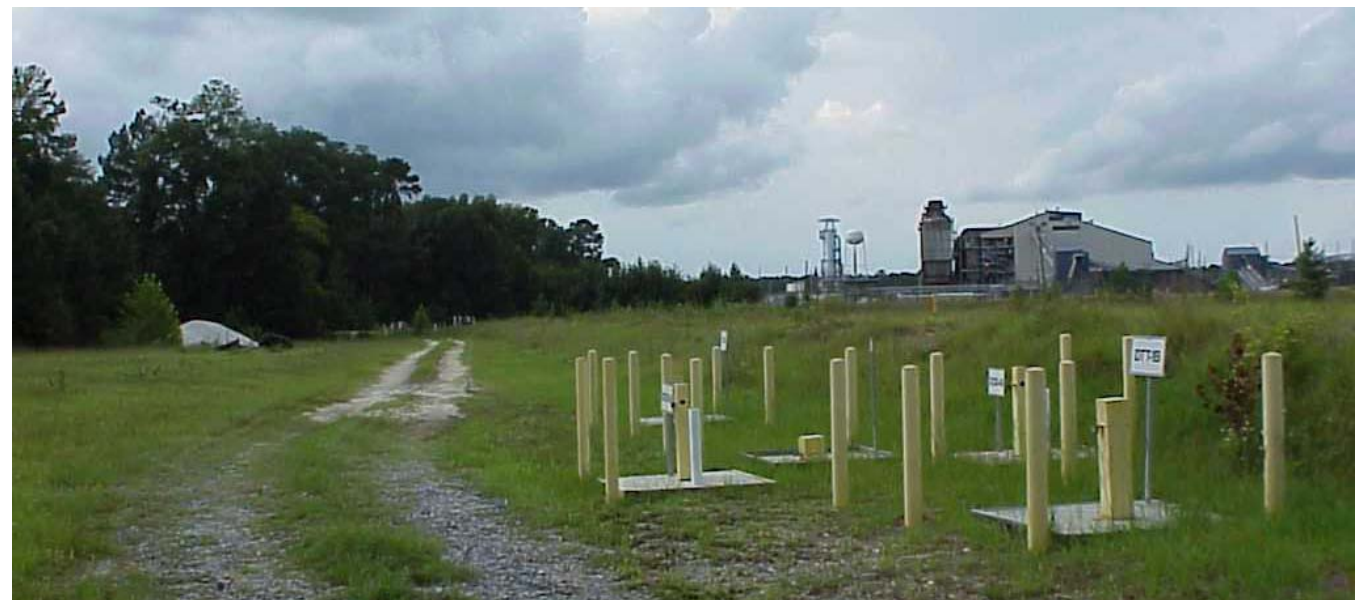

MAY 19, 2004

Westinghouse Savannah River Company

Savannah River Site

Aiken, SC 29808

Prepared for the U.S. Department of Energy Under

Contract Number DE-AC09-96SR18500 


\section{DISCLAIMER}

This report was prepared for the United States Department of Energy under Contract No. DE-AC09-96SR18500 and is an account of work performed under that contract. Neither the United States Department of Energy, nor WSRC, nor any of their employees makes any warranty, expressed or implied, or assumes any legal liability or responsibility for accuracy, completeness, or usefulness, of any information, apparatus, or product or process disclosed herein or represents that its use will not infringe privately owned rights. Reference herein to any specific commercial product, process, or service by trade name, trademark, name, manufacturer or otherwise does not necessarily constitute or imply endorsement, recommendation, or favoring of same by Westinghouse Savannah River Company or by the United States Government or any agency thereof. The views and opinions of the authors expressed herein do not necessarily state or reflect those of the United States Government or any agency thereof.

Printed in the United States of America

Prepared For

U.S. Department of Energy 
Key Words:

Monitored Natural Attenuation Availability, D-Area, Arsenic, Beryllium, Nickel, Uranium Distribution Coefficient

\section{Retention:}

Permanent

\section{MONITORED NATURAL ATTENUATION OF INORGANIC CONTAMINANTS TREATABILITY STUDY FINAL REPORT}

Waste Treatment Technology

Kimberly Powell Crapse, Steven M. Serkiz, and Adrian Pishko

Environmental Sciences and Technology

Pamela C. McKinsey, Robin L. Brigmon, Eugene P. Shine, Carl Fliermans, and Anna S. Knox

MAY 19, 2004

Westinghouse Savannah River Company

Savannah River Site

Aiken, SC 29808

Prepared for the U.S. Department of Energy Under

Contract Number DE-AC09-96SR18500 
WSRC-TR-2004-00124, REVISION 0

REVIEWS AND APPROVALS
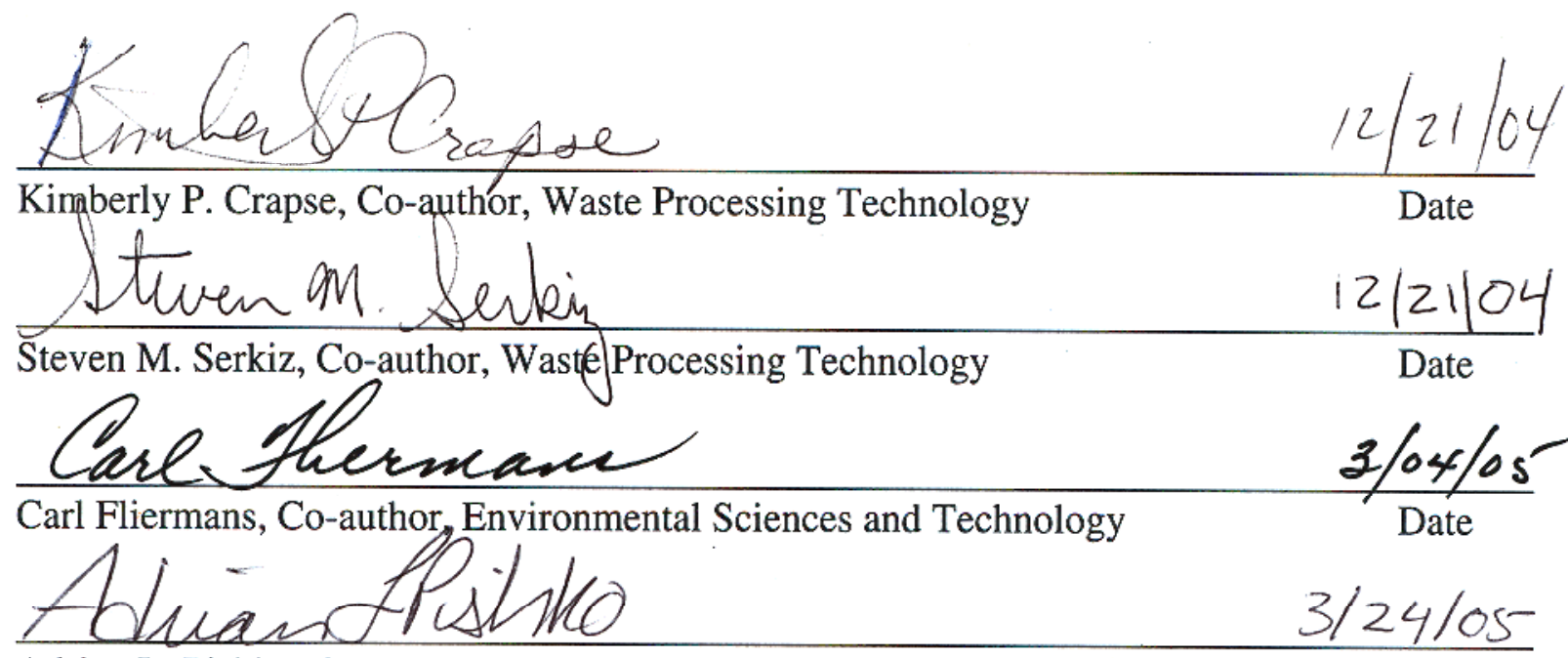

Adrian L. Pishko, Co-author, Waste Processing Technology

Date
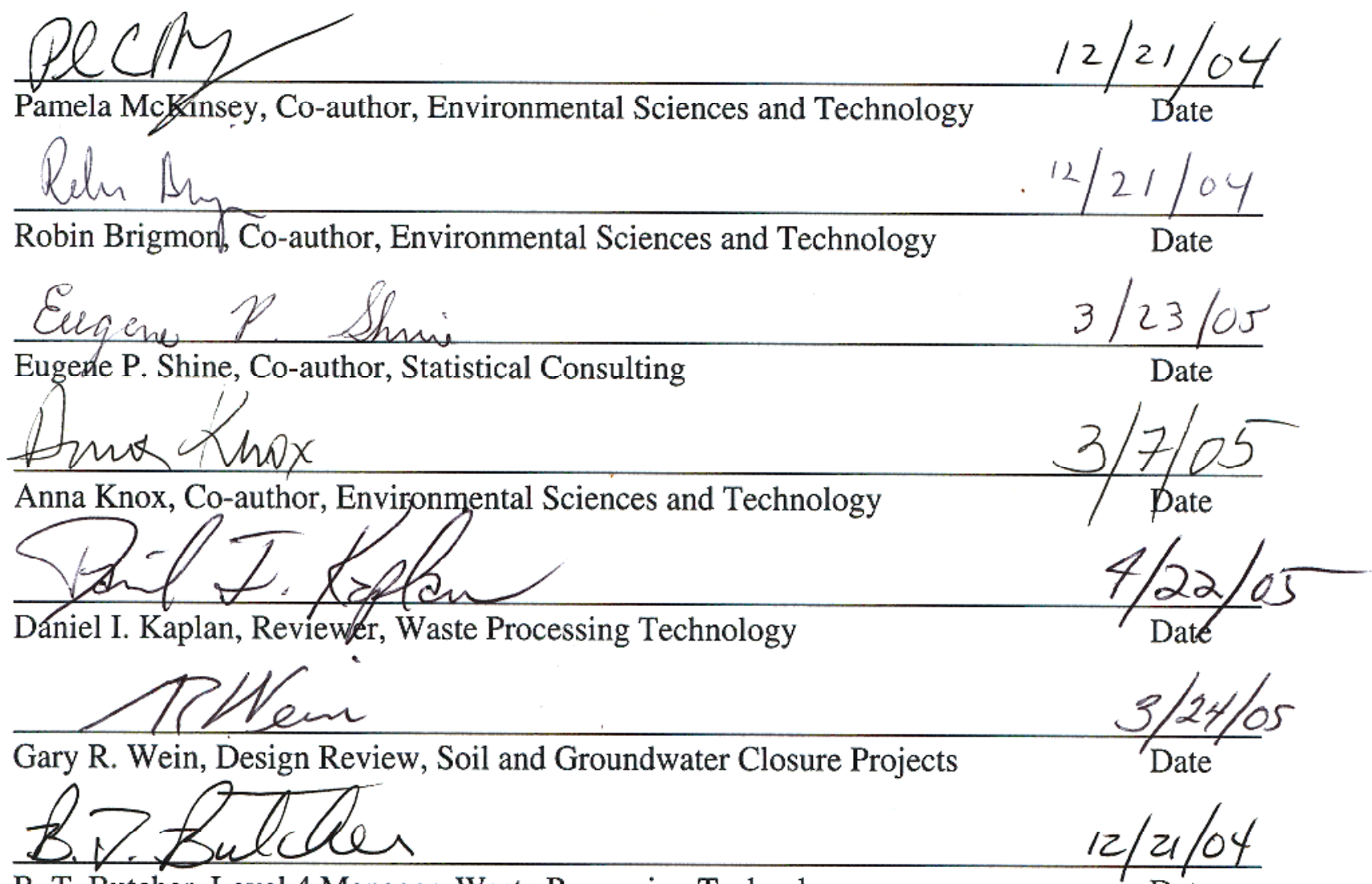

B. T. Butcher, Level 4 Manager, Waste Processing Technology

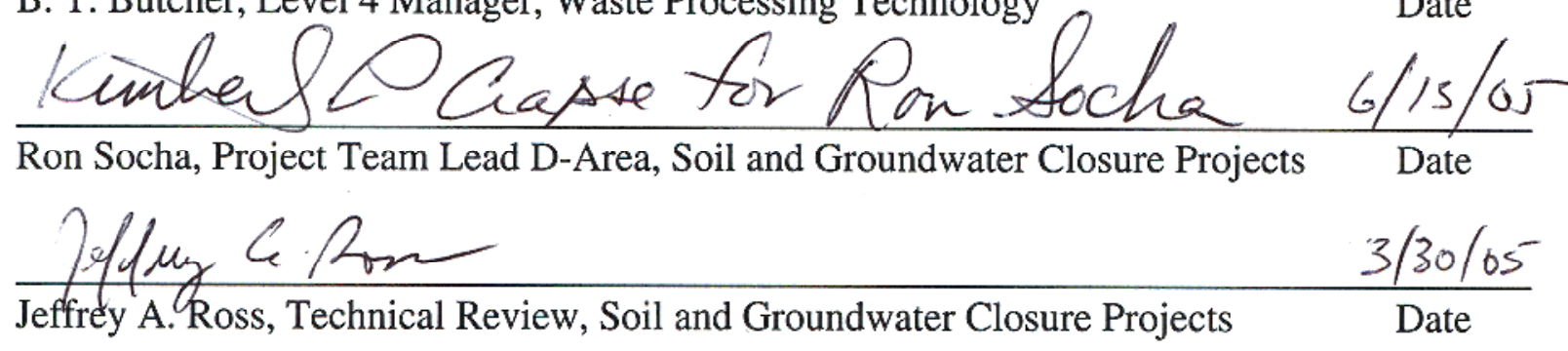

- ii - 


\section{TABLE OF CONTENTS}

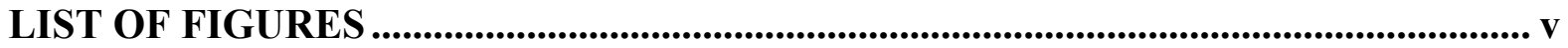

LIST OF TABLES ........................................................................................................... vii

LIST OF ACRONYMS .............................................................................................................. ix

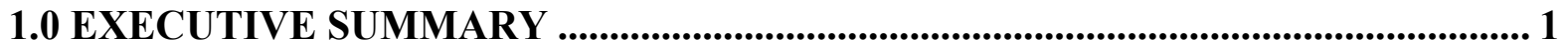

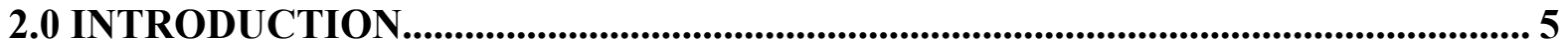

2.1 INORGANIC MONITORED NATURAL ATTENUATION OVERVIEW............5 5

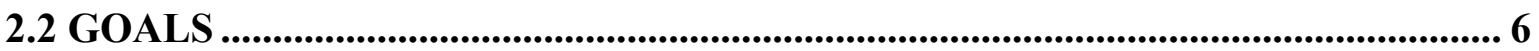

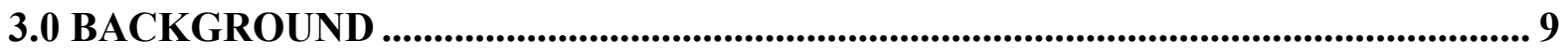

3.1 Site Description ................................................................................................................... 9

3.1.1 D-Area Coal Pile (DCP) and D-Area Coal Pile Runoff Basin (DCPRB) ........... 9

3.1.2 D-Area Ash Basin (DAB) (488-D and 488-4D) ..................................................... 12

3.1.3 D-Area Wetland.......................................................................................................... 12

3.1.4 D-Area Rubble Pit (DRP) ..................................................................................... 12

3.1.5 D-Area Hydrogeology ........................................................................................... 12

3.1.6 Low pH/Metals/Sulfate Plumes..................................................................................... 14

3.2 Conceptual Model of Natural Attenuation at D-Area.................................................. 15

3.3 Metal AVAILABILITY ................................................................................................ 15

3.3.1 Estimation of the Source Term ............................................................................... 15

3.3.2 Distribution Coefficients........................................................................................ 16

3.4 Natural Attenuation Mechanisms .................................................................... 17

3.4.1 Dilution and Dispersion ................................................................................... 17

3.4.2 Geochemical mechanisms .......................................................................................... 17

3.4.3 Geochemical Parameters ............................................................................................... 18

3.4.4 Microbiological mechanisms ................................................................................. 19

3.4.5 Microbiological Parameters ........................................................................................... 20

4.0 METHODS AND SITE DESCRIPTION.................................................................... 21

4.1 SAMPLING .......................................................................................................................... 21

4.1.1 Upland Samples .............................................................................................................. 21

4.1.2 Wetland Samples ..................................................................................................... 22

4.2 GEOCHEMICAL ANALYSES ...................................................................................... 23

4.2.1 Porewater Analyses ........................................................................................................ 23

4.2.2 Soil Digestion Methods............................................................................................... 24

4.2.3 Sources of Analytical Error.................................................................................... 25

4.2.4 Characterization of Soil Properties ......................................................................... 26

4.3 MICROBIOLOGICAL MATERIALS AND METHODS ......................................... 27

4.3.1 Bacteria Densities ............................................................................................................. 27

4.3.2 Total Counts.................................................................................................................... 27

4.3.3 Viable Counts...................................................................................................... 27

4.3.4 Bacteria Identification .................................................................................................. 28

4.3.5 Tests for Bacteria by Metabolic Function ............................................................ 28

4.3.6 Ecofunctional Enzyme Activity................................................................................... 28

4.3.7 Microbial Buffering Activity .................................................................................... 28

5.0 RESULTS 29

5.1 GEOCHEMICAL CHARACTERIZATION........................................................... 29

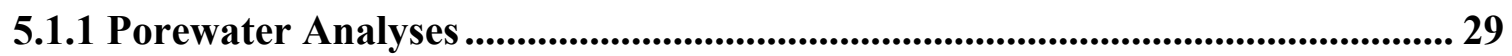

5.1.2 Soil Properties for DAB and DCP Samples ......................................................... 45 


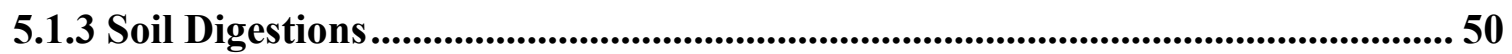

5.2 MICROBIOLOGICAL CHARACTERIZATION.....................................................60

5.3 MICROBIOLOGICAL FUNCTION ........................................................................ 79

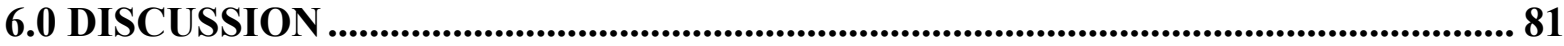

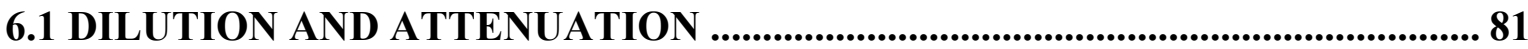

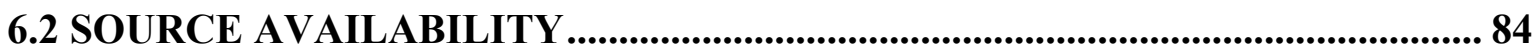

6.2.1 pH, Redox, and Sulfate .............................................................................................. 84

6.2.2 Major Ions in porewater................................................................................................ 89

6.2.3 Trace Metals in porewater ................................................................................ 91

6.2.4 Available Fraction ....................................................................................................... 96

6.3 TRANSPORT FACTORS ....................................................................................... 98

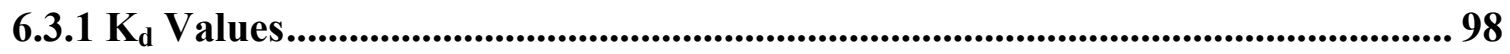

6.4 MICROBIOLOGY ......................................................................................................... 104

6.4.1 Microbial densities ....................................................................................... 104

6.4.2 Ecofunctional Enzymes................................................................................................ 105

6.4.3 Identification of Cultured Isolates .......................................................................... 106

7.0 SUMMARY AND CONCLUSIONS ................................................................................ 107

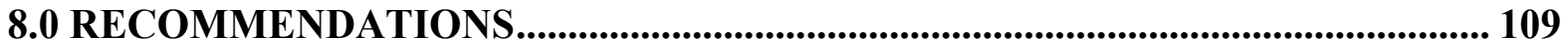

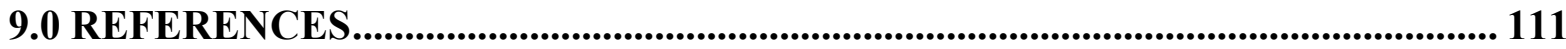

APPENDIX A. SEQUENTIAL EXTRACTION PROCEDURE ................................ 115

APPENDIX B. SEQUENTIAL EXTRACTION DATA................................................... 123

APPENDIX C. AMORPHOUS OXIDE SINGLE STEP EXTRACTION RESULTS

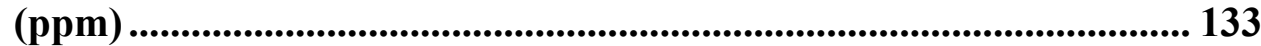

APPENDIX D. NOTES ON DISCRIMINANT ANALYSIS BY REGION ON THE

BASIS OF BIOLOG $^{\circledR}$ TESTING OF SOIL SLURRIES .................... 135

APPENDIX E. D-AREA TREATABILITY STUDY WORK PLAN CROSSWALK 149 


\section{LIST OF FIGURES}

Figure 1. D-Area Map with Sampling Locations. 10

Figure 2. D-Area Site Map with groundwater contaminant plumes for beryllium from

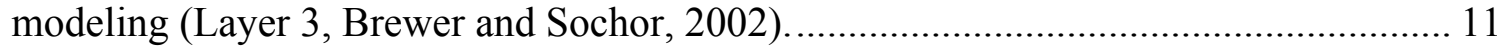

Figure 3. Aerial Photographs Showing Before (1956) and After (1977) Ash-Sluice

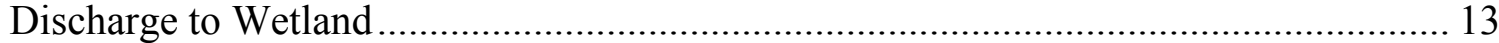

Figure 4. D-Area Expanded Operable Unit Plume Paths ................................................. 37

Figure 5. D-Area Expanded Operable Unit Cross Section B-B' - Porewater pH................ 38

Figure 6. D-Area Expanded Operable Unit Cross Section $\mathrm{A}-\mathrm{A}^{\prime}-$ Porewater $\mathrm{pH}$................ 39

Figure 7. D-Area Expanded Operable Unit Cross Section B-B' - Porewater $E_{h}$ v SHE (mV)

Figure 8. D-Area Expanded Operable Unit Cross Section A-A'- Porewater E $\mathrm{h}$ v SHE (mV)

Figure 9. Area Expanded Operable Unit Cross Section B-B' - Porewater Sulfate (ppm).... 42

Figure 10. D-Area Expanded Operable Unit Cross Section A-A' - Porewater Sulfate (ppm)

Figure 11. Correlation between measured cation exchange capacity and percent clay in

upland soil samples .................................................................................... 48

Figure 12. Correlation between measured cation exchange capacity and clay + silt in upland

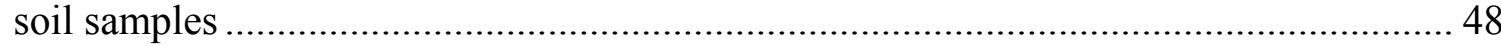

Figure 13. Soil Anion Exchange Capacity vs. Soil Clay Content and Clay + Silt ............. 49

Figure 14. Correlation between measured cation exchange capacity and total iron

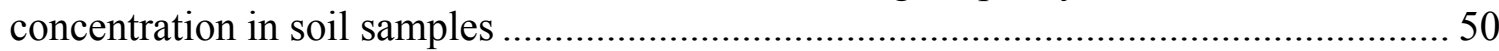

Figure 15. D-Area Expanded Operable Unit Key Plan-Cross Section C-C'-Biological data

Figure 16. D-Area Expanded Operable Unit Cross Section C-C'-Total Direct Counts....... 69

Figure 17. D-Area Expanded Operable Unit Cross Section C-C'-Viable Counts ................ 70

Figure 18. D-Area Expanded Operable Unit Cross Section C-C'-Substrate Utilization by

Biolog $\AA$

Figure 19. Microbiological Data for Wetland Locations.............................................. 72

Figure 20. Plot of pH, Sulfate, and Direct Counts Ordered by Direct Counts..................... 73

Figure 21. Plot of $\mathrm{pH}$, Sulfate, and Direct Counts Ordered by $\mathrm{pH}$.................................... 73

Figure 22. Plot of $\mathrm{pH}$, Sulfate, and 1\% PTYG ( $\mathrm{pH} 5.0)$ Ordered by $\mathrm{pH}$ [less-than detect

$1 \%$ PTYG (values=25) are plotted without coloring in the diamond] ........................... 74

Figure 23. $\mathrm{pH}$, Sulfate (ppm), and Percent Response for All Carbon Sources (Ordered by

Sulfate) .......................................................................................................... 74

Figure 24. Overlay Plot of Percent of Total for all Biolog ${ }^{\circledR}$ Sources by Sample Location .. 75

Figure 25. Posterior Probability that the Microbial Structure as Defined by the Biolog ${ }^{\circledR}$

Assays Belongs to the "Upland Region" Class (Based on a Training Set of the Original

15 DAB and 6 Wetland Sampling Locations)............................................................... 76

Figure 26. Comparison of Substrate Utilization Data from Biolog ${ }^{\circledR}$ with Porewater

Concentrations of COCs (Be, Ni, U, As) and Sulfate ........................................... 77

Figure 27. Porewater concentrations of COCs in D-Area (most impacted by DCPRB (right)

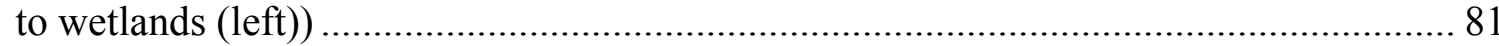

Figure 28. Porewater $\mathrm{pH}$, Sulfate, and Eh values for DAB Upland and Wetland Locations 82

Figure 29. D-Area Coal Pile Runoff Basin plume under 488-D and 488-4D (Layer 3). No

sorption model with $100 \mathrm{ppb}$ line source loaded in the vicinity of DAB $924-6 \ldots \ldots \ldots . . .85$ 
Figure 30. D-Area Coal Pile Runoff Basin plume under 488-D and 488-4D (Layer 4). No sorption model with $100 \mathrm{ppb}$ line source loaded in the vicinity of DAB 92 4-6.......... 86

Figure 31. Plot of Redox Potential $\left(\mathrm{E}_{\mathrm{h}}\right)$ versus $\mathrm{pH}$ for All Porewater Samples.................. 88

Figure 32. $\mathrm{pH}$ versus Sulfate Concentration in Porewater for All Locations ..................... 88

Figure 33. Aluminum Concentration in Porewater as a Function of $\mathrm{pH}$ (log scale) ........... 89

Figure 34. Iron Concentration in Porewater as a Function of $\mathrm{pH}(\log$ scale $)$..................... 90

Figure 35. Manganese Concentration in Porewater as a Function of $\mathrm{pH}$ (log scale)........... 90

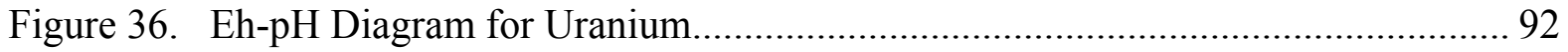

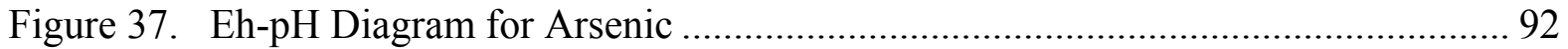

Figure 38. Beryllium Concentration in Porewater as a Function of $\mathrm{pH}$ (log scale)............ 93

Figure 39. Nickel Concentration in Porewater as a Function of $\mathrm{pH}$ (log scale) ................. 93

Figure 40. Uranium Concentration in Porewater as a Function of $\mathrm{pH}$ (log scale) (Data DCP locations not available) (Top - all measured data; Bottom - only data below pH 5.5) .... 94

Figure 41. Arsenic Concentration in Porewater as a Function of $\mathrm{pH}$ (log scale) (Top - all measured data; Bottom - only DAB data below pH 7) ............................................... 95

Figure 42. Beryllium Distribution Coefficients (mL/g; Based on Available Beryllium Sediment Concentrations) versus $\mathrm{pH}$ (log scale) 102

Figure 43. Nickel Distribution Coefficients (mL/g; Based on Available Nickel Sediment Concentrations) versus $\mathrm{pH}$ (log scale) 102

Figure 44. Uranium Distribution Coefficients $(\mathrm{mL} / \mathrm{g}$; Based on Available Uranium

Sediment Concentrations) versus $\mathrm{pH}$ (log scale) 103

Figure 45. Arsenic Distribution Coefficients (mL/g; Based on Available Arsenic Sediment Concentrations) versus $\mathrm{pH}$ for all locations (log scale) 103 


\section{LIST OF TABLES}

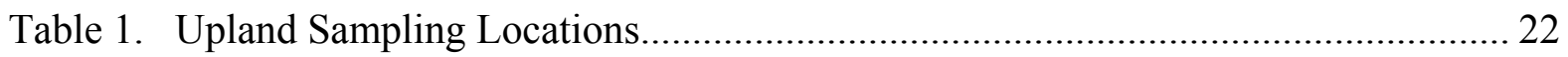

Table 2. Wetland Sampling Locations .................................................................................. 23

Table 3. Description of Sequential Extraction Procedure Steps ............................................ 24

Table 4. Porewater Concentrations for Major Ions (Al, Fe, Mn) for DAB Locations........... 31

Table 5. Porewater Concentrations for Major Ions (Al, Fe, Mn) for DCP Locations ........... 32

Table 6. Porewater Concentrations for Major Ions (Al, Fe, Mn) for Wetland Locations .... 33

Table 7. Porewater Concentrations for Trace Elements (Be, Ni, U, As) for DAB Locations

Table 8. Porewater Concentrations for Trace Elements (Be, Ni, U, As) for DCP Locations 35

Table 9. Porewater Concentrations for Trace Elements at Wetland Locations (ppb) .......... 36

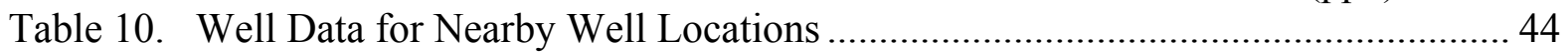

Table 11. General Properties of Upland and Wetland Soil Samples ..................................... 46

Table 12. Measured Cation and Anion Exchange Capacity .................................................... 47

Table 13. Beryllium Concentration (ppm) in Upland Soil ................................................. 53

Table 14. Beryllium Soil Concentration (ppm) in Wetland Soil ...........................................5 53

Table 15. Nickel Concentration (ppm) in Upland Soil ....................................................... 54

Table 16. Nickel Soil Concentration (ppm) in Wetland Soil................................................ 54

Table 17. Uranium Concentration (ppm) in Upland Soil ................................................... 55

Table 18. Uranium Soil Concentration (ppm) in Wetland Soil ............................................ 55

Table 19. Arsenic Concentration (ppm) in Upland Soil .................................................... 56

Table 20. Arsenic Soil Concentration (ppm) in Wetland Samples........................................ 56

Table 21. Selenium Soil Concentration (ppm) in Wetland Samples ..................................... 57

Table 22. Vanadium Soil Concentration (ppm) in Wetland Samples................................... 57

Table 23. Iron Concentration ( $\mathrm{ppm}$ ) in Upland Soil ......................................................... 58

Table 24. Iron Soil Concentration (ppm) in Wetland Samples............................................. 58

Table 25. Aluminum Concentration (ppm) in Upland Soil .................................................. 59

Table 26. Aluminum Soil Concentration (ppm) in Wetland Samples ................................... 59

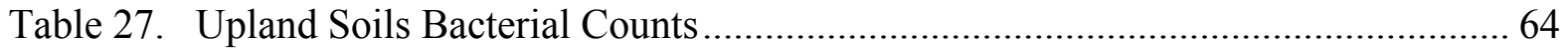

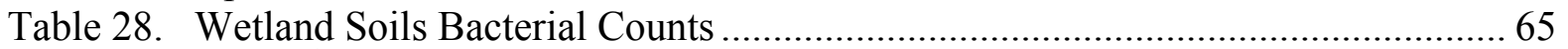

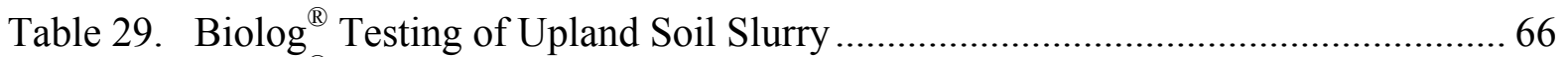

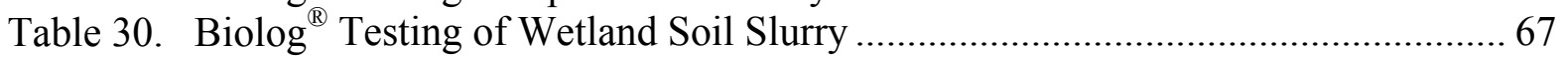

Table 31. Buffering Capacity of Biolog ${ }^{\circledR}$ GN Microplates................................................... 78

Table 32. Identification of Bacteria in Samples DAB 83 and DAB 84 …………….......... 78

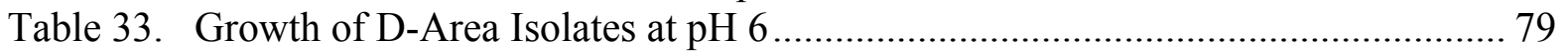

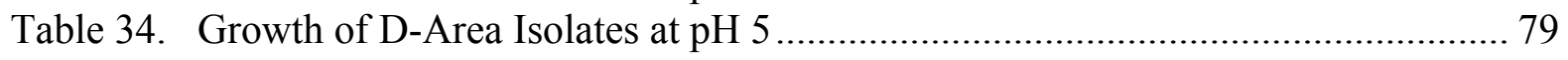

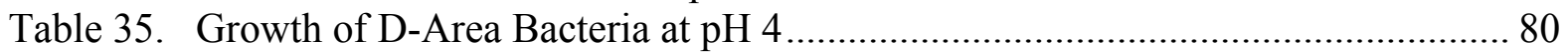

Table 36. Dilution Attenuation Factors from Field Data near DCPRB and DAB ............... 84

Table 37. Summary of Trace Metal Availability ( $\%$ available $=$ available/total x $100 \%) .97$

Table 38. Summary of $\mathrm{K}_{\text {davail }}$ Based on Equation 1; Sum of Sequential Extraction Steps 1 -

6 and Porewater COC Concentrations …………………………………………... 100

Table 39. Correlation Coefficients for $\mathrm{K}_{\text {davail }}, \mathrm{pH}$, and Sulfate Values Presented in Table 38 
Table B- 1. Abbreviations for sequential extraction steps ............................................... 123

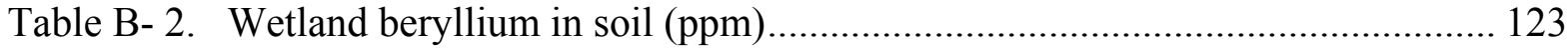

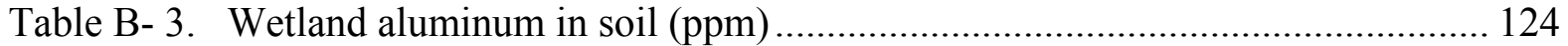

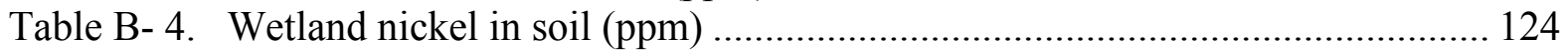

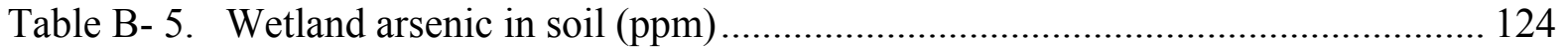

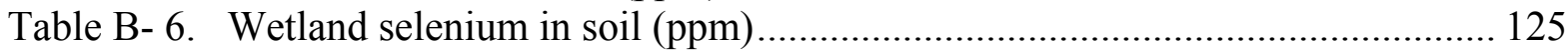

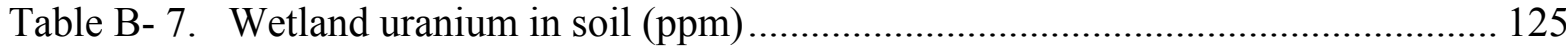

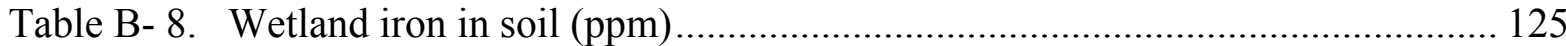

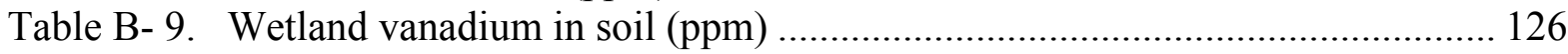

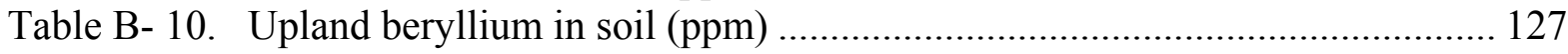

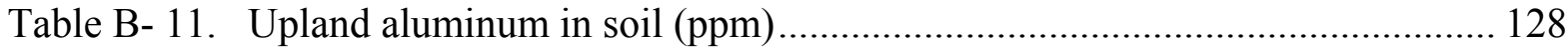

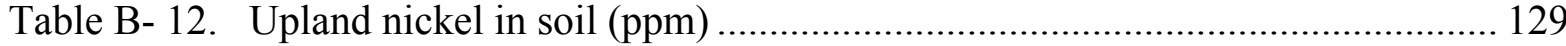

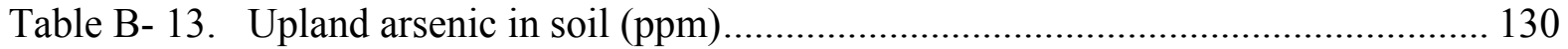

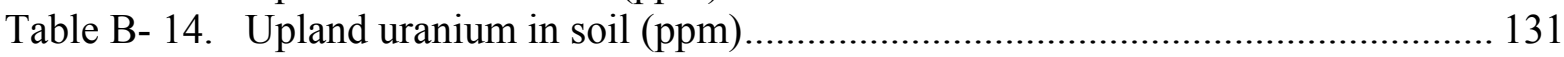

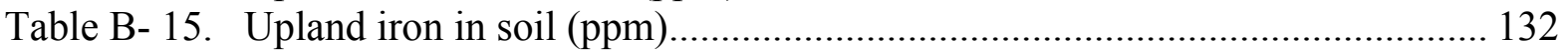




\section{LIST OF ACRONYMS}

\begin{tabular}{|c|c|}
\hline AA & Atomic Absorption \\
\hline $\mathrm{AEC}$ & Anion Exchange Capacity \\
\hline APB & Acid producing bacteria \\
\hline bgs & below ground surface \\
\hline BRA & Baseline Risk Assessment \\
\hline DAB & D-Area Ash Basin \\
\hline DCP & D-Area Coal Pile \\
\hline AMD & acid mine drainage \\
\hline ARDRA & amplified ribosomal DNA restriction analysis \\
\hline $\mathrm{CEC}$ & cation exchange capacity \\
\hline CERCLA & Comprehensive Environmental Response, Compensation, and Liability Act \\
\hline $\mathrm{CFU}$ & colony forming unit \\
\hline $\mathrm{cm}$ & centimeter \\
\hline $\mathrm{cm} / \mathrm{sec}$ & centimeters per second \\
\hline $\mathrm{COC}$ & constituent of concern \\
\hline DCPRB & D-Area Coal Pile Runoff Basin \\
\hline $\mathrm{df}$ & Degrees of freedom \\
\hline $\mathrm{DF}$ & Dilution (and dispersion) Factor \\
\hline DNA & deoxyribonucleic acid \\
\hline DRP & D-Area Rubble Pit \\
\hline EFE & ecofunctional enzymes \\
\hline $\mathrm{Eh}$ & reduction/oxidation (redox) potential \\
\hline $\mathrm{g} / \mathrm{L}$ & grams per liter \\
\hline ICP-AES & inductively coupled plasma-atomic emission spectroscopy \\
\hline ICP-MS & inductively coupled plasma-mass spectroscopy \\
\hline IRB & iron reducing bacteria \\
\hline $\mathrm{Kd}$ & linear partitioning coefficient, distribution coefficient \\
\hline$K_{\mathrm{sp}}$ & solubility constant \\
\hline M & molar (moles per liter) \\
\hline $\mathrm{mg} / \mathrm{kg}$ & milligrams per kilogram \\
\hline $\mathrm{mg} / \mathrm{L}$ & milligram per liter \\
\hline $\mathrm{mL}$ & milliliter \\
\hline MNA & monitored natural attenuation \\
\hline msl & mean sea level \\
\hline $\mathrm{mV}$ & millivolt \\
\hline NA & Not analyzed \\
\hline nd & Not determined \\
\hline $\mathrm{ppb}$ & parts per billion $(\mu \mathrm{g} / \mathrm{L}$ or $\mu \mathrm{g} / \mathrm{kg})$ \\
\hline ppm & parts per million (mg/L or mg/kg) \\
\hline RCRA & Resource Conservation and Recovery Act \\
\hline SCM & surface complexation model \\
\hline SRB & sulfate reducing bacteria \\
\hline SRS & Savannah River Site \\
\hline st dev & standard deviation \\
\hline
\end{tabular}


TCE trichloroethylene

TD total digestion

USDOE United States Department of Energy

USEPA United States Environmental Protection Agency

UTRA Upper Three Runs aquifer

WPT Waste Processing Technology

WSRC Westinghouse Savannah River Company 
WSRC-TR-2004-00124, REVISION 0

\subsection{EXECUTIVE SUMMARY}

The identification and quantification of key natural attenuation processes for inorganic contaminants at D-Area is detailed herein. Two overarching goals of this evaluation of monitored natural attenuation (MNA) as a remediation strategy were 1) to better define the availability of inorganic contaminants as potential sources for transport to groundwater and uptake by environmental receptors and 2) to understand the site-specific mechanisms controlling attenuation of these inorganic contaminants through tandem geochemical and biological characterization. Data collected in this study provides input for more appropriate site groundwater transport models.

Significant natural attenuation is occurring at D-Area as evidenced by relatively low aqueous concentrations of constituents of concern (COCs) (Be, Ni, U, and As) at all locations characterized and the decrease in groundwater concentrations with increasing distance from the source. The observed magnitude of decrease in groundwater concentrations of COCs with distance from the D-Area Coal Pile Runoff Basin (DCPRB) could not be accounted for by the modeled physical attenuation processes of dilution/dispersion. This additional attenuation, i.e., the observed difference between the groundwater concentrations of COCs and the modeled physical attenuation, is due to biogeochemical processes occurring at the DArea. In tandem geochemical and microbiological characterization studies designed to evaluate the mechanisms contributing to natural attenuation, $\mathrm{pH}$ was the single parameter found to be most predictive of contaminant attenuation. The increasing $\mathrm{pH}$ with distance from the source is likely responsible for increased sorption of COCs to soil surfaces within the aquifer at D-Area. Importantly, because the sediments appear to have a high buffering capacity, the acid emanating from the DCPRB has been neutralized by the soil, and these conditions have led to large $\mathrm{K}_{\mathrm{d}}$ values at the site.

Two major types of soils are present at D-Area and were evaluated in this study: upland subsurface soils associated with a low $\mathrm{pH} /$ high sulfate/metals plume down-gradient of the D-Area Coal Pile Runoff Basin (DCPRB) and surface ash material discharged to the wetland from the D-Area Ash Basin (488-D). Sequential extraction studies were carried out to better define the availability of inorganic contaminant sources at D-Area.

The availability of the sorbed contaminants in the solid phase was found to depend on the contaminant geochemical conditions (e. g., pH), as well as the soil type (e.g., upland soil verses wetland ash). Typically, for cations ( $\mathrm{Be}, \mathrm{Ni}, \mathrm{U})$, the amount of the contaminant associated with the available fraction increased with the total contaminant concentration in upland soils near the DCPRB. For the more mobile contaminants such as beryllium, the soils closer to the most impacted areas (lowest $\mathrm{pH}$, highest sulfate) may contribute less as a long term source of COC transport to groundwater (lower concentrations of contaminants that are less available) whereas soils down-gradient where contaminant attenuation has occurred have higher soil concentrations with a larger amount of the contaminant in the available fraction. 
In contrast to the results for cationic contaminants, arsenic, which occurs predominately as an anion, was typically found associated with the less available (more crystalline) solid phases in upland soils down-gradient of the DCPRB. This tendency of arsenic to be associated with the more crystalline solid phases is likely due to favorable sorption of As to iron oxides at low $\mathrm{pH}$ values accounting for the high degree of attenuation of this contaminant near the DCPRB. At wetland locations, relatively high concentrations of all contaminants $(\mathrm{Be}, \mathrm{Ni}, \mathrm{U}$, As) were measured demonstrating the potential of the wetlands to have a high attenuation capacity. Typically, less than $50 \%$ of the total cationic contaminant concentration was associated with the more available solid phases, however, greater than $90 \%$ of the total concentration of arsenic was available which is potentially a concern because the ash material is located at the surface where it is potentially accessible for ingestion by environmental receptors.

The tendency of the sediments to sorb $\mathrm{Be}, \mathrm{Ni}$, and $\mathrm{U}$ followed well-established geochemical trends. Sediment sorption for $\mathrm{U}$ was greater than for Ni, which in turn was greater than for Be. Furthermore, over the range of $\mathrm{pH} 3$ to 8, there was a significant logarithmic relationship between in situ $\mathrm{K}_{\mathrm{d}}$ values (for $\mathrm{U}$ the $\mathrm{pH}$ range was 3 to 5.5) and groundwater $\mathrm{pH}$. Arsenic, an anion, was sorbed strongly to wetland ash $\left(\mathrm{K}_{\mathrm{d}}\right.$ values $\left.>10,000 \mathrm{~mL} / \mathrm{g}\right)$. This is important because it appears that the wetland is acting as an As sink. Similarly, As is also sorbed strongly to both the upland and wetland soils, albeit less strongly than the wetland ash. Based on sequential extraction procedures, it is postulated that the numerous Fe minerals in these sediments are responsible for much of the sorption capacity for the COCs. Arsenic is bound to the Fe phases (perhaps as solid solutions, i.e., poorly defined Fe precipitates) in upland soils near the DCPRB, but in the wetland ash arsenic is removed in the sequential extraction step targeting the organic matter. Because arsenic in a sample of ash taken directly from the ash basin is also associated with the organic matter extraction step, this solid phase speciation observed in the wetland ash is probably due to the As speciation in the waste as well as more favorable sorption conditions in the wetland soils.

In general, distribution of microbes at the site followed expected trends. Total activity and diversity (as measured by substrate utilization) was generally greatest in the wetlands and in zones least impacted by the plume. Conversely, upland and impacted zones of the plume generally contained fewer microbes and less diversity. Overall, the microbial community at the operable unit was relatively diverse. This is important because it suggests that several different microbial processes have the potential to interact with the COCs. These interactions can be active including biotransformation or passive including biosorption of COCs to bacteria cells or their products. The microbe, Stenotrophomonas maltophilia, was isolated in several upland locations. Its potential for aerobic metal biotransformation and complex formation may be an indicator of aerobic metal interactions occurring in the upland area. Bacterial isolates from a number of upland soil locations were tested for the ability to alter the groundwater $\mathrm{pH}$. All six bacterial isolates were able to raise the ambient $\mathrm{pH}$ from 2 to 3 $\mathrm{pH}$ units within 24 hours. An isolated gram negative Enterobacter sp. was able to raise the $\mathrm{pH}$ of the $\mathrm{pH} 4$ growth media, and it effected a $3 \mathrm{pH}$ unit change within 24 hours. Enterobacter have also been demonstrated to reduce metals. While there is strong evidence for the participation of microbes at the D-Area site in the natural attenuation processes, a quantification of these microbial processes is not possible with the current data. 
Ecofunctional enzyme results showed that wetland locations revealed two distinct groupings. These could be categorized as impacted, or those wetland sites nearest the source area, or nonimpacted, those locations furthest from the sources. A number of sites with ash deposition were categorized as nonimpacted while others with ash were classified as impacted based on microbiological activity. A potential indicator of MNA would be future conversion of those wetland impacted sites microbiological activity to that more like nonimpacted.

Geochemical processes can be invoked to describe attenuation at locations near the DCPRB where porewater and soil concentrations of contaminants exhibited the largest variations. A simplified conceptual hydro-geochemical model at the site is (1) the introduction of low-pH water and metals from the DCPRB; (2) soils downgradient of the source buffer the acidity (i.e., raise the $\mathrm{pH}$ of the groundwater); and (3) the high aqueous concentrations of dissolved ions such as $\mathrm{As}, \mathrm{Be}, \mathrm{Ni}, \mathrm{U}, \mathrm{Fe}, \mathrm{Mn}$, and $\mathrm{Al}$ are removed from the aqueous phase forming soil sorbed species, metal oxide/hydroxide surface coatings and precipitates. The ability of metal oxide/hydroxides in soil to possess variable surface charge accounts for sorption of both cationic and anionic contaminants. The favorable sorption of arsenic as an anion occurs at locations very near the DCPRB where the accumulation of positive charge due to the sorption of hydrogen ions (low $\mathrm{pH}$ ) is greatest. Cations such as $\mathrm{Be}, \mathrm{Ni}$, and $\mathrm{U}$ compete with hydrogen ions for sorption sites and, therefore, tend to be more mobile with sorption increasing with increasing $\mathrm{pH}$ (decreasing hydrogen ion concentration). Although sufficient numbers of microorganisms exist at locations near the DCPRB, no clear correlation between biological parameters measured in this study (including total and viable counts as well as substrate utilization) and inorganic attenuation close to the DCPRB was observed. Because the majority of the natural attenuation was observed prior to groundwater interactions with wetland soils, the inorganic attenuation capacity of this regime could not be quantified.

Given the geochemistry (elevated $\mathrm{pH}$ and high cation exchange capacity) and high level of microbial activity, the wetlands should provide an additional sink for COCs at the D-Area.

Because there is a large variability in transport factors (i.e., the distribution coefficients $\left(\mathrm{K}_{\mathrm{d}}\right.$ values) range over several orders of magnitude) that depends largely on the groundwater $\mathrm{pH}$, a traditional single $\mathrm{K}_{\mathrm{d}}$ approach will not be sufficient for modeling contaminant transport at the site. Finally, this work is consistent with the $\mathrm{pH}$ dependant transport conceptual geochemical model used in earlier modeling efforts of the operable unit (Brewer and Sochor, 2002). By reducing the uncertainty of the biogeochemical conceptual model and by providing site-specific $K_{d}$ values, this study will permit future modeling efforts to: (1) use less conservative geochemical input values, and (2) more accurately account for the naturally attenuation processes occurring at the site. 
This page intentionally left blank. 
WSRC-TR-2004-00124, REVISION 0

\subsection{INTRODUCTION}

\subsection{INORGANIC MONITORED NATURAL ATTENUATION OVERVIEW}

MNA has received considerable attention as an attractive alternative to more active remediation technologies. MNA is the "reliance on natural attenuation processes (within the context of a carefully controlled and monitored site cleanup approach) to achieve sitespecific remediation objectives within a timeframe that is reasonable compared to that offered by other more active methods" (USEPA, 1999). Natural attenuation processes in the subsurface reduce the transport and/or environmental availability of contaminants. These natural attenuation processes include a range of physical, chemical, and biological mechanisms that reduce the mass, toxicity, mobility, volume, or concentration of contaminants in soil or groundwater.

To implement MNA for remediation of inorganic contaminants in soil, a given site must first be evaluated and designated as an appropriate MNA site according to United States Environmental Protection Agency (USEPA) protocols and guidelines using site-specific data (USEPA, 1999). Data necessary for this evaluation include: historical groundwater and soil chemistry measurements, including the source term definition (quantity, chemical and physical form, and time period of contaminants released to the environment), are useful in demonstrating natural attenuation. These site-specific data should represent decreasing trends in groundwater contaminant concentrations or mass over time. Hydrogeological and geochemical data indirectly demonstrate types of active processes and rates of attenuation and are also important, as are field data, in demonstrating particular attenuation mechanisms. In situ mechanisms that may contribute to natural attenuation include dilution, dispersion, sorption, radioactive decay, and biodegradation as well as chemical or biological stabilization, transformation or destruction.

Because inorganic contaminants are not degraded in natural systems like many organic contaminants, the attenuation of inorganic contaminants will necessarily entail decreases in metal toxicity and mobility primarily through sorption (including adsorption and absorption) and precipitation. These mechanisms maybe abiotically or biotically mediated; for example, reduction of inorganic contaminants often reduces both metal toxicity (e.g., chromium (Cr) VI to Cr III) and mobility primarily through precipitation (e.g., $\mathrm{UO}_{2}$ (VI) to U (IV)) and enhanced sorption.

At the Savannah River Site (SRS) D-Area, the potential for implementing MNA as a stand alone remediation is being evaluated. Alternatively, since natural attenuation options are often preferred alternatives for distal areas of contaminant plumes, MNA could be implemented at D-Area in combination with more aggressive source zone treatments (Phifer, 2001). MNA is being evaluated both for upland areas impacted by a low $\mathrm{pH} / \mathrm{sulfate} / \mathrm{metals}$ groundwater plume as well as wetland areas down-gradient impacted both by the metalcontaminated groundwater plume as well as high $\mathrm{pH} /$ sulfate/metals contaminated surface ash material. The success of MNA is based on physical, chemical, geological, and biological interactions associated with subsurface, near surface, and surface water conditions along D-Area wetlands and subsurface. 


\subsection{GOALS}

This Treatability Study report is a summary of the results from studies designed to evaluate MNA for inorganic constituents of concern (COCs) at the D-Area Expanded Operable Unit (DEXOU). Tandem geochemical and microbiological investigations were carried out to identify and attempt to quantify the natural processes both abiotic and biotic controlling attenuation of the metal COCs - beryllium, nickel, uranium, and arsenic.

The goals of the work addressed in this report include:

- Evaluation of contaminant sources in D-Area in terms of COC availability for transport into ground water and for uptake by environmental receptors

o Development of a technically defensible definition of the contaminant sources (i.e., source term definition) by operationally defining the environmentally available fraction using a sequential extraction method which approximates a range of environmental conditions under which contaminants might potentially be leached

o Comparison of sequential extraction methods to other more traditionally used and aggressive methods [EPA 3050b (hot nitric acid) and total digestion (hydrofluoric acid)] as well as to a simplified but equivalent alternative method (single step extraction)

- Identification and quantification of key natural processes (both abiotic and biotic) contributing to and controlling inorganic contamination attenuation processes occurring in D-Area

o Abiotic mechanisms addressed:

- Physical processes including dilution and dispersion

- Geochemical processes including: sorption [metals, sulfate, and hydrogen ion (soil buffering)], precipitation (COCs, Fe, Al), and the relationship of these geochemical processes to reductive and oxidative chemical processes (redox)

o Biological mechanisms addressed: Bioreduction, biosorption, and $\mathrm{pH}$ buffering 
- Measurement and identification of the geochemical and/or biological parameters that can be used to model the attenuation processes and the attenuation capacity of the aquifer system at D-Area for inorganic contaminants.

o Development of more appropriate transport parameters based on site specific in situ sorption measurements (i.e., distribution (partition) coefficients, Kds) from matched porewater and soil pairs collected throughout D-Area at a range of locations from near-source to distal to portions of the groundwater plume.

o Characterization of the soil geochemistry at the site to understand its relationship to sorption processes.

o Measurement geochemical "master variables" of $\mathrm{pH}, \mathrm{Eh}$, and sulfate

o Determination of biotic factors specific to MNA of metals.

- Determination of the concentration of the bacterial components of the microbial community present at D-Area.

- Characterization of specific bacterial populations present and assess their activity with respect to attenuation of inorganic contaminants

- Development of recommendations for D-Area-specific MNA protocols for future long-term monitoring. 
This page intentionally left blank. 
WSRC-TR-2004-00124, REVISION 0

\subsection{BACKGROUND}

\subsection{SITE DESCRIPTION}

The D-Area Coal Plant, associated D-Area Coal Pile (DCP), and D-Area Ash Basins (DAB: 488-D and 488-4D), operating continuously since the early 1950s, are some of the oldest facilities at SRS (Figure 1). The D-Area Coal Pile Runoff Basin (DCPRB) was built in 1978 to minimize direct runoff from the DCP to Beaver Dam Creek. A large metal/sulfate/acid groundwater plume emanates from the vicinity of the DCP/DCPRB and flows from the area of highest impact (lowest $\mathrm{pH}$, highest groundwater concentrations of metals) near the north western tip of the DCPRB continuing under the Ash Basins, 488-D and 488-4D, with the distal portion of the plume extending toward the wetland and Savannah River. In addition to the evaluation of natural attenuation processes associated with the large plume emanating from the vicinity of the DCP/DCPRB, surface ash contamination in the wetland originating from activities associated with operation of the DAB, 488-D and 488-4D, was also considered in this study. Additionally, the west end of the DAB (488-D and 488-4D) is a source of low $\mathrm{pH}$ and metal contaminants. This plume is coincident with the flow path of the plume associated with the DCP/DCPRB. Another source of low $\mathrm{pH}$ and metals contamination in D-Area is the D-Area Rubble Pit (DRP). Based on current modeling the DRP plume is not coincident with the plume emanating from the DCP/DCPRB. Much uncertainty is associated with the distal regions in and around the wetland area as to relative contribution from each of the respective point sources, including the DCP, DCPRB, DAB (488-4D) and D-Area wetlands. Figure 2 shows the beryllium plumes associated with each of these sources based on previous modeling efforts (Brewer and Sochor, 2002). Beryllium is one of the more mobile contaminants at D-Area. (Figure 2)

\subsubsection{D-Area Coal Pile (DCP) and D-Area Coal Pile Runoff Basin (DCPRB)}

The D-Area Coal Pile (DCP) and Coal Pile Runoff Basin (DCPRB) are sources of acidity, sulfate, and metals generated from sulfuric acid leachate produced by oxidation of pyrite in coal. Oxidation of pyrite occurs chemically but can also be facilitated by the catalytic coupling of bacterial oxidation of $\mathrm{Fe}^{2+}$ to $\mathrm{Fe}^{3+}$ (Equation 1) with the chemical reaction of $\mathrm{Fe}^{3+}$ with pyrite $\left(\mathrm{FeS}_{2}\right)$ releasing sulfate and regenerating $\mathrm{Fe}^{2+}$ to propagate the cycle (Equation 2 ) leading to high levels of acidity.

\section{Equation $1 \quad \mathrm{Fe}^{2+}+0.25 \mathrm{O}_{2}+\mathrm{H}^{+} \rightarrow \mathrm{Fe}^{3+}+0.5 \mathrm{H}_{2} \mathrm{O}$}

Equation $2 \quad \mathrm{FeS}_{2}+14 \mathrm{Fe}^{3+}+8 \mathrm{H}_{2} \mathrm{O} \rightarrow 15 \mathrm{Fe}^{2+}+2 \mathrm{SO}_{4}{ }^{2-}+16 \mathrm{H}^{+}$

The acid produced leaches toxic trace metals from coal and soil and dissolves mineral surfaces leading to groundwater contamination with high levels of the major ions iron, manganese, aluminum, and sulfate. 

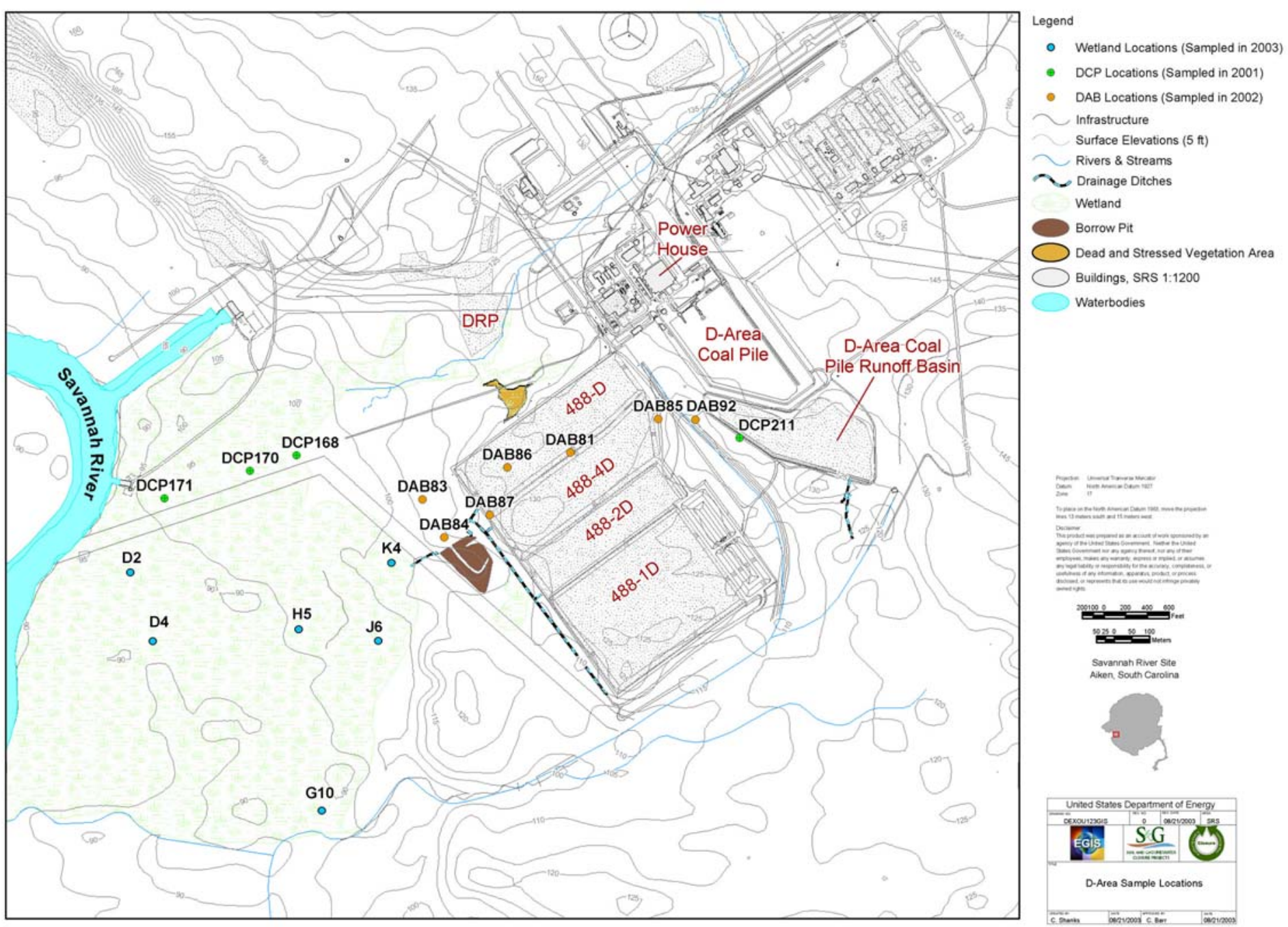

Figure 1. D-Area Map with Sampling Locations 


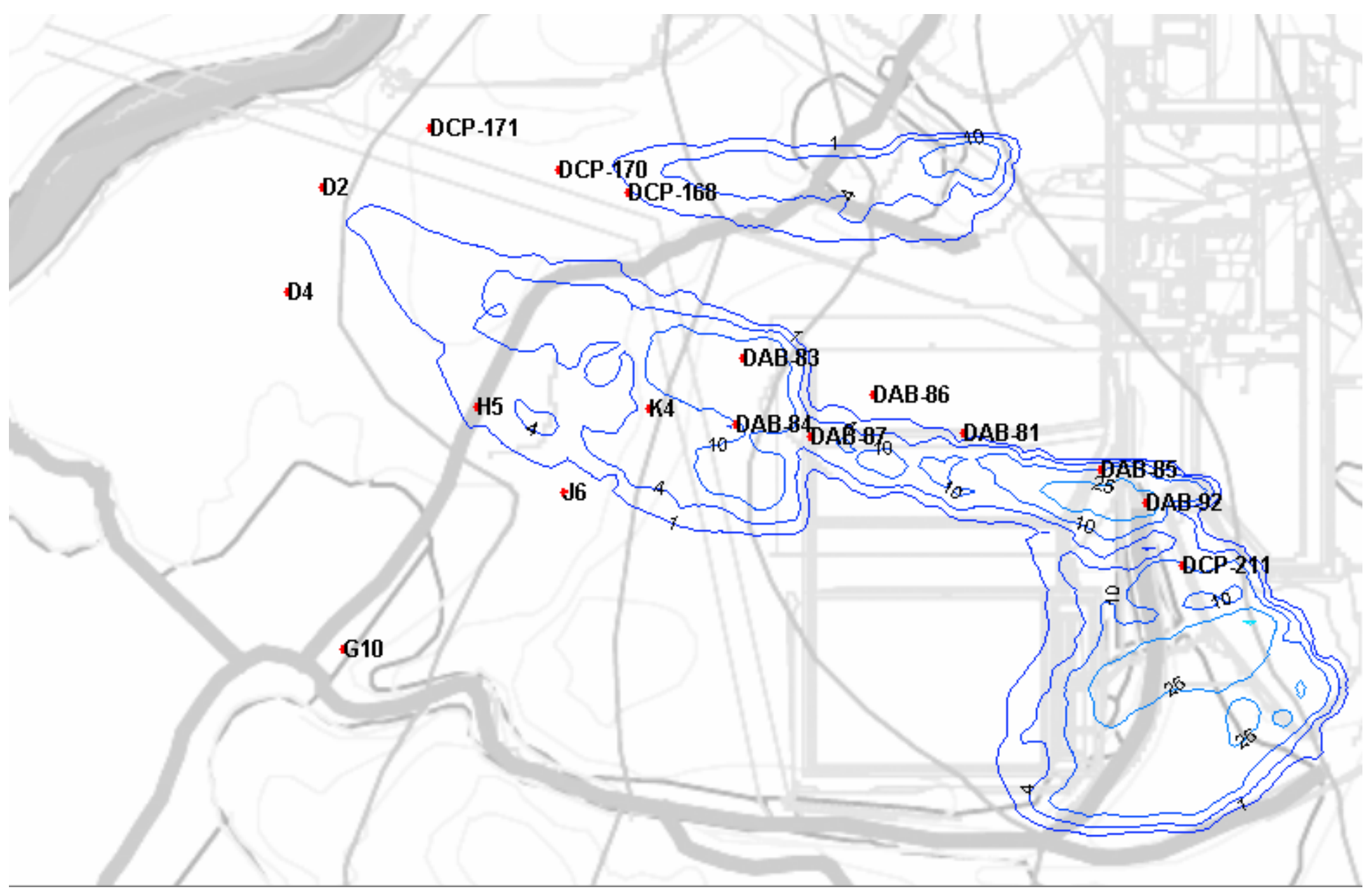

Figure 2. D-Area Site Map with groundwater contaminant plumes for beryllium from modeling (Layer 3, Brewer and Sochor, 2002). 


\subsubsection{D-Area Ash Basin (DAB) (488-D and 488-4D)}

The 488-D Ash Basin is an unlined containment basin constructed above grade to receive ash-sluice water prior to discharge to local surface streams. After the basin was closed to ash sluice in 1976, the basin received only dry ash and coal rejects. Coal rejects were stored on the north and east edges of the basin and later were distributed throughout the surface of the basin. The western end of the 488-D is characterized by a region of low $\mathrm{pH}$ associated with standing water in that end of the basin. This low $\mathrm{pH}$ region is in contrast to the high $\mathrm{pH}$ perched water that characterizes the majority of the basin. Immediately beneath the DAB is a tight layer of natural clay. For this reason, transport from the DAB to the groundwater beneath the $\mathrm{DAB}$ is thought to be minimal. On the western end, however, the clay layer becomes thinner allowing contaminants to seep into the groundwater toward the west end and downgradient of the DAB.

\subsubsection{D-Area Wetland}

Historical aerial photography indicates that ash sluice was routinely discharged from the 488-D into the wetland area primarily in the 1970s prior to the closing of the basin. Figure 3 shows the aerial photography from 1956 before the ash deposition and from 1977 showing the impact to the forested wetland. (Compare the white circled area in the 1956 photo with the 1977 photo.) Figure 3 also shows the thermal delta created by discharge of Beaver Dam Creek. These disposal activities were prior to the closing of 488-D and also prior to the disposal of coal rejects in the DAB 488-D. Consequently, the ash discharged in the wetland area is not expected to contain coal rejects and should be higher than background $\mathrm{pH}$ rather than lower.

\subsubsection{D-Area Rubble Pit (DRP)}

An additional source of acidity and inorganic COCs found in D-Area is the DRP. The majority of the sampling locations characterized in this work were upgradient and far from the currently modeled plume associated with the DRP. A number of locations (DCP168, DCP 170, DCP171) evaluated in previous work (Powell et al., 2001) are distal to the plume emanating from the DCP-DCPRB. (Figure 2)

\subsubsection{D-Area Hydrogeology}

The Upper Three Runs Aquifer (UTRA) is the aquifer system of concern for this Treatability Study. This aquifer system has been divided into three hydrostratigraphic zones (upper UTRA, "tan clay," and lower UTRA) based on the hydraulic geologic properties of the zones. The upper UTRA and the "tan clay" are not present in D-Area, and the water table aquifer is located in the lower UTRA. The lower UTRA is composed primarily of sands and clays deposited as Quaternary alluvium and sand, clayey sand, and calcareous sand of the Tinker/Santee Formation. The shallowest continuous unit that constitutes an aquitard below the water table aquifer is the Gordon confining unit (i.e., the "green clay") (WSRC, 2000). 

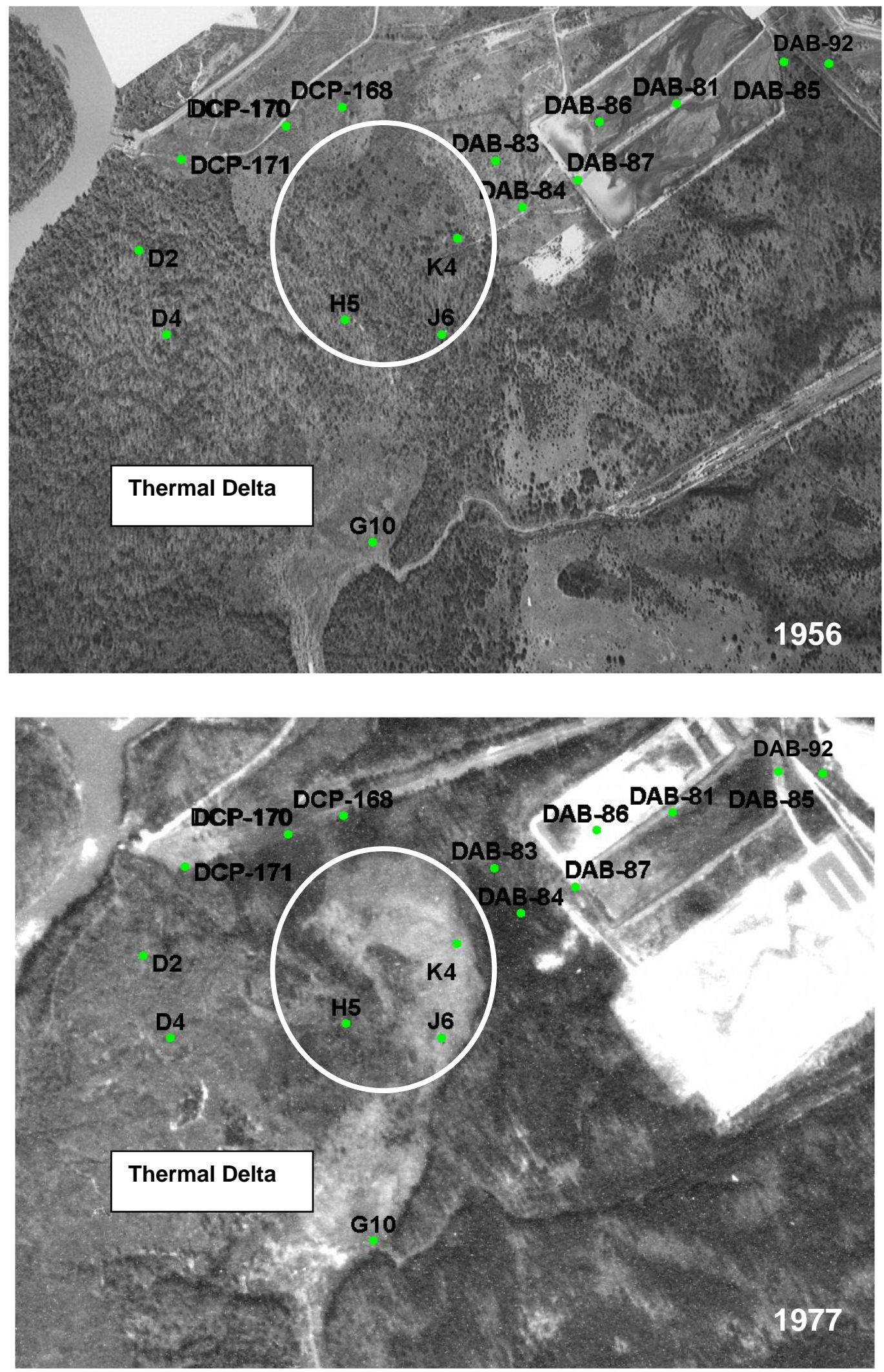

Figure 3. Aerial Photographs Showing Before (1956) and After (1977) Ash-Sluice Discharge to Wetland 
Groundwater flow in the D-Area water table aquifer is predominantly east to west toward the Savannah River. Water table elevations, gathered from monitoring wells, indicate that the potentiometric surface ranges from 96.8 to 134.2 feet mean sea level (msl) at D-Area. The water table aquifer underneath D-Area ranges in thickness from approximately 40 to 60 feet. Generally, the depth of the water table below decreases until the groundwater emerges in wetlands to the west of the ash basins, east of the Savannah River. The most shallow groundwater flow is influenced by local features such as the DCPRB, the unnamed tributary to Beaver Dam Creek (i.e., the discharge ditch), the wetlands between the DCPRB and the ash basins, the ash basins, Beaver Dam Creek, and other wetland/swamp areas. The head gradient across the green clay influences deeper water table aquifer flow (Phifer et al., 1996, WSRC, 2000).

\subsubsection{Low pH/Metals/Sulfate Plumes}

Chemical and biological oxidation of the sulfur compounds (primarily pyrite) associated with coal produces sulfuric acid. Within the D-Area coal pile, rainwater and sulfuric acid combine to leach other trace elements from the coal, producing an acidic runoff that contains substantial metal contaminants and sulfate (low $\mathrm{pH} /$ metals/sulfate contamination). The predominant trace elements found in coal include aluminum, silica, sulfur, iron, calcium, zinc, magnesium, and lead (Gluskoter, 1975). Other trace elements found in coal in lesser amounts include arsenic, barium, chromium, cobalt, copper, nickel, lanthanum, manganese, thorium, uranium, and vanadium (Horton et al., 1977). Beryllium, nickel, and uranium were the three contaminants selected for previous modeling studies (Brewer and Sochor, 2002).

The runoff from the D-Area coal pile is subsequently discharged into the DCPRB where the oxidation and leaching process continues as a result of coal and coal fines within the DCPRB, and the contaminated water from the basin seeps into the water table aquifer (UTRA). The maximum extent of impact to the groundwater can be represented by sulfate, which is highly soluble and provides the highest resolution as an indicator parameter of plume migration. Groundwater sulfate concentrations exceeding 5,000 mg/L occur immediately adjacent to the coal pile and the $\mathrm{DCPRB}$, and groundwater $\mathrm{pH}$ values of less than 3 occur in this vicinity. Sulfate concentrations are lower and $\mathrm{pH}$ is higher north and east of the coal pile and DCPRB (WSRC, 1991, Phifer et al., 1996, WSRC, 2000), indicating the significance of DCPRB contributions to groundwater contamination.

The groundwater beneath 488-D and the other ash basins flows westward toward the Savannah River and wetlands. The projected western boundary of the plume hydrologically extends into the wetland area near the Savannah River. This projection is based on elevated groundwater sulfate levels (greater than $100 \mathrm{mg} / \mathrm{L}$ ) and depressed $\mathrm{pH}(<5)$ and flow predictions. The leachate plume appears to be limited to the water table aquifer (UTRA) at D-Area. Groundwater samples collected from wells below the Gordon confining unit do not show depressed $\mathrm{pH}$ or elevated sulfate levels. Until powerhouse operation is discontinued and the facility is decontaminated and decommissioned, the D-Area coal pile and the DCPRB are expected to continue to be a source of metals contamination to groundwater. 


\subsection{CONCEPTUAL MODEL OF NATURAL ATTENUATION AT D-AREA}

Due to contaminated runoff from the D-Area coal pile to DCPRB, a low $\mathrm{pH} / \mathrm{metals} /$ sulfate groundwater contaminant plume emanates from DCPRB. Furthermore, based on historical aerial photographs, field observations, and analytical data, it appears that a significant amount of sluiced ash overflowed from the DAB in the 1970s into the wetland area west of the $\mathrm{DAB}$, providing a source of contamination in the wetland. Additionally, the west end of the 488-D DAB appears to be a source of low $\mathrm{pH} /$ sulfate/metals.

The D-Area site was chosen to evaluate the use of MNA to remediate inorganic constituents because it is a relatively large area with low levels of contamination. It was anticipated that environmental conditions would be favorable to this approach. For example, the groundwater plume becomes more anaerobic as it moves towards the Savannah River, and the low-pH plume would be buffered (i.e., neutralized) by the soils at the site. Both of these conditions, more reducing and increased $\mathrm{pH}$, are expected to attenuate metal contaminants by sorption and precipitation processes as the plume moves towards the Savannah River.

Two distinct areas exist within the low $\mathrm{pH}$ and sulfate plumes. Each area is thought to have different controlling mechanisms. One area is near the DCP/DCPRB source, where the groundwater chemistry shows the highest degree of variability. In this area where the metals concentrations are highest and the $\mathrm{pH}$ is lowest, it is thought that the groundwater will be toxic to indigenous microbial populations and geochemical controls such as sorption will dominate attenuation processes. In the second area of the contaminant plume where the $\mathrm{pH}$ of the system is elevated from dilution, dispersion, and buffering from the aquifer sediments, other biotic processes (e.g., microbially mediated removal of metals by sulfate reduction and precipitation as a metal sulfide) could dominate the overall attenuation process.

\subsection{METAL AVAILABILITY}

In order to evaluate MNA of inorganics, more appropriate methods for determining the estimation of COCs in soil were evaluated in terms of source term and transport.

\subsubsection{Estimation of the Source Term}

Risk modeling typically defines the contaminant source through disposal inventories and site characterization data. Because disposal inventory records are often incomplete or absent, site characterization data must be used to estimate waste site source terms. These estimates are obtained in various ways, including analyzing contaminant concentrations in soil and groundwater samples collected from the waste site. Typically, soil concentration data are determined using partial digestions, for example USEPA Method 3050b hot nitric acid extraction. This method typically overestimates the amount of metal available to the environment under almost all environmental conditions. Source terms have also been estimated from groundwater concentrations measures at the site by calculating source terms (i.e., soil concentrations) from site-specific groundwater contaminant concentrations using a linear partitioning coefficient. These approaches are subject to large uncertainties and can lead to unrealistic estimates of risks or selection of inappropriate remediation strategies. 
WSRC-TR-2004-00124, REVISION 0

An estimation of the source term is needed that is based on characterized soil concentrations of COCs that does not rely on historical records and provides a technically defensible approach to estimating current COC sources in situ. EPA Method 3050b (hot nitric acid extraction) is an aggressive method and likely over-estimates the metal available for transport. Consequently, an eight step sequential extraction method (Miller, 1986) was evaluated.

Sequential extraction is a desorption technique that has been useful for identifying both leachate and solid-phase chemistry. When considering the source term and transport of the contaminant, the leachate chemistry and the solid-phase form are important in defining the environmental availability of the contaminant (where environmental availability is defined by Amonette et al (1994) as "the ability of a soil to maintain an aqueous concentration of [contaminants] in the soil solution"). The first six extraction steps in this operationally defined extraction sequence (described in detail in Section 4.2.2 Table 3) represent an approximation of the total of all the metals that would possibly be available if the soil were perturbed under a range of environmental conditions. The last two steps of the extraction procedure target crystalline mineral phases. Inorganic contaminants associated with these crystalline phases would likely not be readily available for transport. Similarly, the harsh conditions of the EPA 3050B standard method (hot nitric acid) also do not represent conditions likely to be encountered in the environment. By considering only the environmentally available fraction, (approximated by summing the first six steps of the sequential extraction method) a large fraction of the naturally occurring trace metals is eliminated from consideration in this measure of metal availability. Findley (1998) has demonstrated that the bulk of trace metals in soil are only accessible under harsher extraction conditions (sequential extraction steps 7 and 8) that are not likely to represent conditions present in the environment. A single-step extraction equivalent to the first six steps of the sequential extraction procedure was also evaluated.

Associated with natural attenuation of metals in groundwater by soil is the changing profile of COCs based on location in the plume and attenuation mechanism. Highest soil concentrations of mobile COCs are likely located some distance from the original source.

\subsubsection{Distribution Coefficients}

Once the source term has been estimated, a mathematical model that relates source concentration to groundwater concentration is developed. Typically, a linear partitioning coefficient $\left(\mathrm{K}_{\mathrm{d}}\right)$ is used in groundwater models. $\mathrm{K}_{\mathrm{d}}$ values are either obtained from published literature or generated from site-specific data. Variations of three to four orders of magnitude are not uncommon for $\mathrm{K}_{\mathrm{d}}$ values from the literature or even from the same waste site where there are large geochemical gradients.

The distribution coefficient $\left(\mathrm{K}_{\mathrm{d}}\right)$ is defined as follows:

$$
\mathrm{K}_{\mathrm{d}}=\frac{\text { Contaminant concentration in soil }(\mathrm{mg} / \mathrm{kg})}{\text { Contaminant conc. in the solution contacting the soil }(\mathrm{mg} / \mathrm{L})}
$$


Groundwater transport models account for hydrodynamic processes such as advection and dispersion. These models are also capable of accounting for contaminant mass-reduction by processes such as radioactive decay and biodegradation. Partitioning between the groundwater and soil phases is most often represented by a single linear partitioning coefficient $\left(\mathrm{K}_{\mathrm{d}}\right)$ that does not vary over the flow path of the model. However, previous studies (Powell et al., 2001) show that the manner in which metal contaminants at D-Area partition during groundwater transport is highly variable, but systematic with $\mathrm{pH}$, along the groundwater flow path.

Distribution coefficients can be measured from matched porewater and soil samples to provide a more accurate estimation of transport. Because the value of the $\mathrm{K}_{\mathrm{d}}$ depends not only on the porewater concentration, but also on the soil concentration, a relationship exists between the source term definition and the distribution coefficient such that overestimation of the source term leads to the development of a larger or less conservative $K_{d}$.

Once the mechanisms controlling contaminant transport have been identified, a groundwater transport model can be developed to incorporate the attenuation capacity of the system. The model should be mechanistically based and this Treatability Study is designed to identify and quantify the mechanisms controlling attenuation of the low $\mathrm{pH}$ and heavy metal contaminant plumes.

\subsection{NATURAL ATTENUATION MECHANISMS}

To implement MNA it is not enough to know that contaminant partitioning is variable and systematic with $\mathrm{pH}$. Rather, to help ensure that the attenuation of COCs is persistent, a predictive model that considers the controlling attenuation mechanisms is important. In the case of D-Area, it is believed that geochemical adsorption/precipitation and microbially mediated redox processes are the main mechanisms controlling the attenuation of metal contaminants and acidity at the site.

\subsubsection{Dilution and Dispersion}

Dilution and dispersion are physical processes contributing to abiotic natural attenuation. SRS groundwater transport models can account for these processes. Geochemical and biological processes are responsible for attenuation not directly attributed to dilution and dispersion and must be accounted for as well in site models.

\subsubsection{Geochemical mechanisms}

\subsubsection{Precipitation}

Under specific conditions, the environmental availability of certain contaminants can be limited by the precipitation of solid phases. Examples of this process are numerous and include the precipitation of metals as sulfide and hydroxide solids. Thermodynamically, the following generalized reaction and mass action equation can describe this process:

\section{Equation $3 \quad \mathbf{a M y}_{\mathbf{y}}+\mathrm{bAz}_{z}=\mathrm{MaAb}_{\mathbf{a}}(\mathbf{s})$}

where a mole of metal $(\mathrm{M})$ reacts with $\mathrm{b}$ moles of an anion (A) to form a solid with composition MaAb. 
The degree to which the reaction proceeds is:

\section{Equation $4 \quad K_{s p}=\left(\{M\}_{a x}\{A\} b\right)-1$}

Where $K_{s p}$ is the solubility constant, $\{\mathrm{M}\}$ and $\{\mathrm{A}\}$ are the activities of the metal and anion in solution, each raised to their respective stoichiometric coefficients a and b. Solubility constants for many solid phases are available in the literature from laboratory studies.

The selection of controlling solid phases in field settings, however, is nontrivial, as many metastable solid phases (solids that can undergo dissolution and re-precipitation as a solid with a lower $\mathrm{K}_{\mathrm{sp}}$ ) are often possible. Relevant to this work is the formation of metal oxides including hydrous ferric oxide (HFO) which is the solid formed upon rapid hydrolysis of ferric iron solutions. Upon aging in aqueous solution, HFO transforms to crystalline iron oxide. Freshly precipitated HFO particles are quite small (1 to $10 \mathrm{~nm}$ ) although with aging HFO coagulates forming porous aggregates that can be micrometer sized (Dzombak, 1990).

\subsubsection{Soil Buffering Capacity}

SRS upland soils are composed primarily of weather resistant quartz. Kaolinite (a clay mineral made of silica and aluminum) dominates the clay fraction of these soils (Looney et al., 1990). Quartz and kaolinite typically serve to provide surfaces for more reactive minerals such as iron, aluminum, and manganese oxides to coat. Metal oxides/hydroxides, kaolinite, and soil organic matter are able to possess variable surface charge and can react with hydrogen ions to buffer acidity. Organic matter is generally confined to the top twelve inches of SRS soils and would be expected to play a more important role in the buffering capacity in the wetland than in the upland subsurface.

\subsubsection{Cation/Anion Sorption}

This ability of soils to possess variable surface charge allows for favorable sorption of both cations and anions. Typically, cation sorption increases with increasing $\mathrm{pH}$ (decreasing hydrogen ion concentration) due to competition with hydrogen ions for sorption sites. Anion sorption exhibits the opposite trend as anions are attracted to the accumulation of positive charge at low $\mathrm{pH}$. It follows that sorption of anions decreases with increasing $\mathrm{pH}$ (decreasing positive charge.

\subsubsection{Geochemical Parameters}

In order to better account for geochemical contributions to natural attenuation, a number of geochemical parameters were measured and evaluated as indicators of natural attenuation in light of site-specific metal availability data from selective extractions and site-specific distribution coefficients $\left(\mathrm{K}_{\mathrm{d}} \mathrm{s}\right)$. Parameters measured included $\mathrm{pH}$, Eh, cation exchange capacity, extractable Fe and Al, and particle size distribution. These parameters are indicative of changes in soil properties both due to the natural heterogeneity of the soils as well as modifications due to impact from contaminant sources. Sequential extraction profiles are useful not only in considering the availability of contaminants in soil, but are also indicative of distinctive attenuation mechanisms and provide information regarding the various mineral phases present. 


\subsubsection{Microbiological mechanisms}

The potential for success of MNA is based on a combination of several parameters, including the microbial transformation and/or sorption of contaminants in groundwater and sediments. There are two main strategies whereby metals may be detoxified or removed from groundwater and sediments as a result of bacterial activity. The first of these generally involves bacteria oxidation of metals to less toxic states. The second strategy involves reduction of metals to less mobile or bioavailable states. Some metals can even be volatilized by biological processes. For example fungi are capable of converting arsenic compounds (both organic and inorganic) into methylarsines. This process involves the aerobic conversion to arsenite, followed by stepwise methylation ending with trimethylarsines.

Bacteria (live and dead) have the ability to attenuate metals in groundwater and sediments through biosorption (Volesky, 1989). Biosorption or metal sequestration by microorganisms can occur though complexation, chelation, ion exchange, direct sorption to cell surfaces, or inorganic precipitation. Dead bacteria and fungi can act as biosorbents, which can adsorb the ionic and colloidal forms of metals. Some microbes adsorb metals selectively enough to be used for metal recovery (Odum, 2000). Humic compounds from sediments comprised of organic matter contents can also influence and/or limit contaminant bioavailability and attenuate contaminated groundwater (Fan et al., 2000) Dead microbial cells and associated structures are usually turned over rapidly in the environment (Alexander, 1994). However their sheer numbers and presence on sediment biofilms makes the biomass important in biodegradation and bioremediation of groundwater contaminants. Biosorption allows adaptation to the environment by sensitive organisms while some react and attenuate contaminants. The heavy growth of trees and other plants in the D-Area wetland in areas with several feet of deposited ash in the rhizosphere indicates an active adapting biological system.

Many bacteria that inhabit extreme (acidic) or polluted (heavy metals) possess specialized adaptive physiological features. These adaptive features have been extensively studied and include the ability to change the $\mathrm{pH}$ of their surrounding environment. This physiological adaptation is accomplished through the production of buffering compounds including exopolysaccharides and proteins. Bacterial capabilities to adapt to and alter extreme $\mathrm{pH}$ environments like this ash basin area are important to long term MNA. 


\subsubsection{Microbiological Parameters}

Biological contributions to MNA were investigated in D-Area sediment porewater by several microbial techniques. Total bacterial densities in sediments are a measurement of overall biomass and can be used to determine site bioremediation potential. The total densities measure aerobic and anaerobic populations as well as both live and dead cells. Dead cells can also bind metals through biosorption. Aerobic culturable bacterial densities were determined since the site is mostly aerobic and these would be expected to be the dominant organisms in this system.

Anaerobic populations and specific microbial types were also measured including iron reducing bacteria (IRB), acid producing bacteria (APB), and sulfate reducing bacteria (SRB) from the upland sediments. IRB reduce $\mathrm{Fe}$ (III) to $\mathrm{Fe}(\mathrm{II})$ and would be active in an iron-rich reducing environment like D-Area. SRB reduce sulfate to sulfide and can directly convert some metal COCs from more mobile oxidized forms to less mobile reduced forms. APB are commonly iron-oxidizing autotrophic bacteria that use $\mathrm{Fe}^{2+}$ as an energy source and can contribute to groundwater acidity due to coal pile leachate.

The biological activities associated with MNA can also be measured by ecofunctional enzyme assessment. This assessment can be rapidly performed on fresh field samples through the Biolog ${ }^{\circledR}$ system. Ecofunctional enzymes (EFE) are enzymes that are being expressed or are used by or within a microbial community to enable individuals or microbial populations to survive, maintain, and grow. Alternatively, EFE may be latent enzymes ready to be expressed. Such enzymes are present in every microbial community. It is expected that in subsurface microbial communities the suite of EFE expressed is a direct reflection of the microbial populations that comprise and dominate that community and of the environmental factors impacting the ecosystem at the time of collection. Understanding ecofunctional enzyme activity in the microbial community of the ash basin area gives an understanding of the vitality and diversity of the microbial communities that are instrumental in MNA of the site. 
WSRC-TR-2004-00124, REVISION 0

\subsection{METHODS AND SITE DESCRIPTION}

\subsection{SAMPLING}

Soil and porewater samples analyzed herein were collected in three sets of sampling events. Upland samples (DCP 170, 171, 168, and 211) were collected previously for geochemical characterization and were not analyzed for microbiological activity. A second set of upland samples (DAB 81- 87 and 92) was collected and cores were split in the field to be used for both geochemical and microbiological characterization. DAB 86 (ash basin sample) was not analyzed for microbial activity. A third set of samples was collected from the wetland area: D-2, D-4, G-10, H-5, J-6, and K-4. Separate cores were collected for microbiological and geochemical characterization in the same sampling event from adjacent (within several inches) hand-augered cores.

\subsubsection{Upland Samples}

Upland soil and porewater samples from four locations (DCP 170, 171, 168, and 211; Table 1 and Figure 1) were collected in March 2001. The details of their collection and the results of sample analyses were described in a previous report (Powell et al, 2001). The analysis of samples collected in March 2001 indicated that significant attenuation of metals from the DCPRB had occurred and that the majority of the attenuation had occurred upgradient of these sample locations.

In order to implement natural attenuation as a remediation, it is necessary to identify and quantify the mechanisms responsible for natural attenuation. To this end, samples from eight additional locations (DAB 81- 87 and 92) were collected in closer proximity to the DAB than the four previous upland sample locations. Locations DAB 85 and DAB 92 were selected as locations upgradient of 488-D with DAB 92 targeting the area of lowest $\mathrm{pH}$ at the DEXOU slightly downgradient from the DCPRB. Subsurface samples from directly underneath the berm between 488-D and 488-4D were taken at locations DAB 81 and DAB 87 . Locations DAB 83 and DAB 84 were selected as locations immediately down gradient of 488-D between $488-\mathrm{D}$ and the wetland area.

Location DAB 86 was selected for collection of source material directly from the center of the ash basin (488-D) in perched water just above the clay layer immediately below the ash basin. A second location on the berm on the west side of 488-D, DAB 82, was also investigated for collection of source material. This sample rendered only fill material from the berm and was not analyzed further. Ash material from 488-D (DAB 86) was evaluated further to provide information regarding geochemical characteristics and COC composition of potential source material with very different origin, composition, and potential COC signature than the source term generated by the D-Area Coal Pile and DCPRB. 
See Table 1 and Table 2 for approximate locations with respect to the DCPRB and DAB, for SRS coordinates, and for ground elevation at each location. Samples at DAB 82 (from ash basin berm) and DAB 86 (from ash basin) were collected as macrocore samples using a track rig. DAB 92 was collected as a macrocore sample using a drill rig. All other samples (DAB $81,83,84,85$, and 87 ) were collected using a rotasonic rig. Cores for samples DAB 82, 86 and 92 were $4 \mathrm{ft}$ long and $1 \frac{1}{2}$ inches in diameter (as were DCP samples collected previously), while DAB 81,83, 84, 85, and 87 were larger 4-inch diameter 10-ft long sections which were divided in order to transport the retained interval.

Table 1. Upland Sampling Locations

\begin{tabular}{|l|l|ccc|}
\hline \multicolumn{1}{|c|}{ Location } & \multicolumn{1}{|c|}{ Description } & $\begin{array}{c}\text { SRS } \\
\text { Northing }\end{array}$ & $\begin{array}{c}\text { SRS } \\
\text { Easting }\end{array}$ & $\begin{array}{c}\text { Ground } \\
\text { elev. (ft) }\end{array}$ \\
\hline DAB 92 & Near source (DCPRB, high impact) & 63907.03 & 19717.73 & 116.20 \\
DAB 85 & Up gradient of 488-D & 64109.05 & 19447.76 & 130.51 \\
DAB 81 & Beneath 488-D & 64335.39 & 18608.53 & 127.95 \\
DAB 87 & Beneath 488-D & 64309.34 & 17670.53 & 125.02 \\
DAB 84 & Down gradient of 488-D & 64389.99 & 17211.00 & 108.26 \\
DAB 83 & Down gradient of 488-D & 64790.61 & 17252.27 & 107.30 \\
DAB 86 & 488-D, Ash & 64566.37 & 18058.12 & 127.37 \\
DAB 82 & West berm 488-D (not analyzed) & 64622.50 & 17646.01 & 125.45 \\
DCP 211 & Near source (DCPRB) & 63523.28 & 19950.48 & 122.75 \\
DCP 168 & Distal portion of the plume & 65799.12 & 16552.25 & 97.30 \\
DCP 170 & Distal portion of the plume & 65935.51 & 16123.21 & 97.06 \\
DCP 171 & Distal portion of the plume & 66195.82 & 15337.16 & 97.53 \\
\hline
\end{tabular}

Within several hours of collection, all samples were taken directly to the laboratory for further analysis. The sample of ash, DAB 86, from 488-D was analyzed in a similar manner to all other samples collected. Prior to analysis samples were stored in a refrigerator at $4{ }^{\circ} \mathrm{C}$ in clear plastic liners used to collect the samples.

\subsubsection{Wetland Samples}

Two samples of soil (D-2 and D-4) from a presumed unimpacted area were collected. Samples G-10, H-5, J-6, and K-4 were collected from the top 1 foot of ash deposition in the wetland area (Table 2). These samples (G-10, H-5, J-6, K-4) compacted on collection considerably more than the presumed impacted soils (D-2 and D-4) due to the ash composition. 
Table 2. Wetland Sampling Locations

\begin{tabular}{|l|l|ccc|}
\hline Location & \multicolumn{1}{|c|}{ Description } & $\begin{array}{c}\text { SRS } \\
\text { Northing }\end{array}$ & $\begin{array}{c}\text { SRS } \\
\text { Easting }\end{array}$ & $\begin{array}{c}\text { Ground } \\
\text { elev. (ft) }\end{array}$ \\
\hline D-2 & Wetland soil, unimpacted & 65824.6 & 14683.9 & nd \\
D-4 & Wetland soil, unimpacted & 65189.1 & 14477.7 & nd \\
G-10 & Wetland ash, least impacted & 63010.3 & 14808.5 & nd \\
H-5 & Wetland ash & 64483.6 & 15631.7 & nd \\
J-6 & Wetland ash & 63966.2 & 16162.5 & nd \\
K-4 & Wetland ash, most impacted & 64485.1 & 16676.0 & nd \\
\hline
\end{tabular}

nd $=$ not determined

\subsection{GEOCHEMICAL ANALYSES}

Previously, "matched" porewater and soil samples (DCP168-211) were collected at adjacent but discrete depths. For the samples DAB 81-92 both porewater and soil analyses were carried out with porewater and soil separated from the same soil core sample. Porewater samples were analyzed within 6 months of collection, and soil samples were stored for up to 2 months prior to drying in air and sieving through a $2 \mathrm{~mm}$ sieve in preparation for further analysis.

\subsubsection{Porewater Analyses}

Porewater was separated from the soil of the sample core within 12 hours of the sample collection. The separation of soil and porewater was carried out using $50-\mathrm{mL}$ centrifuge filter tubes each fitted with a $20-\mathrm{mL}$ capacity filter insert with either a $0.45 \mu \mathrm{m}$ polypropylene membrane or $10 \mu \mathrm{m}$ polypropylene mesh. Typically, six tubes were filled to the insert capacity with soil and centrifuged at $7000 \mathrm{rpm}$ for 10 minutes $(0.45 \mu \mathrm{m}$ filter $)$ or at $1000 \mathrm{rpm}$ for 10 minutes $(10 \mu \mathrm{m}$ filter). The insert was removed and the soil reserved for further analysis.

Porewater redox potential and $\mathrm{pH}$ for each sample were measured immediately following separation from the soil. Flow-through $\mathrm{pH}$ and redox $\left(\mathrm{E}_{\mathrm{h}}\right)$ electrodes with an $\mathrm{Ag} / \mathrm{AgCl}$ flowthrough reference electrode (Microelectronics, Inc) were used for these measurements.

Porewater analyses for DAB upland samples were carried out at the Chemical Analysis Laboratory at the University of Georgia in Athens, GA. Porewater samples were analyzed for sulfate $\left(\mathrm{SO}_{4}{ }^{2-}\right)$ using a Braun+Luebbe Auto Analyzer II Continuous Flow System. 


\subsubsection{Soil Digestion Methods}

Four methods were used to measure COC concentration in the soils collected. Sequential extractions (Table 3) were carried out by Clemson University or WPT in SRNL. A singlestep extraction corresponding to the amorphous iron oxide step $\left(6^{\text {th }}\right.$ step) of the same sequential extraction procedure was conducted by WPT in SRNL. Total digestion (4.2.2.1) was carried out by ADS in SRNL or Clemson University. EPA Method 3050b (4.2.2.2) along with analyses of the leachate by Inductively Coupled Plasma-Atomic Emission Spectroscopy (ICP-AES) (suite of 30 elements) and Inductively Coupled Plasma-Atomic Mass Spectroscopy (ICP-MS) (suite of 19 elements) was performed on soil samples at the Chemical Analysis laboratory at the University of Georgia in Athens, GA.

Table 3. Description of Sequential Extraction Procedure Steps

\begin{tabular}{|c|c|c|c|c|}
\hline Fraction & Reagent & Description & Extraction Conditions & Targeted Phase \\
\hline $\begin{array}{c}1 \\
\text { DDI }\end{array}$ & $\begin{array}{l}\text { Distilled deionized } \\
\text { water }\end{array}$ & & $\begin{array}{l}\text { Tumble for } 16 \text { hours } \\
\text { at room temperature }\end{array}$ & $\begin{array}{c}\text { easily soluble salts and ions } \\
\text { already present in the soil } \\
\text { solution }\end{array}$ \\
\hline $\begin{array}{c}2 \\
\mathrm{CN} \text { or } \mathrm{MC}\end{array}$ & $\begin{array}{l}0.5 \mathrm{M} \text { calcium nitrate } \\
\text { or } \mathrm{MgCl}_{2}\end{array}$ & neutral salt & $\begin{array}{l}\text { Tumble for } 16 \text { hours } \\
\text { at room temperature }\end{array}$ & $\begin{array}{l}\text { Easily exchangeable } \\
\text { ions on soil surfaces }\end{array}$ \\
\hline $\begin{array}{c}3 \\
\mathrm{AA}\end{array}$ & $\begin{array}{l}0.44 \mathrm{M} \text { acetic acid } \& \\
0.1 \mathrm{M} \text { calcium nitrate }\end{array}$ & $\begin{array}{l}\text { weak acid w/ } \\
\text { neutral salt }\end{array}$ & $\begin{array}{l}\text { Tumble for } 8 \text { hours } \\
\text { at room temperature }\end{array}$ & $\begin{array}{l}\text { carbonate minerals, acid } \\
\text { exchangeable metals on the } \\
\text { soil surfaces }\end{array}$ \\
\hline $\begin{array}{c}4 \\
\mathrm{HH}\end{array}$ & $\begin{array}{l}0.01 \mathrm{M} \\
\text { hydroxylamine- } \\
\text { hydrochloride \& } \\
0.1 \mathrm{M} \text { nitric acid }\end{array}$ & $\begin{array}{l}\text { weak reducing } \\
\text { agent }\end{array}$ & $\begin{array}{l}\text { Tumble for } 0.5 \text { hours } \\
\text { at room temperature }\end{array}$ & Manganese oxides \\
\hline $\begin{array}{c}5 \\
\text { SP or HP }\end{array}$ & $\begin{array}{c}0.1 \text { M sodium } \\
\text { pyrophosphate (SP) } \\
\text { or hydrogen peroxide } \\
\text { (HP) }\end{array}$ & oxidizing agent & $\begin{array}{c}\text { Tumble } 24 \text { hours } \\
\text { at room temperature/SP } \\
\text { or } \\
85^{\circ} \mathrm{C} \text { for } 5 \text { hours } / \mathrm{HP}\end{array}$ & Organic matter \\
\hline $\begin{array}{c}6 \\
\mathrm{AO}\end{array}$ & $\begin{array}{c}0.175 \mathrm{M} \text { ammonium } \\
\text { oxalate \& } \\
0.1 \mathrm{M} \text { oxalic acid }\end{array}$ & $\begin{array}{l}\text { buffered mild } \\
\text { reducing agent }\end{array}$ & $\begin{array}{l}\text { Tumble } 4 \text { hours } \\
\text { in darkness } \\
\text { at room temperature }\end{array}$ & Amorphous iron oxides \\
\hline $\begin{array}{c}7 \\
\text { SD }\end{array}$ & $\begin{array}{c}0.15 \mathrm{M} \text { sodium } \\
\text { citrate, } 0.05 \mathrm{M} \text { citric } \\
\text { acid, \& } 25 \mathrm{~g} / \mathrm{L} \\
\text { sodium dithionite }\end{array}$ & $\begin{array}{l}\text { buffered strong } \\
\text { reducing agent }\end{array}$ & $\begin{array}{l}\text { Shake for } 0.5 \text { hours } \\
\text { in water bath at } 50^{\circ} \mathrm{C}\end{array}$ & Crystalline iron oxides \\
\hline $\begin{array}{c}8 \\
\text { PD }\end{array}$ & $\begin{array}{l}48 \% \text { hydrofluoric } \\
\text { acid \& } \\
\text { aqua regia }\end{array}$ & $\begin{array}{l}\text { Strong } \\
\text { corrosive }\end{array}$ & Microwave digestion & all remaining solids \\
\hline $\begin{array}{l}\text { Total } \\
\text { Digestion } \\
\text { TD }\end{array}$ & $\begin{array}{l}48 \% \text { hydrofluoric } \\
\text { acid \& } \\
\text { aqua regia }\end{array}$ & $\begin{array}{l}\text { Strong } \\
\text { corrosive }\end{array}$ & Microwave digestion & $\begin{array}{c}\text { Total digestion of untreated } \\
\text { soil }\end{array}$ \\
\hline
\end{tabular}

Note: Adapted from Miller et al. (1986). 
WSRC-TR-2004-00124, REVISION 0

\subsubsection{Total Digestion}

Total digestions were carried out in the same manner as partial digestion Step 8 in the sequential extraction procedure.

\subsubsection{EPA Method 3050b}

Soil samples for the EPA Method 3050b were air dried and 1.0-2.0 g of a sieved material (10-20 mesh) were placed into a conical beaker and $10 \mathrm{~mL}$ of $50 \%$ nitric acid added. The beaker was covered with a watch glass and heated to $90{ }^{\circ} \mathrm{C}$ on a hot plate and refluxed for 10 minutes. This step was repeated if necessary, then evaporated to $5 \mathrm{~mL}$, cooled, hydrogen peroxide added, then $\mathrm{HCl}$ and refluxed for 15 more minutes. The sample was allowed to settle or filtered as needed.

\subsubsection{Sources of Analytical Error}

\subsubsection{Data $Q A$}

A subset $(10 \%)$ of all soil digestion calculations was recalculated from original data to validate.

\subsubsection{Analytical Method Interferences}

For the four COCs (Be, Ni, U, As) the primary analytical method utilized for both porewater and soil analyses was ICP-MS. This method can provide a suite of elements in a single analytical run, however, as with any analytical method, errors peculiar to each analyte and matrix are possible. Johnson (1995) identified several contamination and ICP-MS analytical interference issues associated with the sequential extraction procedure used herein. In particular, nickel results from the easily exchangeable step are typically poor because there is an analytical interference for all isotopes of mass 56 through 65 due to polyatomic complexes of $\mathrm{CaO}^{+}, \mathrm{CaOH}^{+}$, and $\mathrm{NO}_{3}{ }^{+}$from the $0.5 \mathrm{M}$ calcium nitrate solution. The acid soluble step shares these interferences from the $0.1 \mathrm{M}$ calcium nitrate. High nickel blanks (relative to sample concentration) are observed in both the acid soluble and easily exchangeable sequential extraction steps. There are also matrix interferences associated with the digestion steps due to the presence of polyatomic ions of chloride and fluoride from the $\mathrm{HCl}$ and $\mathrm{HF}$ acids which affect the nickel and arsenic results. Typically a digestion matrix blank subtraction was carried out to account for this type of interference; however, matrix interferences from other elements in the soil itself are expected. Where multiple blanks were measured the error in the blank subtraction was propagated.

For arsenic, ICP-MS data was validated for all DCP soil samples by graphite furnace Atomic Absorption (AA) spectroscopy, and total digestion samples were validated by comparison with cold vapor AA.

For comparable methods, data was plotted to validate [e.g., single step extraction versus the sum of the first six steps of the sequential extraction procedure (SE sum 1-6) and also total digestion versus the sum of the eight steps (SE sum 1-8)]. This method was used to identify spurious data (typically greater than $20 \%$ error). The most variability was found for nickel. Some variability was observed for uranium data as well for soil digestions although uranium concentrations in these samples in general were low and subject to matrix interferences as compared to the matrix blank. 
Where available, sequential extraction data was used to determine the available (SE sum of steps 1-6) and total (SE sum of steps 1-8) COC concentrations in D-Area soils. Where sequential extraction data was not available, single-step extraction data was used for the available, and total digestion was used for the total COC concentration in soil.

In general, for the four trace metals $\mathrm{Be}, \mathrm{Ni}, \mathrm{U}$, and As data from the single step extraction and SE sum 1-6 were combined to form one set of data to describe the available COC fraction in soil for all locations and total digestion and SE sum 1-8 data were combined to form a single set to describe the total COC.

\subsubsection{Characterization of Soil Properties}

\subsubsection{Cation and Anion Exchange Capacity}

The cation exchange capacity (CEC) was determined using an unbuffered salt extraction method by Sumner and Miller (1996), which allowed analysis of the CEC at the "field pH" of the soil. It consisted of the following steps: Saturation of the soil exchange sites with five extractions of the sample with $0.2 \mathrm{M}$ ammonium chloride, followed by removal of the entrained salt with three $0.04 \mathrm{M}$ ammonium chloride washes. Next, the volume of solution entrained in the soil was measured, and finally the bound ammonium ions were displaced with five extractions of the soil sample with a $0.2 \mathrm{M}$ solution of potassium nitrate. The potassium nitrate extract (combined extracts diluted to a final volume of $250 \mathrm{~mL}$ with $0.2 \mathrm{M}$ potassium nitrate) was analyzed for ammonium concentration (solution ppm) and the CEC, in centimoles of cation charge per kilogram, was calculated using the following equation:

$$
\mathrm{CEC}=\left(\text { weight of soil }(\mathrm{g}) \times \mathrm{NH}_{4}{ }^{+}\right) / 18-0.80 \times \text { volume entrained solution }(\mathrm{mL})
$$

The anion exchange capacity (AEC) was calculated using the measured solution ppm of chloride ions in the potassium nitrate extract:

$$
\mathrm{AEC}=0.14 \times \mathrm{Cl}^{-}-0.80 \times \text { milliliters entrained solution }
$$

\subsubsection{Particle Size Distribution by Micro-Pipette Method}

Soil texture was measured with a modified method for soil mechanical analysis (Miller, 1987). Four grams of soil were shaken overnight with a dilute dispersant $\left(1.25 \%\left(\mathrm{NaPO}_{3}\right)_{13}\right.$ in $1 \mathrm{M} \mathrm{NaOH}$ ), then allowed to settle for two hours before $2.5 \mathrm{~mL}$ solution was slowly sampled with an adjustable pipette from a depth of $2.5 \mathrm{~cm}$ for determination of clay (particles $<2 \mu \mathrm{m}$ ). The sample solution was dried at $105^{\circ} \mathrm{C}$ to obtain a dry mass of clay. Next, the suspension was sieved with a 270 -mesh sieve to remove sand. The sand was dried and weighed as well, and silt was determined by the difference in mass of the original soil and the sum of the clay and sand fractions. 
WSRC-TR-2004-00124, REVISION 0

\subsection{MICROBIOLOGICAL MATERIALS AND METHODS}

\subsubsection{Bacteria Densities}

Comprehensive analysis of specific microbial populations and characterization of the metabolic activity of site microbial communities can be an effective tool to predict an environmental system's bioremediation potential. These analyses can enable monitoring the activity of specific microorganisms in reducing and/or removing harmful groundwater contaminants. In this project sediment samples were collected from fresh cores and transported to the lab for immediate microbiological processing. Five grams of sediment from each fresh core sample was weighed and mixed with $45 \mathrm{ml}$ sterile Bacto FA Buffer (Difco Laboratories phosphate buffer) and vortexed for four minutes to form a 1:10 sediment slurry dilution.

\subsubsection{Total Counts}

Total microbial population densities in sediments were determined by a direct count method (Balkwill, 1989). The 1:10 soil slurry (Section 4.3.1) was further diluted and ten microliters of two sediment slurry dilutions $(1: 10,000$ and 1:100,000) were placed onto wells of toxoplasmosis slides. The slides were stained with fluorescein isothiocyanate (FITC) and total bacteria were counted at 1000X magnification on a Zeiss Axioskop Epifluorescent microscope.

\subsubsection{Viable Counts}

The viable, culturable microbial population densities of aerobic and facultatively anaerobic, heterotrophic bacteria in sediments were determined using agar plate techniques. Viable, culturable sediment bacteria were enumerated on Nucleopore $47 \mathrm{~mm}, 0.45 \mu \mathrm{m}$ polycarbonate filters, which were placed on solid agar plates. Three agar plate media types were utilized.

- Peptone-Try tone-Yeast extract-Glucose (PTYG) medium

- One percent PTYG medium (a more dilute Peptone-Try tone-Yeast extract-Glucose)

- Commercially prepared anaerobic PYG plates (Peptone-Yeast Extract-Glucose) by Anaerobe Systems of Morgan Hill, CA

One percent PTYG was used as it is a low nutrient medium simulating SRS oligotropic groundwater (Balkwill, 1989). Although the PTYG and the one percent PTYG plates contained no fungal inhibitor, i.e., cycloheximide, little fungal was detected directly from porewater. The $\mathrm{pH}$ of the PTYG and one percent PTYG plates was adjusted to $\mathrm{pH} 3.00, \mathrm{pH}$ 4.00, and $\mathrm{pH} 5.00$ for testing of the upland sediments in order to better simulate environmental conditions. The $\mathrm{pH}$ was adjusted to $\mathrm{pH} 7.00$ for testing of the wetland samples. The initial dilution and two additional dilutions (1:1,000 and 1:100,000) of this slurry were filtered onto the Nucleopore filter and the filters were placed on the agar medium. All plates were incubated at $30^{\circ} \mathrm{C}$, and microbial colony forming units (CFU) determined at both 24 and 48 hours. Plates for anaerobic viable and culturable bacteria were incubated in Bio-Bag Environmental Chamber Type A by Becton Dickinson Microbiology Systems, Cockeysville, MD, or in BBL Anaerobic Gas Pak System Jars. Not all media types were used for all samples. Table 27 and Table 28 indicate the media types used for each sample. 


\subsubsection{Bacteria Identification}

Select bacterial colonies from upland agar plates were picked, streaked and restreaked for purity onto Tryptic Soy Agar plates (Difco Laboratories) before being gram stained (BBL ${ }^{\mathrm{TM}}$ Gram Stain Kit) for gram reaction and cell morphology. The bacterial isolates were then streaked onto BUG (Biolog ${ }^{\circledR}$ Universal Media + 5\% sheep blood), diluted into Biolog ${ }^{\circledR}$ inoculating fluid at $20 \%$ to $52 \% \mathrm{~T}$ (depending upon Gram reaction and cell type), and then inoculated into Biolog GramNegative2 or GramPositive2 plates. The Biolog® plates were read on a Biolog ${ }^{\circledR}$ plate reader after 15 to 24 hour incubation and the bacteria were identified using MicroLog 3 Software and databases.

\subsubsection{Tests for Bacteria by Metabolic Function}

The upland sediments were tested for iron reducing bacteria, sulfate reducing bacteria, and acid producing bacteria using MICkits ${ }^{\mathrm{TM}}$ by Bioindustrial Technologies, Inc. (BTI). Results are recorded as acid producing, iron reducing, and sulfate reducing viable bacteria per gram wet weight sediment.

\subsubsection{Ecofunctional Enzyme Activity}

Community-level physiological analysis using Biolog ${ }^{\circledR} \mathrm{GN} 2$ plates can determine the substrate utilization rate of 95 carbon sources by microorganisms in the sediments. The 1:10 soil slurry (Section 4.3.1) and further dilutions of this slurry was diluted and used to inoculate duplicate Biolog ${ }^{\circledR}$ GN2 microtiter plates to determine ecofunctional enzyme activity at numerous slurry dilutions $-1 / 10,1 / 100,1 / 1000$, and $1 / 10,000$. At 24 and 48 hours incubation, the Biolog ${ }^{\circledR}$ plates were read on a Biolog ${ }^{\circledR}$ plate reader (wavelength $590 \mathrm{~nm}$ ) so that the optical density of each well in the plate could be assessed. The color intensity due to substrate utilization in the Biolog ${ }^{\circledR}$ GN2 wells was expressed and calculated as the mean of the 95-absorbance values corrected for the background control.

A trial was run to access the buffering capacity of the Biolog ${ }^{\circledR}$ GN2 microtiter plates. This trial would help in understanding if fluctuations in ecofunctional enzyme activity could be attributed to $\mathrm{pH}$ differences of the slurries added to them. Duplicate sets of Biolog ${ }^{\circledR}$ GN2 Microplates were inoculated with sterile filtered nano pure water that was adjusted with dilute $\mathrm{HCl}$ to $\mathrm{pH} 5, \mathrm{pH} 4$ and $\mathrm{pH} 3$ respectively. All of the liquid in each duplicate set was tested for $\mathrm{pH}$ at time zero, 24 and 48 hours. Sterile tips and sterile reservoirs were changed for each $\mathrm{pH}$ setup.

\subsubsection{Microbial Buffering Activity}

Select aerobic bacteria isolates were tested from 2002 D-Area sediment samples for influence on $\mathrm{pH}$. The isolates were inoculated into prepared low nutrient 1\% Peptone Tryptone Yeast Extract Glucose (PTYG) broth. The cultures were then incubated on shaking platforms at room temperature. The $1 \%$ PTYG broth was selected since it is low in nutrients similar to D-Area sediment pore water. The 1\% PTYG broth included 3 sets of duplicates; $\mathrm{pH} 4$, pH 5 and $\mathrm{pH}$ 6. Based on the sulfurous D-Area coal pile conditions $6 \mathrm{~mol} \mathrm{H}_{2} \mathrm{SO}_{4}$ was used to adjust the broth $\mathrm{pH}$ to $4,1 \mathrm{~mol} \mathrm{H}_{2} \mathrm{SO}_{4}$ was used for $\mathrm{pH} 5$, and $0.1 \mathrm{~mol}$ was used for preparation of the $\mathrm{pH} 6$ media. The cultures were then observed for growth at 24, 48, and 72 hours. Those that did not grow in the low $\mathrm{pH}$ media were tested for viability on $\mathrm{pH} 71 \%$ PTYG plates. 
WSRC-TR-2004-00124, REVISION 0

\subsection{RESULTS}

\subsection{GEOCHEMICAL CHARACTERIZATION}

\subsubsection{Porewater Analyses}

Geochemical porewater analyses are summarized in Table 4 through Table 6 (major ions), and Table 7 through Table 9 (trace metals). Sampling depth and elevation, and porewater $\mathrm{pH}$, Eh and sulfate are included at each location for comparison.

\subsubsection{D-Area Ash Basin (488-D) Porewater}

Porewater from the subsurface ash sample, DAB 86, corresponds to perched water just above the tight clay residing in at the bottom of 488-D. This porewater was characterized by both oxidizing conditions $(\mathrm{Eh}=341.3 \mathrm{mV})$ and high $\mathrm{pH} 7.50$ (Table 4). Trace metals found in high concentrations included uranium (224 ppb) and arsenic (19 ppb) in levels exceeding their primary MCLs (Table 7). Major ions aluminum, iron and manganese were present in relatively low levels (Table 4$)$. High levels of sulfate $(1785 \mathrm{ppm})$, an order of magnitude greater than its secondary MCL, were also present.

\subsubsection{2 pH, Redox (Eh), and Sulfate}

\subsection{Upland porewater samples}

Areas of low $\mathrm{pH}$, high $\mathrm{Eh}$, and high sulfate serve to delineate the paths of relatively welldefined coincident plumes in the vicinity of the DCPRB (Figure 4 through Figure 10). Increasing $\mathrm{pH}$, decreasing $\mathrm{Eh}$, and sulfate follow the general groundwater flow path from the DCPRB beneath the 488-D toward the Savannah River with greatest impact (lowest $\mathrm{pH}$, highest Eh and highest sulfate) near DAB 92 (adjacent to the DCPRB). Field measurements of $\mathrm{pH}$ were found to be in the range of 3.18 to 7.98 for all locations sampled (See Table 4 and Table 5).

\subsection{Wetland porewater samples}

Based on the on the assumption that the groundwater between the wetland and upland regions is connected, comparisons are made between the upland and wetland section microbiology and geochemistry. Both microbiologicals and geochemical characteristics of the groundwater change significantly between the two regions. The wetland porewater samples contained only low levels of COCs with none of the four COCs considered here over the MCL. Sulfate levels were lower by almost two orders of magnitude lower than both the ash sample (DAB 86) and the DAB upland samples such as DAB 8428 which based on high sulfate and trace metals was likely in the center of the plume. 


\subsubsection{Major Ion and Trace Metal Analyses}

Given the high concentrations of COCs measured in the 488-D ash (DAB 86) and known to exist in the DCPRB, porewater collected from all other sampling locations contained relatively low concentrations of COCs. Of the four primary trace metals analyzed $(\mathrm{Be}, \mathrm{Ni}$, $\mathrm{U}, \mathrm{As}$ ), beryllium had the largest number of porewater samples exceeding its MCL of $4 \mathrm{ppb}$. Uranium concentrations in porewater exceed its MCL only for the ash sample from 488-D, DAB 86. Porewater data for the elements beryllium and uranium were only available for DAB and not DCP sampling locations. Nickel exceeds the Region 9 PRG of 730 ppb at two locations near the DCPRB and at a single distal location, DCP 170-p4.

\subsubsection{Comparison of Porewater Data to Existing Wells}

Sampling locations in this study were selected, in part, based on proximity to existing well locations (Table 10). This design was to provide a reference point for comparison of data collected in this study with existing well data. In order to implement MNA, long-term monitoring will be required to validate natural attenuation. This attenuation should be demonstrated through decreasing trends in groundwater concentration of COCs over time.

Porewater data followed similar trends to existing wells for the locations listed in Table 10. For example, DAB 92 4-6 $(\mathrm{Be}=30 \mathrm{ppb}, \mathrm{Ni}=1770 \mathrm{ppb}, \mathrm{U}=20 \mathrm{ppb}, \mathrm{As}=0.86 \mathrm{ppb})$ collocated with well DCP 70A ( $\mathrm{Be}=26 \mathrm{ppb}, \mathrm{Ni}=790 \mathrm{ppb}, \mathrm{U}=14 \mathrm{ppb}, \mathrm{As}=$ no data). Typical well screens are approximately $10 \mathrm{ft}$. Given the vertical stratification of the COC concentrations in the subsurface due to the relatively narrow vertical range of plume impact (particularly in close proximity to the DCPRB), it is not surprising that the data collected in this study over approximately 1 foot intervals does not represent exactly a given adjacent well screen. Sample data from this study might be collected from a section of a given well screen with higher or lower COC concentrations than the average value measured over the heterogeneous well screen. 
Table 4. Porewater Concentrations for Major Ions (Al, Fe, Mn) for DAB Locations

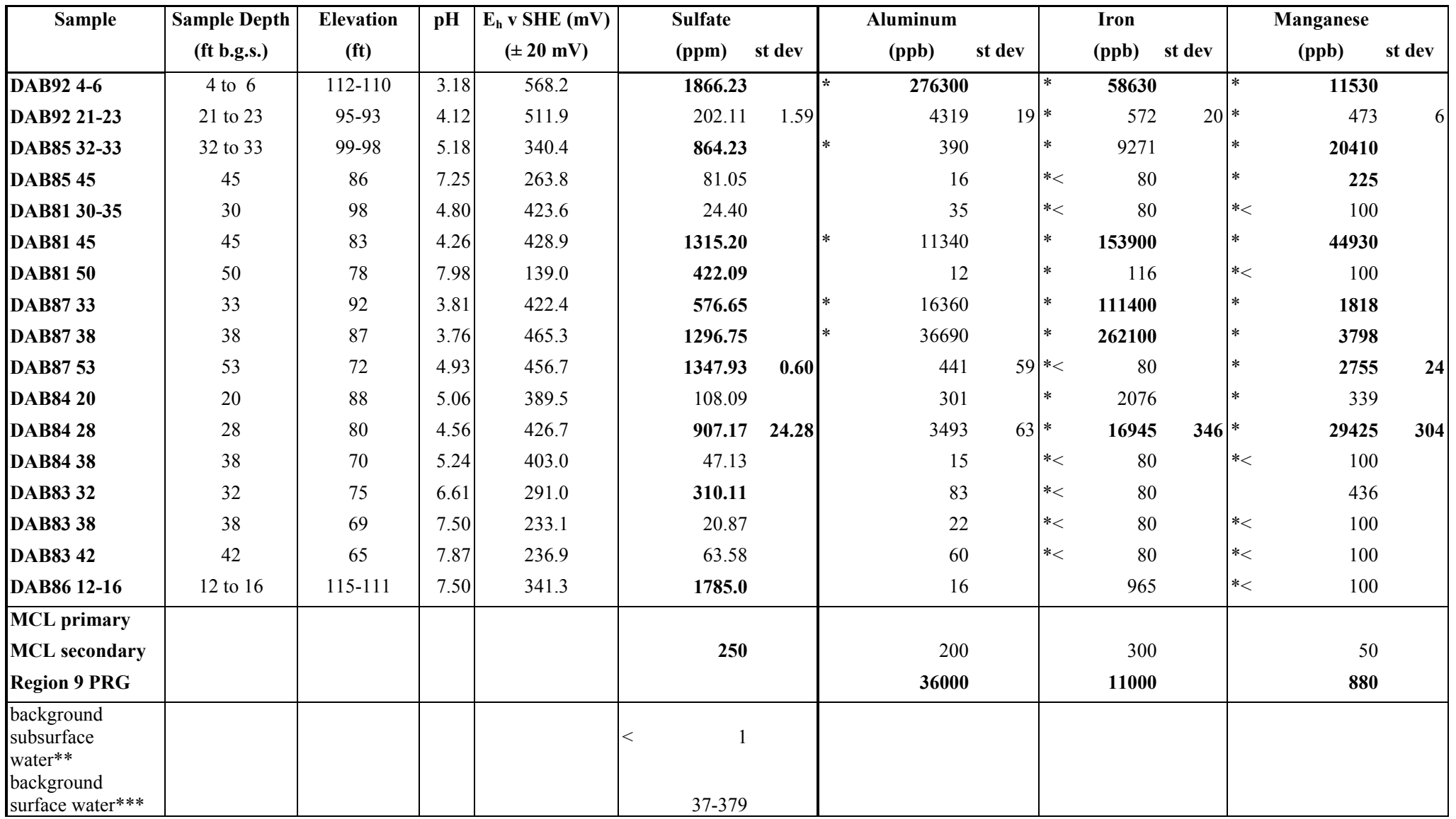

*ICP-ES

**Johnson (1995).

***WSRC-RP-99-4067 Rev 0 
WSRC-TR-2004-00124, REVISION 0

Table 5. Porewater Concentrations for Major Ions (Al, Fe, Mn) for DCP Locations

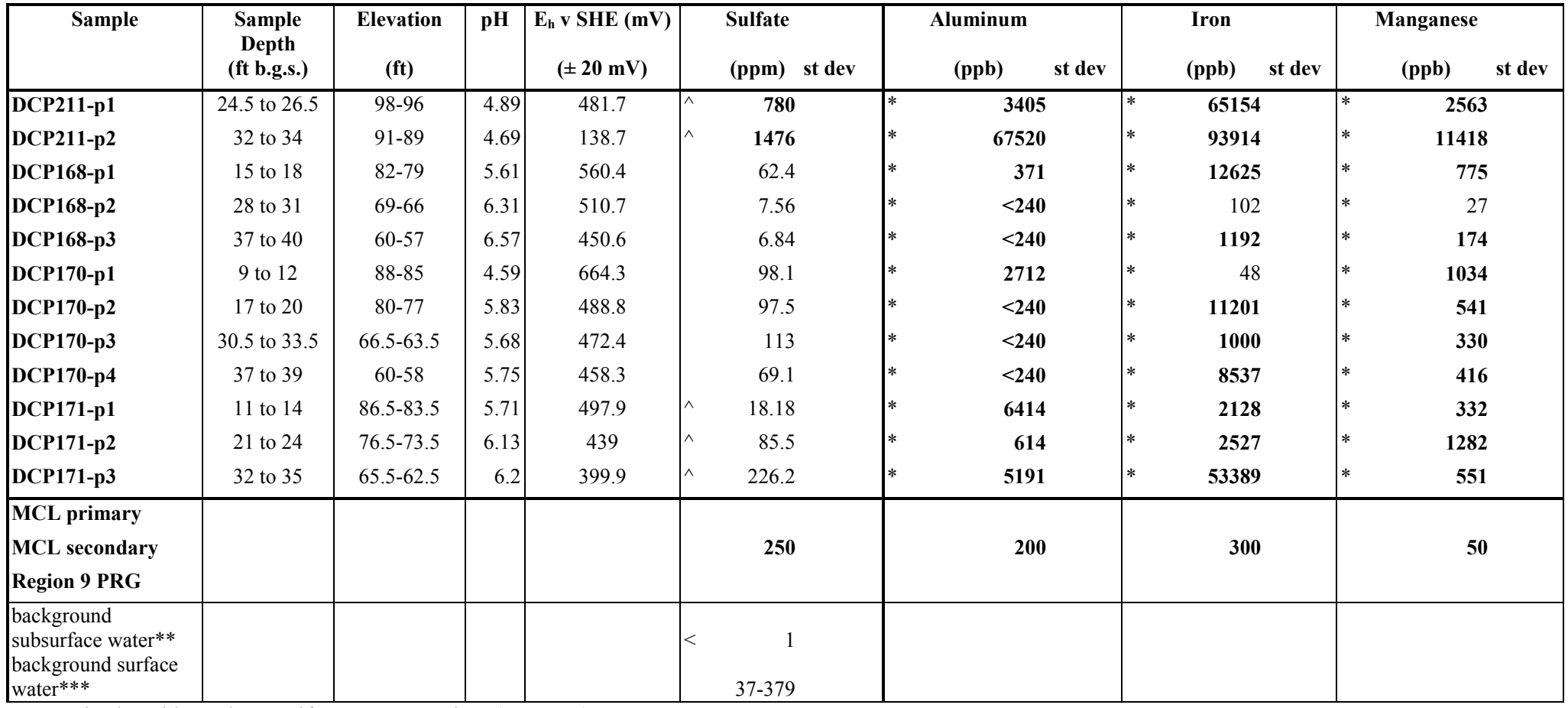

$\wedge=$ calculated based on sulfur concentration (ICP-ES)

*ICP-ES

**Johnson (1995).

***WSRC-RP-99-4067 Rev 0 
Table 6. Porewater Concentrations for Major Ions (Al, Fe, Mn) for Wetland Locations

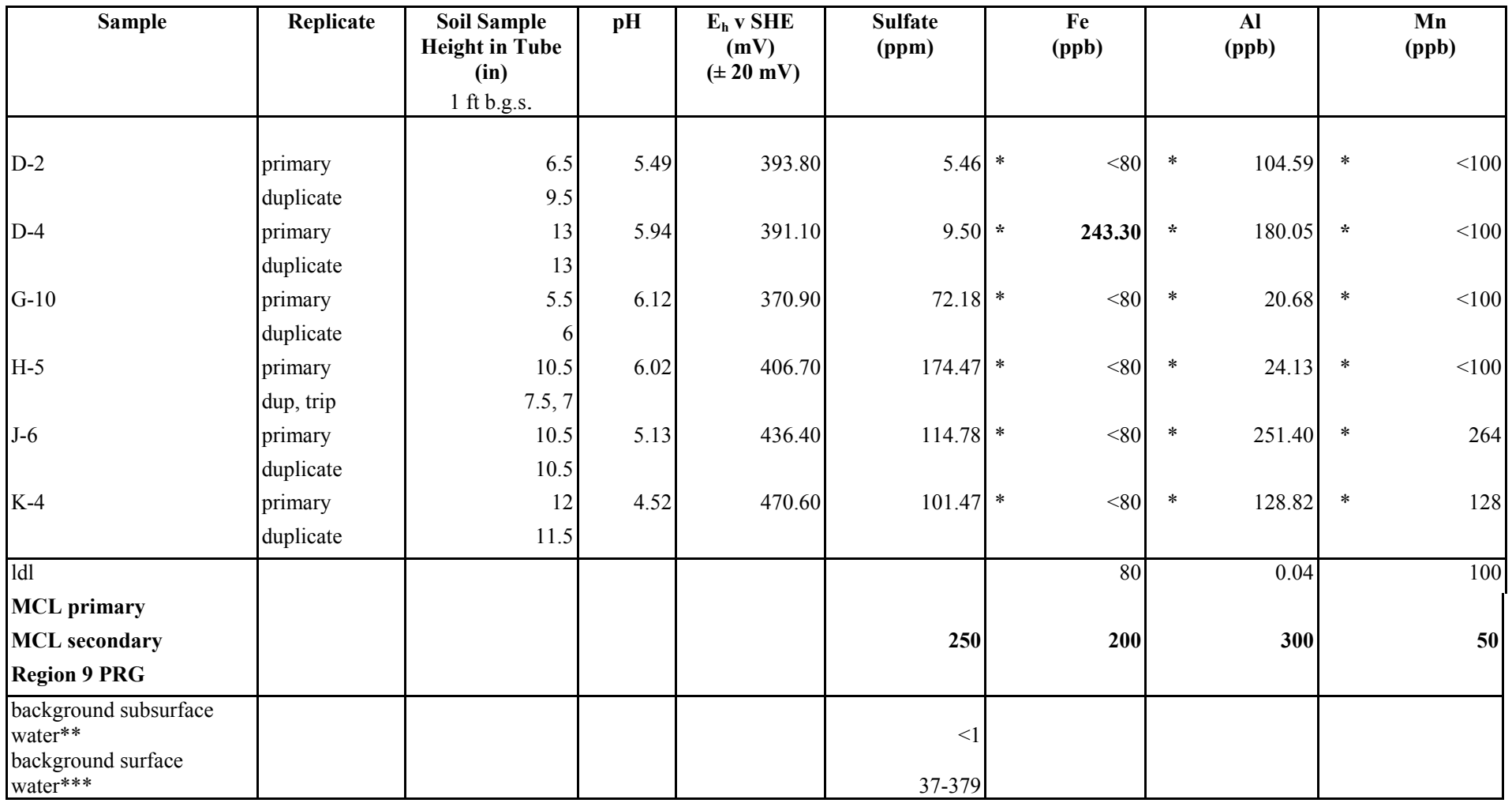

*ICP-ES

**Johnson (1995).

***WSRC-RP-99-4067 Rev 0 
WSRC-TR-2004-00124, REVISION 0

Table 7. Porewater Concentrations for Trace Elements (Be, Ni, U, As) for DAB Locations

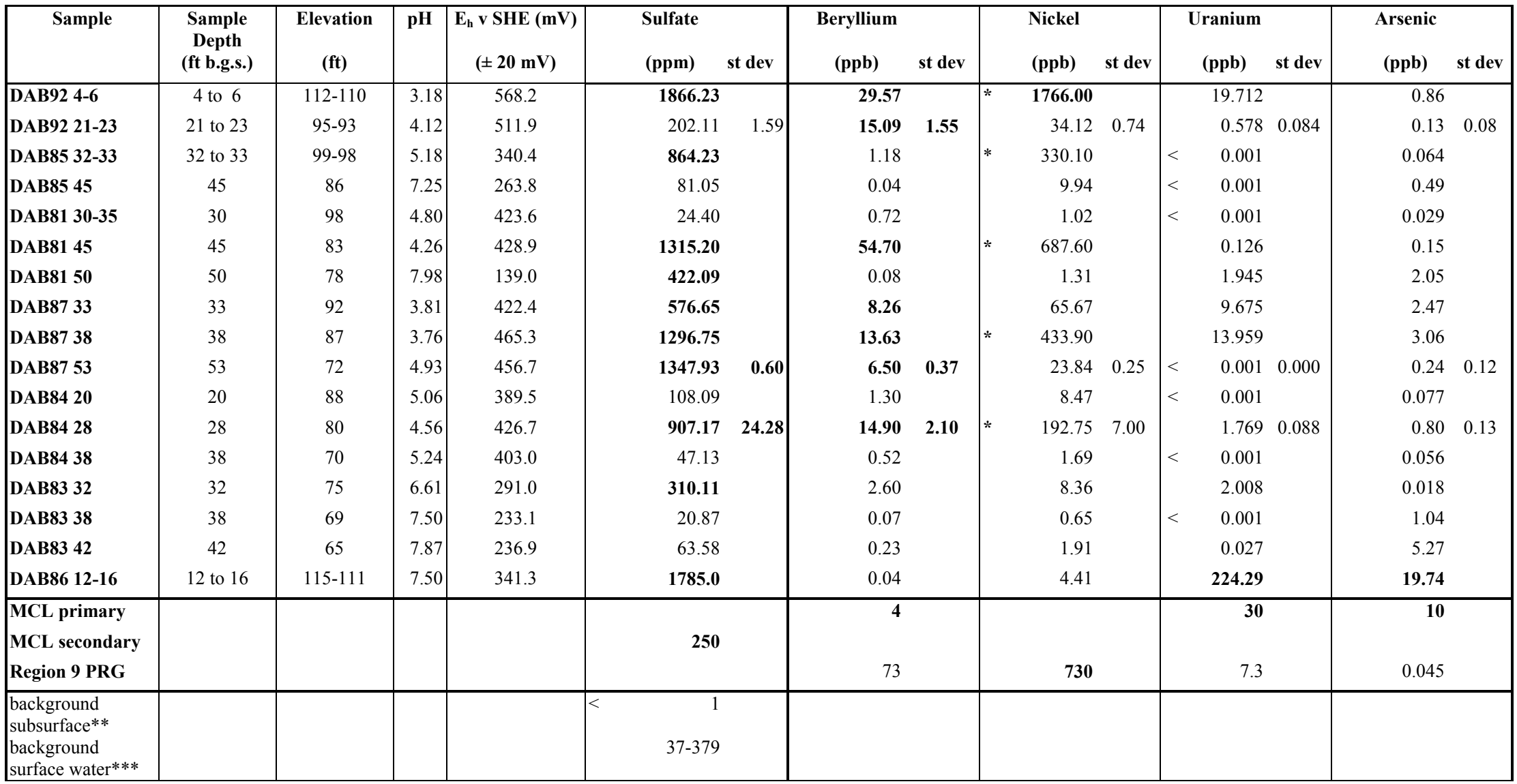

surface water***

*ICP-ES

**Johnson (1995).

***WSRC-RP-99-4067 Rev 0 
WSRC-TR-2004-00124, REVISION 0

Table 8. Porewater Concentrations for Trace Elements (Be, Ni, U, As) for DCP Locations

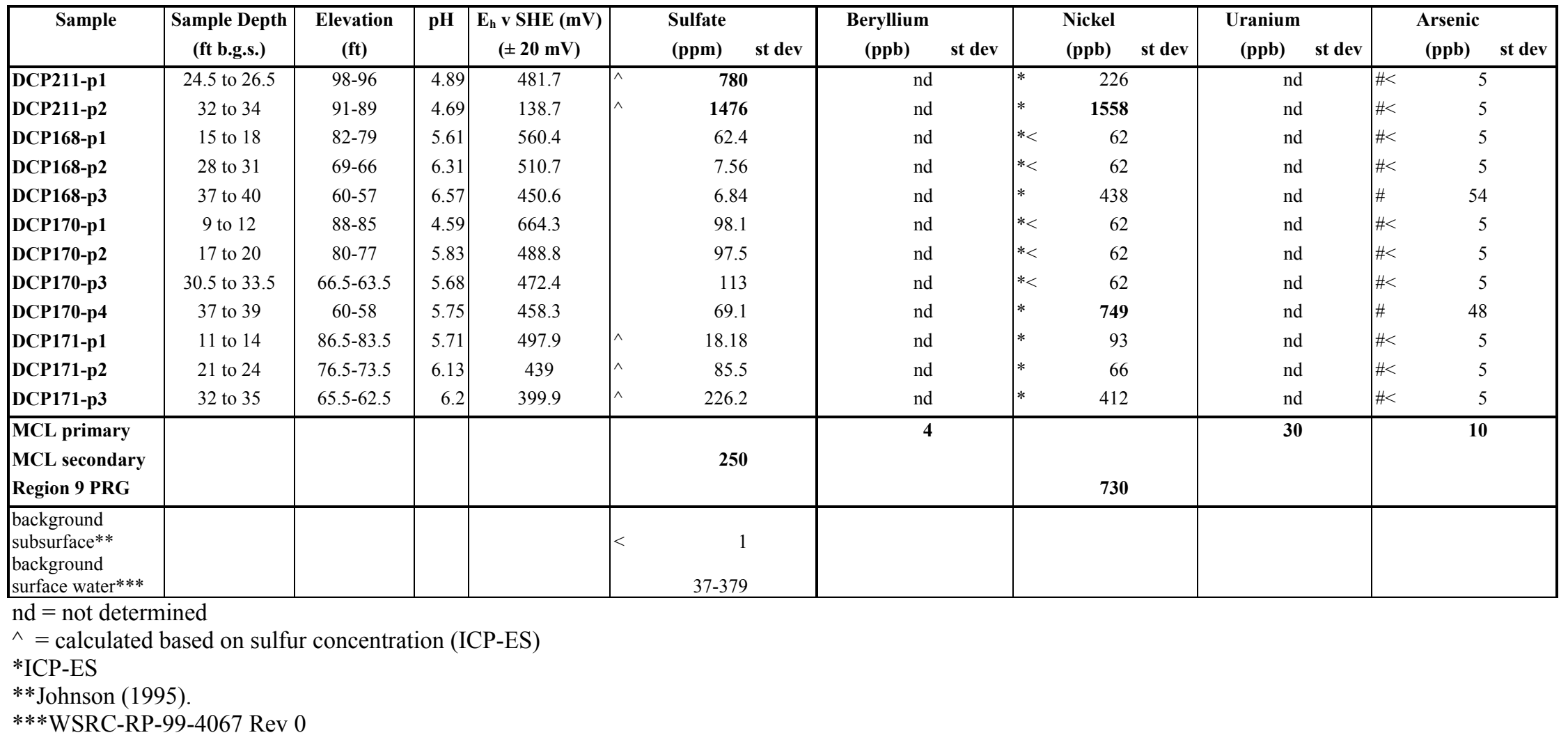


WSRC-TR-2004-00124, REVISION 0

Table 9. Porewater Concentrations for Trace Elements at Wetland Locations (ppb)

\begin{tabular}{|c|c|c|c|c|c|c|c|c|c|c|}
\hline Sample & $\begin{array}{c}\text { Sample Depth } \\
\text { (ft b.g.s.) }\end{array}$ & pH & $\begin{array}{c}\begin{array}{c}\text { Sulfate } \\
(\mathrm{ppm})\end{array} \\
\end{array}$ & $\begin{array}{l}\text { Beryllium } \\
(\text { ppb) }\end{array}$ st dev & $\begin{array}{l}\text { Nickel } \\
(p p b) \quad \text { st dev }\end{array}$ & $\begin{array}{l}\text { Uranium } \\
(\mathrm{ppb}) \quad \text { st dev } \\
\end{array}$ & $\begin{array}{l}\begin{array}{c}\text { Arsenic } \\
(p p b)\end{array} \quad \text { st dev } \\
\end{array}$ & $\begin{array}{l}\begin{array}{l}\text { Selenium } \\
(\text { ppb) }\end{array} \quad \text { st dev } \\
\end{array}$ & $\begin{array}{c}\text { Vanadium } \\
(\mathbf{p p b})\end{array}$ & st dev \\
\hline D-2 & 1 & 5.49 & 5.46 & 0.09 & 3.19 & 16.00 & 0.41 & 0.39 & 0.41 & \\
\hline D-4 & 1 & 5.94 & 9.50 & 0.54 & 2.90 & 4.51 & 0.48 & $<0.20$ & 0.48 & \\
\hline H-5 & 1 & 6.02 & 174.47 & 1.04 & 11.84 & 0.93 & 3.87 & 1.34 & 3.87 & \\
\hline $\mathrm{J}-6$ & 1 & 5.13 & 114.78 & 0.59 & 35.88 & 0.59 & 1.29 & 3.55 & 1.29 & \\
\hline K-4 & 1 & 4.52 & 101.47 & 1.26 & 18.76 & 0.44 & 2.26 & 1.49 & 2.26 & \\
\hline $\begin{array}{l}\text { MCL primary } \\
\text { MCL secondary } \\
\text { Region } 9 \text { PRG }\end{array}$ & & & 250 & 4 & 730 & 30 & 10 & 30 & 10 & \\
\hline $\begin{array}{l}\text { background } \\
\text { subsurface** } \\
\text { background } \\
\text { surface water*** }\end{array}$ & & & $\begin{array}{r}< \\
\quad 37-379 \\
\end{array}$ & & & & & & & \\
\hline
\end{tabular}

*ICP-ES

** Johnson (1995).

***WSRC-RP-99-4067 Rev 0 


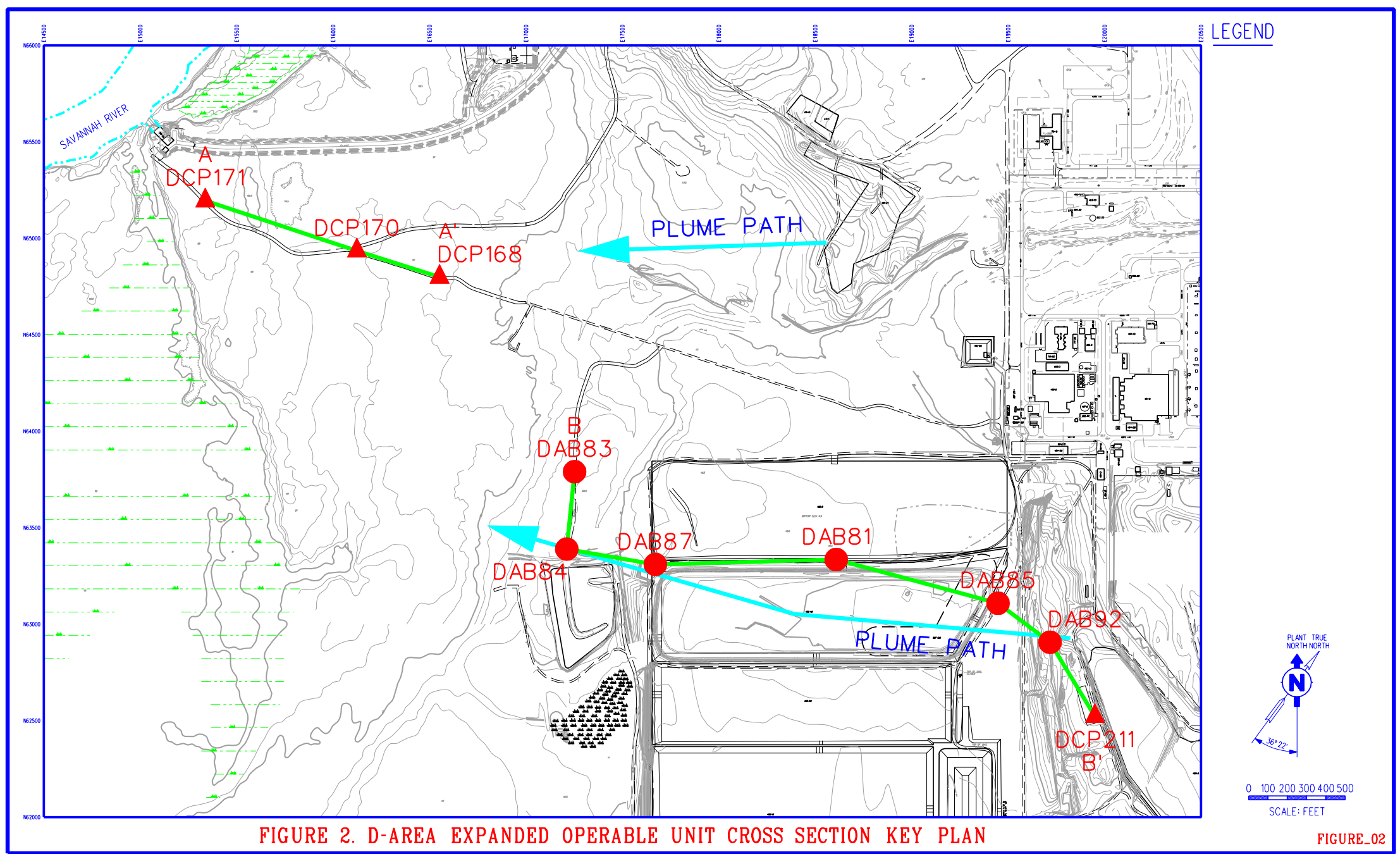

Figure 4. D-Area Expanded Operable Unit Plume Paths 
WSRC-TR-2004-00124, REVISION 0

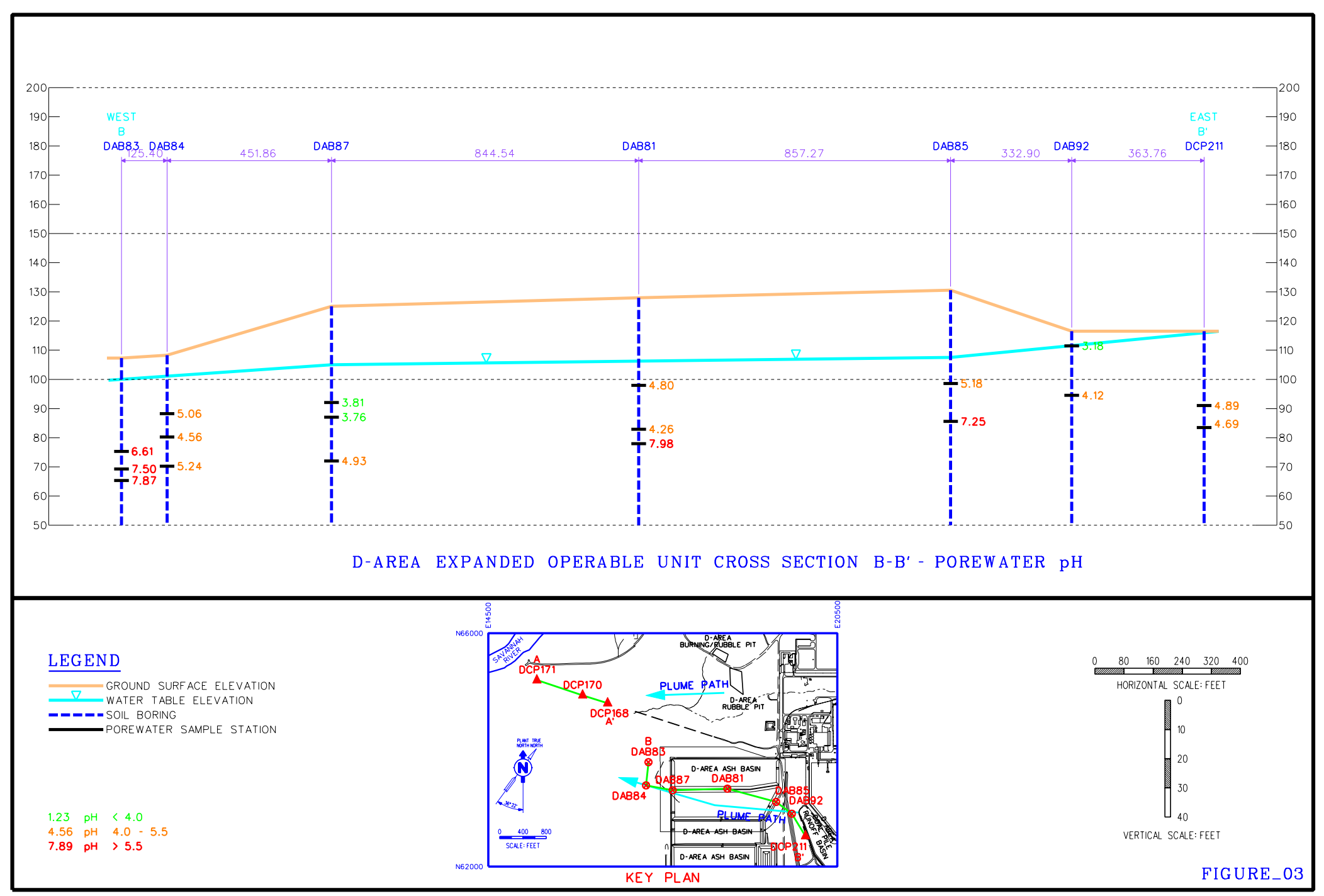

Figure 5. D-Area Expanded Operable Unit Cross Section B-B' - Porewater pH 
WSRC-TR-2004-00124, REVISION 0

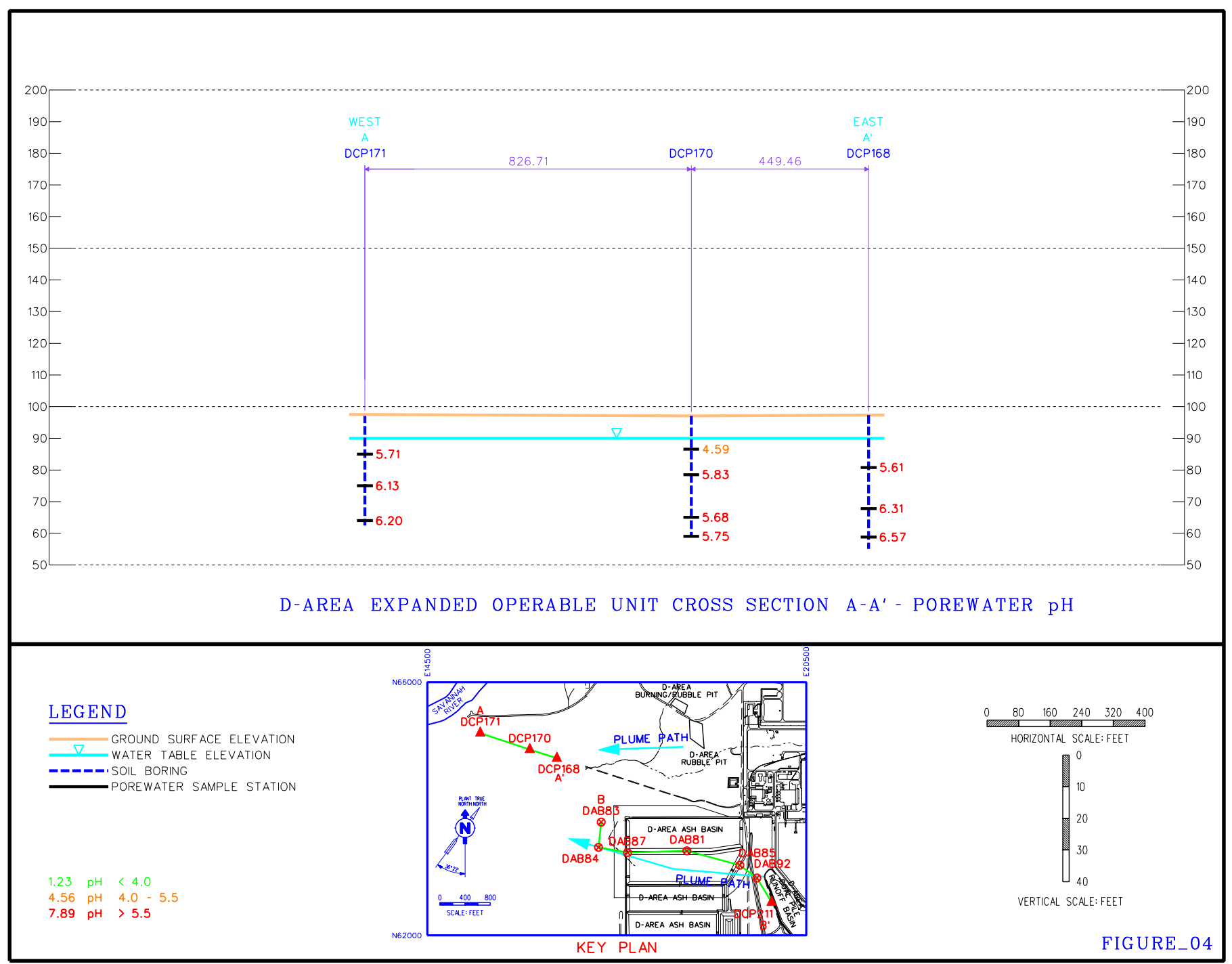

Figure 6. D-Area Expanded Operable Unit Cross Section A-A' - Porewater pH 
WSRC-TR-2004-00124, REVISION 0

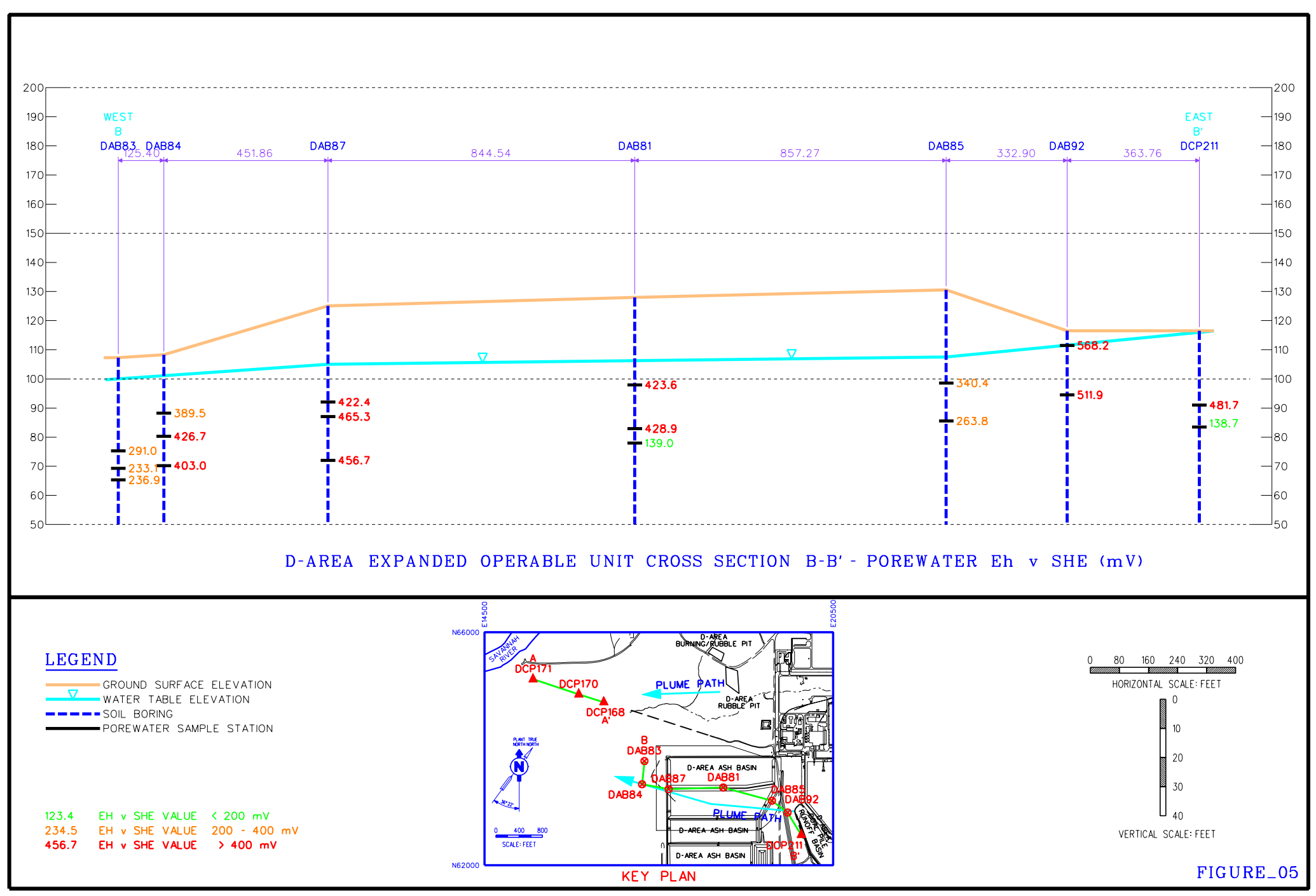

Figure 7. D-Area Expanded Operable Unit Cross Section B-B' - Porewater $E_{h} v$ SHE (mV) 
WSRC-TR-2004-00124, REVISION 0

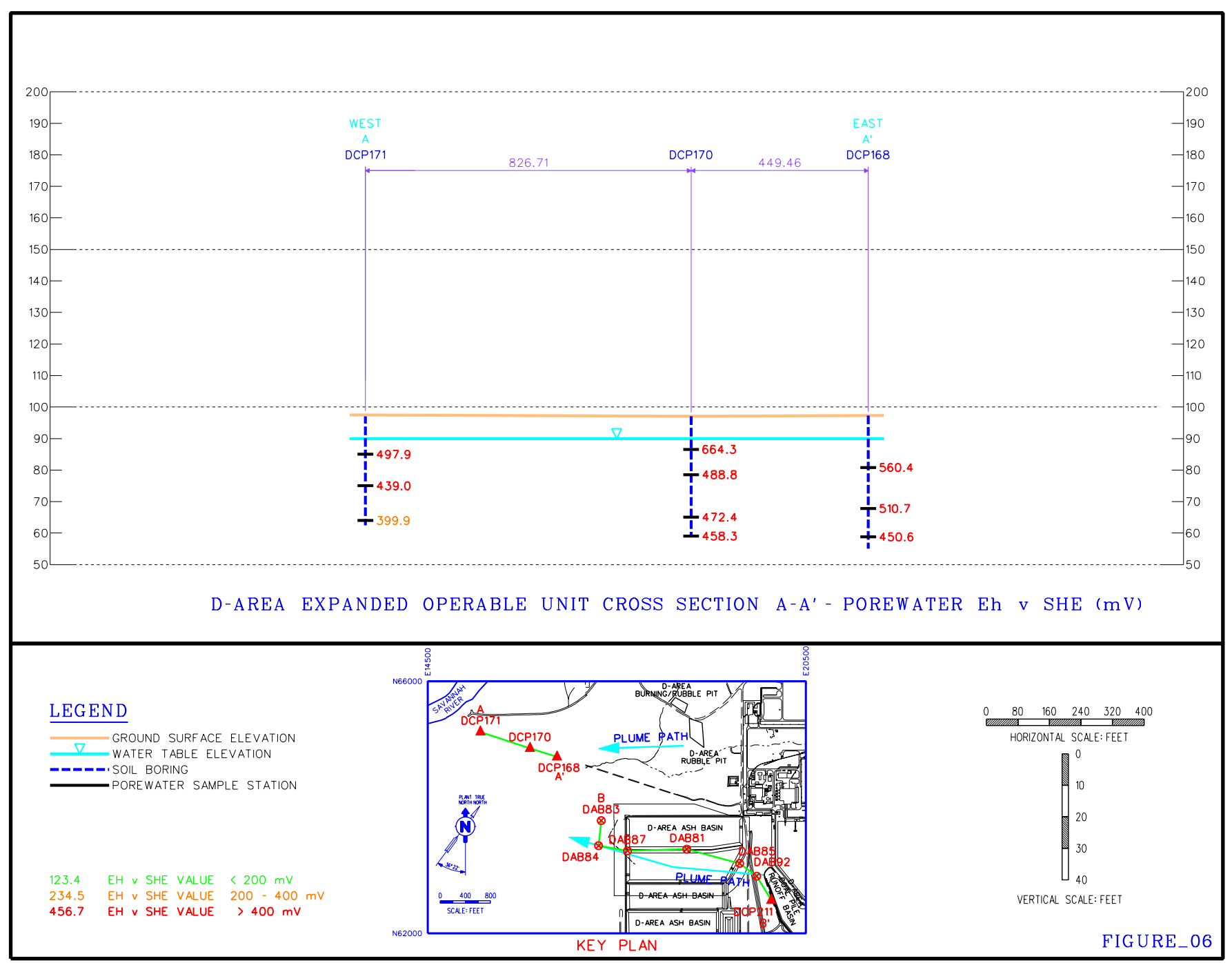

Figure 8. D-Area Expanded Operable Unit Cross Section A-A'- Porewater $\mathbf{E}_{\mathrm{h}} \mathrm{v}$ SHE (mV) 
WSRC-TR-2004-00124, REVISION 0

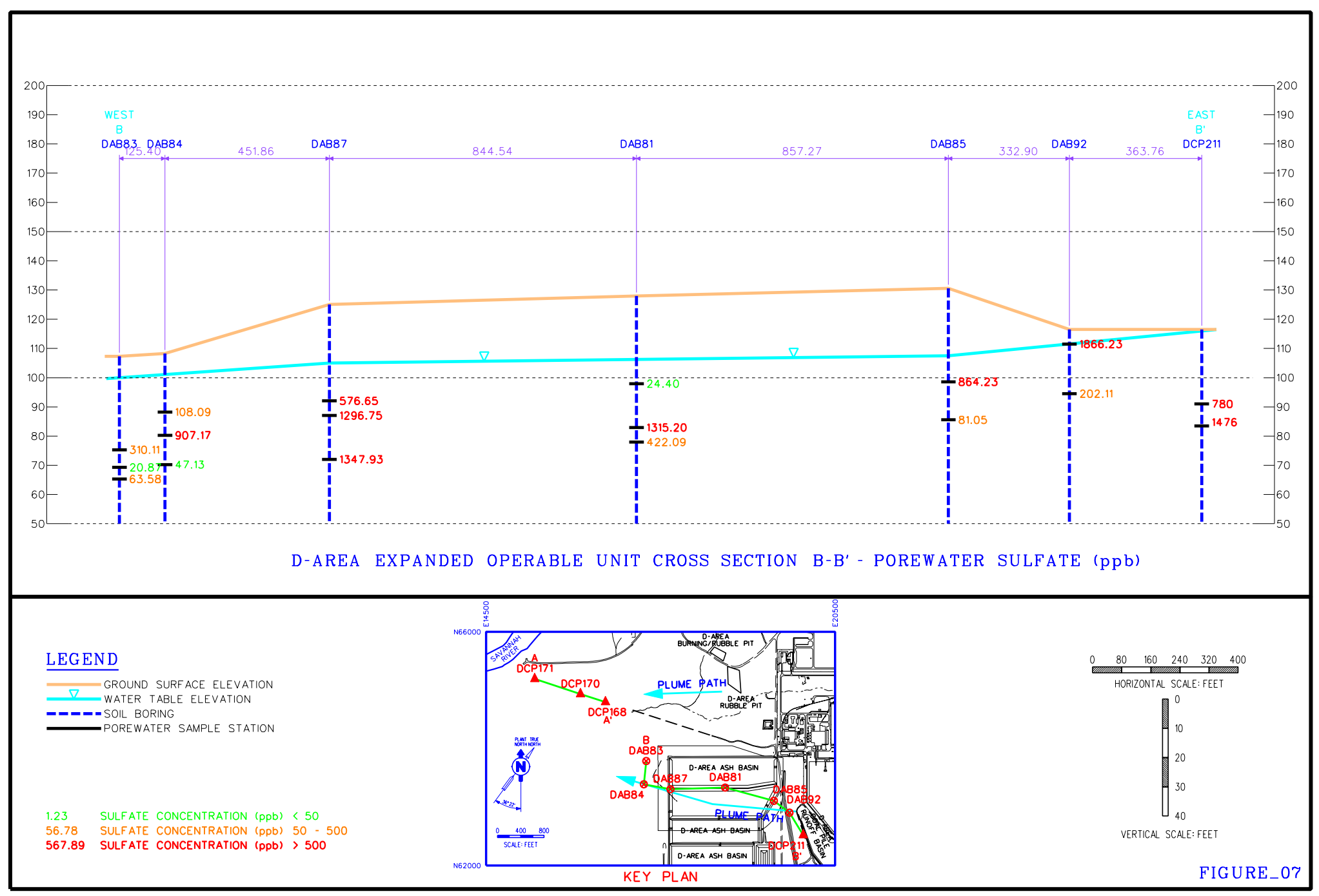

Figure 9. Area Expanded Operable Unit Cross Section B-B' - Porewater Sulfate (ppm) 
WSRC-TR-2004-00124, REVISION 0

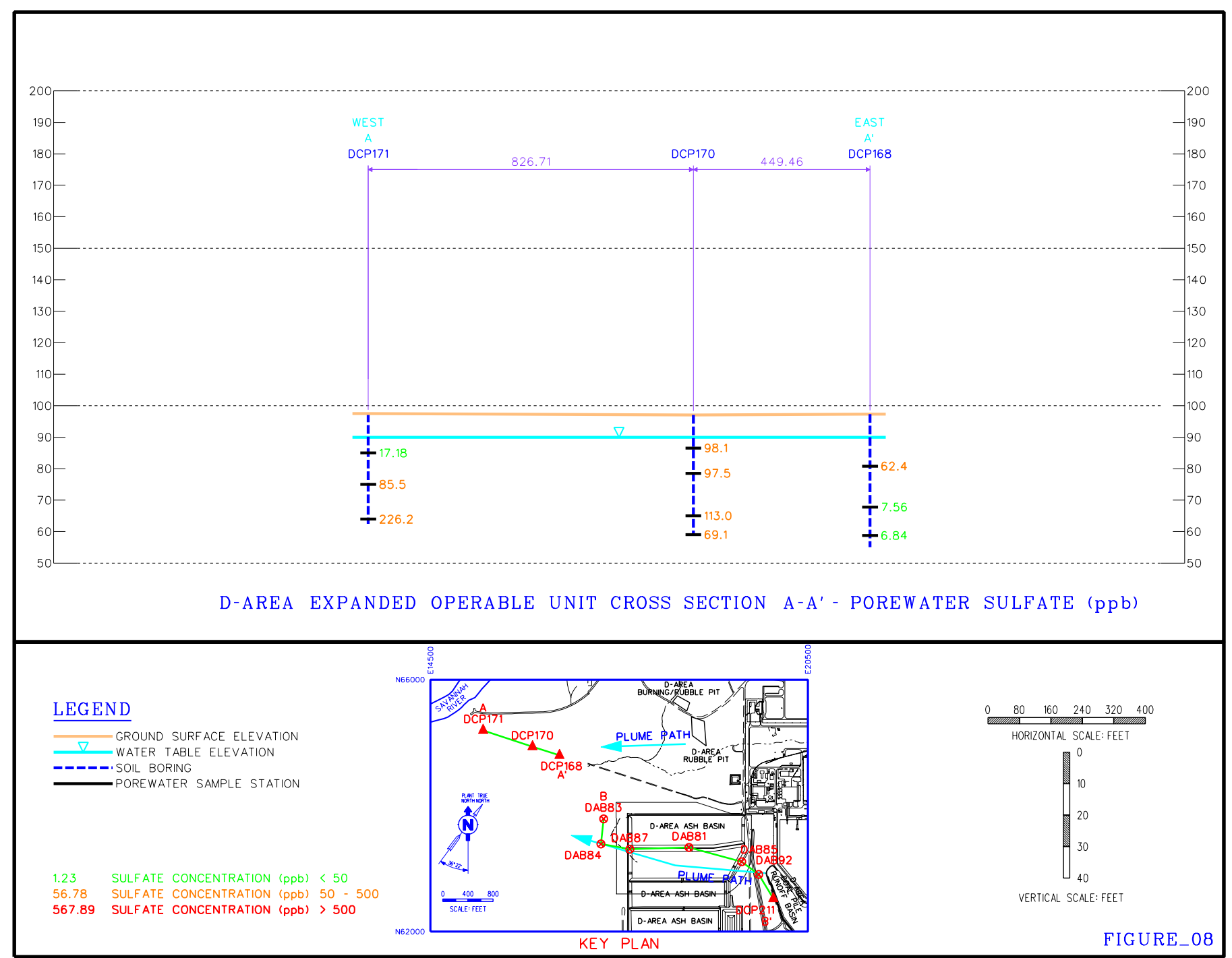

Figure 10. D-Area Expanded Operable Unit Cross Section A-A' - Porewater Sulfate (ppm) 
WSRC-TR-2004-00124, REVISION 0

Table 10. Well Data for Nearby Well Locations

\begin{tabular}{|c|c|c|c|c|c|c|c|c|}
\hline Sample & $\begin{array}{l}\text { Sample } \\
\text { Depth } \\
\text { (ft b.g.s.) }\end{array}$ & $\begin{array}{c}\text { Sample } \\
\text { Elevation } \\
\text { (ft) }\end{array}$ & $\begin{array}{c}\text { Well } \\
\text { Name }\end{array}$ & $\begin{array}{c}\text { Well } \\
\text { screen } \\
\text { Elevation } \\
\text { (ft) }\end{array}$ & $\begin{array}{c}\text { Beryllium } \\
\text { (ppb) }\end{array}$ & $\begin{array}{l}\text { Nickel } \\
\text { (ppb) }\end{array}$ & $\begin{array}{c}\text { Uranium } \\
\text { (ppb) }\end{array}$ & $\begin{array}{c}\text { Arsenic } \\
\text { (ppb) }\end{array}$ \\
\hline DAB92 4-6 & 4 to 6 & $112-110$ & DCB 70 A & $\begin{array}{c}114.5- \\
104.5\end{array}$ & 26.4 & 788 & 14 & No data \\
\hline DAB92 21-23 & 21 to 23 & $95-93$ & DCB 70 B & $95.6-90.6$ & 2.3 & $5.1 \mathrm{~J}$ & $0.04 \mathrm{~J}$ & No data \\
\hline DAB85 32-33 & 32 to 33 & $99-98$ & & & & & & \\
\hline DAB85 45 & 45 & 86 & DCB 38C & $90-80$ & 353 & 128 & 3.3 & $42 \mathrm{U}$ \\
\hline DAB81 30-35 & 30 & 98 & DCB 46C & $96-86$ & $112 J$ & 415 & 0.3 & $42 \mathrm{U}$ \\
\hline DAB81 45 & 45 & 83 & & & & & & \\
\hline DAB81 50 & 50 & 78 & & & & & & \\
\hline DAB87 33 & 33 & 92 & & & & & & \\
\hline DAB87 38 & 38 & 87 & & & & & & \\
\hline DAB87 53 & 53 & 72 & & & & & & \\
\hline DAB84 20 & 20 & 88 & DCB15R & $94.5-85.2$ & $30 \mathrm{~J}$ & 300 & 7 & 20 \\
\hline DAB84 28 & 28 & 80 & & & & & & \\
\hline DAB84 38 & 38 & 70 & & & & & & \\
\hline DAB83 32 & 32 & 75 & DCB 48A & $81-76$ & $2 \mathrm{~J}$ & 26 & 0.03 & $42 \mathrm{U}$ \\
\hline DAB83 38 & 38 & 69 & & & & & & \\
\hline DAB83 42 & 42 & 65 & & & & & & \\
\hline DAB86 12-16 & 12 to 16 & $115-111$ & DCB 67A & $114-112$ & & & & \\
\hline $\begin{array}{l}\text { MCL primary } \\
\text { MCL secondary } \\
\text { Region } 9 \text { PRG }\end{array}$ & & & & & 4 & 730 & 30 & 10 \\
\hline
\end{tabular}

Data with $\mathrm{J}$ and $\mathrm{U}$ designations is considered below detection. 


\subsubsection{Soil Properties for DAB and DCP Samples}

Table 11 contains the general soil properties for the DAB and DCP samples. Cation exchange capacity (CEC), soil texture, USDA classification, and total aluminum and iron concentrations are listed. These data provide input for more sophisticated geochemical models which can be used to support future groundwater modeling efforts. Such models would provide a more robust alternative to describing the $\mathrm{COC}$-sediment interaction by the single linear $\mathrm{K}_{\mathrm{d}}$ construct. Such a model can vary COC sorption as a function of various geochemical parameters. The samples had a range of CEC values from essentially $0 \mathrm{meq} / \mathrm{kg}$ soil to $88 \mathrm{meq} / \mathrm{kg}$ soil. Some of the most contaminated sediments, e.g., DCP 211 8-12 and DCP 211 18-19 (samples collected from near the DCPRB source), had the highest CEC levels. DCP 168 20-22 also had a very large CEC considering the low clay content. This high CEC suggests that location DCP 168 is close to a source with high dissolved metals (potentially the DRP rather than the DCPRB).

Excluding DCP 211 18-19 and DCP 168 20-22 the data indicated CEC values were significantly ( $\mathrm{p} \leq 0.05, \mathrm{R}^{2}=0.77$ ) correlated to clay content (Figure 11$)$, but had a stronger correlation with the sum of clay and silt content $\left(\mathrm{R}^{2}=0.91\right)$ (Figure 12). The comparatively weaker correlation with clay content is likely in part the result of the surprisingly narrow range of clay concentrations: 0 to $2 \mathrm{wt} \%$. With the low percentage of clay in the soils, they were all classified by their sand content and fell in the Silt Loam, Sandy Loam, Loamy Sand, and Sand categories. The data from locations DCP 168 20-22 and DCP 211 18-19 were included in the data set for comparison of CEC with clay or clay and silt content (Figure 11). However, they do not fit the observed trend. The cause of this may be attributed to the formation of precipitates since high concentrations of $\mathrm{Fe}$ and $\mathrm{Al}$ are present in porewater.

Across DCP and DAB soils there was a wide range of both total aluminum and total iron concentrations, from approximately 300 to $388,000 \mathrm{mg} / \mathrm{kg}$ and from 400 to 32,000 mg/kg, respectively. Iron is ubiquitous in SRS sediments and is involved in several different types of reactions (Denham et al. 1999). Of primary interest is that iron precipitates on sediment surfaces to form highly reactive coatings (Stumm and Morgan 1996). These coatings constitute essentially all of the exchange capacity of subsurface sediments (Kaplan 2003). Not surprisingly, the measured CEC were highly correlated to the total Fe concentration in sediments $\left(\mathrm{R}^{2}=0.6247 ; \mathrm{p} \leq 0.001 ; \mathrm{df}=22\right)$. (Figure 14)

Table 12 includes both CEC and anion exchange capacity (AEC). Anion exchange capacity is similar to CEC, except it is a measure of the capacity of the sediment to exchange anions. It was anticipated that it would provide some insight into the geochemical behavior of $\mathrm{AsO}_{4}{ }^{-}$ $/ \mathrm{AsO}_{3}{ }^{-}$and $\mathrm{SeO}_{4}{ }^{2-} / \mathrm{SeO}_{3}{ }^{2-}$. An important observation that can be made from the data in Table 12 is that the same sediment can hold both anions and cations. Typically, as $\mathrm{pH}$ increases, the CEC increases and the AEC decreases. Not surprisingly, AEC was significantly correlated to clay content $\left(\mathrm{R}^{2}=0.396, \mathrm{p} \leq 0.05, \mathrm{df}=12\right.$; Figure 14). This can be attributed to AEC being a surface area phenomenon, greater the surface area, greater the concentration of anion exchange sites. 
WSRC-TR-2004-00124, REVISION 0

Table 11. General Properties of Upland and Wetland Soil Samples

\begin{tabular}{|c|c|c|c|c|c|}
\hline Sample ID & $\begin{array}{c}\text { CEC } \\
(\mathrm{meq} / \mathrm{kg})\end{array}$ & $\begin{array}{c}\text { Soil Texture } \\
\text { Sand/Silt/Clay } \\
\text { (percent) }\end{array}$ & $\begin{array}{c}\text { USDA } \\
\text { Classification }\end{array}$ & $\begin{array}{c}\text { Total Al } \\
(\mathrm{mg} / \mathrm{kg})^{* *}\end{array}$ & $\begin{array}{c}\text { Total Fe } \\
(\mathrm{mg} / \mathrm{kg})^{* *}\end{array}$ \\
\hline DAB 925 & $34.56^{*}$ & $74 / 24.3 / 1.7$ & Loamy Sand & $26887 \pm 1377$ & $7364 \pm 273$ \\
\hline DAB 9221 & $2.83 *$ & $94.2 / 5.7 / 0.1$ & Sand & $5385 \pm 1095$ & $2192 \pm 454$ \\
\hline DAB 85 32-33 & $5.84 \pm 3.06$ & $92.5 / 7.2 / 0.3$ & Sand & $20420 \pm 5722$ & $2078 \pm 597$ \\
\hline DAB 8545 & $0^{*}$ & $99.7 / 0.3 / 0$ & Sand & $6453 \pm 646$ & $1060 \pm 169$ \\
\hline DAB 8130 & $7.03 *$ & $88.8 / 10.8 / 0.4$ & Loamy Sand & $36688 \pm 3106$ & $10230 \pm 1208$ \\
\hline DAB 8145 & 0 & $96.7 / 3.2 / 0.1$ & Sand & $13761 \pm 4904$ & $12253 \pm 10399$ \\
\hline DAB 8150 & $16.42 *$ & $61.6 / 37.6 / 0.8$ & Sandy Loam & $323 \pm 73$ & $5004 \pm 500$ \\
\hline DAB 8733 & $36.10 *$ & $78.3 / 20$ / 1.7 & Loamy Sand & $388386 \pm 4840$ & $12170 \pm 901$ \\
\hline DAB 8738 & $0.76 \pm 0.54$ & $92.4 / 7.1 / 0.5$ & Sand & $18580 \pm 453$ & $2558 \pm 62$ \\
\hline DAB 8753 & $36.08 *$ & $72.7 / 25.6 / 1.7$ & Loamy Sand & $49370 \pm 3225$ & $13573 \pm 721$ \\
\hline DAB 8420 & $1.56^{*}$ & 98.4 / 1.5 / 0.1 & Sand & $8887 \pm 335$ & $437 \pm 30$ \\
\hline DAB 8428 & $7.30 \pm 3.31$ & $93.1 / 6.5 / 0.4$ & Sand & $10599 \pm 161$ & $4485 \pm 50$ \\
\hline DAB 8438 & $31.01^{*}$ & $66.1 / 31.8 / 2$ & Sandy Loam & $51005 \pm 2846$ & $32715 \pm 1727$ \\
\hline DAB 8332 & $42.36^{*}$ & $77.7 / 20.3 / 2$ & Loamy Sand & $32649 \pm 5230$ & $8341 \pm 913$ \\
\hline DAB 8338 & $30.51 *$ & $66.4 / 32.1 / 1.5$ & Sandy Loam & $37302 \pm 18769$ & $15092 \pm 6635$ \\
\hline DAB 8342 & $18.14 \pm 0.28$ & $45.8 / 53.3 / 0.9$ & Silt Loam & $486 \pm 91$ & $5179 \pm 144$ \\
\hline DCP $2111-2$ & $7.03 \pm 3.31$ & $77 / 22.5 / 0.5$ & Loamy Sand & $15990 \pm 1966$ & $6975 \pm 445$ \\
\hline DCP $2118-12$ & $46.90 \pm 3.58$ & $65.3 / 3.9 / 1.8$ & Sandy Loam & $60400 \pm 13718$ & $13050 \pm 495$ \\
\hline DCP 211 18-19 & $88.08 \pm 7.82$ & $76.1 / 23.1 / 0.8$ & Loamy Sand & $20250 \pm 212$ & $4300 \pm 1414$ \\
\hline DCP $21134-35$ & $0.18 \pm 0.34$ & $97.9 / 2$ / 0.1 & Sand & $1125 \pm 92$ & $3370 \pm 438$ \\
\hline DCP 168 1.5-3.5 & $25.19 \pm 0.19$ & 39.4 / 59.3 / 1.3 & Silt Loam & $43000 \pm 1556$ & $13700 \pm 141$ \\
\hline DCP 168 20-22 & $40.88 \pm 1.69$ & $95.6 / 4.4 / 0$ & Sand & $15250 \pm 495$ & $20200 \pm 707$ \\
\hline DCP $16831-33$ & $5.64 \pm 0.38$ & 87.4 / 12.4 / 0.2 & Loamy Sand & $3715 \pm 1252$ & $4240 \pm 127$ \\
\hline DCP 170 1-3 & $14.12 \pm 0.00$ & $68.7 / 30 / 1.3$ & Sandy Loam & $50850 \pm 778$ & $16500 \pm 0$ \\
\hline DCP 170 14-16 & $2.33 \pm 1.58$ & $96.1 / 3.8 / 0.1$ & Sand & $21000 \pm 1131$ & $3560 \pm 71$ \\
\hline DCP 170 20-22 & $1.28 \pm 0.07$ & $95.2 / 4.7 / 0.1$ & Sand & $31650 \pm 1909$ & $12650 \pm 778$ \\
\hline DCP 171 1-3 & $18.75 \pm 0.03$ & 59.7 / 39.3 / 1 & Sandy Loam & $36850 \pm 6576$ & $13300 \pm 424$ \\
\hline DCP $17124-26$ & $0.00 \pm 0.36$ & $96.2 / 3.7 / 0.1$ & Sand & $18900 \pm 2404$ & $3495 \pm 163$ \\
\hline D-2 & $44.00 \pm 0.68$ & & & $51162 \pm 14971$ & $27724 \pm 3939$ \\
\hline D-4 & $60.63 \pm 0.45$ & & & $77305 \pm 2331$ & $38027 \pm 2924$ \\
\hline G-10 & $13.91 \pm 8.02$ & & & $68112 \pm 6713$ & $18349 \pm 1211$ \\
\hline $\mathrm{H}-5$ & $62.17 \pm 0.79$ & & & $44752 \pm 7415$ & $26402 \pm 2358$ \\
\hline$J-6$ & $12.21 \pm 0.12$ & & & $70372 \pm 8585$ & $24731 \pm 2458$ \\
\hline $\mathrm{K}-4$ & 0 & & & $54409 \pm 6319$ & $20435 \pm 2016$ \\
\hline
\end{tabular}

* Indicates values that were not measured. These values were estimated from the data in Figure 12.

** Denotes total concentration values determined by SE method. All others determined by TD. 
Table 12. Measured Cation and Anion Exchange Capacity

\begin{tabular}{|c|c|c|}
\hline Sample ID & $\begin{array}{c}\text { Cation Exchange Capacity } \\
(\mathrm{meq} / \mathrm{kg})\end{array}$ & $\begin{array}{c}\text { Anion Exchange Capacity } \\
(\mathrm{meq} / \mathrm{kg})\end{array}$ \\
\hline DAB 8532 & $5.84 \pm 3.06$ & 0 \\
\hline DAB 8145 & 0 & 0 \\
\hline DAB 8738 & $0.76 \pm 0.54$ & $7.21 \pm 5.10$ \\
\hline DAB 8428 & 0 & 0 \\
\hline DAB 8342 & $34.38 \pm 0.28$ & $12.78 \pm 0.45$ \\
\hline DCP $2111-2$ & $7.03 \pm 3.31$ & $4.16 \pm 5.89$ \\
\hline DCP $2118-12$ & $46.90 \pm 3.58$ & $38.35 \pm 13.67$ \\
\hline DCP 211 18-19 & $88.08 \pm 7.82$ & $20.11 \pm 3.64$ \\
\hline DCP 211 34-35 & $0.24 \pm 0.34$ & $1.66 \pm 2.35$ \\
\hline DCP 168 1.5-3.5 & $25.19 \pm 0.19$ & $13.37 \pm 2.26$ \\
\hline DCP 168 20-22 & $40.88 \pm 1.69$ & $10.88 \pm 4.82$ \\
\hline DCP $16831-33$ & $5.64 \pm 0.38$ & $12.70 \pm 1.77$ \\
\hline DCP $1701-3$ & $14.12 \pm 0.00$ & $5.07 \pm 0.00$ \\
\hline DCP 170 14-16 & $2.33 \pm 1.58$ & $4.32 \pm 0.25$ \\
\hline DCP 170 20-22 & $1.28 \pm 0.07$ & $5.93 \pm 6.57$ \\
\hline DCP 171 1-3 & $18.75 \pm 0.06$ & $4.53 \pm 1.67$ \\
\hline DCP 171 24-26 & $0.26 \pm 0.36$ & $3.81 \pm 5.38$ \\
\hline D-2 & $44.00 \pm 0.68$ & $20.47 \pm 1.64$ \\
\hline D-4 & $60.63 \pm 0.45$ & $28.93 \pm 3.28$ \\
\hline G-10 & $13.91 \pm 8.02$ & $30.80 \pm 1.86$ \\
\hline $\mathrm{H}-5$ & $62.17 \pm 0.79$ & $34.55 \pm 0.64$ \\
\hline $\mathrm{J}-6$ & $12.21 \pm 0.12$ & $33.67 \pm 1.27$ \\
\hline $\mathrm{K}-4$ & 0 & $40.89 \pm 4.62$ \\
\hline
\end{tabular}




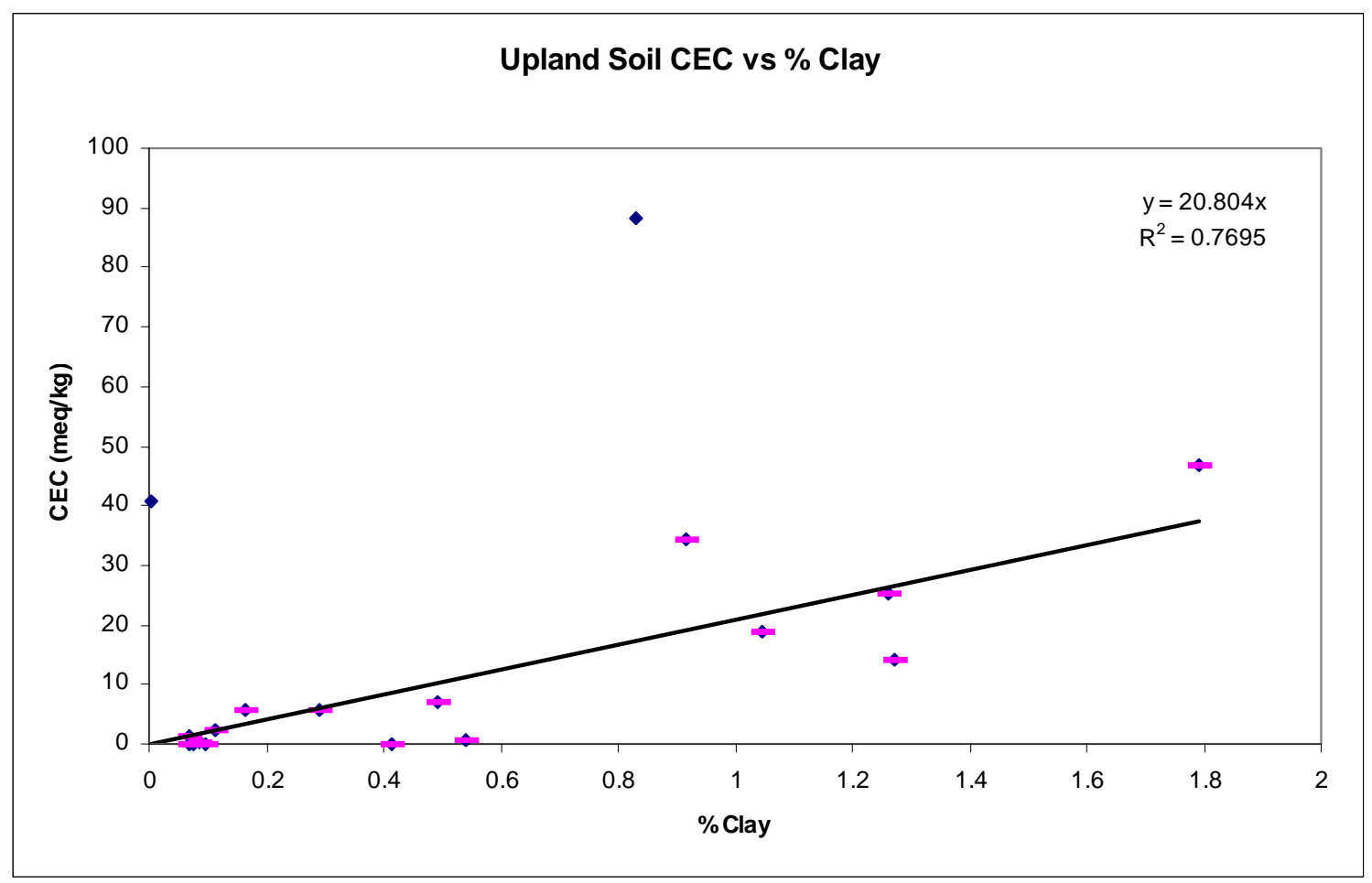

Figure 11. Correlation between measured cation exchange capacity and percent clay in upland soil samples

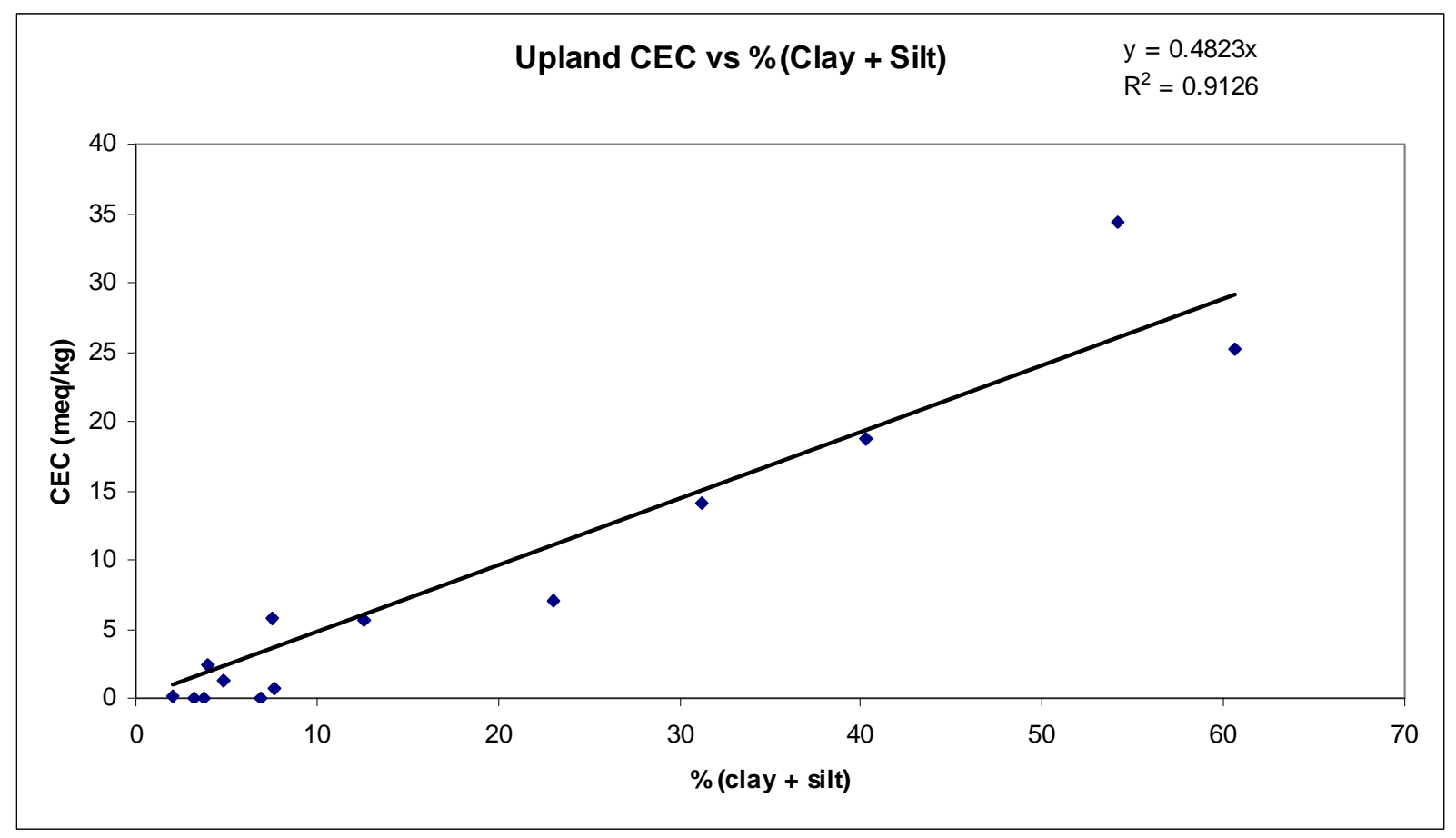

Figure 12. Correlation between measured cation exchange capacity and clay + silt in upland soil samples 

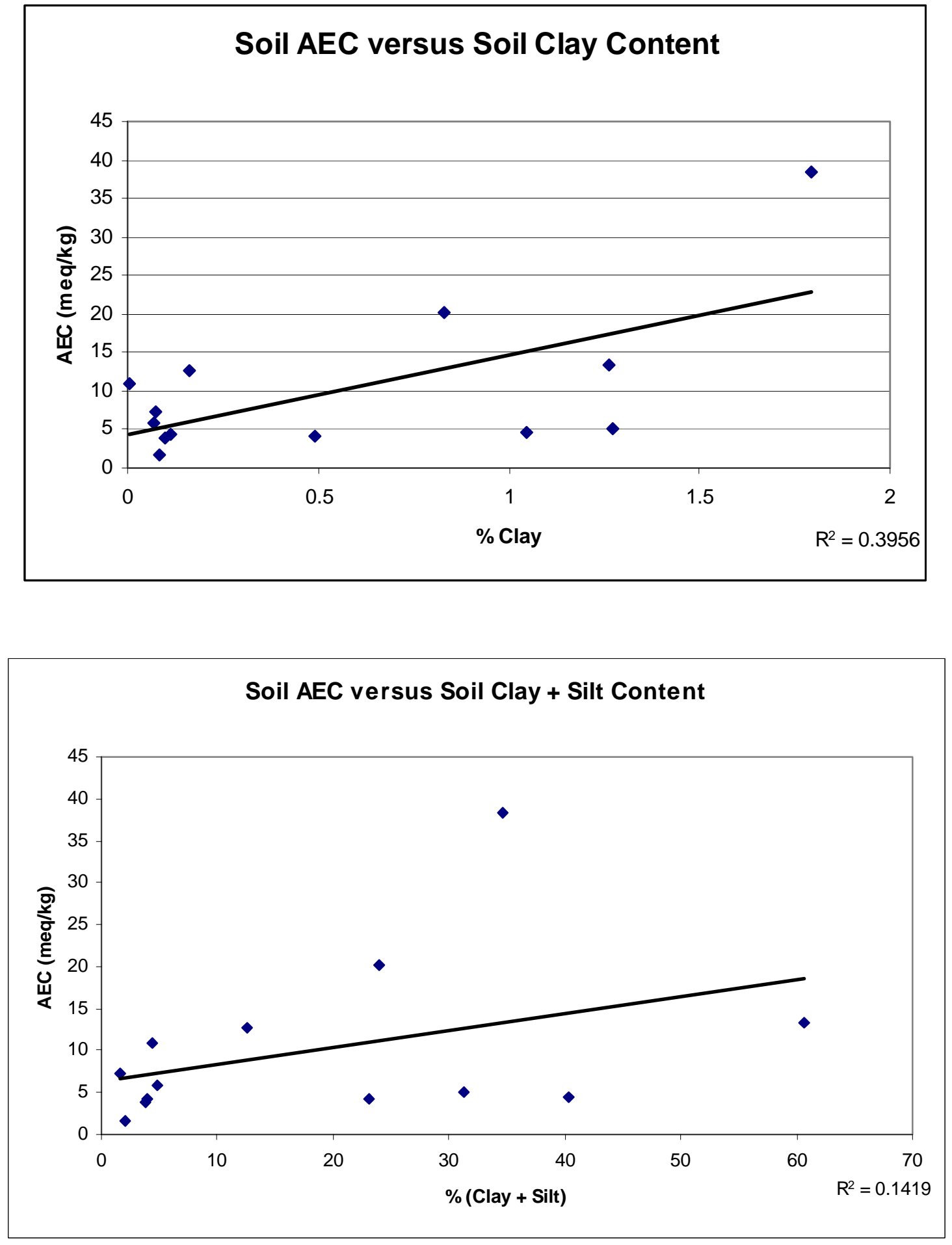

Figure 13. Soil Anion Exchange Capacity vs. Soil Clay Content and Clay + Silt 


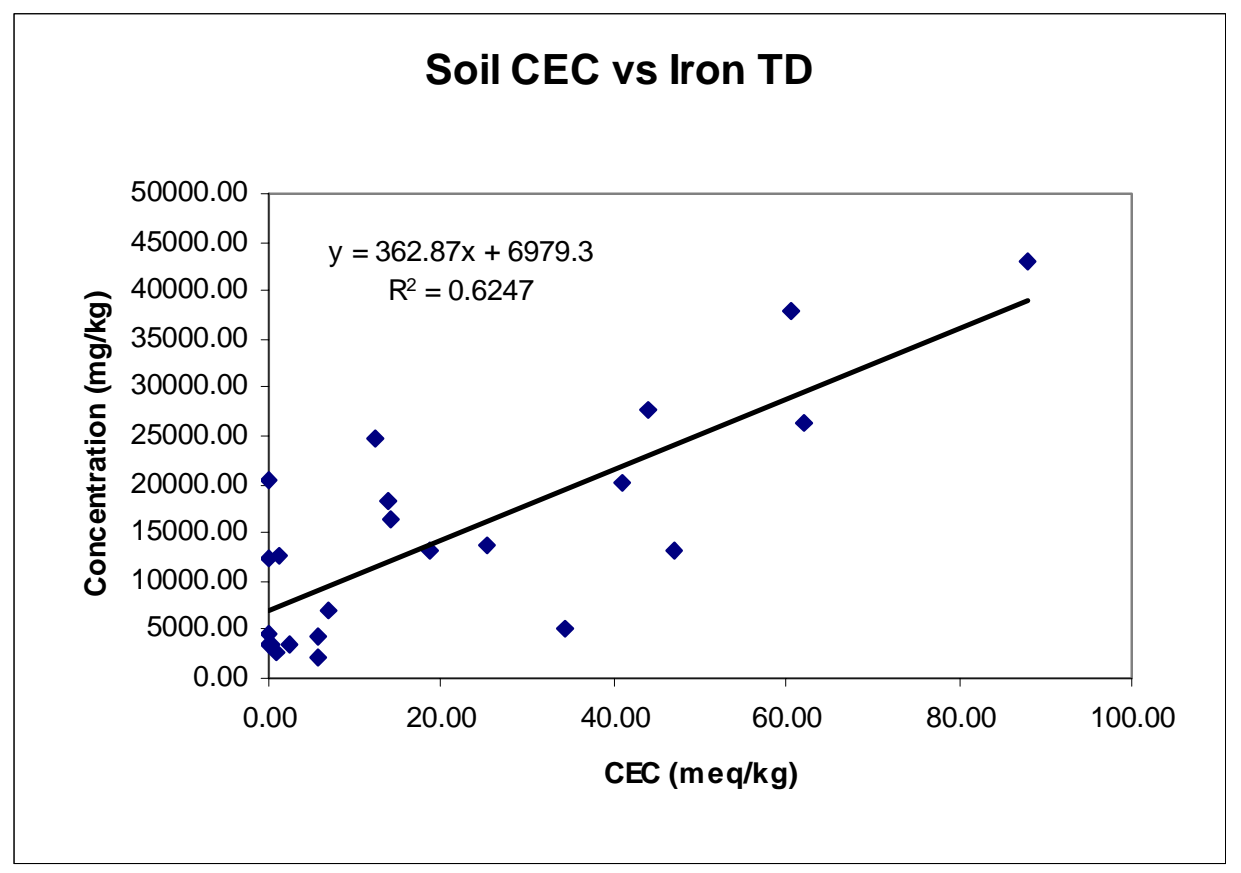

\section{Figure 14. Correlation between measured cation exchange capacity and total iron concentration in soil samples}

\subsubsection{Soil Digestions}

Four measures of COC concentrations are presented in Table 13 through Table 26, they are sum of sequential extraction steps $1-6$, sum of sequential extraction steps $1-8$, total digestion, and $3050 \mathrm{~b}$ digestion. The sequential extraction steps are described in Table 3. The sum of steps $1-6$ provides a measure of the concentration of COCs that are available for entering into the aqueous phase. This operational definition includes those fractions that may be expected to be desorbed from the sediment under a broad range of environmental conditions. The sum of steps $1-6$ was used to define solid-phase concentrations for the $\mathrm{K}_{\mathrm{d}}$ calculations presented in Section 5.2. The sum of steps $1-8$ should provide an approximation of the total digestion concentration. The last step in the sequential extractions, Step 8, is a total digestion of the remaining sediment remaining after the previous 7 digestions. The same acids and procedure are used in Step 8 as is used in the total digestion procedure. Differences between the two values can be attributed to laboratory and analytical error associated with adding eight measurements as well as the heterogeneity between the soil samples themselves. In fact, total digestion values are commonly used as a quality assurance that the sequential extractions values are correct. Because the total digestion value is a single extraction, this approach is generally believed to be a better measure of the total COC concentrations than the Sum 1-8 value. The $3050 \mathrm{~b}$ method uses strong acids but does not dissolve the silicates (no hydrofluoric acid). Thus, it provides a measure of all the COC, except that held in the silicate phases. The difference between the total digestions and the $3050 \mathrm{~b}$ concentrations would be a measure of the mineral/silicate bound COC concentrations. 
As shown by this discussion, the procedures are expected to yield metals concentrations in the following order: Sum $1-6<3050 \mathrm{~b}<$ Sum $1-8=$ Total Digestions. This ranking was generally observed for the Be, (Table 13 and Table 14), Ni (Table 15 and Table 16), U (Table 17 and Table 18), As (Table 19 and Table 20), and Se (Table 21).

Total-digestion Be concentrations at the DEXOU (Table 13 and Table 14) were all greater than the $2 \mathrm{x}$ average unit background value of $0.20 \mathrm{mg} / \mathrm{kg}$ Be (Table 2.3-9 in WSRC-RP-994067). Total-digestion Be concentrations in the 488-D (DAB 86, located within the ash basin) were the highest measured, $7.1 \mathrm{mg} / \mathrm{kg}$. Total-digestion Be concentrations near the DCPRB (DCP211; coal pile runoff basin) were similar to values elsewhere along the sampling transect. Beryllium total concentrations in wetland soils determined by sequential extraction (sum 1-8) are higher than upland soils and similar to the concentrations found in ash material from the 488-D (DAB 86).

Total-digestion Ni concentrations at the DEXOU (Table 15) were essentially all (except at location DAB 84) greater than the $2 \mathrm{x}$ average unit background value of $1.81 \mathrm{mg} / \mathrm{kg} \mathrm{Ni}$ (Table 2.3-9 in WSRC-RP-99-4067). Total-digestion Ni concentrations in the 488-D (DAB 86, within the ash basin) were the highest measured, $59.26 \mathrm{mg} / \mathrm{kg} \mathrm{Ni}$. Total-digestion Ni concentrations near the DCPRB (DCP 211; coal pile runoff basin) were similar to values elsewhere along the sampling transect (Table 16). Ni (sum 1-8) total concentrations in wetland soils were similar to upland soils and lower than the ash material (DAB 86).

Unit-specific background $U$ concentrations are not available; however U concentrations of 0.5 to $1.5 \mathrm{mg} / \mathrm{kg}$ commonly exist in uncontaminated portions of the SRS (Looney et al. 1990). Based on these values, the only soils to have elevated U concentrations are from the 488-D (sample DAB 86) and DCP 168 (Table 17), located adjacent to the wetland (Figure 1). The sediments collected from near the DCPRB contained $<2.12 \mathrm{mg} / \mathrm{kg} \mathrm{U}$ in their total digestions, indicating the DCPRB is likely not an important source term for U. (Table 18)

Total digestion As concentrations at the DEXOU (Table 19) were all, except at four locations, greater than the $2 \mathrm{x}$ average unit background value of $0.70 \mathrm{mg} / \mathrm{kg}$ As (Table 2.3-9 in WSRC-RP-99-4067). It may be that this background concentration was measured on soils that were not representative of D-Area soils, because based on other parameters, such as $\mathrm{pH}$ and $\mathrm{S}$ concentrations, many of the sediments analyzed were not impacted or very slightly impacted by operations (discussed in more detail in Section 6.0). However, total-digestion As concentrations were elevated relative to background in the 488-D (Sample DAB 86; 37.05 $\mathrm{mg} / \mathrm{kg} \mathrm{As}$ ), indicating the ash basin is likely a source term for As. Sample DCP 168 also exhibited elevated As concentrations (ranging from 3.35 to $15.86 \mathrm{mg} / \mathrm{kg} \mathrm{As}$ ). This location also had elevated $\mathrm{Be}, \mathrm{Ni}$, and U concentrations. Locations DCP 168, 170, and 171 are distal to the plume emanating from the DCPRB although they appear to be impacted by the plume from the DRP. 
Total digestion As concentrations near the DCPRB (DCP 211; coal pile runoff basin) were moderately higher than the $2 \mathrm{x}$ average unit background value. As total concentrations in the wetland soils were measured by SE (sum of steps 1-8) and were the highest values of all locations analyzed. These high concentrations of arsenic are likely due to the high concentrations of As found in the ash material in 488-D (DAB 86). (Table 20) Despite high arsenic concentrations in the DCPRB sediment (Kaplan and Knox, 2004), the soil concentrations at locations underneath 488-D were relatively low compared to distal samples (DCP 168, DCP 170) and DAB 83 located just down gradient of 488-D. This suggests that the DCPRB is not the source for the As in these distal locations. Low solubility of As(V) likely accounts for the low mobility of As in the low $\mathrm{pH}$ plume from the DCPRB.

Selenium data are not available for the upland sediments, but were measured in the wetland samples (Table 21). Unit-specific background Se concentrations are not reported in the RCRA Facility Investigation/Remedial Investigation Work Plan (WSRC-RP-99-4067), however Se concentrations of $<0.4$ to $1.1 \mathrm{mg} / \mathrm{kg}$ commonly exist in uncontaminated portions of the SRS (Looney et al. 1990; Table 6.15). Based on these values, many of the wetland soils appear to have elevated Se concentrations.

Vanadium data are not available for the upland sediments, but was measured in the wetland samples (Table 22). Twice unit-specific background V concentrations are $5.12 \mathrm{mg} / \mathrm{kg}$ (RCRA Facility Investigation/Remedial Investigation Work Plan; WSRC-RP-99-4067). All $\mathrm{V}$ concentrations in the wetland sediments greatly exceeded this value. The cause for these high values is not known, given the limited amount of data.

Iron and aluminum are not COCs, yet they can provide a valuable indirect indication of how well COCs will sorb to the soils. Most of the Fe in SRS sediments is from Fe-oxyhydroxides that account for most of the sorption capacity in subsurface soils. Aluminum exists primarily in the lattice of kaolinite and other minerals and to a smaller extent as Al-oxide (gibbsite) surface coatings on minerals. A high total Al concentration in a soil may indicate the presence of gibbsite, a mineral with high cation and anion sorption capacities. Totaldigestion $\mathrm{Fe}$ and $\mathrm{Al}$ concentrations varied greatly (436 to $73,632 \mathrm{mg} / \mathrm{kg} \mathrm{Fe}$ and 323 to $51,005 \mathrm{mg} / \mathrm{kg} \mathrm{Al}$ ) and not in a systematic manner with either distance from point source or depth below ground level (Table 23 - Table 26). 
Table 13. Beryllium Concentration (ppm) in Upland Soil

\begin{tabular}{|c|c|c|c|c|c|c|c|c|c|c|}
\hline Soil Sample & $\begin{array}{c}\text { Elevation } \\
\mathrm{ft}\end{array}$ & $\begin{array}{r}\text { Pore- } \\
\text { water } \\
\text { pH }\end{array}$ & \begin{tabular}{|c|} 
Berylliı \\
(ppm) \\
Sum \\
$1-6$
\end{tabular} & st dev & $\begin{array}{c}\text { Sum } \\
1-8\end{array}$ & st dev & TD & st dev & $3050 b$ & st dev \\
\hline DAB92 4-6 & $112-110$ & 3.18 & 0.24 & 0.19 & 1.18 & 0.19 & 1.12 & 0.70 & 0.50 & 0.40 \\
\hline DAB92 21-23 & $95-93$ & 4.12 & 0.07 & 0.01 & 0.52 & 0.04 & 0.27 & 0.04 & 0.33 & 0.29 \\
\hline DAB85 32-33 & $99-98$ & 5.18 & 0.25 & 0.05 & 1.49 & 0.27 & 1.52 & 0.14 & 1.04 & 0.12 \\
\hline DAB85 45 & 86 & 7.25 & nd & nd & nd & nd & 0.24 & 0 & nd & \\
\hline DAB81 30-35 & 98 & 4.80 & nd & nd & nd & nd & 2.01 & 0.17 & nd & \\
\hline DAB81 45 & 83 & 4.26 & 0.33 & 0.08 & 0.98 & 0.30 & 1.17 & 0.35 & 0.85 & 0.2 \\
\hline DAB81 50 & 78 & 7.98 & nd & nd & nd & nd & 2.38 & 0.09 & nd & \\
\hline DAB87 33 & 92 & 3.81 & nd & nd & nd & nd & 1.03 & 0.15 & nd & \\
\hline DAB87 38 & 87 & 3.76 & 0.05 & 0.01 & 0.45 & 0.02 & 0.56 & 0.04 & 0.76 & 0.27 \\
\hline DAB87 53 & 72 & 4.93 & nd & nd & nd & nd & 3.10 & 0.11 & nd & J \\
\hline DAB84 20 & 88 & 5.06 & nd & nd & nd & nd & 0.15 & 0.01 & nd & nd \\
\hline DAB84 28 & 80 & 4.56 & 0.08 & 0.01 & 0.64 & 0.11 & 0.43 & 0.04 & 0.50 & 0.12 \\
\hline DAB84 38 & 70 & 5.24 & nd & nd & nd & nd & 8.10 & 0.71 & nd & \\
\hline DAB83 32 & 75 & 6.61 & nd & nd & nd & nd & 2.35 & 0.32 & nd & \\
\hline DAB83 38 & 69 & 7.50 & nd & nd & nd & nd & 1.98 & 1.00 & nd & \\
\hline DAB83 42 & 65 & 7.87 & 3.48 & 0.07 & 4.23 & 0.14 & 1.29 & 0.27 & 4.30 & 0.03 \\
\hline DAB86 12-16 & $115-111$ & 7.50 & 1.67 & 0.20 & 8.80 & 0.69 & 7.10 & 0.30 & 6.22 & 0.11 \\
\hline DCP211/2-3 & $121-120$ & vadose & 0.03 & 0.01 & 0.22 & 0.05 & 0.39 & 0.04 & 0.24 & 0.04 \\
\hline DCP211/9-10 & $114-113$ & nd & 0.01 & 0.00 & 0.59 & 0.08 & 0.84 & 0.03 & 0.36 & 0.06 \\
\hline DCP211/19-20 & $104-103$ & 4.89 & 0.56 & 0.02 & 2.63 & 0.19 & 2.73 & 0.07 & 1.55 & 0.24 \\
\hline DCP211/35-36 & $88-87$ & 4.69 & 0.26 & 0.03 & 0.84 & 0.03 & 1.98 & 0.14 & 0.51 & 0.05 \\
\hline DCP168/1.5-3.5 & $96-94$ & vadose & 0.85 & 0.17 & 2.05 & 0.24 & 2.15 & 0.18 & 0.59 & 0.08 \\
\hline DCP168/20-22 & $77-78$ & 5.61 & 4.79 & 0.27 & 5.21 & 0.30 & 3.99 & 1.33 & 2.41 & 0.25 \\
\hline DCP168/31-33 & $66-64$ & 6.31 & 1.68 & 0.23 & 1.86 & 0.23 & 2.12 & 0.12 & 0.49 & 0.09 \\
\hline DCP170/1-3 & $96-94$ & vadose & 0.06 & 0.04 & 0.31 & 0.15 & 0.46 & 0.17 & 0.29 & 0.09 \\
\hline DCP170/14-16 & $83-81$ & 4.59 & 0.06 & 0.01 & 0.28 & 0.01 & 0.24 & 0.08 & 0.17 & 0.01 \\
\hline DCP170/20-22 & $77-75$ & 5.83 & 0.19 & 0.04 & 0.83 & 0.06 & 0.85 & 0.07 & 0.93 & 0.16 \\
\hline DCP171/1-3 & $96.5-94.5$ & vadose & nd & nd & nd & nd & nd & nd & 1.11 & 0.07 \\
\hline DCP171/24-26 & $73.5-71.5$ & 6.13 & nd & nd & nd & nd & nd & nd & 0.25 & 0.04 \\
\hline
\end{tabular}
nd $=$ not determined

Table 14. Beryllium Soil Concentration (ppm) in Wetland Soil

\begin{tabular}{|l|c|cccccccc|}
\hline \multicolumn{1}{|c|}{ Sample } & $\begin{array}{c}\text { Pore- } \\
\text { water } \\
\text { pH }\end{array}$ & Sum 1-6 & st dev Sum 1-8 & st dev & TD & st dev & 3050b & st dev \\
\hline D-2 & 5.49 & 0.77 & 0.12 & 1.48 & 0.15 & nd & nd & 1.44 & 0.28 \\
D-4 & 5.94 & 0.69 & 0.04 & 1.83 & 0.27 & nd & nd & 1.68 & 0.14 \\
G-10 & 6.12 & 1.39 & 0.20 & 7.07 & 0.31 & nd & nd & 5.24 & 0.63 \\
H-5 & 6.02 & 1.40 & 0.15 & 4.55 & 0.59 & nd & nd & 3.70 & 0.28 \\
J-6 & 5.13 & 1.11 & 0.04 & 6.08 & 0.83 & nd & nd & 3.95 & 0.20 \\
K-4 & 4.52 & 1.41 & 0.05 & 5.27 & 0.69 & nd & nd & 3.40 & 0.66 \\
\hline
\end{tabular}

nd $=$ not determined 
Table 15. Nickel Concentration (ppm) in Upland Soil

\begin{tabular}{|c|c|c|c|c|c|c|c|c|c|c|}
\hline Soil Sample & $\begin{array}{c}\text { Elevation } \\
\mathrm{ft}\end{array}$ & $\begin{array}{c}\text { Pore- } \\
\text { water } \\
\text { pH }\end{array}$ & $\begin{array}{r}\text { Nicl } \\
\text { (soil p } \\
\text { Sum } \\
1-6\end{array}$ & $\begin{array}{l}\text { kel } \\
\text { pm) } \\
\text { st dev }\end{array}$ & Sum 1-8 & st dev & TD & st dev & $3050 b$ & st dev \\
\hline AB92 4-6 & $112-110$ & 3.18 & 0.34 & 0.05 & 12.51 & 0.18 & 42.88 & 1.48 & 6.93 & 0.78 \\
\hline DAB92 21-23 & $95-93$ & 4.12 & 1.68 & 1.09 & nd & 1.09 & 15.66 & 3.91 & 0.59 & 0.03 \\
\hline DAB85 32-33 & $99-98$ & 5.18 & 26.65 & 5.55 & 38.25 & 6.84 & 42.51 & 3.78 & 6.31 & 0.27 \\
\hline DAB85 45 & 86 & 7.25 & nd & nd & nd & nd & 14.50 & 2.65 & nd & nd \\
\hline DAB81 30-35 & 98 & 4.80 & nd & nd & nd & nd & 33.35 & 3.02 & nd & nd \\
\hline DAB81 45 & 83 & 4.26 & 18.31 & 1.59 & 21.00 & 2.75 & 26.79 & 3.09 & 1.74 & 0.04 \\
\hline DAB81 50 & 78 & 7.98 & nd & nd & nd & nd & 22.16 & 0.85 & nd & d \\
\hline DAB87 33 & 92 & 3.81 & nd & nd & nd & nd & 39.58 & 2.75 & nd & nd \\
\hline DAB87 38 & 87 & 3.76 & 31.91 & 7.64 & 40.34 & 8.19 & 2.73 & 0.13 & 3.44 & 0.46 \\
\hline DAB87 53 & 72 & 4.93 & nd & nd & nd & nd & 16.71 & 9.78 & nd & nd \\
\hline DAB84 20 & 88 & 5.06 & nd & nd & nd & nd & 0.003 & & nd & nd \\
\hline DAB84 28 & 80 & 4.56 & 22.81 & 0.43 & 25.75 & 0.50 & 0.47 & 0.66 & 1.44 & 0.04 \\
\hline DAB84 38 & 70 & 5.24 & nd & nd & nd & nd & 9.72 & 0.33 & nd & nd \\
\hline DAB83 32 & 75 & 6.61 & nd & nd & nd & nd & 3.71 & 1.19 & nd & 4 \\
\hline DAB83 38 & 69 & 7.50 & nd & nd & nd & nd & 7.21 & 4.03 & nd & nd \\
\hline DAB83 42 & 65 & 7.87 & 54.10 & 1.78 & 56.49 & 1.79 & 2.08 & 0.33 & 39.02 & 1.09 \\
\hline DAB86 12-16 & $115-111$ & 7.50 & 13.89 & 2.56 & 60.40 & 4.41 & 59.26 & 2.27 & 41.56 & 0.09 \\
\hline DCP211/2-3 & $121-120$ & vadose & 4.19 & 2.87 & 14.84 & 5.10 & nd & $\overline{\mathrm{nd}}$ & 3.78 & 1.00 \\
\hline DCP211/9-10 & $114-113$ & nd & 2.52 & 0.37 & 15.85 & 2.58 & nd & nd & 3.87 & 0.48 \\
\hline DCP211/19-20 & $104-103$ & 4.89 & 5.88 & 1.69 & 24.43 & 3.21 & nd & nd & 8.25 & 1.20 \\
\hline DCP211/35-36 & $88-87$ & 4.69 & 7.12 & 1.23 & 13.43 & 1.24 & 9.51 & 0.00 & 0.99 & 0.08 \\
\hline DCP168/1.5-3.5 & $96-94$ & vadose & 0.81 & 0.18 & 44.83 & 42.58 & 24.23 & 4.24 & 5.28 & 0.55 \\
\hline DCP168/20-22 & $77-78$ & 5.61 & 21.51 & 0.74 & 36.14 & 12.59 & 29.78 & 6.18 & 19.12 & 1.91 \\
\hline DCP168/31-33 & $66-64$ & 6.31 & 3.67 & 0.28 & 17.36 & 10.91 & 13.18 & 3.57 & 4.77 & 1.33 \\
\hline DCP170/1-3 & $96-94$ & vadose & 0.59 & 0.18 & 26.21 & 10.76 & 13.96 & 0.34 & 4.69 & 1.79 \\
\hline DCP170/14-16 & $83-81$ & 4.59 & 0.86 & 0.23 & 9.13 & 0.37 & 7.96 & 1.23 & 1.76 & 0.21 \\
\hline DCP170/20-22 & $77-75$ & 5.83 & 5.68 & 0.37 & 18.34 & 3.41 & 13.87 & 0.68 & 7.50 & 0.12 \\
\hline DCP171/1-3 & $96.5-94.5$ & vadose & nd & nd & nd & nd & nd & nd & 8.99 & 0.21 \\
\hline DCP171/24-26 & 73.5-71.5 & 6.13 & nd & nd & nd & nd & nd & nd & 1.87 & 0.35 \\
\hline
\end{tabular}

nd $=$ not determined

Table 16. Nickel Soil Concentration (ppm) in Wetland Soil

\begin{tabular}{|l|c|cccccccc|}
\hline \multicolumn{1}{|c|}{ Sample } & $\begin{array}{c}\text { Pore- } \\
\text { water } \\
\text { pH }\end{array}$ & Sum 1-6 & st dev & Sum 1-8 & st dev & TD & st dev & 3050b & st dev \\
\hline D-2 & 5.49 & 20.60 & 11.29 & 32.81 & 11.38 & nd & nd & 21.26 & 1.28 \\
D-4 & 5.94 & 4.93 & 2.65 & 24.44 & 2.66 & nd & nd & 31.01 & 0.25 \\
G-10 & 6.12 & 11.15 & 5.77 & 48.44 & 7.77 & nd & nd & 39.88 & 0.55 \\
H-5 & 6.02 & 10.72 & 2.91 & 39.60 & 7.37 & nd & nd & 40.60 & 3.48 \\
J-6 & 5.13 & 10.21 & 2.20 & 46.82 & 4.50 & nd & nd & 34.28 & 0.58 \\
K-4 & 4.52 & 6.84 & 2.73 & 36.36 & 3.63 & nd & nd & 27.33 & 1.89 \\
\hline
\end{tabular}

nd $=$ not determined 
Table 17. Uranium Concentration (ppm) in Upland Soil

\begin{tabular}{|c|c|c|c|c|c|c|c|c|c|c|}
\hline \multirow[t]{2}{*}{ Soil Sample } & \multirow{2}{*}{$\begin{array}{c}\text { Elevation } \\
\mathrm{ft}\end{array}$} & \multirow{2}{*}{$\begin{array}{c}\text { Pore- } \\
\text { water } \\
\text { pH }\end{array}$} & \multicolumn{2}{|c|}{ Uranium } & \multirow[b]{2}{*}{ Sum 1-8 } & \multirow[b]{2}{*}{$\begin{array}{c}\text { st } \\
\text { dev }\end{array}$} & \multirow[b]{2}{*}{ TD } & \multirow[b]{2}{*}{ st dev } & \multirow[b]{2}{*}{$3050 b$} & \multirow[b]{2}{*}{ st dev } \\
\hline & & & $\begin{array}{c}\text { Sum } \\
1-6\end{array}$ & st dev & & & & & & \\
\hline DAB92 4-6 & $112-110$ & 3.18 & 5.55 & 1.77 & 6.96 & 1.77 & 1.11 & 0.08 & 0.79 & 0.19 \\
\hline DAB92 21-23 & $95-93$ & 4.12 & 1.20 & 0.58 & 1.23 & 0.59 & 0.29 & 0.09 & 0.15 & 0.08 \\
\hline DAB85 32-33 & $99-98$ & 5.18 & 0.41 & 0.11 & 0.79 & 0.12 & 0.78 & 0.12 & 0.65 & 0.35 \\
\hline DAB85 45 & 86 & 7.25 & nd & nd & nd & nd & 0.28 & 0.08 & nd & nd \\
\hline DAB81 30-35 & 98 & 4.80 & nd & nd & nd & nd & 1.28 & 0.04 & nd & nd \\
\hline DAB81 45 & 83 & 4.26 & 3.65 & 1.14 & 4.95 & 1.90 & 2.66 & 2.94 & 0.54 & 0.34 \\
\hline DAB81 50 & 78 & 7.98 & nd & nd & nd & nd & 0.74 & 0.07 & nd & nd \\
\hline DAB87 33 & 92 & 3.81 & nd & nd & nd & nd & 2.24 & 0.13 & nd & nd \\
\hline DAB87 38 & 87 & 3.76 & 0.28 & 0.05 & 1.12 & 0.5 & 0.70 & 0.02 & 1.11 & 0.27 \\
\hline DAB87 53 & 72 & 4.93 & nd & nd & nd & nd & 1.22 & 0.09 & nd & nd \\
\hline DAB84 20 & 88 & 5.06 & nd & nd & nd & nd & 0.21 & 0.01 & nd & nd \\
\hline DAB84 28 & 80 & 4.56 & 0.78 & 0.15 & 1.59 & 0.16 & 0.75 & 0.12 & 3.10 & 1.15 \\
\hline DAB84 38 & 70 & 5.24 & nd & nd & nd & nd & 4.55 & 0.04 & nd & nd \\
\hline DAB83 32 & 75 & 6.61 & nd & nd & nd & nd & 3.12 & 0.46 & nd & nd \\
\hline DAB83 38 & 69 & 7.50 & nd & nd & nd & nd & 1.52 & 0.89 & nd & nd \\
\hline DAB83 42 & 65 & 7.87 & 2.44 & 0.55 & 2.51 & 0.55 & 0.63 & 0.06 & 1.77 & 0.10 \\
\hline DAB86 12-16 & $115-111$ & 7.50 & 3.14 & 0.79 & 13.25 & 2.82 & 7.27 & 0.17 & 5.12 & 0.01 \\
\hline DCP211/2-3 & $121-120$ & vadose & 0.41 & 0.05 & 0.83 & 0.05 & 1.48 & 0.02 & $\overline{\mathrm{nd}}$ & $\overline{\mathrm{nd}}$ \\
\hline DCP211/9-10 & $114-113$ & $\mathrm{nd}$ & 0.79 & 0.07 & 1.33 & 0.23 & 1.30 & 0.15 & nd & nd \\
\hline DCP211/19-20 & $104-103$ & 4.89 & 1.04 & 0.03 & 2.09 & 0.16 & 2.12 & 0.06 & nd & nd \\
\hline DCP211/35-36 & $88-87$ & 4.69 & 0.15 & 0.05 & 0.23 & 0.05 & 0.29 & 0.01 & nd & $\mathrm{nd}$ \\
\hline DCP168/1.5-3.5 & $96-94$ & vadose & nd & nd & nd & nd & 4.03 & 0.35 & nd & nd \\
\hline DCP168/20-22 & $77-78$ & 5.61 & nd & nd & nd & nd & 6.72 & 2.37 & nd & nd \\
\hline DCP168/31-33 & $66-64$ & 6.31 & 1.73 & 0.36 & 3.10 & 0.42 & 2.99 & 0.14 & nd & nd \\
\hline DCP170/1-3 & $96-94$ & vadose & 0.45 & 0.04 & 1.05 & 0.21 & 1.20 & 0.24 & nd & nd \\
\hline DCP170/14-16 & $83-81$ & 4.59 & 0.11 & 0.01 & 0.44 & 0.08 & 0.51 & 0.09 & nd & nd \\
\hline DCP170/20-22 & $77-75$ & 5.83 & 0.02 & 0.00 & 0.92 & 0.07 & 1.21 & 0.27 & nd & nd \\
\hline DCP171/1-3 & $96.5-94.5$ & vadose & nd & nd & nd & nd & nd & nd & nd & nd \\
\hline DCP171/24-26 & |73.5-71.5 & 6.13 & nd & nd & nd & nd & nd & nd & nd & nd \\
\hline
\end{tabular}

$\mathrm{nd}=$ not determined

Table 18. Uranium Soil Concentration (ppm) in Wetland Soil

\begin{tabular}{|l|c|cccccccc|}
\hline Sample & $\begin{array}{c}\text { Pore- } \\
\text { water } \\
\text { pH }\end{array}$ & Sum 1-6 & st dev & Sum 1-8 & st dev & TD & st dev & 3050b & st dev \\
\hline D-2 & 5.49 & 2.45 & 0.47 & 3.71 & 0.58 & nd & nd & 2.46 & 0.19 \\
D-4 & 5.94 & 1.82 & 0.13 & 3.86 & 0.14 & nd & nd & 2.97 & 0.04 \\
G-10 & 6.12 & 2.80 & 0.48 & 5.93 & 0.58 & nd & nd & 4.18 & 0.01 \\
H-5 & 6.02 & 2.85 & 0.42 & 4.94 & 0.63 & nd & nd & 3.22 & 0.00 \\
J-6 & 5.13 & 2.24 & 0.08 & 5.29 & 0.39 & nd & nd & 3.11 & 0.05 \\
K-4 & 4.52 & 2.04 & 0.12 & 3.98 & 0.21 & nd & nd & 2.96 & 0.05 \\
\hline
\end{tabular}

nd $=$ not determined 
Table 19. Arsenic Concentration (ppm) in Upland Soil

\begin{tabular}{|c|c|c|c|c|c|c|c|c|c|c|}
\hline $\begin{array}{c}\text { Sample } \\
\text { Soil }\end{array}$ & $\begin{array}{c}\text { Elevation } \\
\mathrm{ft}\end{array}$ & $\begin{array}{c}\text { Pore- } \\
\text { water } \\
\text { pH }\end{array}$ & $\begin{array}{r}\text { Arser } \\
\text { Sum 1-6 }\end{array}$ & st dev & Sum 1-8 & st dev & TD & st dev & 3050b & st dev \\
\hline DAB92 4-6 & $112-110$ & 3.18 & 0.16 & 0.01 & 2.25 & 0.05 & 1.17 & 0.12 & 1.48 & 0.92 \\
\hline DAB92 21-23 & $95-93$ & 4.12 & 1.12 & 0.42 & 1.56 & 0.49 & 0.46 & 0.05 & 0.98 & 0.18 \\
\hline DAB85 32-33 & $99-98$ & 5.18 & 1.91 & 0.49 & 5.61 & 4.80 & 1.84 & 0.17 & 1.79 & 0.21 \\
\hline DAB85 45 & 86 & 7.25 & nd & nd & nd & nd & 0.21 & 0.03 & nd & nd \\
\hline DAB81 30-35 & 98 & 4.80 & nd & nd & nd & nd & 1.82 & 0.39 & nd & nd \\
\hline DAB81 45 & 83 & 4.26 & 0.11 & 0.04 & 0.58 & 0.51 & 1.03 & 0.53 & 0.66 & 0.22 \\
\hline DAB81 50 & 78 & 7.98 & nd & nd & nd & nd & 2.66 & 0.34 & nd & nd \\
\hline DAB87 33 & 92 & 3.81 & nd & nd & nd & nd & 2.35 & 0.14 & nd & nd \\
\hline DAB87 38 & 87 & 3.76 & 0.05 & 0.01 & 0.72 & 0.03 & 0.84 & 0.40 & 0.59 & 0.12 \\
\hline DAB87 53 & 72 & 4.93 & nd & nd & nd & nd & 2.03 & 0.19 & nd & nd \\
\hline DAB84 20 & 88 & 5.06 & nd & nd & nd & nd & 1.19 & 0.08 & nd & nd \\
\hline DAB84 28 & 80 & 4.56 & 0.03 & 0.01 & 0.11 & 0.07 & 0.99 & 0.07 & 1.22 & 0.26 \\
\hline DAB84 38 & 70 & 5.24 & nd & nd & nd & nd & 2.68 & 0.26 & nd & nd \\
\hline DAB83 32 & 75 & 6.61 & nd & nd & nd & nd & 1.43 & 0.15 & nd & ad \\
\hline DAB83 38 & 69 & 7.50 & nd & nd & nd & nd & 2.00 & 0.39 & nd & \\
\hline DAB83 42 & 65 & 7.87 & 1.82 & 0.07 & 3.17 & 0.14 & 2.20 & 0.24 & 14.62 & 1.05 \\
\hline DAB86 12-16 & $115-111$ & 7.50 & 41.60 & 1.22 & 43.74 & 1.22 & 37.05 & 2.11 & 38.37 & 0.31 \\
\hline DCP211/2-3 & $121-120$ & vadose & 1.22 & 0.20 & 2.78 & 0.21 & 2.01 & 0.04 & 2.14 & 1.21 \\
\hline DCP211/9-10 & $114-113$ & nd & 1.32 & 0.05 & 3.29 & 0.23 & 2.56 & 0.14 & 2.89 & 0.32 \\
\hline DCP211/19-20 & $104-103$ & 4.89 & 1.99 & 0.54 & 4.98 & 0.59 & 3.98 & 0.27 & 6.07 & 0.63 \\
\hline DCP211/35-36 & $88-87$ & 4.69 & 2.31 & 0.50 & 2.81 & 0.51 & 1.32 & 0.04 & 1.56 & 0.39 \\
\hline DCP168/1.5-3.5 & $96-94$ & vadose & 0.67 & 0.03 & 3.13 & 0.50 & 3.35 & 0.15 & 2.51 & 0.55 \\
\hline DCP168/20-22 & $77-78$ & 5.61 & 11.39 & 0.20 & 15.87 & 1.71 & 15.86 & 5.10 & 18.03 & 1.45 \\
\hline DCP168/31-33 & $66-64$ & 6.31 & 3.71 & 0.18 & 7.37 & 0.43 & 8.42 & 0.36 & 6.16 & 1.87 \\
\hline DCP170/1-3 & $96-94$ & vadose & 0.88 & 0.03 & 3.02 & 0.34 & 1.99 & 0.08 & 5.19 & 0.74 \\
\hline DCP170/14-16 & $83-81$ & 4.59 & 0.13 & 0.04 & 0.29 & 0.13 & 0.27 & 0.00 & 0.57 & 0.30 \\
\hline DCP170/20-22 & $77-75$ & 5.83 & 0.34 & 0.03 & 0.75 & 0.09 & 0.79 & 0.05 & 0.99 & 0.43 \\
\hline DCP171/1-3 & $96.5-94.5$ & vadose & nd & nd & nd & nd & nd & nd & 3.33 & 0.05 \\
\hline DCP171/24-26 & $73.5-71.5$ & 6.13 & nd & nd & nd & nd & nd & nd & 2.33 & 1.08 \\
\hline
\end{tabular}

$\mathrm{nd}=$ not determined

Table 20. Arsenic Soil Concentration (ppm) in Wetland Samples

\begin{tabular}{|l|c|rrrrrrrrr|}
\hline \multicolumn{1}{|c|}{ Sample } & $\begin{array}{c}\text { Pore- } \\
\text { water } \\
\text { pH }\end{array}$ & Sum 1-6 & st dev & Sum 1-8 & st dev & TD & st dev & 3050b & st dev \\
\hline D-2 & 5.49 & 3.62 & 0.33 & 6.36 & 0.73 & nd & nd & 3.21 & 0.02 \\
D-4 & 5.94 & 3.75 & 0.41 & 7.75 & 0.61 & nd & nd & 3.00 & 0.88 \\
G-10 & 6.12 & 40.42 & 1.88 & 44.24 & 1.89 & nd & nd & 24.76 & 1.99 \\
H-5 & 6.02 & 75.76 & 13.51 & 77.93 & 13.51 & nd & nd & 53.97 & 1.81 \\
J-6 & 5.13 & 37.66 & 4.38 & 40.81 & 4.42 & nd & nd & 28.48 & 1.43 \\
K-4 & 4.52 & 75.14 & 5.78 & 78.32 & 5.80 & nd & nd & 51.01 & 6.41 \\
\hline
\end{tabular}

nd $=$ not determined 
WSRC-TR-2004-00124, REVISION 0

Table 21. Selenium Soil Concentration (ppm) in Wetland Samples

\begin{tabular}{|l|r|rrrrrrrr|}
\hline Sample & $\begin{array}{c}\text { Pore- } \\
\text { water } \\
\text { pH }\end{array}$ & Sum 1-6 & st dev & Sum 1-8 & st dev & TD & st dev & $\mathbf{3 0 5 0 b}$ & st dev \\
\hline D-2 & 5.49 & 2.09 & 0.83 & 2.09 & 0.83 & nd & nd & 1.53 & 0.32 \\
D-4 & 5.94 & 1.93 & 0.43 & 1.93 & 0.44 & nd & nd & 1.88 & 0.08 \\
G-10 & 6.12 & 6.92 & 1.02 & 6.92 & 1.03 & nd & nd & 5.23 & 0.27 \\
H-5 & 6.02 & 9.91 & 2.57 & 10.06 & 2.58 & nd & nd & 6.18 & 0.49 \\
J-6 & 5.13 & 5.06 & 1.31 & 5.33 & 1.37 & nd & nd & 3.48 & 0.15 \\
K-4 & 4.52 & 4.79 & 0.90 & 5.75 & 1.17 & nd & nd & 3.90 & 0.37 \\
\hline
\end{tabular}

$\mathrm{nd}=$ not determined

Table 22. Vanadium Soil Concentration (ppm) in Wetland Samples

\begin{tabular}{|l|r|rrrrrrrr|}
\hline \multicolumn{1}{|c|}{ Sample } & $\begin{array}{c}\text { Pore- } \\
\text { water } \\
\text { pH }\end{array}$ & Sum 1-6 & st dev & Sum 1-8 & st dev & TD & st dev & 3050b & st dev \\
\hline D-2 & 5.49 & 21.83 & 1.84 & 70.93 & 9.25 & nd & nd & 70.96 & 1.74 \\
D-4 & 5.94 & 27.52 & 1.08 & 100.61 & 7.46 & nd & nd & 103.34 & 0.07 \\
G-10 & 6.12 & 40.68 & 0.37 & 127.01 & 3.50 & nd & nd & 94.36 & 2.72 \\
H-5 & 6.02 & 45.01 & 1.32 & 102.81 & 8.34 & nd & nd & 74.15 & 0.59 \\
J-6 & 5.13 & 25.99 & 2.00 & 119.37 & 13.81 & nd & nd & 61.20 & 2.34 \\
K-4 & 4.52 & 35.99 & 0.41 & 106.98 & 5.06 & nd & nd & 62.49 & 0.37 \\
\hline
\end{tabular}

$\mathrm{nd}=$ not determined 
WSRC-TR-2004-00124, REVISION 0

Table 23. Iron Concentration (ppm) in Upland Soil

\begin{tabular}{|c|c|c|c|c|c|c|c|c|c|c|}
\hline $\begin{array}{c}\text { Sample } \\
\text { Soil } \\
\end{array}$ & Elevation & $\begin{array}{c}\text { Pore- } \\
\text { water } \\
\text { pH }\end{array}$ & $\begin{array}{c}\text { Iron } \\
\text { Sum 1-6 }\end{array}$ & st dev & Sum 1-8 & st dev & TD & st dev & $3050 b$ & st dev \\
\hline DAB92 4-6 & $112-110$ & 3.18 & 1334.45 & 53.11 & nd & 114.24 & 73632.85 & 272.74 & 5435.21 & 65.72 \\
\hline DAB92 21-23 & $95-93$ & 4.12 & 616.70 & 22.18 & nd & 22.89 & 2192.09 & 453.96 & 1435.98 & 157.55 \\
\hline DAB85 32-33 & $99-98$ & 5.18 & 794.62 & 108.07 & 2232.42 & 194.68 & 2077.70 & 596.62 & 1384.70 & 106.32 \\
\hline DAB85 45 & 86 & 7.25 & nd & nd & nd & nd & 1060.34 & 169.08 & nd & nd \\
\hline DAB81 30-35 & 98 & 4.80 & nd & nd & nd & nd & 10230.13 & 1208.18 & nd & nd \\
\hline DAB81 45 & 83 & 4.26 & 312.15 & 120.91 & 11728.36 & 12060.72 & 12253.03 & 10399.3 & 1368.40 & 337.66 \\
\hline DAB81 50 & 78 & 7.98 & nd & nd & nd & nd & 5003.50 & 500.27 & nd & nd \\
\hline DAB87 33 & 92 & 3.81 & nd & nd & nd & nd & 12169.85 & 900.77 & nd & nd \\
\hline DAB87 38 & 87 & 3.76 & 278.21 & 13.36 & 2506.72 & 128.77 & 2558.39 & 62.20 & 1904.12 & 224.26 \\
\hline DAB87 53 & 72 & 4.93 & nd & nd & nd & nd & 13572.85 & 720.75 & nd & nd \\
\hline DAB84 20 & 88 & 5.06 & nd & nd & nd & nd & 436.81 & 29.69 & nd & nd \\
\hline DAB84 28 & 80 & 4.56 & 157.84 & 26.53 & 3721.52 & 443.74 & 4485.47 & 49.80 & 1547.11 & 57.31 \\
\hline DAB84 38 & 70 & 5.24 & nd & nd & nd & nd & 32714.71 & 1727.07 & nd & nd \\
\hline DAB83 32 & 75 & 6.61 & nd & nd & nd & nd & 8341.16 & 912.79 & nd & nd \\
\hline DAB83 38 & 69 & 7.50 & nd & nd & nd & nd & 15091.65 & 6634.69 & nd & nd \\
\hline DAB83 42 & 65 & 7.87 & 5055.30 & 402.89 & 12782.63 & 1012.69 & 5179.26 & 144.02 & 16143.15 & 725.37 \\
\hline DAB86 12-16 & 115-111 & 7.50 & 3460.22 & 399.21 & 5558.67 & 399.67 & 12169.85 & 900.77 & 23906.77 & 12.32 \\
\hline DCP211/2-3 & $121-120$ & vadose & 518.65 & 88.63 & 4250.72 & 174.95 & 6975.00 & 445.48 & 4014.50 & 183.14 \\
\hline DCP211/9-10 & $114-113$ & nd & 405.49 & 10.91 & 8876.36 & 864.37 & 13050.00 & 494.97 & 6472.50 & 144.96 \\
\hline DCP211/19-20 & $104-103$ & 4.89 & 6151.74 & 553.62 & 30682.40 & 1517.27 & 43000.00 & 1414.21 & 27235.00 & 3358.76 \\
\hline DCP211/35-36 & $88-87$ & 4.69 & 461.98 & 15.30 & 3548.04 & 18.19 & 3370.00 & 438.41 & 2984.50 & 253.85 \\
\hline DCP168/1.5-3.5 & $96-94$ & vadose & 999.80 & 21.73 & 17520.63 & 1941.15 & 13700.00 & 141.42 & 7063.00 & 328.10 \\
\hline DCP168/20-22 & $77-78$ & 5.61 & 3974.52 & 139.49 & 14500.54 & 2127.05 & 20200.00 & 707.11 & 10005.00 & 742.46 \\
\hline DCP168/31-33 & $66-64$ & 6.31 & 1757.17 & 416.09 & 6491.02 & 2312.52 & 4240.00 & 127.28 & 4057.50 & 1225.42 \\
\hline DCP170/1-3 & $96-94$ & vadose & 546.40 & 14.68 & 6533.58 & 1008.54 & 16500.00 & 0.00 & 11322.50 & 3899.69 \\
\hline DCP170/14-16 & $83-81$ & 4.59 & 58.68 & 2.94 & 2152.45 & 165.5 & 3560.00 & 70.71 & 980.15 & 50.70 \\
\hline DCP170/20-22 & $77-75$ & 5.83 & 1294.73 & 51.46 & 10877.17 & 1081.57 & 12650.00 & 777.82 & 7783.50 & 164.76 \\
\hline DCP171/1-3 & $96.5-94.5$ & vadose & nd & nd & nd & nd & 13300.00 & 424.26 & 12550.00 & 70.71 \\
\hline DCP171/24-26 & $73.5-71.5$ & 6.13 & nd & nd & nd & nd & 3495.00 & 162.63 & 3388.50 & 70.00 \\
\hline
\end{tabular}

nd $=$ not determined

Table 24. Iron Soil Concentration (ppm) in Wetland Samples

\begin{tabular}{|l|r|rrrrrrrr|}
\hline Sample & $\begin{array}{c}\text { Pore- } \\
\text { water } \\
\text { pH }\end{array}$ & Sum 1-6 & st dev & Sum 1-8 & st dev & TD & st dev & $\mathbf{3 0 5 0 b}$ & st dev \\
\hline D-2 & 5.49 & 8296.42 & 321.27 & 27724.43 & 3938.85 & nd & nd & 28813.39 & 374.77 \\
D-4 & 5.94 & 10266.99 & 472.19 & 38027.96 & 2924.02 & nd & nd & 42488.39 & 226.27 \\
G-10 & 6.12 & 4199.74 & 45.14 & 18349.47 & 1210.72 & nd & nd & 14315.89 & 137.89 \\
H-5 & 6.02 & 8667.03 & 1065.73 & 26402.35 & 2358.32 & nd & nd & 26553.39 & 233.35 \\
J-6 & 5.13 & 3742.10 & 230.64 & 24731.63 & 2457.50 & nd & nd & 16473.39 & 1053.59 \\
K-4 & 4.52 & 6609.40 & 1178.79 & 20434.66 & 2015.63 & nd & nd & 15563.39 & 459.62 \\
\hline
\end{tabular}

$\mathrm{nd}=$ not determined 
WSRC-TR-2004-00124, REVISION 0

Table 25. Aluminum Concentration (ppm) in Upland Soil

\begin{tabular}{|c|c|c|c|c|c|c|c|c|c|c|}
\hline \multirow[t]{2}{*}{ Soil Sample } & \multirow[t]{2}{*}{ Elevation } & \multirow{2}{*}{$\begin{array}{c}\text { Pore- } \\
\text { water } \\
\text { pH }\end{array}$} & \multicolumn{2}{|c|}{ Aluminum } & \multirow[b]{2}{*}{ Sum 1-8 } & \multirow[b]{2}{*}{ st dev } & \multirow[b]{2}{*}{ TD } & \multirow[b]{2}{*}{ st dev } & \multirow[b]{2}{*}{ 3050b } & \multirow[b]{2}{*}{ st dev } \\
\hline & & & Sum 1-6 & st dev & & & & & & \\
\hline DAB92 4-6 & $112-110$ & 3.18 & 320.11 & 38.48 & $\overline{\mathrm{nd}}$ & 39.00 & 28603.09 & 1049.25 & 20007.41 & 2091.76 \\
\hline DAB92 21-23 & $95-93$ & 4.12 & 185.95 & 10.01 & nd & 10.67 & 5384.88 & 1094.62 & 3632.70 & 548.10 \\
\hline DAB85 32-33 & $99-98$ & 5.18 & 23.06 & 1.65 & 19041.12 & 219.65 & 20420.21 & 5721.73 & 8669.16 & 503.79 \\
\hline DAB85 45 & 86 & 7.25 & nd & nd & nd & nd & 6453.47 & 645.75 & nd & nd \\
\hline DAB81 30-35 & 98 & 4.80 & nd & nd & nd & nd & 36687.64 & 3106.07 & nd & nd \\
\hline DAB81 45 & 83 & 4.26 & 42.95 & 5.67 & 15271.99 & 9329.49 & 13760.95 & 4903.58 & 2175.74 & 245.54 \\
\hline DAB81 50 & 78 & 7.98 & nd & nd & nd & nd & 323.17 & 72.96 & nd & nd \\
\hline DAB87 33 & 92 & 3.81 & nd & nd & nd & nd & 38385.74 & 4840.10 & nd & nd \\
\hline DAB87 38 & 87 & 3.76 & 45.01 & 2.28 & 18987.54 & 166.03 & 18579.78 & 452.71 & 8755.14 & 1128.54 \\
\hline DAB87 53 & 72 & 4.93 & nd & nd & nd & nd & 49370.24 & 3225.11 & nd & nd \\
\hline DAB84 20 & 88 & 5.06 & nd & nd & nd & nd & 8886.81 & 334.66 & nd & nd \\
\hline DAB84 28 & 80 & 4.56 & 40.76 & 3.75 & 13301.22 & 6756.92 & 10599.10 & 160.59 & 4570.27 & 124.42 \\
\hline DAB84 38 & 70 & 5.24 & nd & nd & nd & nd & 51005.05 & 2846.27 & nd & nd \\
\hline DAB83 32 & 75 & 6.61 & nd & nd & nd & nd & 32649.23 & 5229.62 & nd & nd \\
\hline DAB83 38 & 69 & 7.50 & nd & nd & nd & nd & 37301.56 & 18768.72 & nd & nd \\
\hline DAB83 42 & 65 & 7.87 & 33.08 & 2.56 & 3186.08 & 832.82 & 486.48 & 90.95 & 6353.72 & 46.61 \\
\hline DAB86 12-16 & $115-111$ & 7.50 & 14.26 & 5.38 & 113.08 & 32.25 & 38385.74 & 4840.10 & 28333.90 & 52.10 \\
\hline DCP211/2-3 & $121-120$ & vadose & 29.16 & 1.90 & 7704.23 & 616.81 & 15990 & 1965.76 & 5635.50 & 1331.48 \\
\hline DCP211/9-10 & $114-113$ & nd & 43.53 & 7.08 & 11043.28 & 88.93 & 60400 & 13717.87 & 11496.00 & 2381.54 \\
\hline DCP211/19-20 & $104-103$ & 4.89 & 32.58 & 6.34 & 10959.44 & 166.55 & 20250 & 212.13 & 6641.00 & 1712.61 \\
\hline DCP211/35-36 & $88-87$ & 4.69 & 320.29 & 8.16 & 972.94 & 8.26 & 1125 & 91.92 & 356.10 & 7.50 \\
\hline DCP168/1.5-3.5 & $96-94$ & vadose & 1005.17 & 18.37 & 11660.69 & 1468.32 & 43000 & 1555.63 & 13360.00 & 1725.34 \\
\hline DCP168/20-22 & $77-78$ & 5.61 & 402.86 & 17.54 & 5004.49 & 1231.26 & 15250 & 494.97 & 2212.50 & 348.60 \\
\hline DCP168/31-33 & $66-64$ & 6.31 & 160.37 & 4.77 & 1795.35 & 465.44 & 3715 & 1251.58 & 420.10 & 44.41 \\
\hline DCP170/1-3 & $96-94$ & vadose & 495.73 & 13.15 & 12168.59 & 830.99 & 50850 & 777.82 & 10769.50 & 2617.00 \\
\hline DCP170/14-16 & $83-81$ & 4.59 & 340.00 & 3.48 & 11346.44 & 426.80 & 21000 & 1131.37 & 3207.00 & 173.95 \\
\hline DCP170/20-22 & $77-75$ & 5.83 & 59.14 & 1.13 & 10875.96 & 168.37 & 31650 & 1909.19 & 4651.50 & 137.89 \\
\hline DCP171/1-3 & $96.5-94.5$ & vadose & nd & nd & nd & nd & 36850 & 6576.09 & 15865.00 & 120.21 \\
\hline DCP171/24-26 & $73.5-71.5$ & 6.13 & nd & nd & nd & nd & 18900 & 2404.16 & 2695.50 & 457.50 \\
\hline
\end{tabular}

Table 26. Aluminum Soil Concentration (ppm) in Wetland Samples

\begin{tabular}{|l|r|rrrrrrrr|}
\hline \multicolumn{1}{|c|}{ Sample } & $\begin{array}{r}\text { Pore- } \\
\text { water } \mathbf{p H}\end{array}$ & Sum 1-6 & st dev & Sum 1-8 & st dev & TD & st dev & 3050b & st dev \\
\hline D-2 & 5.49 & 45.17 & 1.78 & 51162 & 14971 & nd & nd & 46961.95 & 3641.60 \\
D-4 & 5.94 & 43.68 & 5.10 & 77305 & 2331 & nd & nd & 79766.95 & 1385.93 \\
G-10 & 6.12 & 30.11 & 1.72 & 68112 & 6713 & nd & nd & 36924.45 & 661.14 \\
H-5 & 6.02 & 26.54 & 0.45 & 44752 & 7415 & nd & nd & 21871.95 & 21.21 \\
J-6 & 5.13 & 105.60 & 11.54 & 70372 & 8585 & nd & nd & 27176.95 & 1258.65 \\
K-4 & 4.52 & 131.92 & 8.30 & 54409 & 6319 & nd & nd & 23276.95 & 353.55 \\
\hline
\end{tabular}

nd $=$ not determined 
WSRC-TR-2004-00124, REVISION 0

\subsection{MICROBIOLOGICAL CHARACTERIZATION}

Table 27 presents results of the total bacterial densities, viable and culturable bacterial densities, and results from anaerobic, iron reducing bacteria (IRB), acid producing bacteria (APB), and sulfate reducing bacteria (SRB) from the upland sediments. Table 28 presents results of the total bacterial densities and viable, culturable microbial colony forming units (CFU) from the wetland sediments. Results for both Table 27 and Table 28 are reported in cells or CFU for viable, culturable bacteria per gram wet weight sediment. Biological data (total counts, viable counts, and substrate utilization) are also represented in cross-sectional form (Figure 15 through Figure 18) for a subset of upland and wetland locations to show vertical stratification. Biological data for all wetland locations is posted to map locations in Figure 19.

IRB are involved in the reduction of $\mathrm{Fe}(\mathrm{III})$ to $\mathrm{Fe}(\mathrm{II})$, and as such, would be expected to be more abundant in reducing environments. SRB are involved in reducing sulfate to sulfide; they generally require a more reducing environment than IRB. SRB may be desirable for MNA of many inorganic contaminants in the DEXOU because they may either directly convert some COCs, such as U (Lovely et al. 1991), from the more mobile oxidized form to the less mobile reduced form, or they may form sulfides that form sparingly soluble precipitates with the COC, such as $\mathrm{Ni}$ or $\mathrm{UO}_{2}{ }^{2+}$ (Stumm and Morgan 1996). APB are commonly iron-oxidizing autotrophic bacteria that use $\mathrm{Fe}^{2+}$ as an energy source and $\mathrm{CO}_{2}$ as a $\mathrm{C}$ source. They occur widely in mining regions where coal and mineral deposits contribute sulfide minerals (e.g., pyrite) to the soil and sediment. Such bacteria are typically believed to be responsible for the acidity associated with coal pile leachate.

Acid-producing bacteria (APB) were detected in only two Upland soil samples - DAB 9221 and DAB 81 50. The presence of APB in DAB 9221 is not surprising given the close proximity of this sample to the coal pile (DCPRB). Iron reducing bacteria (IRB) were detected in only one Upland soil sample, DAB 8150 . Sulfate reducing bacteria (SRB) were detected in only one Upland soil sample, DAB 9221 . This finding suggests that the sampling transect is largely aerobic, with limited chance for biological reduction to occur. The lack of APB, IRB, and SRB detection, with the exception of three sediment samples, typically indicate low nutrients conditions in the associated sediment and groundwater. Addition of nutrients to groundwater can stimulate the growth of these bacteria at this site (Phifer et al., 2001). Their absence may be attributed to lack of nutrients or to the redox status of the wetland.

Bacterial densities for both plate (viable) counts and total (direct) counts were generally higher in the Wetland sediments (Table 28) as compared to the Upland sediments (Table 27, Figure 16 and Figure 17). However, it is important to note that the upland sediment samples were generally collected from deeper locations ( 4 ' to $53^{\prime}$ ) than the wetland samples (surface 1 $\mathrm{ft} \mathrm{depth).} \mathrm{In} \mathrm{Figure} \mathrm{20,} \mathrm{all} \mathrm{locations} \mathrm{were} \mathrm{sorted} \mathrm{by} \mathrm{direct} \mathrm{counts} \mathrm{with} \mathrm{the} \mathrm{wetland} \mathrm{locations}$ demonstrating the highest total numbers of organisms (right side of graph). 
The wetland sediments also could be further separated into groupings based on locations and microbiological results (Table 28). Samples H-5, J-6, and K-4 (Figure 19), are located near or in an area that received sluiced coal ash (Figure 3 ) and to another area with a contaminated outcropping from the DCPRB plume (Figure 2). These samples had lower total direct counts and plate counts compared to wetland samples G-10, D-2, and D-4, located further from the impacted areas. G-10 is an ash sample from the ash deposition area, and D-2 and D-4 are soil samples from an area presumed to be unimpacted. Porewater from sediments at locations K-4 and J-6 had the lowest $\mathrm{pH}$ of the wetlands. Therefore, the lower bacterial densities could be a result of contaminant exposure as well as other environmental factors including nutrient availability.

Microbial data from sediments using Biolog ${ }^{\circledR}$ for substrate utilization demonstrated different trends for all cores tested (Table 29 and Table 30, Figure 18 and Figure 19). In Table 29 and Table 30, the difference in the number of Biolog ${ }^{\circledR}$ positives represents the quantity of total substrates in a particular class utilized (of 95 total substrates) in sediments. Overall there appeared to be more activity in the wetland (Table 30) ash as compared to the upland soils (Table 29). Greater and wider usage of Biolog ${ }^{\circledR}$ substrates by bacteria from the wetland sediments indicates higher species diversity. Higher diversity indicates a healthy robust microbial population with multiple functions including ability to absorb/alter contaminants. However, as mentioned previously, comparisons between these sediment samples can only be viewed as general trends because of the differences in the depth of collection.

Figure 18, Figure 19, and Figure 24 demonstrate comparative differences of Biolog ${ }^{\circledR}$ ecofunctional enzyme activity as a function of sample location. Figure 23 is sorted by sulfate concentrations and shows the percent responses to all the carbon sources. Pore water $\mathrm{pH}$ varies between 3 and 8 and may have slightly decreased as the sulfate concentrations increased. Clearly, there is no linear trend with percent response versus sample locations as they are arranged in either figure. The Wetland samples appear to fall in two groups. The wetland locations D-2, D-4, and G-10 all have $>40 \%$ substrate activity (all carbon sources tested) while $\mathrm{H}-5, \mathrm{~J}-6$, and $\mathrm{K}-4$ all have $<15 \%$ activity (all carbon sources tested). D-4 and G-10 had particularly active aerobic populations with $\sim 70 \%$ substrate activity (all carbon sources tested). These locations can also be related to physical position with relation to the sites (Figure 19 and Figure 24). The wetland locations D-2, D-4, and G-10 are furthest from potential contaminant sources (including the DCP, the DCPRB (D-Area Coal Pile Runoff Basin), DAB (488-D) (Figure 3), and the wetland outcropping located north and east of sample H5 (Figure 2). Therefore the increase microbial activity associated with these latter sites is likely due to natural conditions and lack of contamination. Conversely, locations $\mathrm{H}$ 5 , J-6, and K-4 are all nascent to the contaminant source areas. The Biolog ${ }^{\circledR}$ results indicate that even though H-5, J-6, and K-4 are in the wetland area and sediment samples were taken at the same depths $(1 \mathrm{ft})$ as locations D-2, D-4 and G-10, the microbial activity is significantly different. 
Discriminant Analysis of the Biolog ${ }^{\circledR}$ testing of the soil slurry indicated that the Biolog structures of $\mathrm{H}-5$ and K-4, (i.e., the way microbial communities in sample $\mathrm{H}-5$ and K-4 utilized various carbon substrates) were more similar to microbial communities in Upland soils than wetland soils (Figure 25). By way of example, the red lines in Figure 25 identify the region where the microbial community has a $75 \%$ chance of having the typical Upland type of Biolog ${ }^{\circledR}$ test results. The cause for this result may be attributed to a number of spatial attributes, including the proximity of these sample locations to: 1) the sluiced coal ash, 2) a potential contaminant groundwater outcropping, and 3) to the Upland area. Another possibility is that this outcome is the result of simple natural heterogeneity. This latter explanation is less likely because this discussion is already based on statistics, which by definition accounts for variability. The implications of this finding may be that the microbial community of H-5 and K-4 are impacted by operations in a manner similar to Upland microbial communities. As such, the ability of the transformed microbial community to contribute to attenuation contaminant transport will take on more of the character of the Upland communities than of the Wetland communities. It may also indicate that the microbial communities may be expected to change as the plume moves through a site, not an altogether surprising conclusion. Additional notes on the Discriminant Analysis are presented in Appendix D.

Ecofunctional enzyme activity also varied as a function of physical and chemical parameters (Figure 26). As was stated previously, the wetland samples were all taken at shallow depths while the upland samples varied in depth (Figure 26). When comparing chemical parameters including $\mathrm{As}, \mathrm{Be}, \mathrm{Ni}, \mathrm{SO}_{4}$, and $\mathrm{U}$, porewater concentrations, two or three of the wetlands samples would often demonstrate distinctive differences (Figure 26). Since these porewater contaminant concentrations are below the toxicity concentration for most microbes, the diversity between samples should be associated with removal, not with toxicity to the microorganisms. Examination of the analytical and microbiological data indicates that both contaminant concentrations and location were correlated with microbial activity. D-2 and D4, the two wetland sites closest to the Savannah River and furthest from the source zone, had very low porewater sulfate concentrations $(<10 \mathrm{ppm})$ (Table 6$)$ and had high ecofunctional enzyme activity. G-10 also had low sulfate porewater concentration in comparison to other wetland sample locations (Table 6) and had very high $(69 \%$, all carbon sources tested) aerobic ecofunctional enzyme activity. Conversely, H-5, J-6, and K-4 had high porewater sulfate concentrations $(>100 \mathrm{ppm})$ (Table 6$)$ and low $(<15 \%$, all carbon sources tested) aerobic ecofunctional enzyme activity (Figure 25).

Figure 26 demonstrates the relationship between EFE (all carbon sources tested by Biolog) and $\mathrm{As}, \mathrm{Be}, \mathrm{Ni}, \mathrm{S}$, and $\mathrm{U}$. While all metal concentrations were lower than toxicity levels, there were relationships observed between microbial activity and contaminant concentrations. Wetlands were higher in As porewater concentrations than most upland samples, especially G-10, H-5, and K-4. Of the higher As wetland grouping only G-10 showed high EFE activity. Nonimpacted wetland locations D-4 and D-2 also showed high EFE activity. For $\mathrm{Ni}$ and $\mathrm{Be}$, the uplands generally tested higher than wetland sediments and there was little relation to EFE activity. U was similar to As in that wetland locations were higher that correlated to increased EFE activity. 
The results of the $\mathrm{pH}$ buffering capacity test are given in Table 31 . The Biolog ${ }^{\circledR}$ GN Microplates, as used in the ecofunctional enzyme study, have a strong and immediate buffering capacity to the liquids added to them. Any initial differences in the $\mathrm{pH}$ range of 4 to 5 of the added soil slurries would be buffered to near neutral when added to the Biolog ${ }^{\circledR}$ GN Microplates. As such, this strong buffering capacity is an experimental artifact in that it tests the microbes at a $\mathrm{pH}$ other than their natural $\mathrm{pH}$. Although these culture conditions may compromise the data, it still remains that the tests provide a useful index that may not be possible if the $\mathrm{pH}$ was permitted to fluctuate.

In a subsequent series of experiments the ability of isolated D-Area bacteria (Table 32) to adjust $\mathrm{pH}$ was successfully tested. See Table 33 through Table 35 for further information. 
WSRC-TR-2004-00124, REVISION 0

\section{Table 27. Upland Soils Bacterial Counts}

(Results expressed as a percentage of positive responses for carbon substrates tested by type of substrate as well as for all carbon sources.)

\begin{tabular}{|c|c|c|c|c|c|c|c|c|c|c|c|c|c|c|c|}
\hline & $\begin{array}{c}\text { DAB-92 } \\
4^{\prime}-6^{\prime}\end{array}$ & \begin{tabular}{|c|} 
DAB-92 \\
21'
\end{tabular} & $\begin{array}{c}\text { DAB-92 } \\
\text { 23' }^{\prime}\end{array}$ & $\begin{array}{c}\text { DAB-81 } \\
\text { 30 }^{\prime}\end{array}$ & $\begin{array}{c}\text { DAB-81 } \\
4^{\prime}\end{array}$ & \begin{tabular}{|c|} 
DAB-81 \\
$5^{\prime}$
\end{tabular} & $\begin{array}{c}\text { DAB-87 } \\
\text { 33' }\end{array}$ & \begin{tabular}{|c|} 
DAB-87 \\
38'
\end{tabular} & $\begin{array}{c}\text { DAB-87 } \\
\text { 53' }^{\prime}\end{array}$ & $\begin{array}{c}\text { DAB-84 } \\
2^{\prime}\end{array}$ & \begin{tabular}{|c|} 
DAB-84 \\
28
\end{tabular} & \begin{tabular}{|c|} 
DAB-84 \\
38'
\end{tabular} & $\begin{array}{c}\text { DAB-83 } \\
\text { 32' }\end{array}$ & $\begin{array}{c}\text { DAB-83 } \\
\text { 38' }\end{array}$ & $\begin{array}{c}\text { DAB-83 } \\
42^{\prime}\end{array}$ \\
\hline Sampling Date & $6 / 12 / 02$ & $6 / 12 / 02$ & $6 / 12 / 02$ & $7 / 25 / 02$ & $7 / 25 / 02$ & $7 / 25 / 02$ & $7 / 29 / 02$ & $7 / 29 / 02$ & $7 / 29 / 02$ & $7 / 30 / 02$ & $7 / 30 / 02$ & $7 / 30 / 02$ & $7 / 23 / 02$ & $7 / 23 / 02$ & $7 / 23 / 02$ \\
\hline $\begin{array}{l}\text { Total Direct Counts } \\
\text { (\# cells/g wet wt) }\end{array}$ & $2.11 \mathrm{E}+08$ & $7.77 \mathrm{E}+08$ & $6.88 \mathrm{E}+08$ & $8.68 \mathrm{E}+05$ & $2.78 \mathrm{E}+06$ & $2.21 \mathrm{E}+07$ & $5.60 \mathrm{E}+07$ & $8.89 \mathrm{E}+08$ & $9.38 \mathrm{E}+07$ & $1.10 \mathrm{E}+07$ & $2.59 \mathrm{E}+08$ & $1.20 \mathrm{E}+08$ & $6.24 \mathrm{E}+06$ & $2.18 \mathrm{E}+07$ & $2.27 \mathrm{E}+08$ \\
\hline IRB* / (\# cells/g wet wt $)$ & $<10$ & $<10$ & $<10$ & $<10$ & $<10$ & $\begin{array}{c}1.00 \mathrm{E}+01 \text { to } \\
1.00 \mathrm{E}+02\end{array}$ & $<10$ & $<10$ & $<10$ & $<10$ & $<10$ & $<10$ & $<10$ & $<10$ & $<10$ \\
\hline APB* / (\# cells/g wet wt) & $<10$ & $\begin{array}{l}1.00 \mathrm{E}+01 \text { to } \\
1.00 \mathrm{E}+02\end{array}$ & $<10$ & $<10$ & $<10$ & $\begin{array}{c}1.00 \mathrm{E}+04 \text { to } \\
1.00 \mathrm{E}+05\end{array}$ & $<10$ & $<10$ & $<10$ & $<10$ & $<10$ & $<10$ & $<10$ & $<10$ & $<10$ \\
\hline $\mathrm{SRB}^{*} /$ (\# cells/g wet wt) & $<10$ & $\begin{array}{c}1.00 \mathrm{E}+01 \text { to } \\
1.00 \mathrm{E}+02\end{array}$ & $>10 \mathrm{E}+06$ & $<10$ & $<10$ & $<10$ & $<10$ & $<10$ & $<10$ & $<10$ & $<10$ & $<10$ & $<10$ & $<10$ & $<10$ \\
\hline $\begin{array}{l}\text { PTYG (CFU/g) pH } 7.0 \\
\text { incubated aerobically }\end{array}$ & $1.10 \mathrm{E}+04$ & $2.50 \mathrm{E}+04$ & $<25$ & ND & ND & ND & ND & ND & ND & ND & ND & ND & ND & ND & ND \\
\hline $\begin{array}{l}\text { PTYG }(\mathrm{CFU} / \mathrm{g}) \mathrm{pH} 5.0 \\
\text { incubated aerobically }\end{array}$ & $4.00 \mathrm{E}+04$ & $>3.00 \mathrm{E}+06$ & $1.10 \mathrm{E}+05$ & $5.00 \mathrm{E}+04$ & $5.00 \mathrm{E}+05$ & $6.00 \mathrm{E}+04$ & $<25$ & $1.48 \mathrm{E}+06$ & $2.40 \mathrm{E}+05$ & ND & $3.90 \mathrm{E}+06$ & $>3.00 \mathrm{E}+06$ & $9.00 \mathrm{E}+04$ & $3.00 \mathrm{E}+04$ & $6.00 \mathrm{E}+04$ \\
\hline $\begin{array}{c}\text { PTYG }(\mathrm{CFU} / \mathrm{g}) \mathrm{pH} 4.0 \\
\text { incubated aerobically }\end{array}$ & $<25$ & $5.00 \mathrm{E}+04$ & $2.00 \mathrm{E}+03$ & $5.00 \mathrm{E}+04$ & $>3.00 \mathrm{E}+05$ & $>3.00 \mathrm{E}+06$ & $<25$ & $6.50 \mathrm{E}+05$ & $1.76 \mathrm{E}+06$ & ND & $2.00 \mathrm{E}+06$ & $2.00 \mathrm{E}+06$ & $1.70 \mathrm{E}+05$ & $6.10 \mathrm{E}+05$ & $1.11 \mathrm{E}+06$ \\
\hline $\begin{array}{l}\text { PTYG (CFU/g) pH } 3.0 \\
\text { incubated aerobically }\end{array}$ & $2.40 \mathrm{E}+04$ & $1.00 \mathrm{E}+03$ & $3.00 \mathrm{E}+04$ & $2.00 \mathrm{E}+04$ & $1.10 \mathrm{E}+05$ & $1.10 \mathrm{E}+05$ & $<25$ & $<25$ & $1.56 \mathrm{E}+06$ & ND & $>3.00 \mathrm{E}+06$ & $7.40 \mathrm{E}+05$ & $7.20 \mathrm{E}+04$ & $1.20 \mathrm{E}+04$ & $1.00 \mathrm{E}+03$ \\
\hline $\begin{array}{c}1 \% \text { PTYG (CFU/g) pH } 7.0 \\
\text { incubated aerobically }\end{array}$ & $7.90 \mathrm{E}+04$ & $<25$ & $<25$ & ND & ND & ND & ND & ND & ND & ND & ND & ND & ND & ND & ND \\
\hline $\begin{array}{c}1 \% \text { PTYG }(\mathrm{CFU} / \mathrm{g}) \mathrm{pH} 5.0 \\
\text { incubated aerobically }\end{array}$ & $6.00 \mathrm{E}+04$ & $1.50 \mathrm{E}+05$ & $3.00 \mathrm{E}+04$ & $<25$ & $<25$ & $3.00 \mathrm{E}+05$ & $<25$ & $>3.00 \mathrm{E}+06$ & $<25$ & ND & ND & $<25$ & $1.50 \mathrm{E}+05$ & $1.12 \mathrm{E}+06$ & $1.26 \mathrm{E}+06$ \\
\hline $\begin{array}{c}1 \% \text { PTYG }(\mathrm{CFU} / \mathrm{g}) \mathrm{pH} 4.0 \\
\text { incubated aerobically }\end{array}$ & $7.00 \mathrm{E}+04$ & $4.00 \mathrm{E}+04$ & $5.00 \mathrm{E}+04$ & $<25$ & $1.00 \mathrm{E}+04$ & $>3.00 \mathrm{E}+05$ & $<25$ & $<25$ & $<25$ & ND & $2.60 \mathrm{E}+06$ & $<25$ & $2.00 \mathrm{E}+05$ & $5.00 \mathrm{E}+04$ & $<25$ \\
\hline $\begin{array}{c}1 \% \text { PTYG }(\mathrm{CFU} / \mathrm{g}) \mathrm{pH} 3.0 \\
\text { incubated aerobically }\end{array}$ & $<25$ & $5.00 \mathrm{E}+03$ & $1.00 \mathrm{E}+02$ & $<25$ & N.D. & $1.10 \mathrm{E}+05$ & $<25$ & $<25$ & $<25$ & ND & $5.60 \mathrm{E}+05$ & $>3.00 \mathrm{E}+05$ & $<25$ & $<25$ & $7.00 \mathrm{E}+03$ \\
\hline $\begin{array}{l}\text { Anaerobic PYG (CFU/g) } \\
\text { incubated anaerobically }\end{array}$ & $<25$ & $<25$ & $<25$ & $<25$ & $<25$ & $<25$ & $<25$ & $<25$ & $<25$ & ND & $<25$ & $<25$ & $<25$ & $<25$ & $<25$ \\
\hline $\begin{array}{c}\text { PTYG pH } 7.0(\mathrm{CFU} / \mathrm{g}) \\
\text { anaerobically }\end{array}$ incubated & ND & ND & ND & ND & ND & ND & ND & ND & ND & ND & ND & ND & ND & ND & ND \\
\hline $\begin{array}{l}1 \% \text { PTYG pH } 7.0 \quad(\mathrm{CFU} / \mathrm{g}) \\
\text { incubated anaerobically }\end{array}$ & ND & ND & ND & ND & ND & ND & ND & ND & ND & ND & ND & ND & ND & ND & ND \\
\hline
\end{tabular}

$\mathrm{CFU} / \mathrm{g}=$ Colony Forming Unit per gram wet weight soil

IRB = Iron Reducing Bacteria

APB $=$ Acid Producing Bacteria

$\mathrm{SRB}=$ Sulfate Reducing Bacteria

$\mathrm{ND}=$ not determined 
Table 28. Wetland Soils Bacterial Counts

\begin{tabular}{|c|c|c|c|c|c|c|}
\hline $\begin{array}{l}\text { Wetland Soils } \\
\text { Bacterial Counts }\end{array}$ & $\begin{array}{c}\text { G-10 } \\
1 \mathrm{ft}\end{array}$ & $\begin{array}{l}\text { D-2 } \\
1 \mathrm{ft}\end{array}$ & $\begin{array}{l}D-4 \\
1 \mathrm{ft}\end{array}$ & $\begin{array}{l}\mathrm{H}-5 \\
1 \mathrm{ft}\end{array}$ & $\begin{array}{l}J-6 \\
1 \mathrm{ft}\end{array}$ & $\begin{array}{c}\text { K-4 } \\
1 \mathrm{ft}\end{array}$ \\
\hline Sampling Date & $6 / 25 / 03$ & $6 / 26 / 03$ & $6 / 26 / 03$ & $7 / 22 / 03$ & $7 / 22 / 03$ & $7 / 22 / 03$ \\
\hline $\begin{array}{l}\text { Total Direct Counts } \\
\text { (\# cells/g wet wt) }\end{array}$ & $2.02 \mathrm{E}+11$ & $2.72 \mathrm{E}+10$ & $7.18 \mathrm{E}+10$ & $1.77 \mathrm{E}+09$ & $2.07 \mathrm{E}+10$ & $3.51 \mathrm{E}+09$ \\
\hline IRB* / (\# cells/g wet wt) & ND & ND & ND & ND & ND & ND \\
\hline APB* / (\# cells/g wet wt) & ND & ND & $\mathrm{ND}$ & ND & ND & $\mathrm{ND}$ \\
\hline SRB* / (\# cells/g wet wt) & ND & ND & ND & ND & ND & ND \\
\hline $\begin{array}{l}\mathrm{PTYG}(\mathrm{CFU} / \mathrm{g}) \mathrm{pH} 7.0 \\
\text { incubated aerobically }\end{array}$ & $1.26 \mathrm{E}+05$ & $2.68 \mathrm{E}+07$ & $1.34 \mathrm{E}+07$ & $1.89 \mathrm{E}+07$ & $1.38 \mathrm{E}+07$ & $1.05 \mathrm{E}+07$ \\
\hline $\begin{array}{l}\text { PTYG (CFU/g) pH } 5.0 \\
\text { incubated aerobically }\end{array}$ & ND & ND & ND & ND & ND & ND \\
\hline $\begin{array}{c}\text { PTYG (CFU/g) pH } 4.0 \\
\text { incubated aerobically }\end{array}$ & ND & ND & ND & $\mathrm{ND}$ & ND & $\mathrm{ND}$ \\
\hline $\begin{array}{l}\text { PTYG (CFU/g) pH } 3.0 \\
\text { incubated aerobically }\end{array}$ & ND & ND & ND & ND & ND & $\mathrm{ND}$ \\
\hline $\begin{array}{l}1 \% \text { PTYG (CFU/g) pH } 7.0 \\
\text { incubated aerobically }\end{array}$ & $2.91 \mathrm{E}+04$ & $1.45 \mathrm{E}+07$ & $1.69 \mathrm{E}+07$ & $1.27 \mathrm{E}+07$ & $6.29 \mathrm{E}+04$ & $1.18 \mathrm{E}+05$ \\
\hline $\begin{array}{l}1 \% \text { PTYG (CFU/g) pH } 5.0 \\
\text { incubated aerobically }\end{array}$ & ND & ND & ND & ND & ND & ND \\
\hline $\begin{array}{c}1 \% \text { PTYG (CFU/g) pH } 4.0 \\
\text { incubated aerobically }\end{array}$ & ND & ND & ND & $\mathrm{ND}$ & ND & $\mathrm{ND}$ \\
\hline $\begin{array}{l}1 \% \text { PTYG (CFU/g) pH } 3.0 \\
\text { incubated aerobically }\end{array}$ & ND & ND & ND & ND & ND & $\mathrm{ND}$ \\
\hline $\begin{array}{l}\text { Anaerobic PYG (CFU/g) } \\
\text { incubated anaerobically }\end{array}$ & ND & ND & ND & $9.27 \mathrm{E}+06$ & $1.33 \mathrm{E}+07$ & $1.31 \mathrm{E}+07$ \\
\hline $\begin{array}{l}\text { PTYG pH } 7.0(\mathrm{CFU} / \mathrm{g}) \\
\text { incubated anaerobically }\end{array}$ & $1.25 \mathrm{E}+04$ & $1.22 \mathrm{E}+07$ & $1.28 \mathrm{E}+07$ & $1.12 \mathrm{E}+07$ & $9.62 \mathrm{E}+03$ & $1.37 \mathrm{E}+04$ \\
\hline $\begin{array}{c}1 \% \text { PTYG pH } 7.0 \quad(\mathrm{CFU} / \mathrm{g}) \\
\text { incubated anaerobically }\end{array}$ & $<25$ & $3.92 \mathrm{E}+06$ & $5.72 \mathrm{E}+06$ & $<25$ & $6.99 \mathrm{E}+03$ & $7.30 \mathrm{E}+03$ \\
\hline
\end{tabular}

$\mathrm{CFU} / \mathrm{g}=$ Colony Forming Unit per gram wet weight soil $\mathrm{IRB}=$ Iron Reducing Bacteria

$\mathrm{APB}=$ Acid Producing Bacteria $\mathrm{SRB}=$ Sulfate Reducing Bacteria $\quad \mathrm{ND}=$ not determined 
Table 29. Biolog $^{\circledR}$ Testing of Upland Soil Slurry

\begin{tabular}{|c|c|c|c|c|c|c|c|c|c|c|c|c|c|}
\hline Sample & Dilu & on Tested & \begin{tabular}{|c|} 
all \\
carbon \\
sources \\
tested \\
$(95$ total $)$
\end{tabular} & $\begin{array}{c}\text { polymers } \\
\text { (5 total) }\end{array}$ & $\begin{array}{l}\text { carbohydrates } \\
\text { (28 total) }\end{array}$ & $\begin{array}{l}\text { esters } \\
\text { ( } 2 \text { total) }\end{array}$ & $\begin{array}{l}\text { carboxylic } \\
\text { acids } \\
\text { (24 total) }\end{array}$ & $\begin{array}{l}\text { amides } \\
\text { ( } 3 \text { total) }\end{array}$ & $\begin{array}{c}\text { amino } \\
\text { acids } \\
(20 \text { total })\end{array}$ & $\begin{array}{c}\text { aromatic } \\
\text { chemicals } \\
\text { (4 total) }\end{array}$ & $\begin{array}{l}\text { amines } \\
\text { (3 total) }\end{array}$ & $\begin{array}{l}\text { alcohols } \\
\text { ( } 2 \text { total) }\end{array}$ & $\begin{array}{l}\text { phosphorylated } \\
\text { chemicals } \\
\text { (3 total) }\end{array}$ \\
\hline DAB $924-6 \mathrm{ft}$ & $1 / 1000$ & $\%$ positive & 16 & 0 & 14 & 0 & 25 & 67 & 10 & 25 & 0 & 0 & 0 \\
\hline DAB $9221 \mathrm{ft}$ & $1 / 1000$ & $\%$ positive & 6 & 0 & 4 & 0 & 8 & 0 & 5 & 0 & 0 & 50 & 0 \\
\hline DAB $9223 \mathrm{ft}$ & $1 / 1000$ & $\%$ positive & 3 & 0 & 7 & 0 & 4 & 0 & 0 & 0 & 0 & 0 & 0 \\
\hline$\overline{D A B} 8130 \mathrm{ft}$ & $1 / 100$ & $\%$ positive & 46 & 40 & 54 & 50 & 54 & 67 & 40 & 0 & 33 & 50 & 0 \\
\hline DAB $8145 \mathrm{ft}$ & $1 / 100$ & $\%$ positive & 2 & 40 & 0 & 0 & 0 & 0 & 0 & 0 & 0 & 0 & 0 \\
\hline DAB $8150 \mathrm{ft}$ & $1 / 100$ & $\%$ positive & 42 & 40 & 7 & 100 & 58 & 33 & 70 & 25 & 67 & 50 & 0 \\
\hline DAB $8733 \mathrm{ft}$ & $1 / 100$ & $\%$ positive & 7 & $\overline{0}$ & 7 & 0 & 13 & 33 & 5 & 0 & 0 & 0 & 0 \\
\hline DAB $8738 \mathrm{ft}$ & $1 / 100$ & $\%$ positive & 0 & 0 & 0 & 0 & 0 & 0 & 0 & 0 & 0 & 0 & 0 \\
\hline DAB $8753 \mathrm{ft}$ & $1 / 100$ & $\%$ positive & 0 & 0 & 0 & 0 & 0 & 0 & 0 & 0 & 0 & 0 & 0 \\
\hline DAB $8420 \mathrm{ft}$ & $1 / 1000$ & $\%$ positive & 2 & 40 & 0 & 0 & 0 & 0 & 0 & 0 & 0 & $\overline{0}$ & 0 \\
\hline DAB $8428 \mathrm{ft}$ & $1 / 1000$ & $\%$ positive & 29 & 20 & 39 & 0 & 42 & 0 & 30 & 0 & 0 & 0 & 0 \\
\hline DAB $8438 \mathrm{ft}$ & $1 / 1000$ & $\%$ positive & 4 & 0 & 7 & 50 & 4 & 0 & 0 & 0 & 0 & 0 & 0 \\
\hline DAB $8332 \mathrm{ft}$ & $1 / 100$ & $\%$ positive & 0 & 0 & 0 & 0 & $\overline{0}$ & 0 & $\overline{0}$ & 0 & 0 & 0 & 0 \\
\hline DAB $8338 \mathrm{ft}$ & $1 / 100$ & $\%$ positive & 0 & 0 & 0 & 0 & 0 & 0 & 0 & 0 & 0 & 0 & 0 \\
\hline DAB $8342 \mathrm{ft}$ & $1 / 100$ & $\%$ positive & 42 & 0 & 46 & 100 & 42 & 0 & 50 & 0 & 0 & 100 & 100 \\
\hline
\end{tabular}


WSRC-TR-2004-00124, REVISION 0

Table 30. Biolog ${ }^{\circledR}$ Testing of Wetland Soil Slurry

\begin{tabular}{|c|c|c|c|c|c|c|c|c|c|c|c|c|c|}
\hline & \multicolumn{2}{|c|}{ Dilution Tested } & \begin{tabular}{|c|} 
all carbon \\
sources \\
tested
\end{tabular} & $\begin{array}{l}\text { polymers } \\
\text { (5 total) }\end{array}$ & $\begin{array}{l}\text { carbohydrates } \\
\text { (28 total) }\end{array}$ & $\begin{array}{l}\text { esters } \\
\text { (2 total) }\end{array}$ & $\begin{array}{l}\text { carboxylic } \\
\text { acids } \\
\text { (24 total }\end{array}$ & $\begin{array}{l}\text { amides } \\
\text { (3 total) }\end{array}$ & $\begin{array}{c}\text { amino } \\
\text { acids } \\
\text { (20 total }\end{array}$ & $\begin{array}{l}\text { aromatic } \\
\text { chemicals }\end{array}$ & $\begin{array}{l}\text { amines } \\
\text { (3 total) }\end{array}$ & $\begin{array}{l}\text { alcohols } \\
\text { (2 total) }\end{array}$ & $\begin{array}{l}\text { phosphorylated } \\
\text { chemicals }\end{array}$ \\
\hline $\mathrm{G}-10,1 \mathrm{ft}$ & $1 / 100$ & $\%$ positive & 69 & 40 & 71 & 50 & 63 & 33 & 80 & 75 & 67 & 100 & 100 \\
\hline $\mathrm{D}-2,1 \mathrm{ft}$ & $1 / 100$ & $\%$ positive & 41 & 0 & 39 & 50 & 46 & 0 & 60 & 50 & 33 & 0 & 33 \\
\hline $\mathrm{D}-4,1 \mathrm{ft}$ & $1 / 100$ & $\%$ positive & 72 & 100 & 86 & 50 & 54 & 0 & 70 & 100 & 67 & 50 & 100 \\
\hline H-5, 1ft & $1 / 100$ & $\%$ positive & 4 & 0 & 7 & 0 & 4 & 0 & 0 & 0 & 0 & 0 & 0 \\
\hline$J-6,1$ ft & $1 / 100$ & $\%$ positive & 14 & 20 & 25 & 0 & 8 & 0 & 5 & 25 & 0 & 0 & 0 \\
\hline $\mathrm{K}-4,1 \mathrm{ft}$ & $1 / 100$ & $\%$ positive & 0 & 0 & 0 & 0 & 0 & 0 & 0 & 0 & 0 & 0 & 0 \\
\hline
\end{tabular}


WSRC-TR-2004-00124, REVISION 0

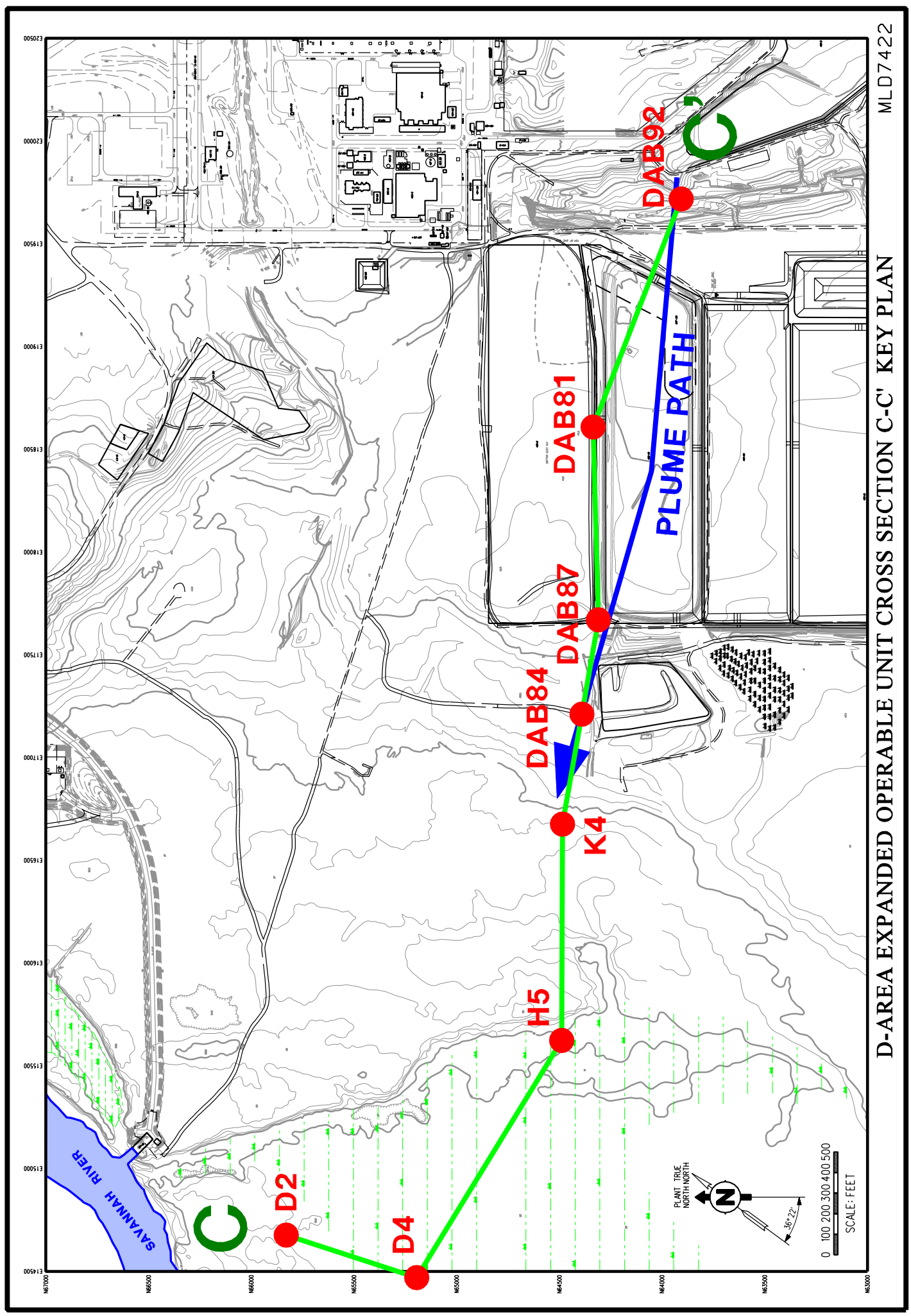

Figure 15. D-Area Expanded Operable Unit Key Plan-Cross Section C-C'-Biological data 
WSRC-TR-2004-00124, REVISION 0

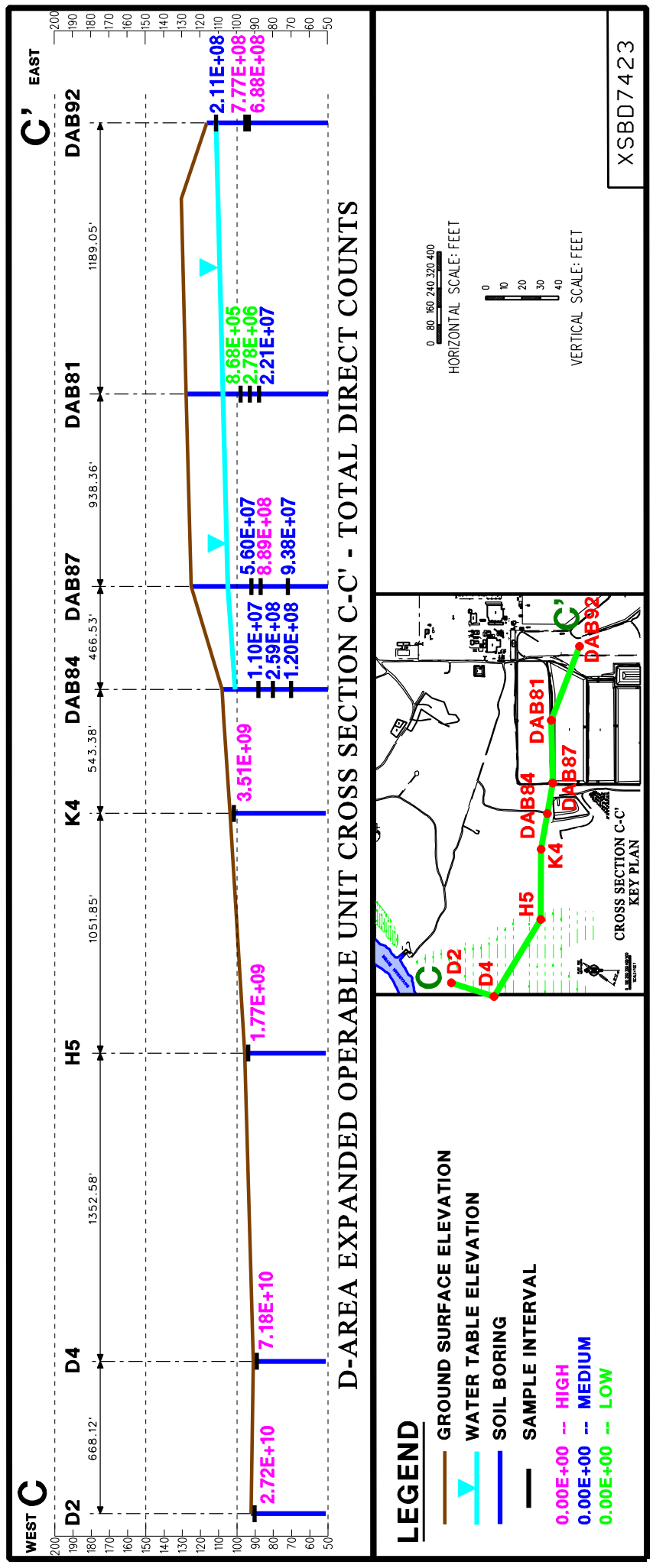

Figure 16. D-Area Expanded Operable Unit Cross Section C-C'-Total Direct Counts 
WSRC-TR-2004-00124, REVISION 0

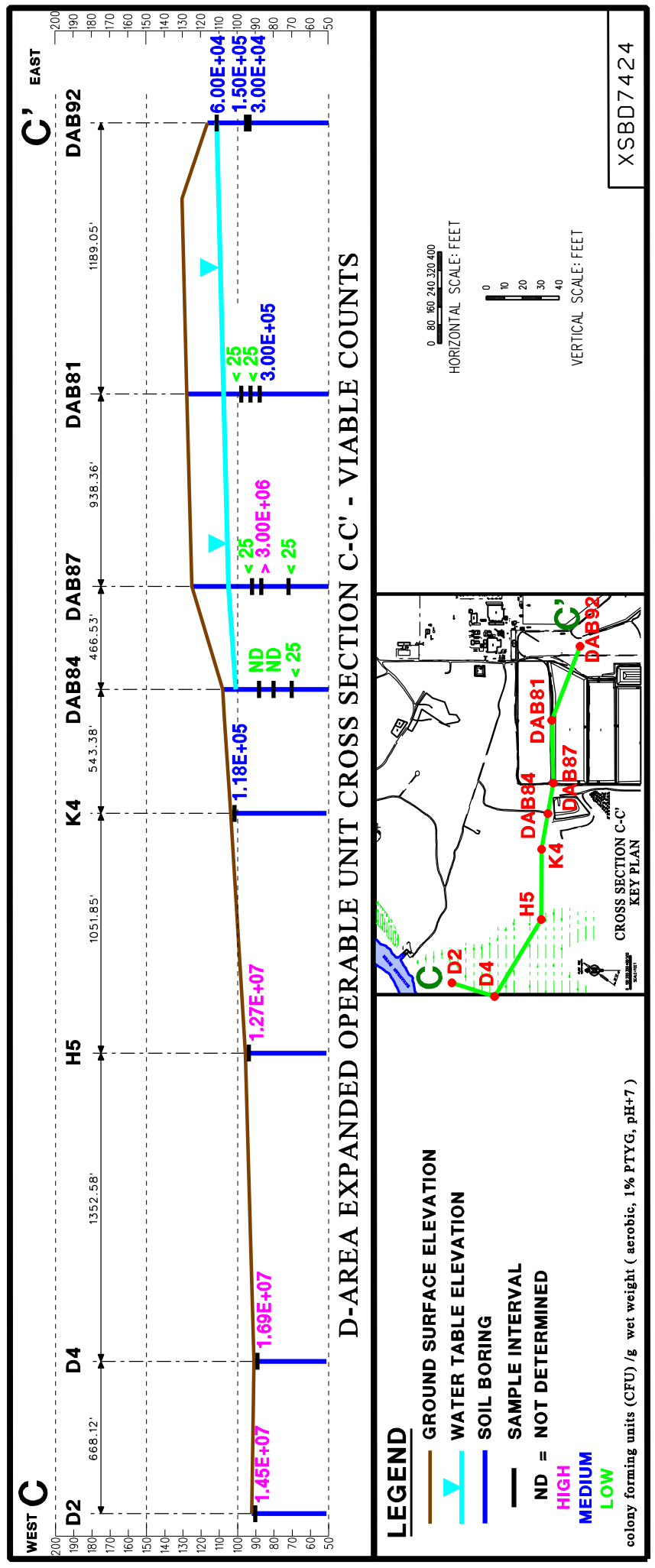

Figure 17. D-Area Expanded Operable Unit Cross Section C-C'-Viable Counts 
WSRC-TR-2004-00124, REVISION 0

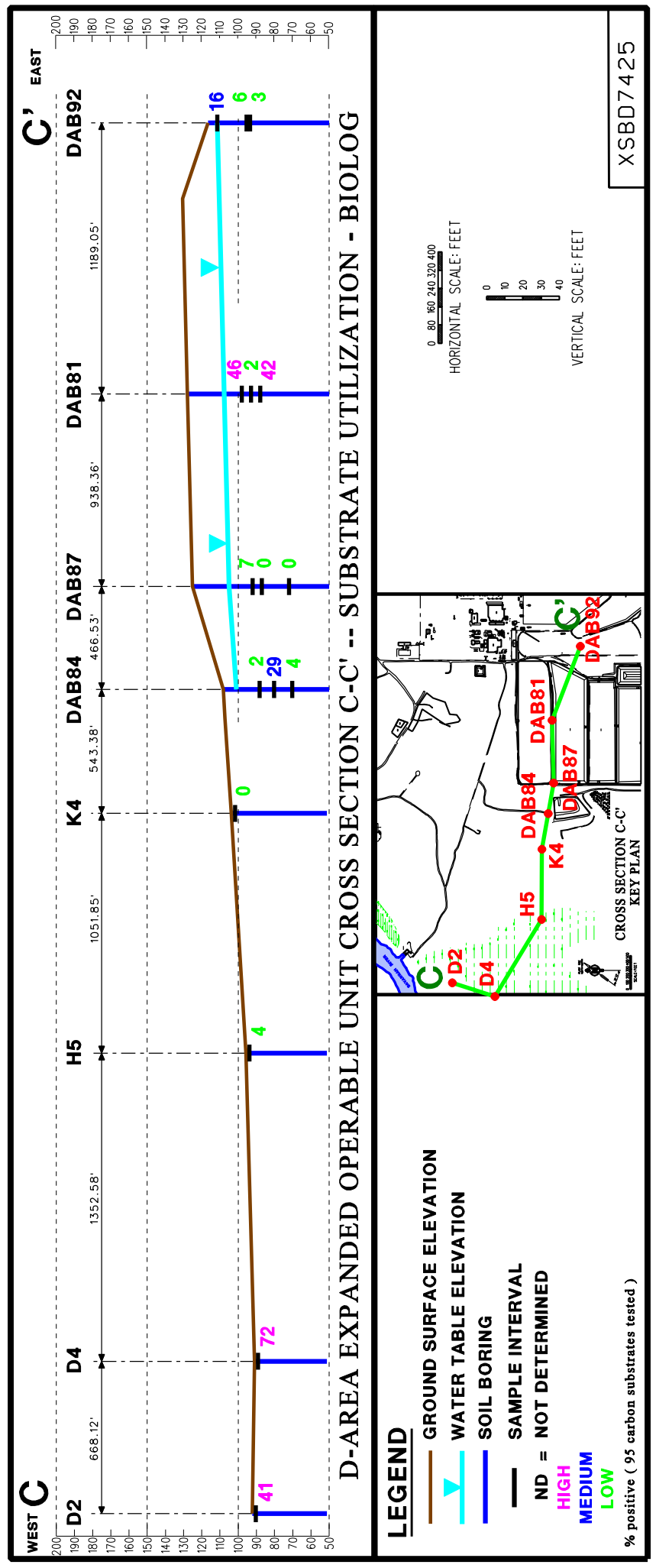

Figure 18. D-Area Expanded Operable Unit Cross Section C-C'-Substrate Utilization by Biolog® 
WSRC-TR-2004-00124, REVISION 0

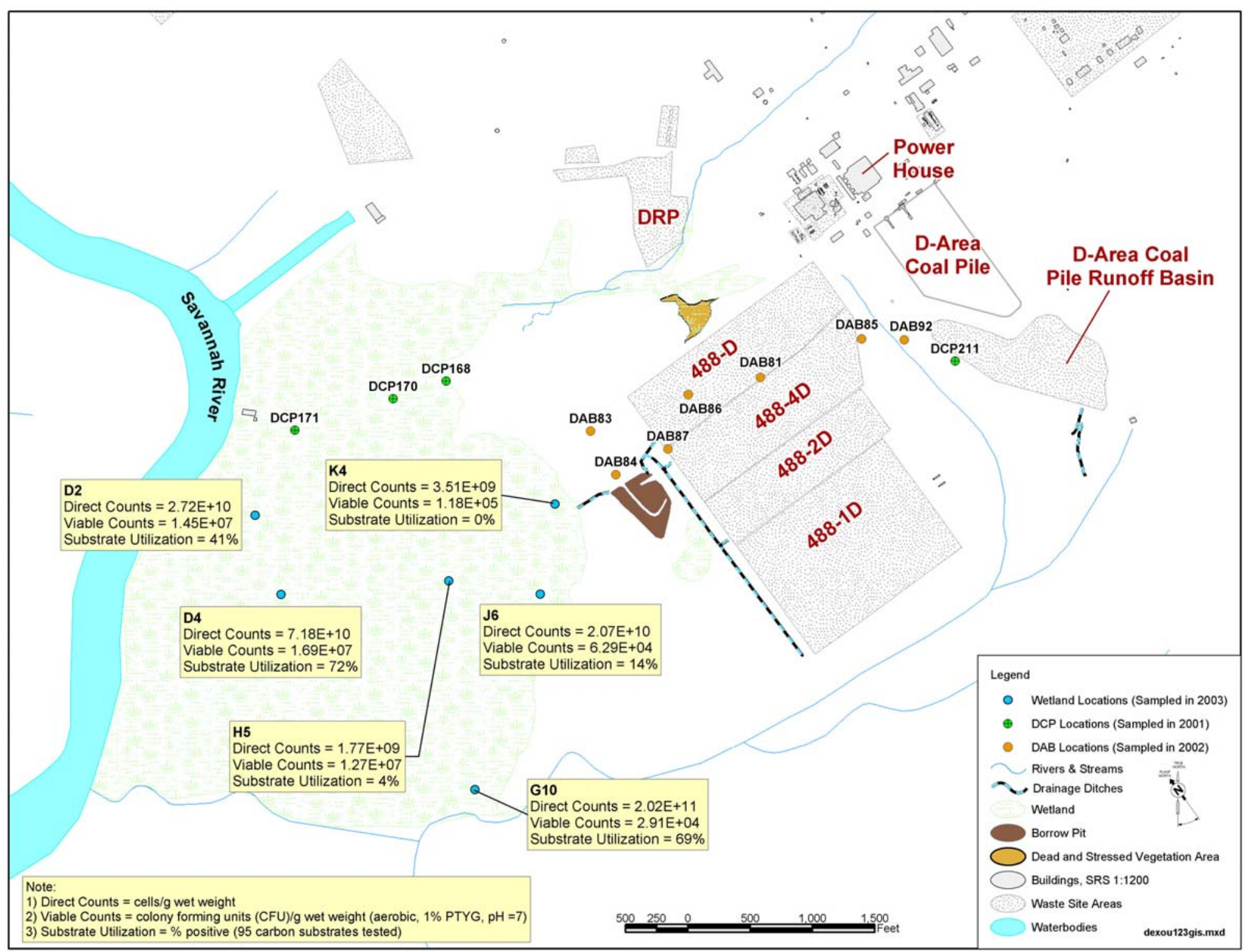

Figure 19. Microbiological Data for Wetland Locations 


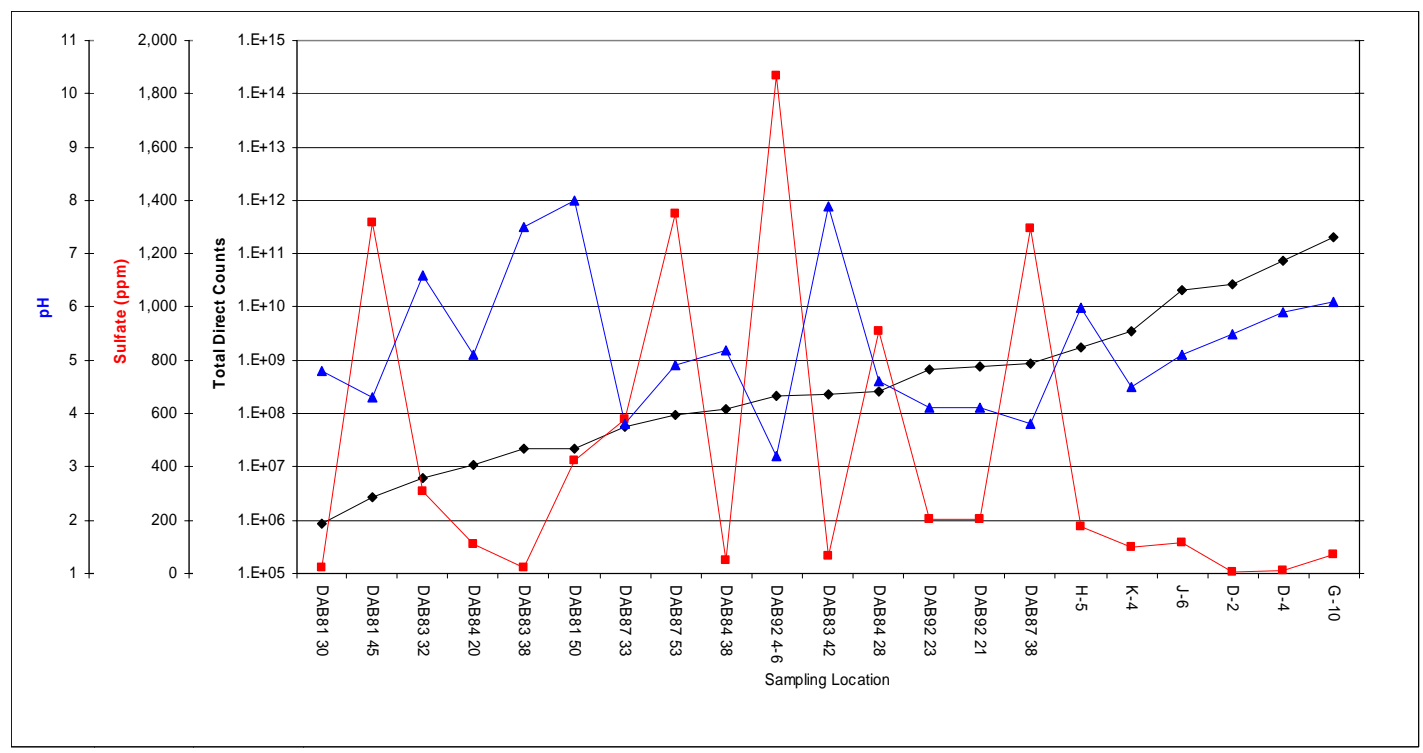

Figure 20. Plot of pH, Sulfate, and Direct Counts Ordered by Direct Counts

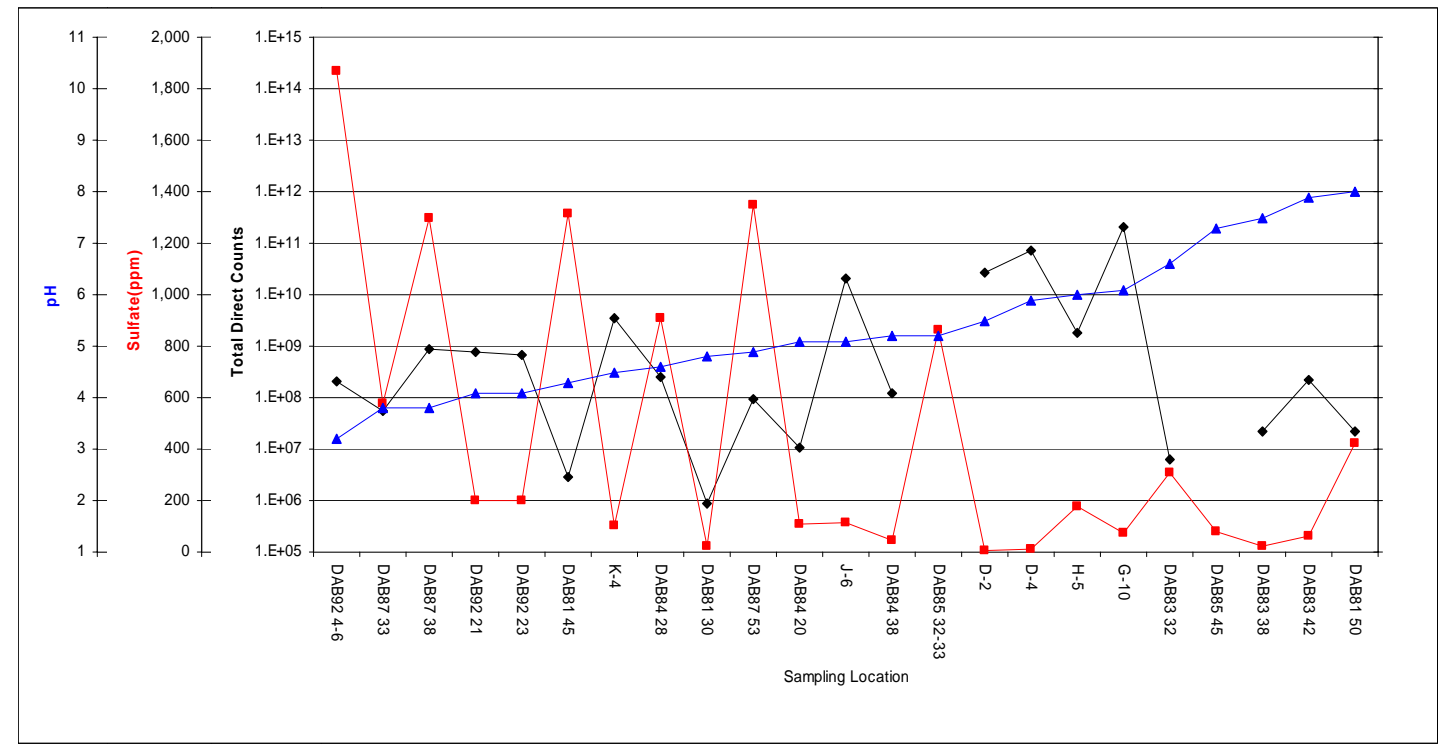

Figure 21. Plot of pH, Sulfate, and Direct Counts Ordered by pH 


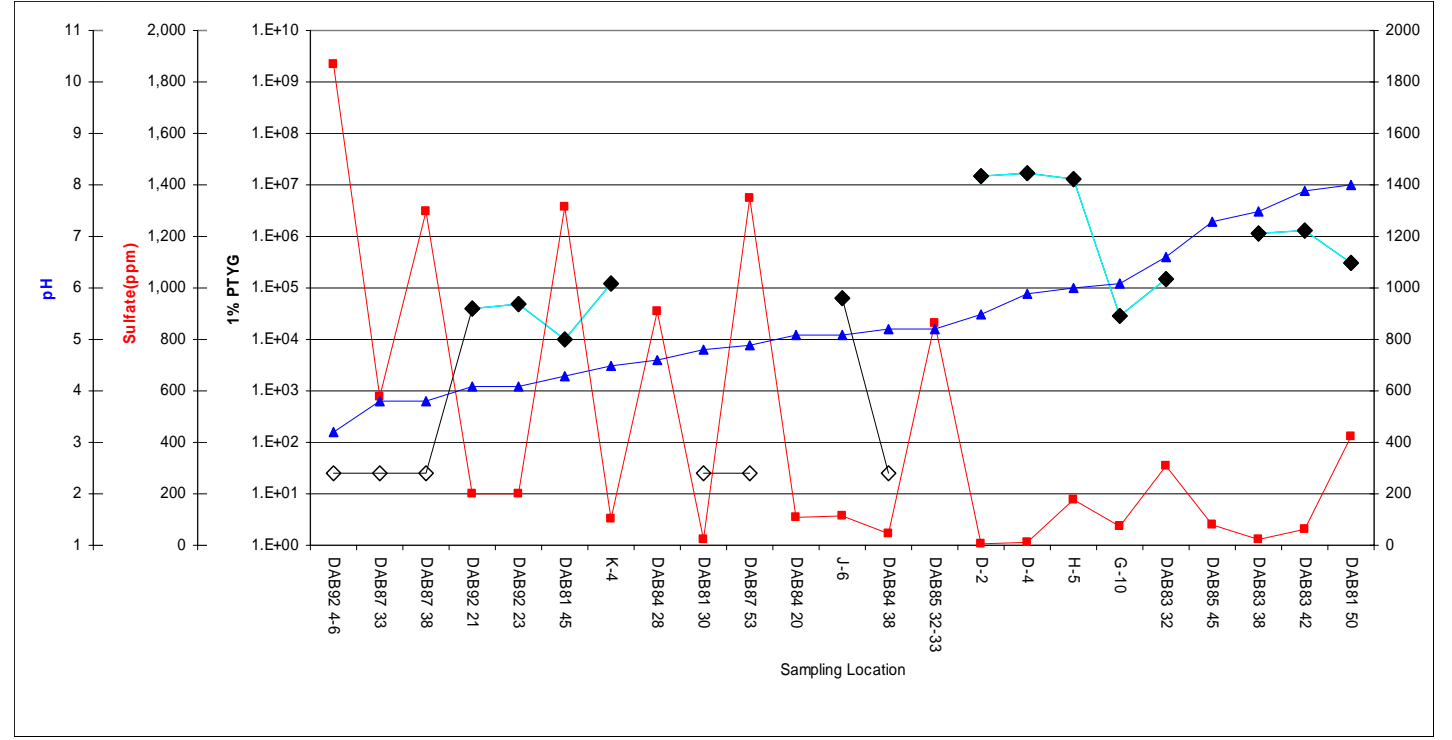

Figure 22. Plot of pH, Sulfate, and 1\% PTYG (pH 5.0) Ordered by pH [less-than detect $1 \%$ PTYG (values=25) are plotted without coloring in the diamond]

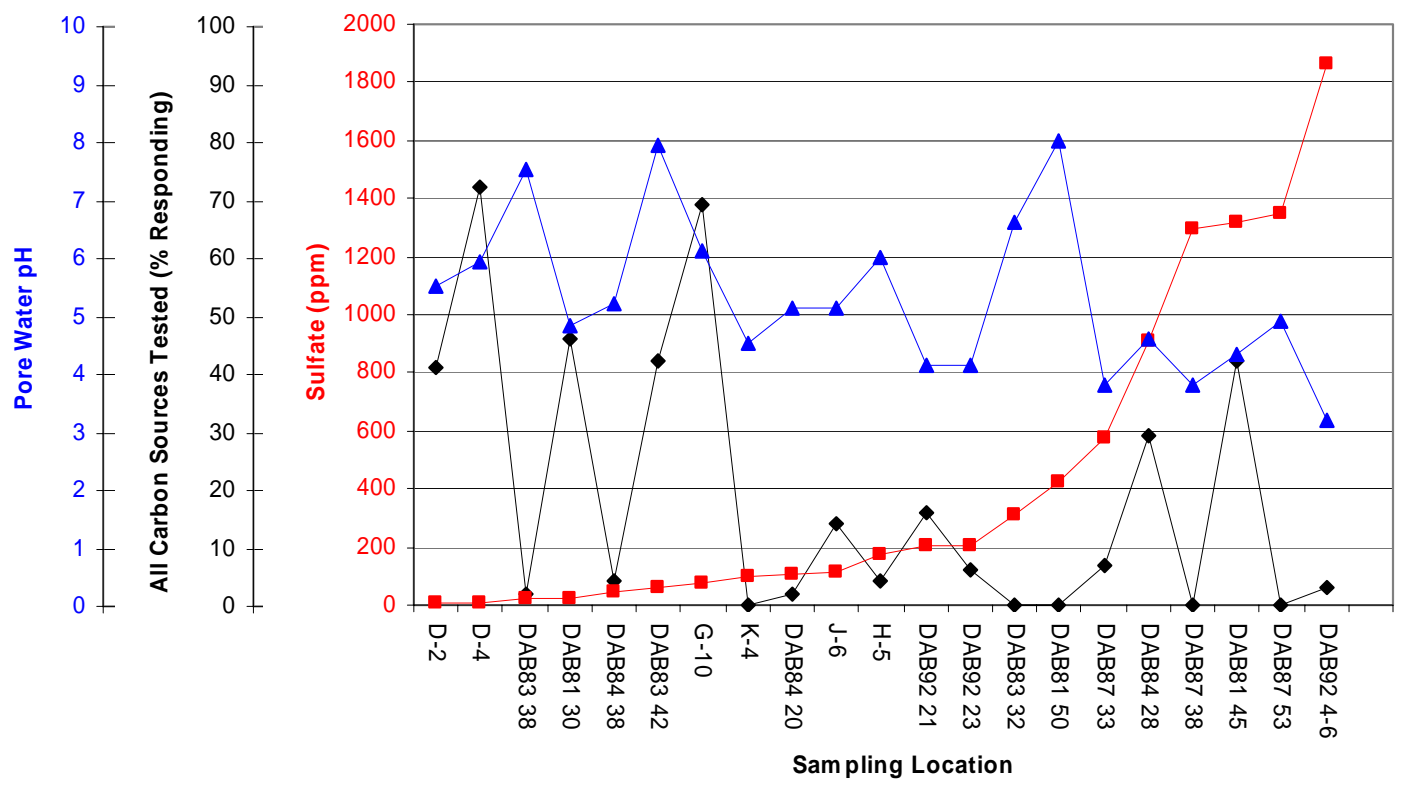

Figure 23. pH, Sulfate (ppm), and Percent Response for All Carbon Sources (Ordered by Sulfate) 


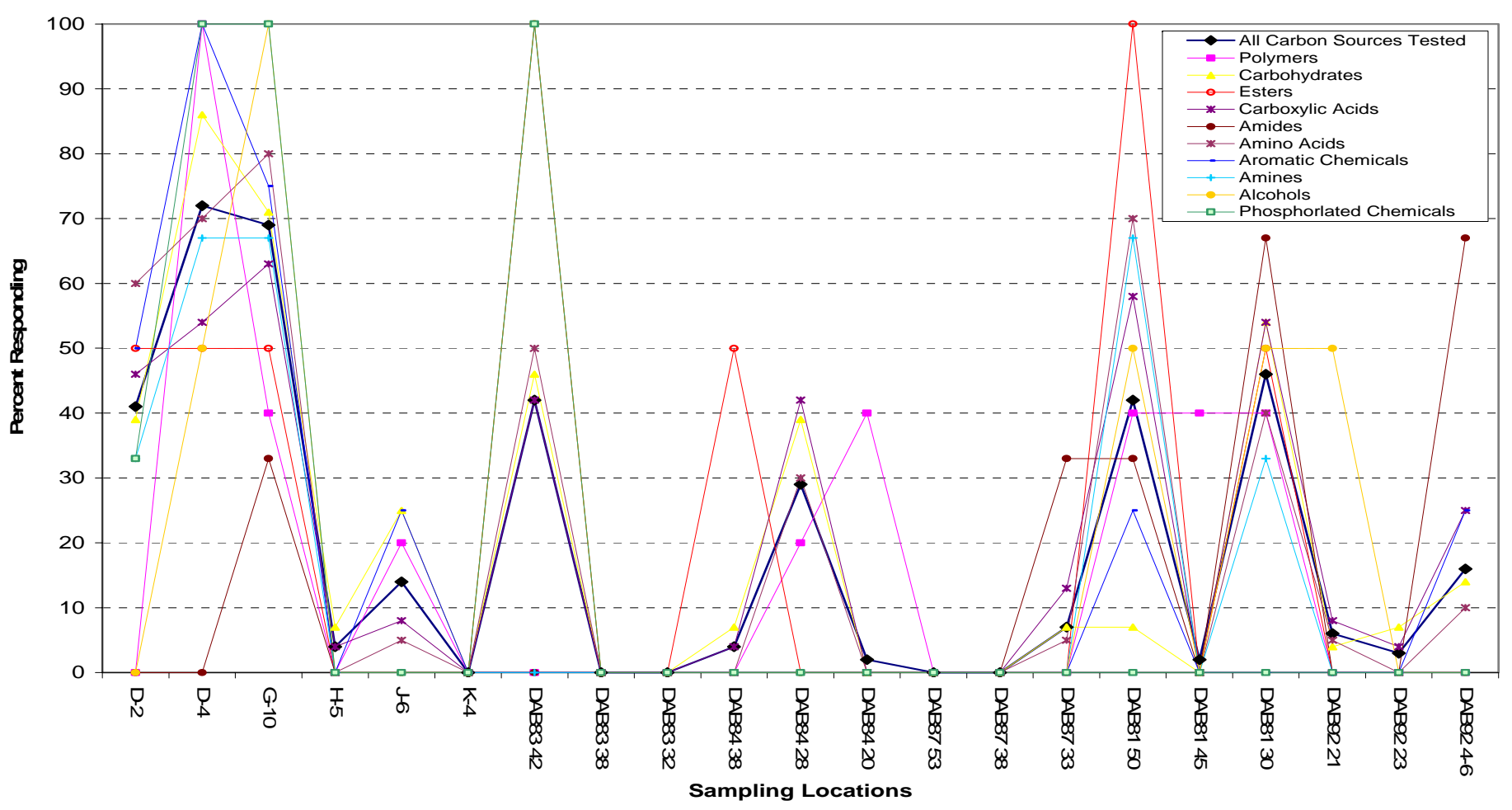

Figure 24. Overlay Plot of Percent of Total for all Biolog ${ }^{\circledR}$ Sources by Sample Location 
WSRC-TR-2004-00124, REVISION 0

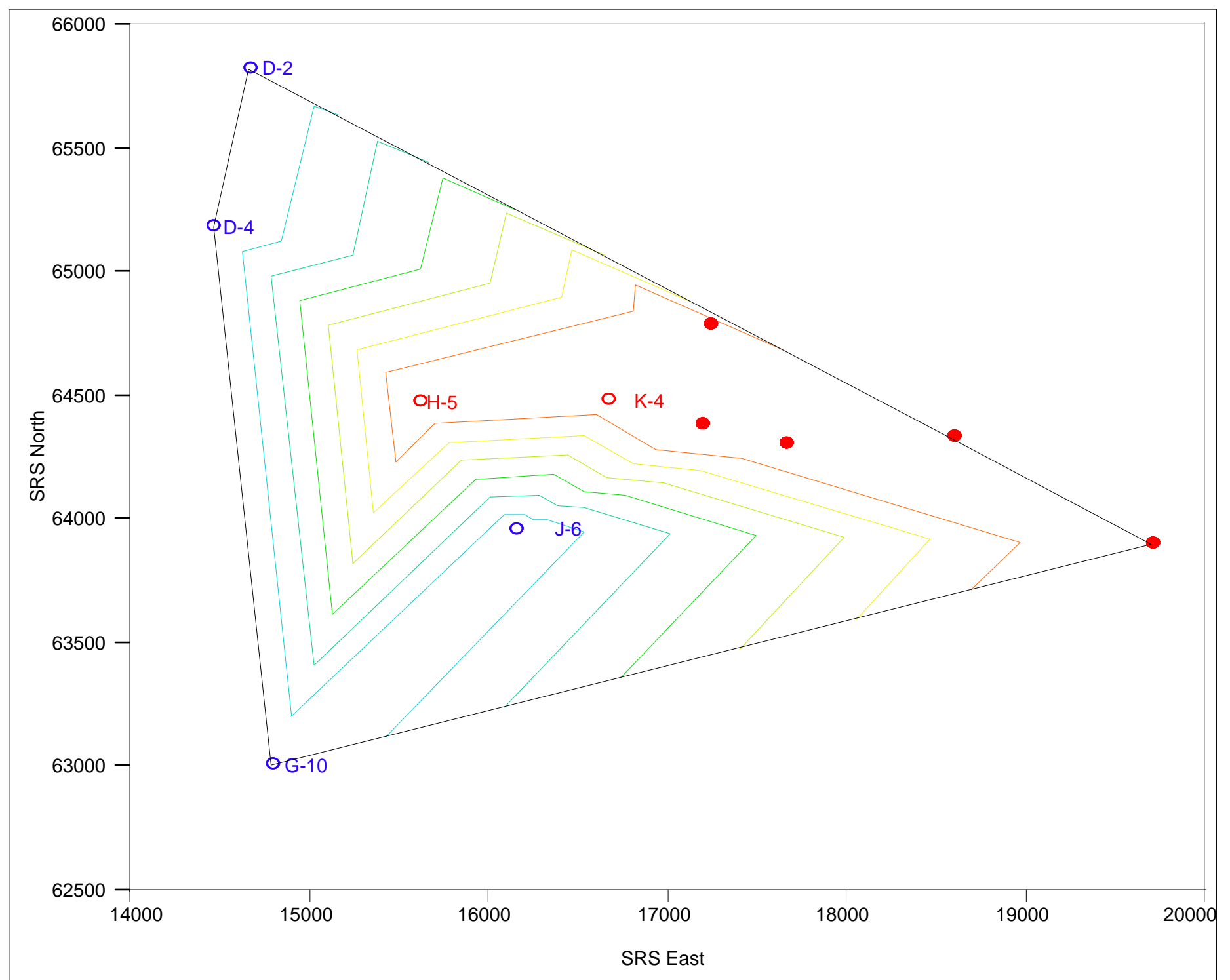

Figure 25. Posterior Probability that the Microbial Structure as Defined by the Biolog ${ }^{\circledR}$ Assays Belongs to the "Upland Region" Class (Based on a Training Set of the Original 15 DAB and 6 Wetland Sampling Locations) 
WSRC-TR-2004-00124, REVISION 0

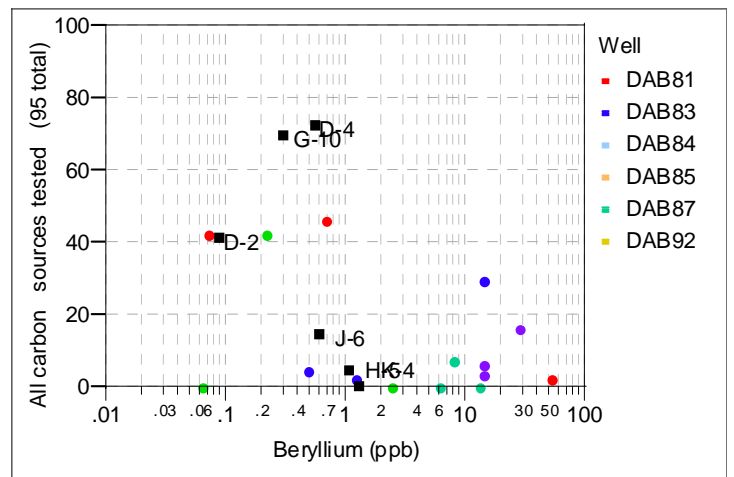

Plot of All carbon sources tested ( 95 total) by Beryllium

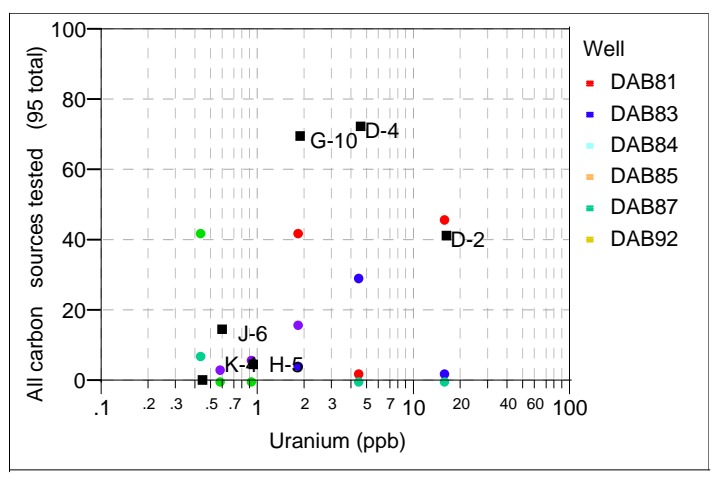

Plot of All carbon sources tested (95 total) by Uranium

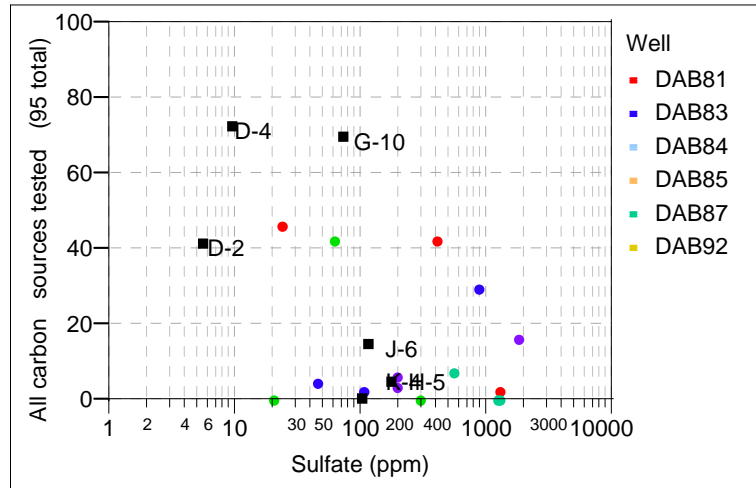

Plot of All carbon sources tested (95 total) by Sulfate

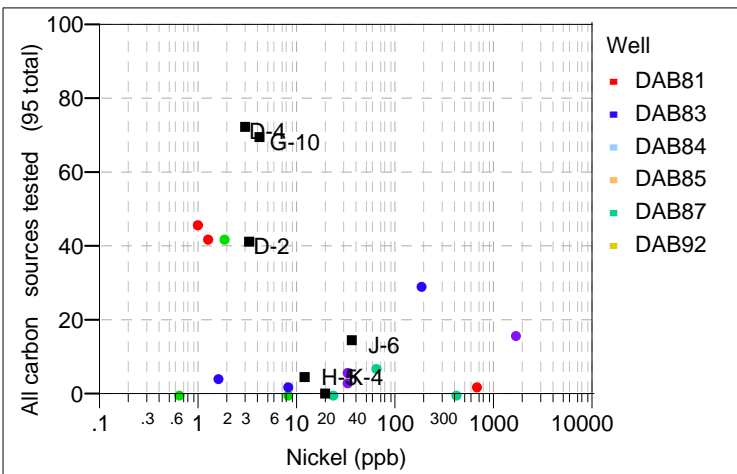

Plot of All carbon sources tested (95 total) by Nickel

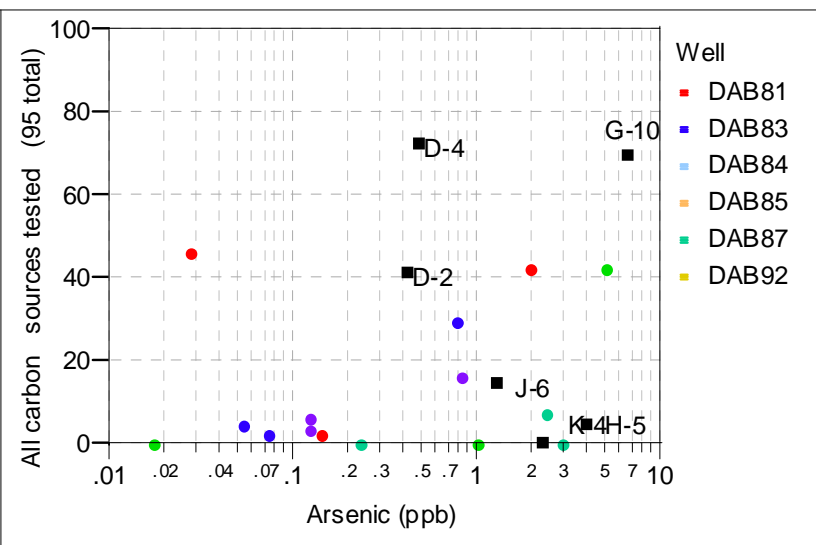

Plot of All carbon sources tested (95 total) by Arsenic

Figure 26. Comparison of Substrate Utilization Data from Biolog® with Porewater Concentrations of COCs (Be, Ni, U, As) and Sulfate 
WSRC-TR-2004-00124, REVISION 0

Table 31. Buffering Capacity of Biolog ${ }^{\circledR}$ GN Microplates

\begin{tabular}{|cccc|}
\hline $\begin{array}{c}\text { pH of added } \\
\text { water }\end{array}$ & $\begin{array}{c}\mathbf{p H} \text { of added water at } \\
\text { Time } 0\end{array}$ & $\begin{array}{c}\mathbf{p H} \text { of added water at } \\
\text { Time } 24 \text { hours }\end{array}$ & $\begin{array}{c}\mathbf{p H} \text { of added water at } \\
\text { Time } 48 \text { hours }\end{array}$ \\
5.00 & 6.91 & 6.94 & 6.99 \\
4.00 & 6.93 & 7.00 & 6.95 \\
3.00 & 6.91 & 6.91 & 6.96 \\
\hline
\end{tabular}

The gross morphology of most of the colonies growing on the agar plates looked similar. These similar colony types were noted particularly on plates from DAB 83 and DAB 84 . In an effort to determine the identity of this predominant colony type, bacterial colonies were picked from DAB 83 and DAB 84 agar plated samples. These colonies were restreaked numerous times for bacterial isolation, and the isolates were gram-stained and processed with Biolog ${ }^{\circledR}$ for identification. Of the 27 isolates that were tested, $70 \%$ of all isolates were identified as Stenotrophomonas maltophilia (Table 32). 19\% of all isolates were identified as Bacillus species, and $11 \%$ of all isolates were identified as Enterobacter species.

Stenotrophomonas maltophilia was the predominant colony type seen on these agar plates. The Bacillus species and Enterobacter species were bacteria that were growing in close conjunction to Stenotrophomonas maltophilia colonies.

Table 32. Identification of Bacteria in Samples DAB 83 and DAB 84

\begin{tabular}{|ccc|}
\hline Origin & $\begin{array}{c}\text { number of } \\
\text { isolates }\end{array}$ & Identification \\
DAB 83 32 & 7 & Stenotrophomonas maltophilia \\
DAB 83 32 & 4 & Bacillus species \\
DAB 83 38 & 4 & Stenotrophomonas maltophilia \\
DAB 83 38 & 1 & Enterobacter species \\
DAB 83 38 38 & 1 & Baillus species \\
DAB 83 42 & 5 & Stenotrophomonas maltophilia \\
DAB 83 42 & 1 & Enterobacter species \\
DAB 84 38 & 3 & Stenotrophomonas maltophilia \\
DAB 84 38 38 & 1 & Enterobacter species \\
& & \\
\hline
\end{tabular}




\subsection{MICROBIOLOGICAL FUNCTION}

Six D-Area bacteria isolates from four 2002 D-Area sediment samples were tested for their impact on $\mathrm{pH}$. Four of these isolates have been identified to be Stenotrophomonas maltophilia, one isolate is a gram-positive rod, Bacillus, and one was an Enterobacter species that is gram negative. The isolates and their sediment origins are as follows:

- DAB 8332

- DAB 8338

- DAB 8342

- DAB 8438

- DAB 8332

- DAB 8342
Stenotrophomonas maltophilia Stenotrophomonas maltophilia Stenotrophomonas maltophilia Stenotrophomonas maltophilia Bacillus sp.

Enterobacter sp. labeled \# $4^{\mathrm{a}}$ labeled \#11 ${ }^{\mathrm{a}}$ labeled \# 6 labeled \# 20 labeled \# 1B labeled \# 13B

Within 24 hours, all $6 \mathrm{D}$-Area bacterial isolates had raised the $\mathrm{pH}$ of the growth media between 2 and $3 \mathrm{pH}$ units that was in the range of $\mathrm{pH} 5$ and $\mathrm{pH} 6$ at time zero, see Table 33 and Table 34. Only one of the D-Area bacterial isolates, the gram negative Enterobacter sp. was able to raise the $\mathrm{pH}$ of the $\mathrm{pH} 4$ growth media, and it effected a $3 \mathrm{pH}$ unit change within 24 hours, see Table 35 . Table 35 shows very little change in $\mathrm{pH}$ over 72 hours for the Stenotrophomonas maltophilia and Bacillus $s p$

Table 33. Growth of D-Area Isolates at pH 6

\begin{tabular}{|c|c|c|c|c|}
\hline Isolate & Time 0 & 24 hours & $\mathbf{4 8}$ hours & $\mathbf{7 2}$ hours \\
\hline & $\mathbf{p H}$ & $\mathbf{p H}$ & $\mathbf{p H}$ & $\mathbf{p H}$ \\
\hline 4A & 6.10 & 8.03 & 7.35 & 8.04 \\
\hline 11A & 6.10 & 7.31 & 8.08 & 8.10 \\
\hline 6 & 6.10 & 8.07 & 8.14 & 8.18 \\
\hline 20 & 6.10 & 8.05 & 8.21 & 8.05 \\
\hline 1B & 6.10 & 7.93 & 8.04 & 8.01 \\
\hline 13B & 6.10 & 7.77 & 7.83 & 7.70 \\
\hline
\end{tabular}

Table 34. Growth of D-Area Isolates at pH 5

\begin{tabular}{|c|c|c|c|c|}
\hline Isolate & Time 0 & $\mathbf{2 4}$ hours & $\mathbf{4 8}$ hours & 72 hours \\
\hline & $\mathbf{p H}$ & $\mathbf{p H}$ & $\mathbf{p H}$ & $\mathbf{p H}$ \\
\hline 4A & 4.90 & 7.91 & 7.86 & 8.00 \\
\hline 11A & 4.90 & 8.08 & 8.25 & 8.17 \\
\hline 6 & 4.90 & 8.10 & 8.10 & 8.16 \\
\hline 20 & 4.90 & 8.09 & 8.00 & 7.95 \\
\hline 1B & 4.90 & 8.13 & 7.98 & 7.96 \\
\hline 13B & 4.90 & 7.31 & 7.70 & 7.60 \\
\hline
\end{tabular}


Table 35. Growth of D-Area Bacteria at pH 4

\begin{tabular}{|c|c|c|c|c|}
\hline Isolate & Time 0 & 24 hours & $\mathbf{4 8}$ hours & 72 hours \\
\hline & $\mathbf{p H}$ & $\mathbf{p H}$ & $\mathbf{p H}$ & $\mathbf{p H}$ \\
\hline 4A & 4.12 & 4.24 & 4.48 & 4.50 \\
\hline 11A & 4.12 & 4.40 & 4.40 & 4.41 \\
\hline 6 & 4.12 & 4.25 & 4.29 & 4.28 \\
\hline 20 & 4.12 & 4.41 & 4.43 & 4.41 \\
\hline 1B & 4.12 & 4.24 & 4.16 & 3.80 \\
\hline 13B & 4.12 & 7.31 & 7.44 & 6.76 \\
\hline
\end{tabular}

All 6 bacterial isolates were plated onto 50\% Tryptic Soy Agar from the pH 4 1\%PTYG media after 72 hours. All 6 isolates were recovered from the $\mathrm{pH} 4$ media demonstrating viability and recovering their colony forming unit capabilities. These results show that all the bacteria isolated from the D-Area sediment were tolerant of $\mathrm{pH} 4$. 


\subsection{DISCUSSION}

\subsection{DILUTION AND ATTENUATION}

Attenuation of some COCs is evidenced by decreasing porewater concentrations of COCs in soil samples collected near the DCPRB (closest to the right side of figure) and wetland area (left side of figure) (Figure 27). For example, Be and Ni concentrations tend to be somewhat greater closer to Well DAB92 (near the DCPRB) than the wetland, sample. Conversely, As concentrations vary greatly and not in a trend with the order of the wells in Figure 27. The lowest sulfate concentrations were found in wetland sites D-2 and D-4 (Figure 28). These sites are furthest from the source area. The metal concentrations at these sites were generally lower than upland and wetland sites closer to the source (Figure 27). Vertical stratification of porewater COC concentrations is evident at location DAB 81 where porewater concentrations of $\mathrm{COCs}(\mathrm{Be}, \mathrm{Ni}, \mathrm{U})$ and major ions (Al, Fe, $\mathrm{Mn}$ ) vary $\sim 3$ orders of magniture between DAB 8130 (or DAB 8150 ) and DAB 8145.

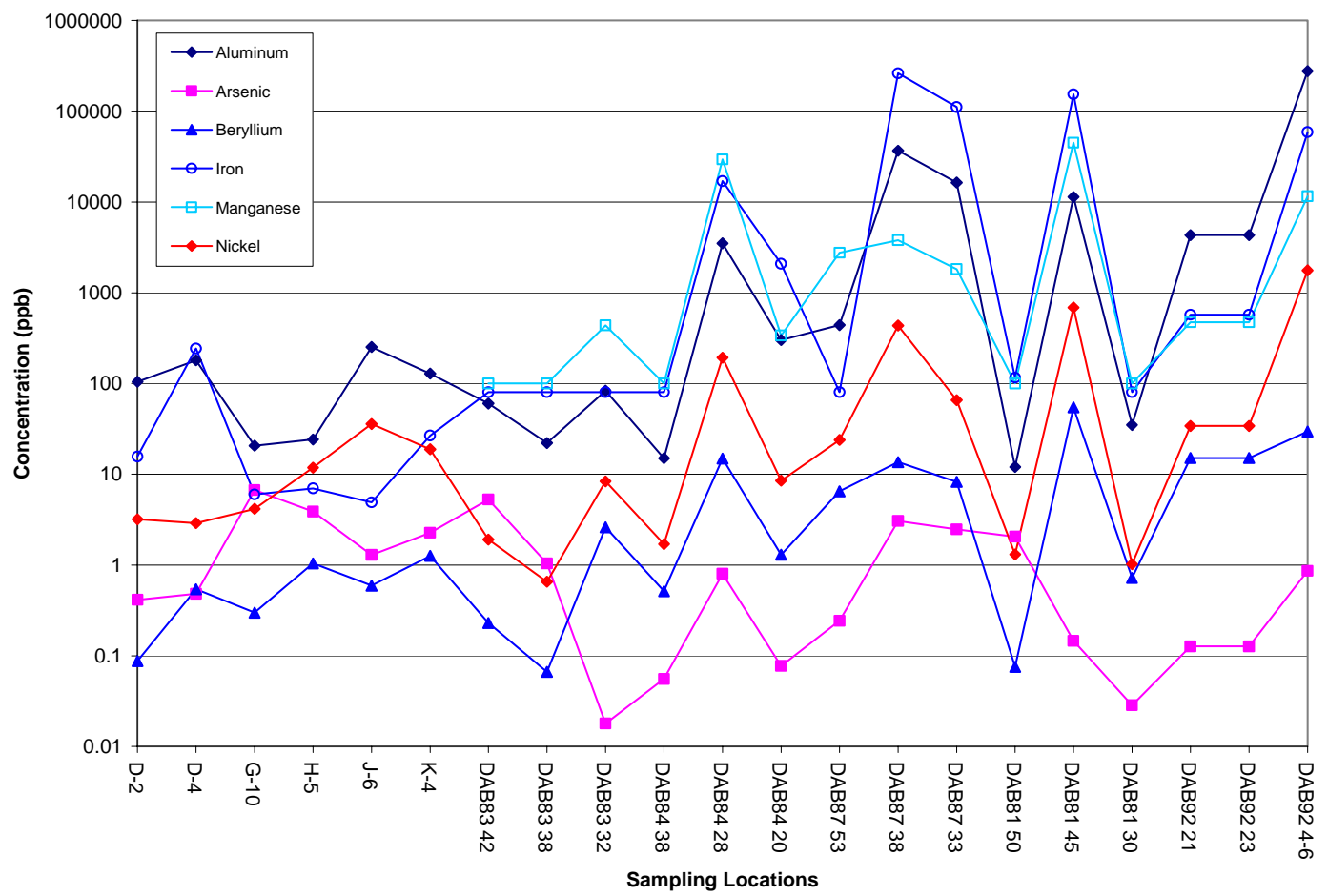

Figure 27. Porewater concentrations of COCs in D-Area (most impacted by DCPRB (right) to wetlands (left)) 


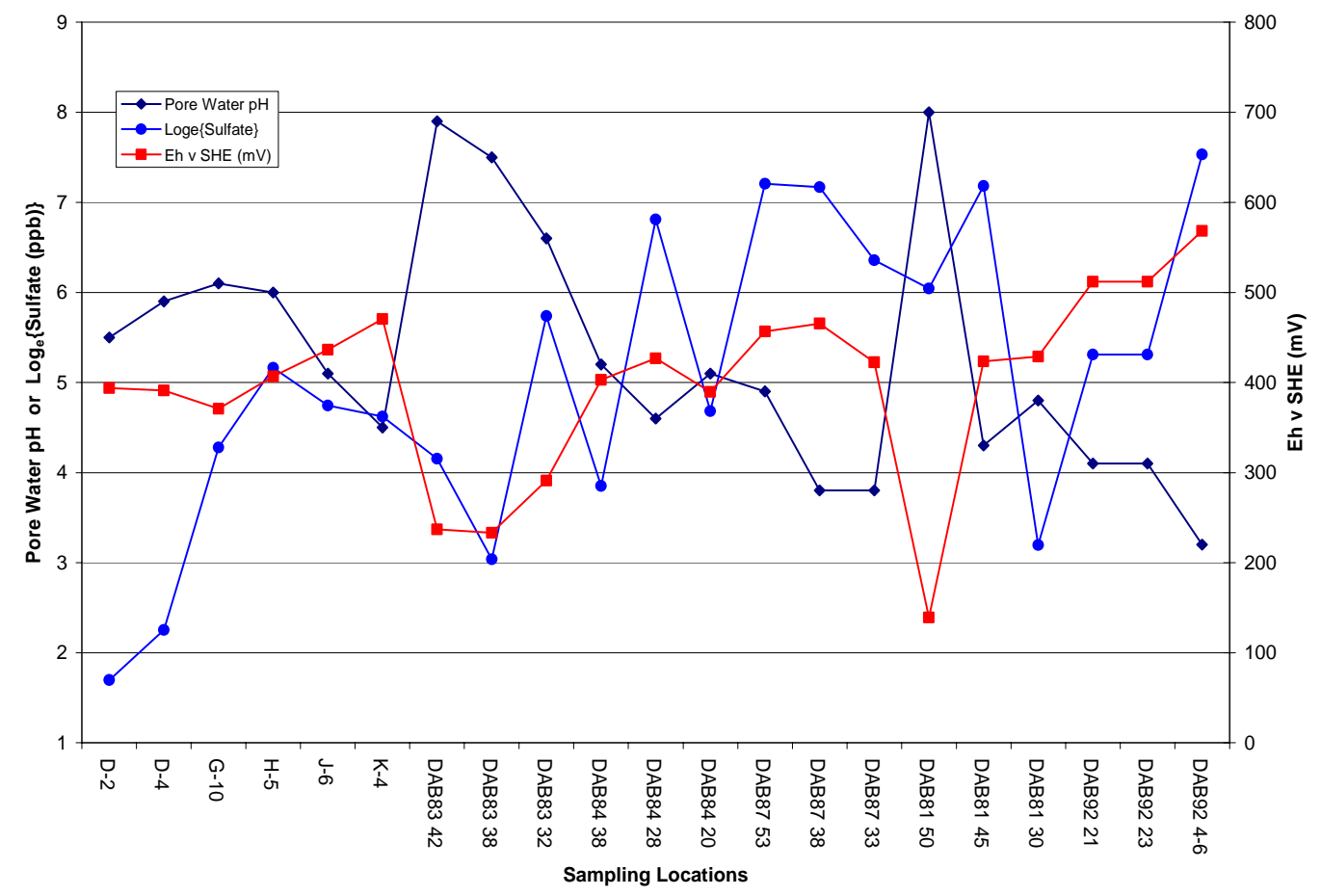

Figure 28. Porewater pH, Sulfate, and Eh values for DAB Upland and Wetland Locations

In order to compare the relative contribution of dilution to other factors contributing to attenuation of COCs in D-Area groundwater (e.g., sorption and microbiological effects), data generated using the D-Area groundwater transport model methodology reported previously (Brewer and Sochor, 2002) was compared with porewater COC concentration data collected in the field. In order to predict relative concentrations based on physical attenuation mechanisms, dilution, and dispersion only, the transport model was run without sorption input with a $100 \mathrm{ppb}$ source line near DAB 92 4-6. The plume shown in Figure 29 and Figure 30 was generated based on only the source loaded near the DCPRB. Figure 2 shows the beryllium plume for multiple sources in D-Area. Likely, there is additional contaminant influx near the end of the DAB (location 87) which is not accounted for based solely on source loading near the DCPRB (DAB 92). It should be noted that this comparison is only based on relative concentration and not actual concentrations used in and predicted by the model. A significant amount of uncertainty is associated with the mass loading and area over which it is loaded. Additionally, the original calibration of the model was not based on porewater data included in this report. 
The extent of dilution and dispersion was estimated using the dilution faction (DF):

Equation $5 \quad D F=\frac{C_{0}}{C_{i}}$

where $C_{0}$ is the source term concentration $(100 \mathrm{ppb})$ and $C_{i}$ is the concentration at location $i$. Therefore, the lower the concentration at location $i$, the greater the dilution factor. The "no sorption" model in layers 3 and 4 (Figure 29 and Figure 30) predicts a dilution (and dispersion) factor (DF) range of 2 to 28 in the vicinity of the upland samples (Table 36).

A second construct referred to as the dilution attenuation factors (DAFs) were calculated according to Equation 6.

Equation $6 \quad D A F=\frac{C_{D A B 92}}{C_{i}}$

where $C_{D A B 92}$ is the porewater solute concentration measured in sample DAB 92 4-6 and $C_{i}$ is the concentration at location $i$. Comparison of DF (modeled) and DAF (field values) provides an estimate of the relative contribution of dilution/dispersion versus all other contributions (i.e., sorption, microbial) to natural attenuation at the site. No numerical transport modeling was conducted to calculate $D A F$; instead the porewater data in Table 36 was used. Dilution attenuation factors ranged from 2 to 40 for sulfate and 0.5 to 700 for beryllium (Table 36). DAF values for nickel and uranium are on average even greater than those for beryllium. DAF values observed for arsenic are lower than the cations beryllium, nickel, and uranium although arsenic concentrations at DAB 92 4-6 are quite low in both porewater as well as soil. Likely, the majority of arsenic in the low $\mathrm{pH}$ source area is attenuated before reaching DAB 92 4-6. This observation is consistent with the low solubility of $\mathrm{As}(\mathrm{V})$ at low $\mathrm{pH}$ and also favorable sorption of $\mathrm{As}(\mathrm{V})$ to $\mathrm{Fe}$-oxyhydroxide at a pH 4. Furthermore, Kaplan and Knox (2004) measured quite high concentrations of arsenic in sediments from the DCPRB (234.6 ppm) indicating that As is as readily sorbed prior to reaching the locations evaluated in this study.

Based on this comparison of field data to modeled dilution, a significant amount of attenuation of the COCs in D-Area can likely be attributed to attenuation by factors other than dilution and dispersion. These geochemical and microbiological processes contributing to this attenuation are addressed in Sections 6.2-6.4. 
WSRC-TR-2004-00124, REVISION 0

Table 36. Dilution Attenuation Factors from Field Data near DCPRB and DAB

\begin{tabular}{|c|c|c|c|c|c|c|c|c|}
\hline $\begin{array}{c}\text { Sample } \\
\text { Soil }\end{array}$ & $\begin{array}{c}\text { Model } \\
\text { Layer }\end{array}$ & $\begin{array}{c}\text { Porewater } \\
\mathbf{p H}\end{array}$ & $\begin{array}{c}\mathbf{C}_{\mathbf{o}} / \mathbf{C} \\
\text { model }\end{array}$ & $\begin{array}{c}\text { DAF } \\
\text { Sulfate }\end{array}$ & $\begin{array}{c}\text { DAF } \\
\text { Be }\end{array}$ & $\begin{array}{c}\text { DAF } \\
\text { Ni }\end{array}$ & $\begin{array}{c}\text { DAF } \\
\text { U }\end{array}$ & $\begin{array}{c}\text { DAF } \\
\text { As }\end{array}$ \\
\hline DAB92 4-6 & 1 & 3.18 & & 1.0 & 1.0 & 1.0 & 1.0 & 1.0 \\
DAB92 21-23 & 3 & 4.12 & 11 & 9.2 & 2.0 & 51.8 & 34.1 & 6.8 \\
DAB85 32-33 & 3 & 5.18 & 3 & 2.2 & 25.1 & 5.3 & $>39424.0$ & 13.5 \\
DAB85 45 & 3,4 & 7.25 & 6 & 23.0 & 710.5 & 177.6 & $>39424.0$ & 1.8 \\
DAB81 45 & 3,4 & 4.26 & 4,5 & 1.4 & 0.5 & 2.6 & 157.0 & 5.9 \\
DAB81 50 & 4 & 7.98 & 5 & 4.4 & 391.9 & 1350.3 & 10.1 & 0.4 \\
DAB87 33 & 3 & 3.81 & 18 & 3.2 & 3.6 & 26.9 & 2.0 & 0.3 \\
DAB87 38 & 3,4 & 3.76 & 18,21 & 1.4 & 2.2 & 4.1 & 1.4 & 0.3 \\
DAB87 53 & 4 & 4.93 & 21 & 1.4 & 4.6 & 74.1 & $>19712.0$ & 3.6 \\
DAB84 20 & 3 & 5.06 & 23 & 17.3 & 22.8 & 208.5 & $>39424.0$ & 11.2 \\
DAB84 28 & 3,4 & 4.56 & 23,28 & 2.1 & 2.0 & 9.2 & 11.1 & 1.1 \\
DAB84 38 & 4 & 5.24 & 28 & 39.6 & 57.3 & 1043.2 & $>39424.0$ & 15.5 \\
DAB83 32 & 4 & 6.61 & 13 & 6.0 & 11.4 & 211.2 & 9.8 & 48.2 \\
DAB83 38 & 4 & 7.50 & 13 & 89.4 & 446.8 & 2701.2 & $>39424.0$ & 0.8 \\
DAB83 42 & 4 & 7.87 & 13 & 29.4 & 129.0 & 925.1 & 738.8 & 0.2 \\
\hline
\end{tabular}

\subsection{SOURCE AVAILABILITY}

\subsection{1 pH, Redox, and Sulfate}

In general, $\mathrm{pH}$ increased with distance from the source as well as with depth. This broad generalization holds true except for two sampling locations directly beneath (DAB 81 and 87) and one location just downgradient (DAB 84) of 488-D. At all three of these locations porewater from the shallowest sampling depth was slightly higher in $\mathrm{pH}$ than the sampling depth below. Lower sulfate concentrations at these depths as compared to the locations directly below them suggest that these more shallow sampling depths are higher in elevation than the most impacted region of the low $\mathrm{pH} /$ high sulfate plume. Another explanation for this observation could be neutralization of the low $\mathrm{pH}$ plume by infiltration from the high $\mathrm{pH}$ perched water within the 488-D (DAB $86 \mathrm{pH}=7.50$ ). Due to the tight clay layer directly below the 488 -D, vertical flow from the ash basin is expected to be minimal, although near the west end of the $\mathrm{DAB}$ low $\mathrm{pH}$ leachate from coal spoils in the basin is potentially breaching the clay layer. In addition to the ash basin material sample DAB 86, three soil sampling locations near 488-D had sampling depths with $\mathrm{pH}>7$. The $\mathrm{pH}$ values at these locations are considerably higher than any $\mathrm{pH}$ measured for distal samples DCP 168-171 despite the closer proximity to the DCPRB, a source of low $\mathrm{pH}$. They are, however, from greater depth below ground surface than samples from the distal region. These distal samples may be impacted by the plume emanating from the DRP (Figure 2). 


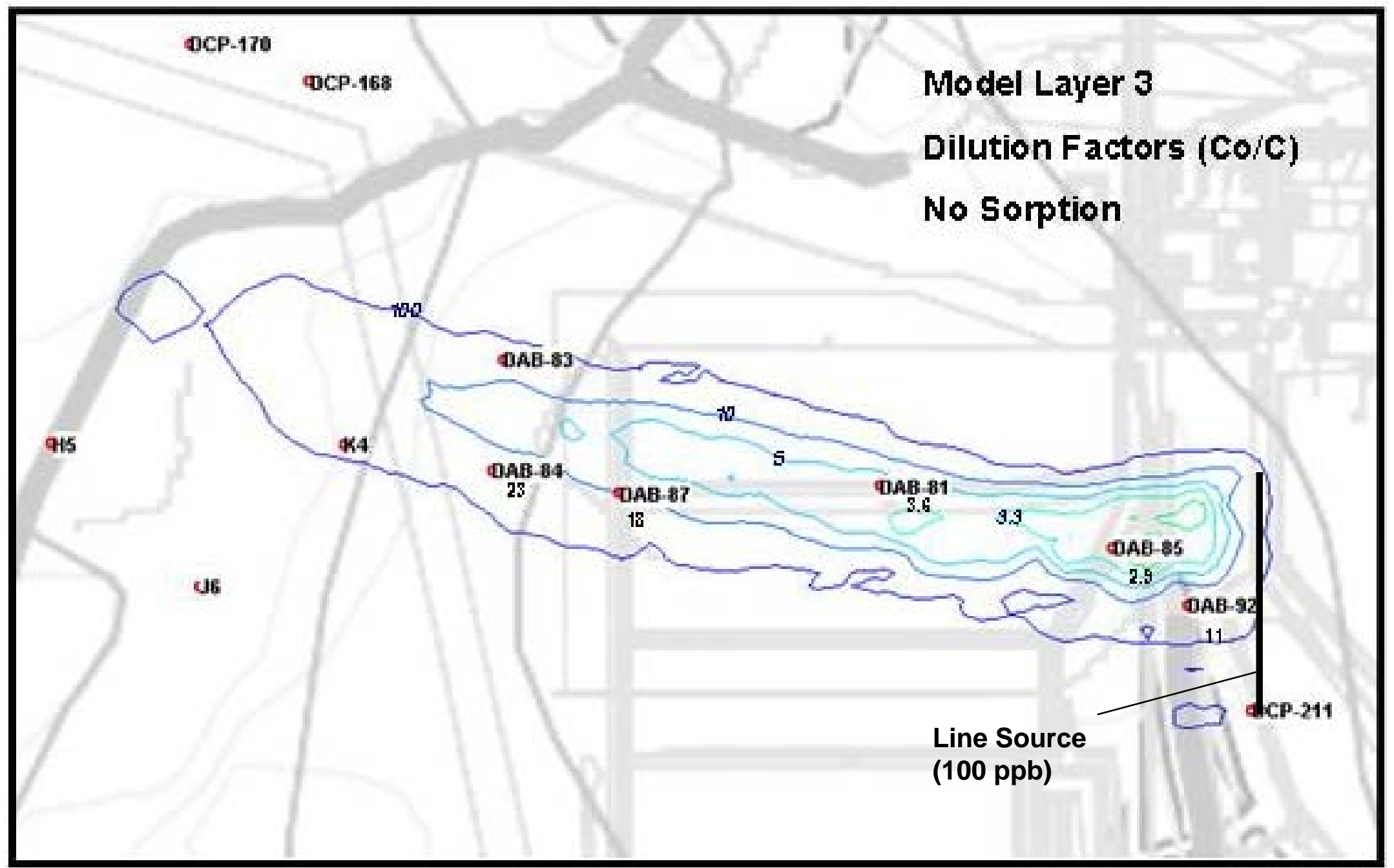

Figure 29. D-Area Coal Pile Runoff Basin plume under 488-D and 488-4D (Layer 3). No sorption model with 100 ppb line source loaded in the vicinity of DAB 92 4-6. 


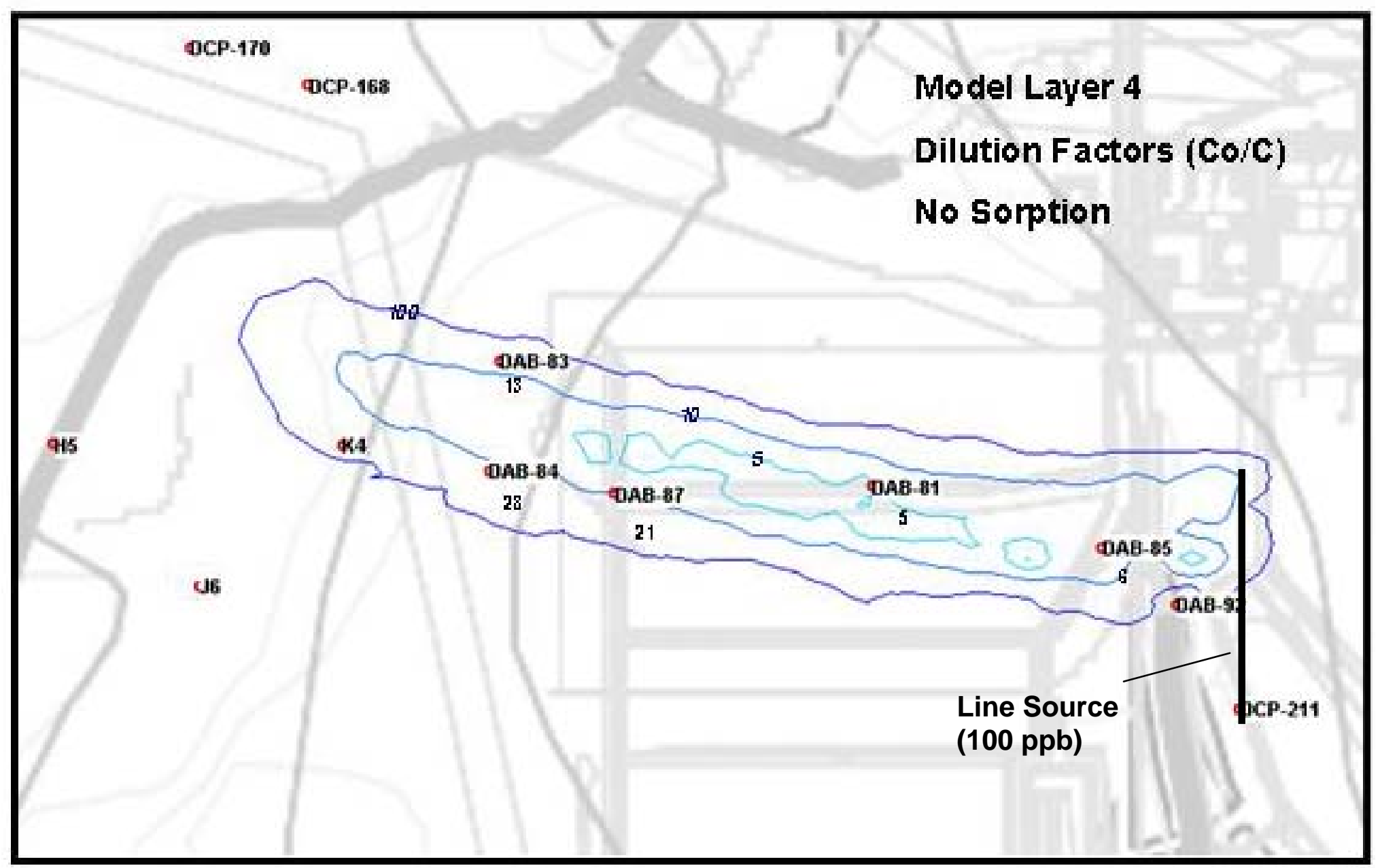

Figure 30. D-Area Coal Pile Runoff Basin plume under 488-D and 488-4D (Layer 4). No sorption model with 100 ppb line source loaded in the vicinity of DAB 92 4-6. 


\section{WSRC-TR-2004-00124, REVISION 0}

It was a significant finding that all 6 of D-Area sediment bacterial isolates tested were able to change the $\mathrm{pH}$ of their media up to 3 units (Table 33 through Table 35). The Enterobacter species tested was found to thrive at $\mathrm{pH} 4$ and adjust it's media to $\mathrm{pH} 7$. Enterobacter sp have also been proven to reduce metal contamination (Rege et al., 1997). Bacteria adjust the media in their surrounding environment to survive and proliferate as one of their physiological adaptations. In this study a low nutrient media was used to emulate D-Area porewater. By raising in situ groundwater $\mathrm{pH}$ they could in turn indirectly reduce associated metal speciation and availability. It was also of interest that all the bacteria tested, even those did not grow at $\mathrm{pH} 4$, were still alive and recovered quickly in other media. This demonstrates that these bacteria are acid tolerant, although it suggests that geochemical mechanisms likely dominate in the regions where $\mathrm{pH}$ is lower than 5 .

Conversely to $\mathrm{pH}$, Eh decreased with increasing distance from the source and increasing depth. Notable exceptions to this generalization were DAB 81, 84 and 87, the same locations and depths that did not follow the general $\mathrm{pH}$ trends. Redox measurements for all locations were in the range of 664.3 to $138.7 \mathrm{mV}$. This range is consistent with a highly oxidized soil environment. These redox potentials are all higher than those necessary for Fe(III) reduction $(<100 \mathrm{mV})$ or sulfate reduction $(<-100 \mathrm{mV})$. Although the overall sediment redox is quite oxidizing, this high overall Eh does not rule out that microbial meditated anaerobic reduction processes could be occurring in microenvironments in the subsurface. The presence of sulfate reducing bacteria in DAB 92 indicates pockets of anaerobic activity. Another consideration is bacterial aerobic biotransformation of metals in this environment. The predominance of Stenotrophomonas maltophilia in some of the upland sediment bacterial isolations is evidence of potential MNA activity in this site although Stenotrophomonas maltophilia was only identified at locations downgradient of the DAB and not at location DAB 92 near the DCPRB.

Eh is correlated with $\mathrm{pH}$ for all porewater samples (Figure 32). As Eh decreases, $\mathrm{pH}$ increases. In a previous report (Powell et al 2001), it was noted that the turbidity of porewater sample DCP 211-p2 $(\mathrm{pH}=4.69, \mathrm{Eh}=138.7 \mathrm{mV}$ v SHE) was likely causing spurious redox measurements for this sample.

As $\mathrm{pH}$ increased and Eh decreased, sulfate concentrations decreased (Figure 28 and Figure 32. Wetland samples of surface ash (K-4, H-5, J-6, G-10) contained lower concentrations of sulfate $(\sim 100 \mathrm{ppm})$ similar to distal samples (DCP 168, 170, 171) $(\sim 100$ $\mathrm{ppm}$ ) rather than to the porewater of the samples of ash (DAB 86) taken from inside 488-D $(\sim 1785 \mathrm{ppm})$. These high concentrations of sulfate in the ash from 488-D are similar to concentrations near DCPRB (DAB 92 4-6, 1866 ppm; DAB 211-p2, 1476 ppm). Interpretation of sulfate, $\mathrm{pH}$, and Eh data at upland locations is complicated by the apparent influx of low $\mathrm{pH}$ leachate from the west end of the DAB (Figure 2) which is reflected on lower $\mathrm{pH}$ at DAB 8733 and DAB 8738 than at upgradient location DAB 81.

For this reason, trends with distance from the DCPRB are complicated due to overlapping plumes. Regardless, despite the potential influx of additional contaminants from the DAB (both directly and indirectly), by the time the DCPRB plume reaches the wetland $\mathrm{pH}$ is only slightly elevated at wetland locations K-4 and H-5. Relative to background wetland soils (D-2, D-4), sulfate at wetland locations has been attenuated by an order of magnitude, and redox conditions $(\mathrm{Eh}=370-470 \mathrm{mV})$ at the surface of the wetland are more reducing than the shallow locations near the DCPRB (DAB $924-6$, Eh $=568.2 \mathrm{mV}$ ). 


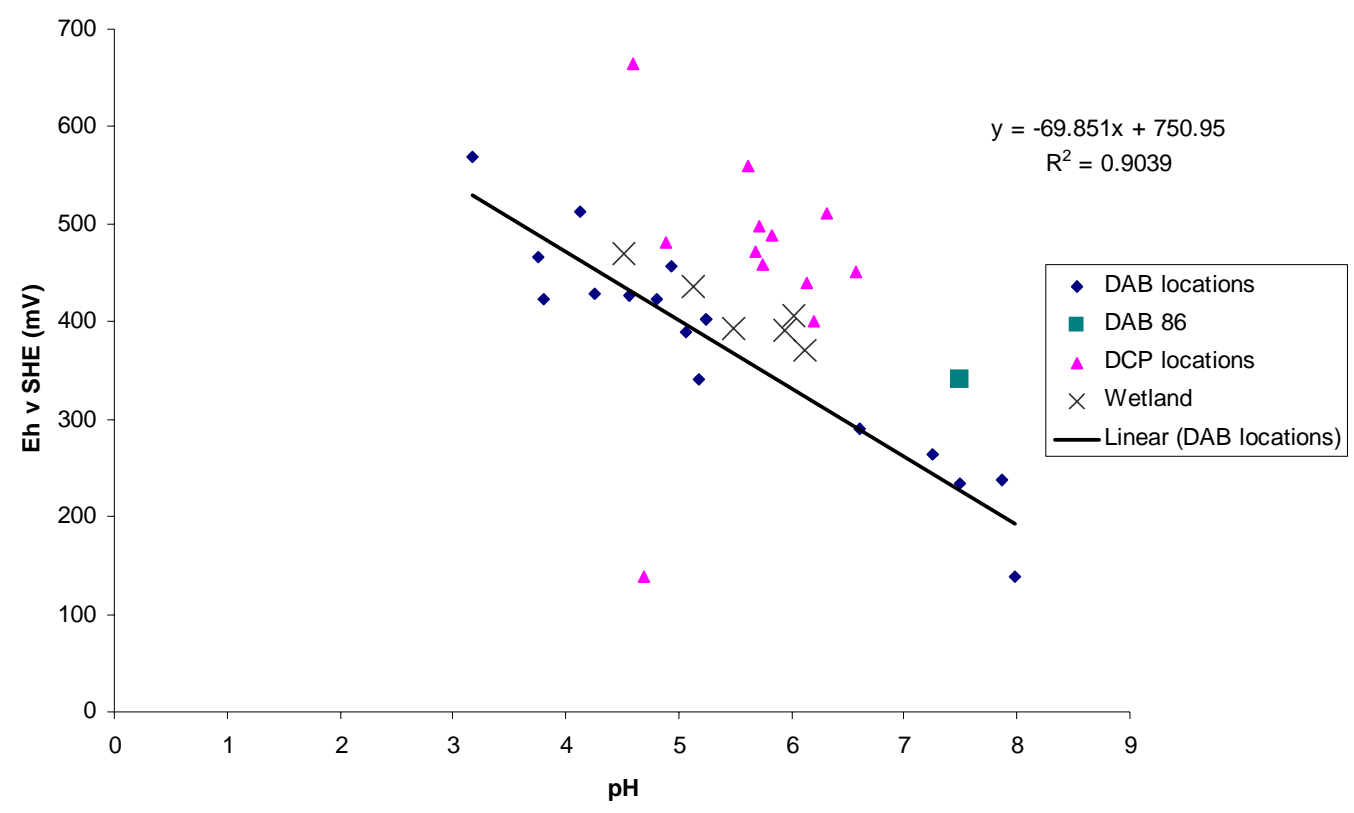

Figure 31. Plot of Redox Potential $\left(\mathrm{E}_{\mathrm{h}}\right)$ versus pH for All Porewater Samples

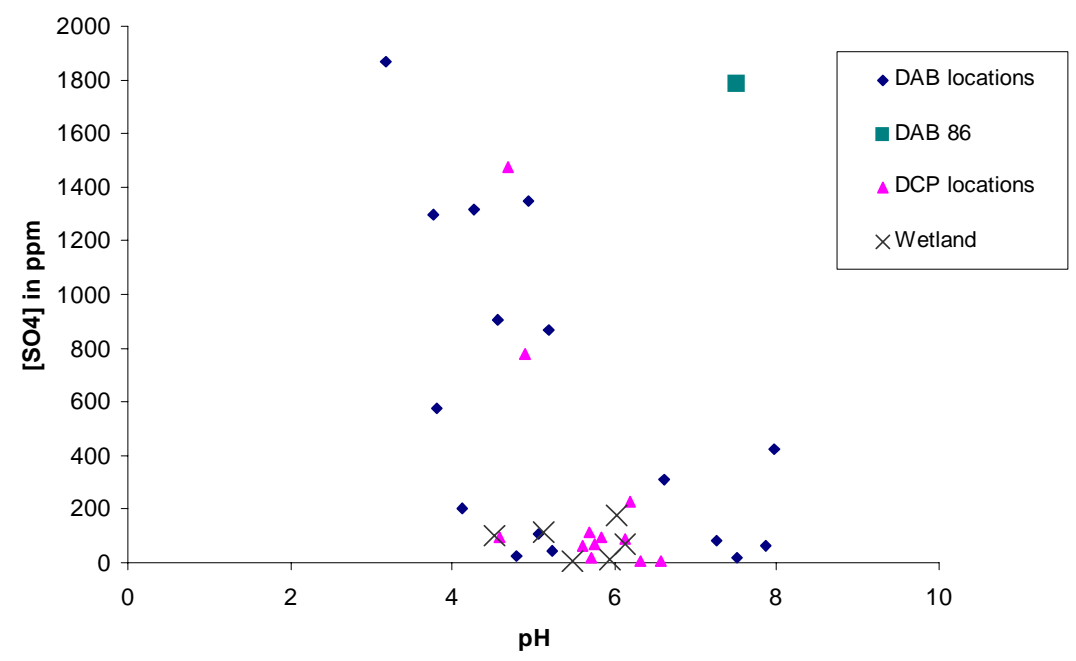

Figure 32. pH versus Sulfate Concentration in Porewater for All Locations 


\subsubsection{Major Ions in porewater}

Low $\mathrm{pH}$ leachate from the DCP/DCPRB promotes the protonative dissolution of aluminum, iron, and manganese oxides/hydroxides found in soil. Consequently, very high concentrations of dissolved aluminum, iron, and manganese are observed in locations near the DCPRB (DAB 92 and DCP 211) and at locations such as DAB 8733 and DAB 8738 with low $\mathrm{pH}$ and high sulfate concentrations (other indicators of plume impact). As mentioned previously, kaolinite, an aluminum-containing mineral, dominates the clay fraction of SRS soils. The dissolution of kaolinite was modeled using a geochemical model, MINTEQA2. Figure 33 shows the curve for the modeled kaolinite data along with the observed porewater concentrations of aluminum for all locations sampled. Decreasing porewater concentrations of aluminum, iron and manganese with increasing $\mathrm{pH}$ is an important indicator of natural attenuation because the formation of metal oxide/hydroxide coatings and precipitates is expected to contribute to natural attenuation by increasing the ability of the soils to sorb trace metals by increasing the cation/anion exchange capacities of the soils. Similarly, iron and manganese concentrations decrease with increasing $\mathrm{pH}$ (Figure 34 and Figure 35, respectively). Trace metals such as the COCs considered herein may sorb to freshly precipitated surfaces and/or form coprecipitates with metal oxides, particularly iron oxides/hydroxides.

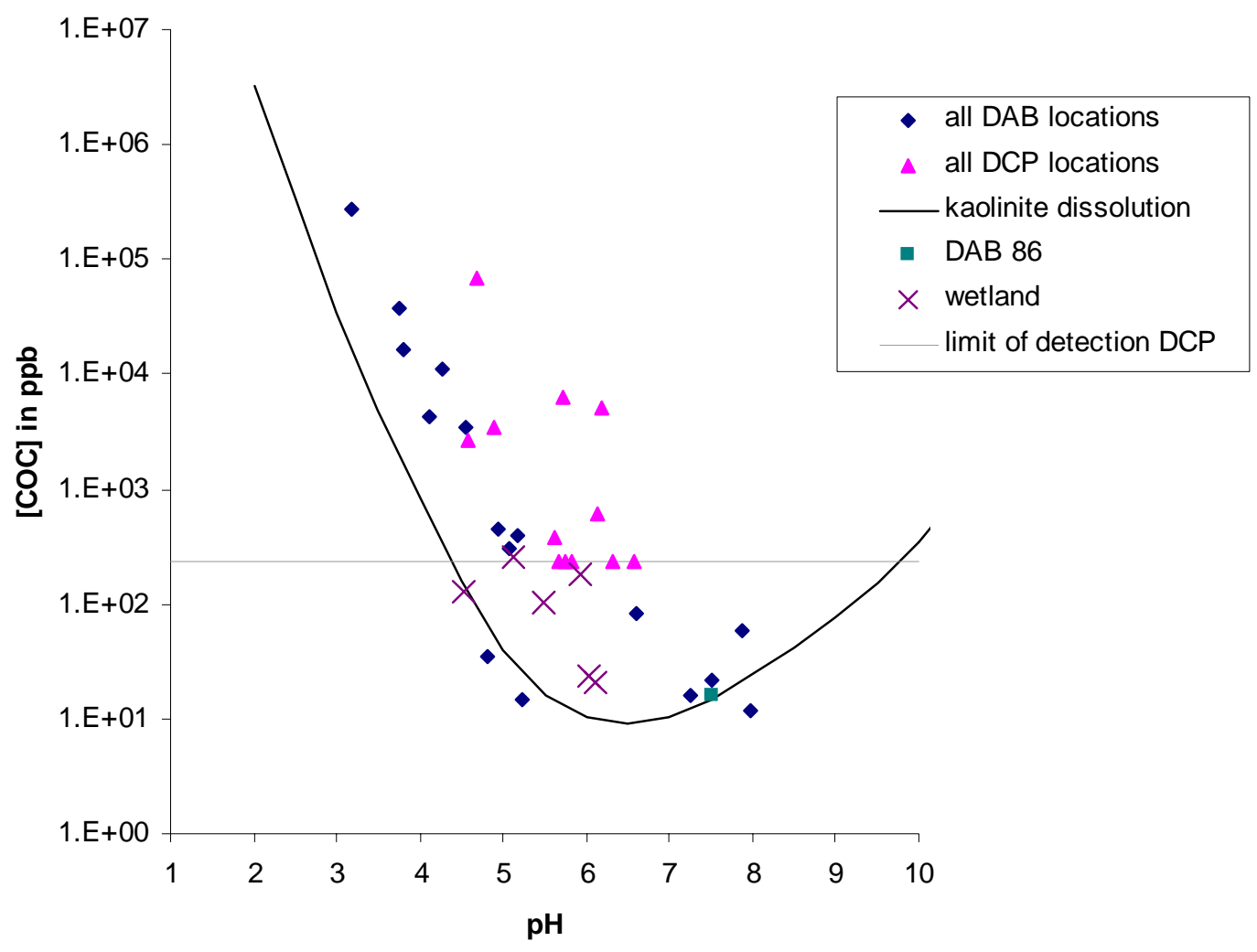

Figure 33. Aluminum Concentration in Porewater as a Function of pH (log scale) 


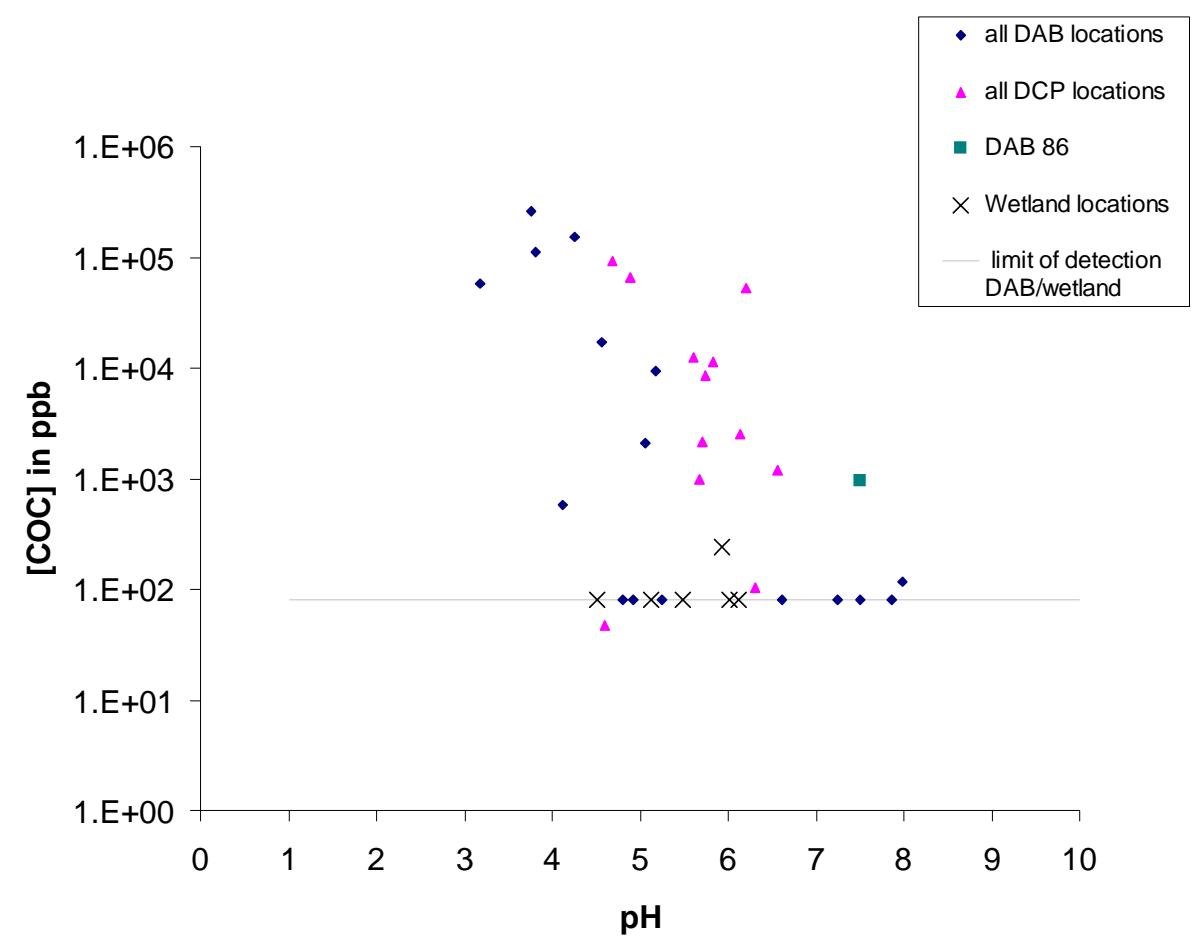

Figure 34. Iron Concentration in Porewater as a Function of pH (log scale)

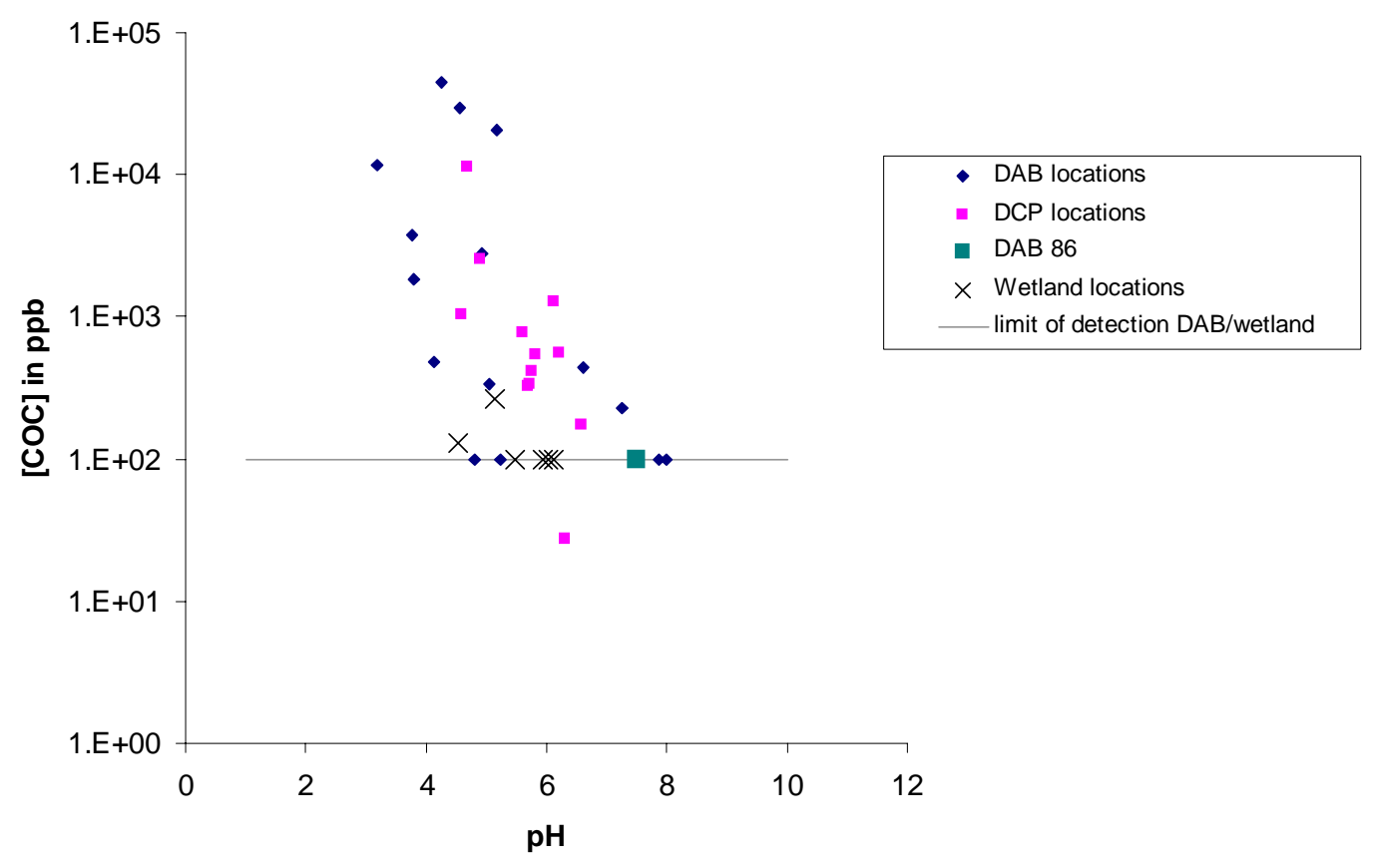

Figure 35. Manganese Concentration in Porewater as a Function of $\mathrm{pH}$ (log scale) 


\subsubsection{Trace Metals in porewater}

The chemical speciation of the trace metal COCs (Be, Ni, U, As) analyzed in this study provides insight into the geochemical mechanisms controlling porewater COC concentrations measured in field samples. It is important to note that trace metals were in relatively low concentrations at most locations analyzed in this study. Beryllium and nickel exist as divalent cations under environmental conditions and would be expected to compete with hydrogen ions for sorption sites on metal oxide/hydroxide surfaces in soils. Consequently, porewater beryllium and nickel concentrations are significantly correlated with $\mathrm{pH}\left[\mathrm{Be}: \mathrm{R}^{2}=\right.$ $0.696, \mathrm{p}<0.001, \mathrm{df}=22$; including porewater data from upland DAB locations, wetland, and ash from 488-D (DAB 86)][Ni: $\mathrm{R}^{2}=0.3048, \mathrm{p}<0.001, \mathrm{df}=30$; including upland $\mathrm{DAB}$ locations, upland DCP locations (excluding data below detection), wetland, and ash from 488-D (DAB 86)](where $\mathrm{R}^{2}=$ correlation coefficient, $\mathrm{p}=$ uncertainty, $\mathrm{df}=$ degrees of freedom). Figure 38 and Figure 39 are plots of beryllium and nickel porewater concentration as a function of porewater $\mathrm{pH}$ for upland and wetland locations. Logarithmic correlation for the DAB sampling locations only is shown on the plots. Despite the differences in composition of the solid phases between upland soil and wetland ash including higher solid phase COC concentrations for most wetland locations as compared to upland, $\mathrm{pH}$ is an excellent predictor of $\mathrm{COC}$ concentrations in porewater for both $\mathrm{Be}$ and $\mathrm{Ni}$. This relationship is likely due to competition between hydrogen ions and cationic COCs for sorption sights.

In contrast to the divalent cations $\mathrm{Be}$ and $\mathrm{Ni}$, uranium can exist as cationic $\left(\mathrm{UO}_{2}{ }^{2+}, \mathrm{UO}_{2}{ }^{+}\right.$, $\left.\mathrm{UO}_{2} \mathrm{OH}^{+}\right)$, neutral $\left(\mathrm{UO}_{2} \mathrm{CO}_{3}\right)$, and/or anionic $\left[\mathrm{UO}_{2}\left(\mathrm{CO}_{3}\right)_{2}{ }^{2-}\right]$ species under the range of environmental conditions at $\mathrm{D}$-Area $(\mathrm{pH}=3$ to 8 ; $\mathrm{Eh}=570 \mathrm{mV}$ to $140 \mathrm{mV})$ (Figure 36). At $\mathrm{pH}$ values less than 5.5, uranium behaves as a cation, and similarly to Be and $\mathrm{Ni}, \mathrm{U}$ porewater concentrations are significantly correlated with $\mathrm{pH}$ (Figure 40). Above $\mathrm{pH} 5.5$ (Figure 36), both neutral and anionic species are possible.

Arsenic exists as anionic species arsenate $\left(\mathrm{AsO}_{4}{ }^{3-}\right)$ and arsenite $\left(\mathrm{AsO}_{3}{ }^{3-}\right)$ in environmental waters (Figure 37). Arsenite [As(III)] is by far the more soluble of the two species although in oxic waters arsenate $[\mathrm{As}(\mathrm{V})]$ is the predominant form. Arsenic is found in low concentrations at locations in this study except for the sample of ash from the 488-D (DAB 86). The high $\mathrm{pH}$ of this sample likely accounts for the solubility of As due to desorption of anions. Likely, most of the arsenic in the coal pile leachate is sorbed as arsenate (AsV) near the DCPRB. Arsenate has a low solubility and tends to be found associated with iron. Sorption of As to HFO is favored at $\mathrm{pH} 4$, and As can also coprecipitate with iron oxides/hydroxide. Arsenic transported downgradient of the DCPRB to the locations analyzed in this study exhibits solubility behavior with $\mathrm{pH}$ that is consistent with arsenite (AsIII) sorption to HFO which has a broad sorption maximum around $\mathrm{pH} 7$ (Figure 41). 


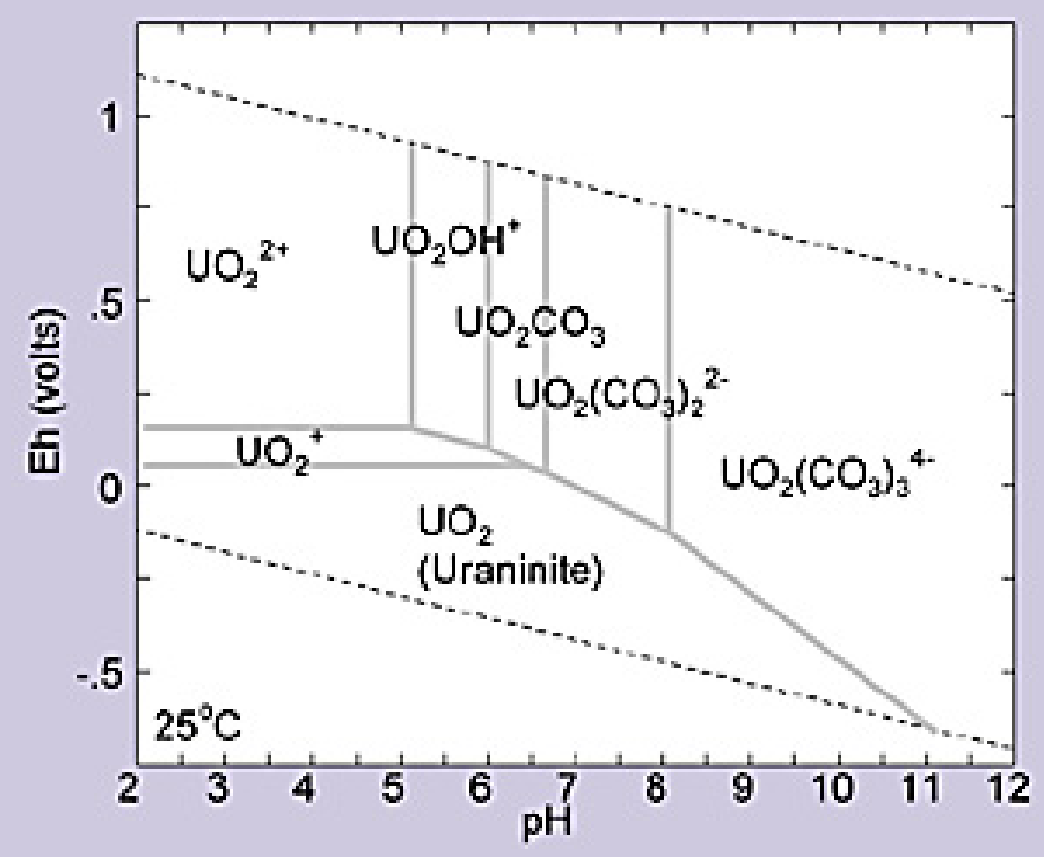

Figure 36. Eh-pH Diagram for Uranium

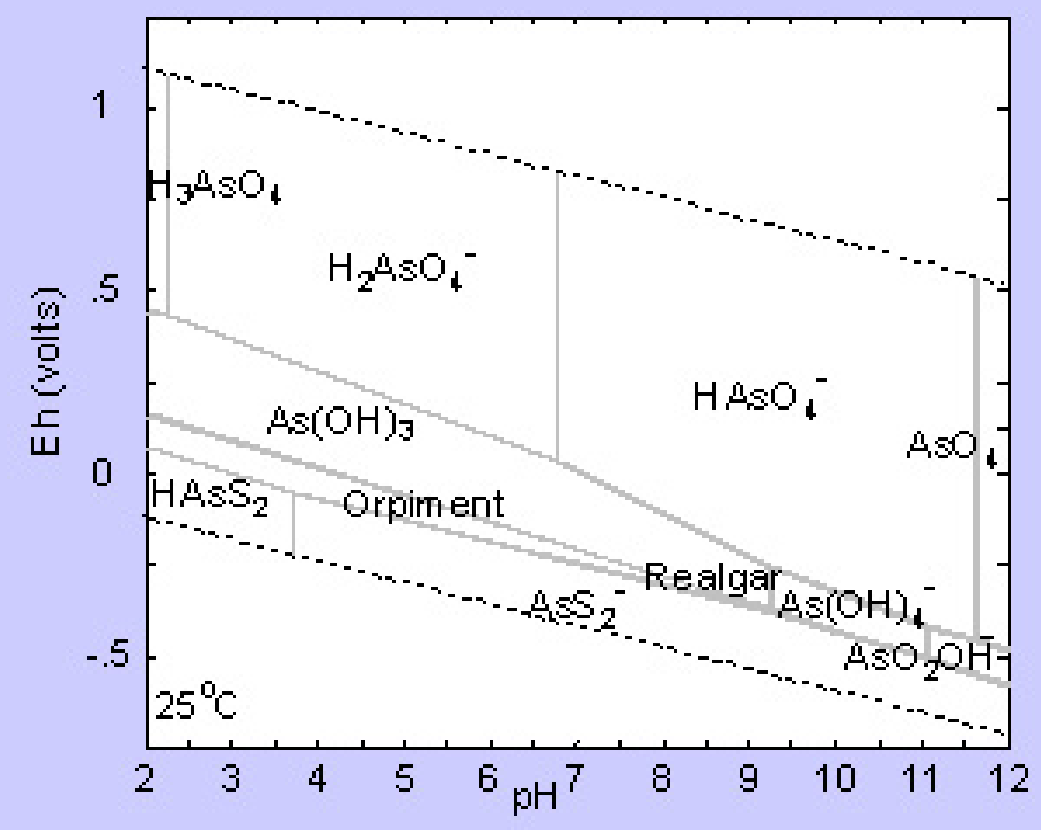

Figure 37. Eh-pH Diagram for Arsenic 


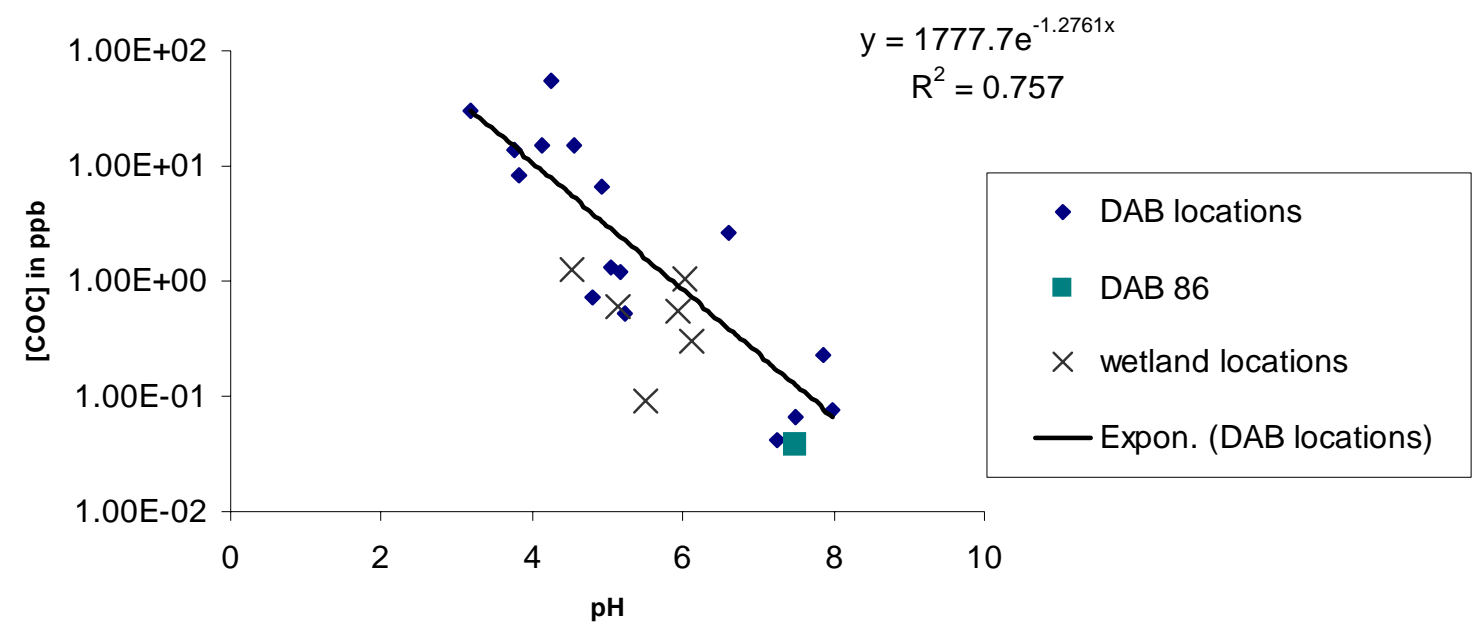

Figure 38. Beryllium Concentration in Porewater as a Function of pH (log scale)

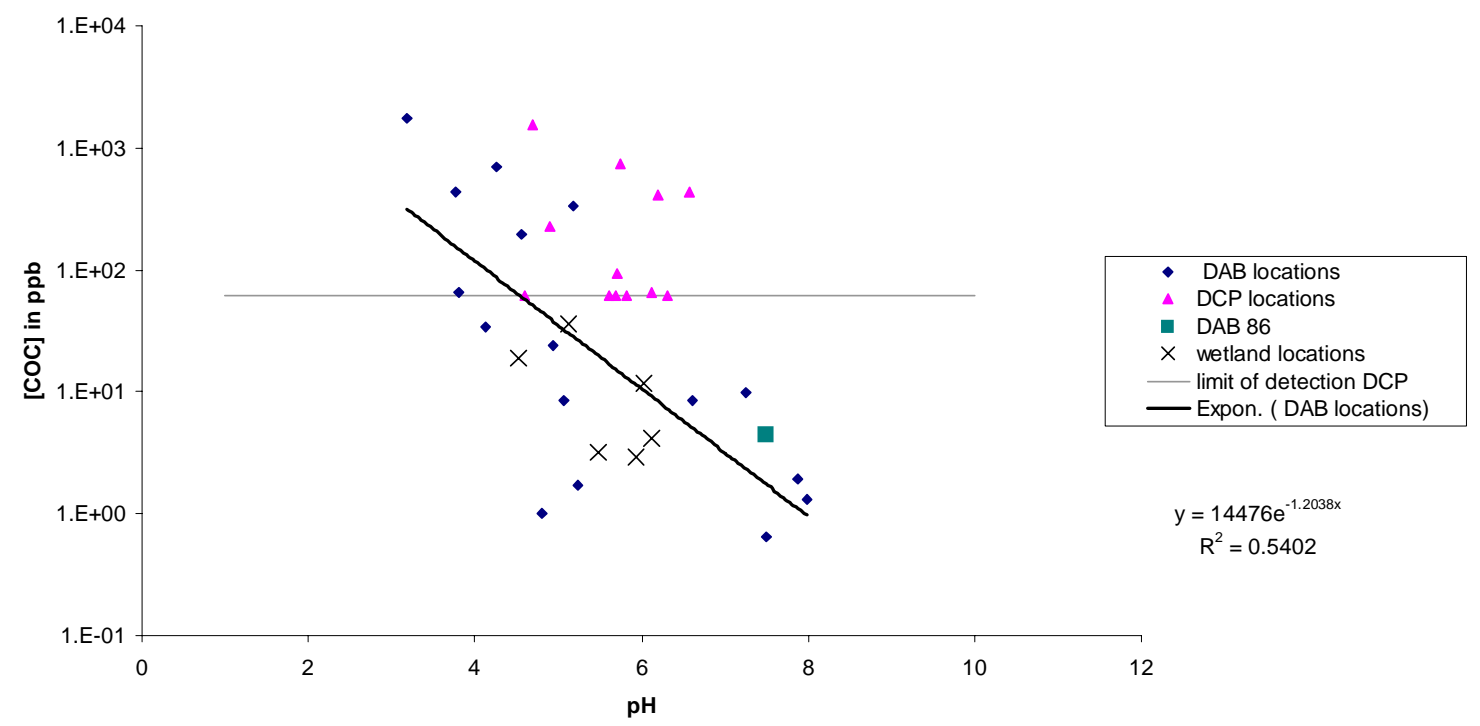

Figure 39. Nickel Concentration in Porewater as a Function of pH (log scale) 

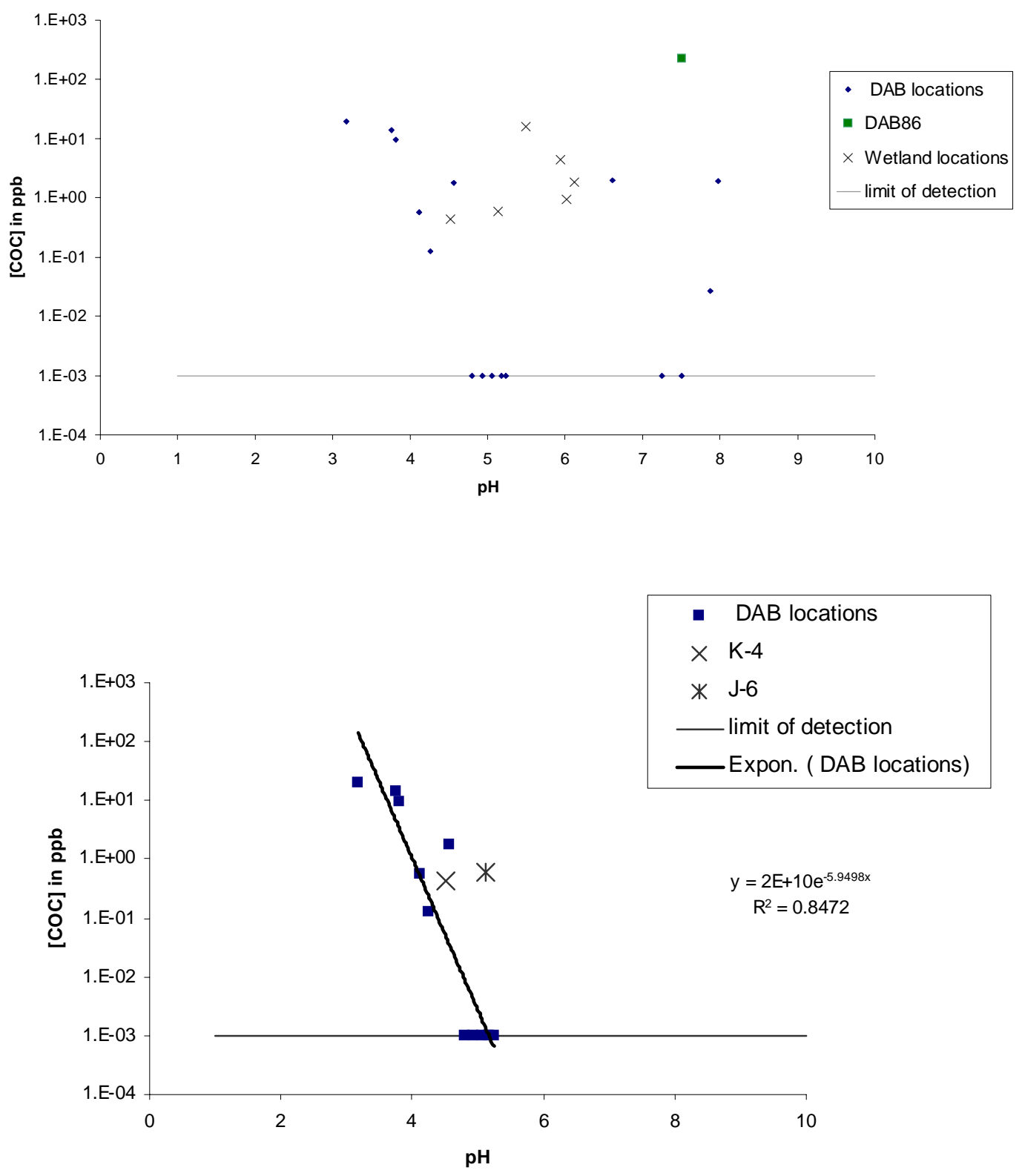

Figure 40. Uranium Concentration in Porewater as a Function of pH (log scale) (Data DCP locations not available) (Top - all measured data; Bottom - only data below pH 5.5) 

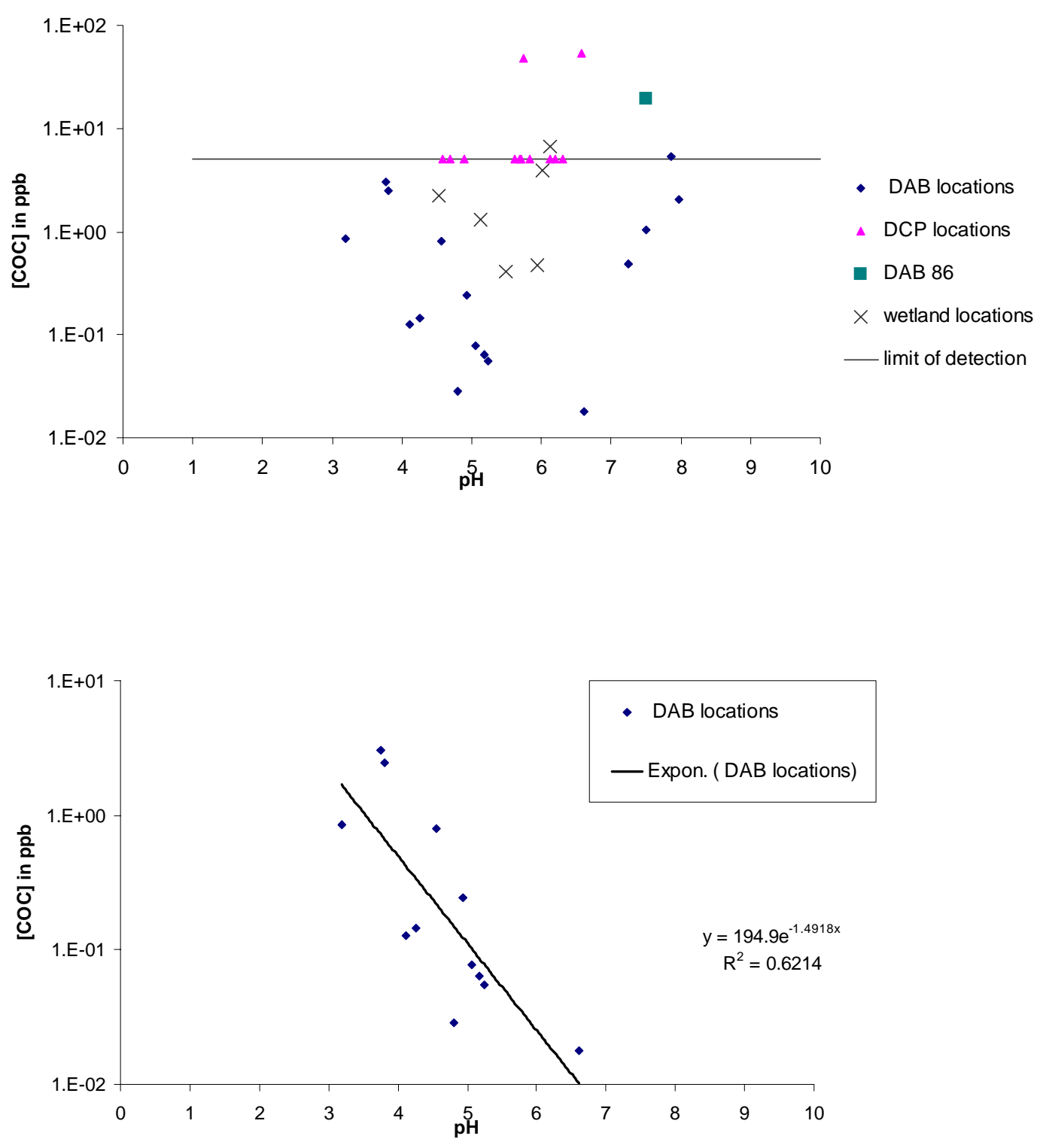

Figure 41. Arsenic Concentration in Porewater as a Function of pH (log scale) (Top all measured data; Bottom - only DAB data below pH 7) 


\subsubsection{Available Fraction}

The sediment metal fraction available to the mobile aqueous phase was estimated using the sequential extraction data (Equation 7):

Equation $7 \quad \%$ Available $=\left(\frac{C_{F 1}+C_{F 2}+C_{F 3}+C_{F 4}+C_{F 5}+C_{F 6}}{C_{F 1}+C_{F 2}+C_{F 3}+C_{F 4}+C_{F 5}+C_{F 6}+C_{F 7}+C_{F 8}}\right) \times 100$

where $\mathrm{C}$ represents constituent concentration and subscripts, F1, F2, F3, F4, F5, F6, F7, and F8 represent sequential extraction fractions 1 through 8 . Where sequential extraction data was not available, the \% Available was calculated based on a single step extraction equivalent to the sum of the first 6 sequential extraction fractions and total digestion data equivalent to the sum of all 8 sequential extraction steps. Trace metal availability values are presented in Table 37.

\subsubsection{Beryllium and Nickel}

Closer to the DCPRB, where soil concentrations of these COCs were highest, the available fraction of $\mathrm{Be}$ and $\mathrm{Ni}$ tended to increase. This observation is consistent with natural attenuation. The soils most impacted by the low $\mathrm{pH}$ plume would be expected to have lower metal concentrations as leaching of any available metals if favored. As natural attenuation occurs, metals removed from the ground water to the soil would tend to be associated with the most available fractions.

Samples from the wetland have concentrations of metals as high as or higher than those closer to the DCPRB although the availability is closer to that of the DAB ash sample (DAB $86,19 \%$ ) rather than upland soil.

\subsubsection{Uranium}

Soil concentrations of uranium at DAB 92 4-6 (the most impacted area nearest the DCPRB) are the highest of any in the plume associated with the DCPRB, which indicates that even close to the source area uranium is likely sorbed by the soil. Samples close to the source tend to have a higher percentage of available uranium.

The ash sample (DAB 86) had higher concentrations of uranium with lower availability $(24 \%)$ and the wetland samples had approximately $50 \%$ availability of uranium.

\subsubsection{Arsenic}

Arsenic concentrations in soil at locations associated with the DCPRB plume tend to be low and also less available. Because porewater concentrations of arsenic are low at these locations, likely much of the arsenic is attenuated prior to reaching the sampling area in the plume associated with the DCPRB. Precipitation/sorption of As V with/to iron oxides/hydroxides could account for both the attenuation of As near the DCPRB as well as its tendency to be associated with the crystalline mineral phases. 
Table 37. Summary of Trace Metal Availability (\% available $=$ available/total $x 100 \%)$

\begin{tabular}{|c|c|c|c|c|c|c|c|c|c|}
\hline $\begin{array}{c}\text { Sample } \\
\text { Soil }\end{array}$ & $\begin{array}{c}\text { Porewater } \\
\text { pH }\end{array}$ & $\begin{array}{l}\text { Be } \\
\text { Total } \\
\text { ppm }\end{array}$ & $\begin{array}{c}\% \\
\text { available }\end{array}$ & $\begin{array}{l}\text { Ni } \\
\text { Total } \\
\text { ppm }\end{array}$ & $\begin{array}{c}\% \\
\text { available }\end{array}$ & $\begin{array}{l}\text { U } \\
\text { Total } \\
\text { ppm }\end{array}$ & $\begin{array}{c}\% \\
\text { available }\end{array}$ & $\begin{array}{l}\text { As } \\
\text { Total } \\
\text { ppm }\end{array}$ & $\begin{array}{c}\% \\
\text { available }\end{array}$ \\
\hline DAB92 4-6 & 3.18 & 1.18 & 20 & 12.51 & 3 & 6.96 & 80 & 2.25 & 7 \\
\hline DAB92 21-23 & 4.12 & 0.52 & 13 & 15.66 & 11 & 1.23 & 98 & 1.56 & 72 \\
\hline DAB85 32-33 & 5.18 & 1.49 & 17 & 38.25 & 70 & 0.79 & 52 & 5.61 & 34 \\
\hline DAB85 45 & 7.25 & 0.24 & $46^{*}$ & & & 0.28 & $25^{*}$ & 0.21 & 42 \\
\hline DAB81 30-35 & 4.80 & 2.01 & $28^{*}$ & & & 1.27 & $134 *$ & 1.82 & 17 \\
\hline DAB81 45** & 4.26 & 0.98 & 34 & 21.00 & 87 & 4.95 & 74 & 0.58 & 19 \\
\hline DAB81 50 & 7.98 & 2.38 & $295^{*}$ & & & 0.74 & $171^{*}$ & 2.66 & 31 \\
\hline DAB87 33 & 3.81 & 1.03 & $14^{*}$ & & & 2.24 & $42 *$ & 2.35 & 14 \\
\hline DAB87 38 & 3.76 & 0.45 & 11 & 40.34 & 79 & 1.12 & 25 & 0.72 & 7 \\
\hline DAB87 53 & 4.93 & 3.10 & $29 *$ & & & 1.22 & $32 *$ & 2.03 & 4 \\
\hline DAB84 20 & 5.06 & 0.15 & $13^{*}$ & & & 0.21 & $25^{*}$ & 1.19 & 1 \\
\hline DAB84 28 & 4.56 & 0.64 & 12 & 25.75 & 89 & 1.59 & 49 & 0.11 & 28 \\
\hline DAB84 38 & 5.24 & 8.10 & $32 *$ & & & 4.55 & $57 *$ & 2.68 & 14 \\
\hline DAB83 32 & 6.61 & 2.35 & $103 *$ & & & 3.12 & $127 *$ & 1.43 & 6 \\
\hline DAB83 38 & 7.50 & 1.98 & $71^{*}$ & & & 1.52 & $108 *$ & 2.00 & 20 \\
\hline DAB83 42 & 7.87 & 4.23 & 82 & 56.49 & 96 & 2.51 & 97 & 3.17 & 57 \\
\hline DAB86 12-16 & 7.50 & 8.80 & 19 & 60.40 & 23 & 13.25 & 24 & 43.74 & 95 \\
\hline DCP211/2-3 & vadose & 0.22 & 14 & 14.84 & 28 & 0.83 & 49 & 2.78 & 44 \\
\hline DCP211/9-10 & nd & 0.59 & 2 & 15.85 & 16 & 1.33 & 59 & 3.29 & 40 \\
\hline DCP211/19-20 & 4.89 & 2.63 & 21 & 24.43 & 24 & 2.09 & 50 & 4.98 & 40 \\
\hline DCP211/35-36 & 4.69 & 0.84 & 31 & 13.43 & 53 & 0.23 & 66 & 2.81 & 82 \\
\hline DCP168/1.5-3.5 & vadose & 2.05 & 42 & 44.83 & 2 & 4.03 & nd & 3.13 & 21 \\
\hline DCP168/20-22 & 5.61 & 5.21 & 92 & 36.14 & 60 & 6.72 & nd & 15.87 & 72 \\
\hline DCP168/31-33 & 6.31 & 1.68 & 100 & 17.36 & 21 & 3.10 & 56 & 7.37 & 50 \\
\hline DCP170/1-3 & vadose & 0.31 & 19 & 26.21 & 2 & 1.05 & 43 & 3.02 & 29 \\
\hline DCP170/14-16 & 4.59 & 0.28 & 21 & 9.13 & 9 & 0.44 & 25 & 0.29 & 45 \\
\hline DCP170/20-22 & 5.83 & 0.83 & 23 & 18.34 & 31 & 0.92 & 2 & 0.75 & 45 \\
\hline D-2 & 5.49 & 1.48 & 52 & 32.81 & 63 & 3.71 & 66 & 6.36 & 57 \\
\hline D-4 & 5.94 & 1.83 & 38 & 24.44 & 20 & 3.86 & 47 & 7.75 & 48 \\
\hline G-10 & 6.12 & 7.07 & 20 & 48.44 & 23 & 5.93 & 47 & 44.24 & 91 \\
\hline H-5 & 6.02 & 4.55 & 31 & 39.60 & 27 & 4.94 & 58 & 77.93 & 97 \\
\hline J-6 & 5.13 & 6.08 & 18 & 46.82 & 22 & 5.29 & 42 & 40.81 & 92 \\
\hline K-4 & 4.52 & 5.27 & 27 & 36.36 & 19 & 3.98 & 51 & 78.32 & 96 \\
\hline
\end{tabular}

* indicates \% available calculated based on single-step extraction and total digestion results 
Wetland samples contained higher concentrations of arsenic with high availability $>90 \%$. The concentration of arsenic in the wetland samples exposed to ash sluice and the ash sample (DAB 86) have comparable concentrations of arsenic ( $>40 \mathrm{ppm})$ with similar high availability. Arsenic in these wetland samples is associated with the organic fraction. It is not clear if this shift from upland (more crystalline) to wetland (more available) is due to a shift in mechanism or rather simply due to the nature of the ash material itself since arsenic is also associated with the organic fraction in the ash sample from 488-D (DAB 86). Evaluation of the soils immediately below the ash deposit would provide relevant information regarding attenuation of As in the wetland.

\subsection{TRANSPORT FACTORS}

\subsection{1 $K_{d}$ Values}

In situ $\mathrm{K}_{\mathrm{d}}$ values based on the available fraction, $\mathrm{K}_{\text {davail, }}$, were calculated for matched sets of soil and porewaters, using Equation 8:

Equation $8 \quad K_{d \text { avail }}=\frac{C_{F 1}+C_{F 2}+C_{F 3}+C_{F 4}+C_{F 5}+C_{F 6}}{C_{\text {porewater }}}$

where $\mathrm{C}$ represents COC concentration and subscripts F1 through F6 represent sequential extraction step fraction 1 through fraction $6 . C_{\text {porewater }}$ represents the porewater COC concentrations. The sum of the first six sequential extraction steps is assumed in these calculations to be representative of the likely desorbable or available fraction. From the point-of-view of modeling groundwater risk, it is more conservative (providing lower $\mathrm{K}_{\mathrm{d}}$ values) if lower soil COC concentrations are assumed. Thus, it is much more conservative with respect to modeling risk for the groundwater pathway to assume the sum of Fractions $1-6$ accounts for the sorbed fraction, and not the total digestible concentration.

The $\mathrm{K}_{\text {davail }}$ values of each of the sediments is presented in Table 38 Each COC has a wide range of $K_{\text {davail }}$ values: Be $\mathrm{K}_{\mathrm{d}}$ values ranged from 4 to $93,000 \mathrm{~mL} / \mathrm{g}, \mathrm{Ni} \mathrm{K}_{\mathrm{d}}$ values ranged from 0.19 to $6,500 \mathrm{~mL} / \mathrm{g}, \mathrm{U} \mathrm{K}_{\mathrm{d}}$ values ranged from 20 to $3,400,000 \mathrm{~mL} / \mathrm{g}$, and $\mathrm{As} \mathrm{K}_{\mathrm{d}}$ values ranged from 16 to $5,200 \mathrm{~mL} / \mathrm{g}$. The overall median $\mathrm{K}_{\text {davail }}$ value for:

- Be was $1114 \mathrm{~mL} / \mathrm{g}$, Ni was $105 \mathrm{~mL} / \mathrm{g}$, U was 3100, and As was $742 \mathrm{~mL} / \mathrm{g}$.

- For the Upland sediments (the DAB and DCP samples), the median $\mathrm{K}_{\text {davail }}$ value for: Be was $212 \mathrm{~mL} / \mathrm{g}$, Ni was $67 \mathrm{~mL} / \mathrm{g}$, U was 29,000, and As was $395 \mathrm{~mL} / \mathrm{g}$.

- For the Wetland sediments ( $\mathrm{D}-\mathrm{K}$ samples), the median $\mathrm{K}_{\text {davail }}$ value for: Be was $1900 \mathrm{~mL} / \mathrm{g}$, Ni was $1700 \mathrm{~mL} / \mathrm{g}$, $\mathrm{U}$ is 3100 , and As is $20,000 \mathrm{~mL} / \mathrm{g}$.

Median $\mathrm{K}_{\mathrm{d}}$ values in the Wetland were greater than in the Upland sediments for $\mathrm{Be}, \mathrm{Ni}$, and As: $\mathrm{U} \mathrm{K}_{\mathrm{d}}$ values were greater in the Upland sediments. The greater $\mathrm{Be}, \mathrm{Ni}$ and $\mathrm{As} \mathrm{K}_{\mathrm{d}}$ values in the Wetland sediments can likely be attributed to the generally greater cation exchange capacity (due to greater organic carbon contents) in the Wetland than the Upland sediments. The cause for the greater $U \mathrm{~K}_{\mathrm{d}}$ values in the Upland sediments is not known. 
Simple correlation coefficients were calculated separately with the Upland and the Wetland sediment data presented in Table 38 (Table 39). For the Upland sediments, $\mathrm{pH}$ was significantly correlated to Be and $\mathrm{Ni} \mathrm{K}_{\mathrm{d}}$ values (Figure 42 and Figure 43). Both these COC exist as cations in SRS groundwater, and therefore the positive correlation with $\mathrm{pH}$ is expected. In the Wetland sediments, As had a significant inverse correlation with $\mathrm{pH}$. Again, this is expected because As is an anion and its tendency to sorb to surfaces increases under acidic conditions.

In the Wetland samples the correlation between $\mathrm{Be}$ and $\mathrm{Ni}$ was highly significant. The fact that $\mathrm{U} \mathrm{K}_{\mathrm{d}}$ values were generally negatively (inversely) correlated Be and $\mathrm{Ni} \mathrm{K}_{\mathrm{d}}$ values, but positively (directly) correlated to As $\mathrm{K}_{\mathrm{d}}$ values suggests that the $\mathrm{U}$ existed primarily as an anion. Additional indirect evidence supporting the contention that $\mathrm{U}$ existed primarily as an anion is that it was significantly correlated to sulfate concentrations in the Upland and Wetland sediments.

For many of the DCP locations, the actual $\mathrm{K}_{\mathrm{d}}$ should be larger that the calculated value due to the porewater concentration falling below the limit of detection.

$\mathrm{pH}$ was significantly correlated $(\mathrm{p} \leq 0.01 ; \mathrm{df}=22)$ to Be (Figure 42$)$ and Ni (Figure 43) Ni $\mathrm{K}_{\text {davail. }}$. With increasing $\mathrm{pH}$ there is a corresponding increase in beryllium and nickel $\mathrm{K}_{\text {davail }}$. This can be attributed in part to the increased cation exchange capacity and increased Fe-oxyhydroxide concentrations in the sediment expected with increased $\mathrm{pH}$.

Likewise for uranium at upland locations with $\mathrm{pH}$ less than $6, \mathrm{pH}$ is correlated with $\mathrm{K}_{\text {davail }}$ $\left(\mathrm{R}^{2}=0.7 ; \mathrm{p} \leq 0.01 ; \mathrm{df}=22\right)$ (Figure 44). At these lower $\mathrm{pH}$ levels, aqueous $\mathrm{U}$ exists primarily as cationic species $\left(\mathrm{UO}_{2}{ }^{2+}, \mathrm{UO}_{2} \mathrm{OH}^{+}\right)$and as such they would tend to sorb more as the cation exchange capacity of the sediment increases with $\mathrm{pH}$. As mentioned earlier, the increased cation exchange capacity can be attributed to changing surface charge of soil minerals and also to the increased formation of Fe-oxyhydroxides. For the wetland samples and for the upland DAB samples with $\mathrm{pH}$ levels greater than $6, \mathrm{pH}$ is not well correlated with $\mathrm{K}_{\text {davail }}$, although these values are quite high $(>650 \mathrm{~mL} / \mathrm{g})$ regardless. The sample taken from the 488-D (DAB 86; ash basin) had the lowest $\mathrm{U} \mathrm{K}_{\text {davail. }}$. This is likely attributable to the relatively high $\mathrm{pH}$ of this sample, $\mathrm{pH} 7.50$, at which essentially all dissolved $\mathrm{U}$ likely exists as neutral or anionic species, such as $\mathrm{UO}_{2} \mathrm{CO}_{3}{ }^{0}(\mathrm{aq}), \mathrm{UO}_{2}(\mathrm{OH})_{2}{ }^{0}(\mathrm{aq}),\left(\mathrm{UO}_{2}\right)_{2} \mathrm{CO}_{3}(\mathrm{OH})_{3}{ }^{-}$, and $\mathrm{UO}_{2}\left(\mathrm{CO}_{3}\right)_{2}{ }^{2-}$ (Krupka et al., 1999) (Figure 36). Neutral and anionic species are not expected to sorb strongly to sediments (Sposito, 1989). 
Table 38. Summary of $K_{\text {davail }}$ Based on Equation 1; Sum of Sequential Extraction Steps $1-6$ and Porewater COC Concentrations

\begin{tabular}{|c|c|c|c|c|c|c|}
\hline $\begin{array}{c}\text { Sample } \\
\text { Soil } \\
\end{array}$ & $\begin{array}{c}\text { Porewater } \\
\text { pH } \\
\end{array}$ & $\begin{array}{c}\text { Porewater } \\
\text { Sulfate } \\
(\mathrm{mg} / \mathrm{L}) \\
\end{array}$ & $\begin{array}{l}\mathrm{Be} \\
\mathrm{Kd}_{\text {avail }} \\
(\mathrm{mL} / \mathrm{g}) \\
\end{array}$ & $\begin{array}{l}\mathrm{Ni} \\
\mathrm{Kd}_{\text {avail }} \\
(\mathrm{mL} / \mathrm{g}) \\
\end{array}$ & $\begin{array}{l}\mathbf{U} \\
\mathbf{K}_{\text {davail }} \\
(\mathbf{m L} / \mathbf{g}) \\
\end{array}$ & $\begin{array}{l}\text { As } \\
\mathbf{K}_{\text {davail }} \\
(\mathbf{m L} / \mathbf{g}) \\
\end{array}$ \\
\hline DAB92 4-6 & 3.18 & 1866.2 & 8 & 0.19 & 282 & 186 \\
\hline DAB92 21-23 & 4.12 & 202.1 & 5 & 49 & $2.1 \mathrm{E}+03$ & $8.8 \mathrm{E}+03$ \\
\hline DAB85 32-33 & 5.18 & 864.2 & 212 & 81 & $8.2 \mathrm{E}+05$ & $3.0 \mathrm{E}+04$ \\
\hline DAB85 45 & 7.25 & 81.1 & $2.6 \mathrm{E}+03^{*}$ & & $1.4 \mathrm{E}+05^{*}$ & $179 *$ \\
\hline DAB81 30-35 & 4.80 & 24.4 & $786^{*}$ & & $3.4 \mathrm{E}+06^{*}$ & $1.1 \mathrm{E}+04 *$ \\
\hline DAB81 45 & 4.26 & 1315.2 & 6 & 27 & $2.9 \mathrm{E}+04$ & 754 \\
\hline DAB81 50 & 7.98 & 422.1 & $9.3 \mathrm{E}+04 *$ & & $655^{*}$ & $395^{*}$ \\
\hline DAB87 33 & 3.81 & 576.7 & $17 *$ & & $97 *$ & $131 *$ \\
\hline DAB87 38 & 3.76 & 1296.7 & 4 & 74 & 20 & 16 \\
\hline DAB87 53 & 4.93 & 1347.9 & $137 *$ & & $3.9 \mathrm{E}+05^{*}$ & $306^{*}$ \\
\hline DAB84 20 & 5.06 & 108.1 & $15^{*}$ & & $1.1 \mathrm{E}+05^{*}$ & $151 *$ \\
\hline DAB84 28 & 4.56 & 907.2 & 5 & 118 & 441 & 38 \\
\hline DAB84 38 & 5.24 & 47.1 & $5.0 \mathrm{E}+03 *$ & & $5.2 \mathrm{E}+06^{*}$ & $6.9 \mathrm{E}+03 *$ \\
\hline DAB83 32 & 6.61 & 310.1 & $928^{*}$ & & $2.0 \mathrm{E}+03^{*}$ & $5.2 \mathrm{E}+03 *$ \\
\hline DAB83 38 & 7.50 & 20.9 & $2.1 \mathrm{E}+04 *$ & & $3.3 \mathrm{E}+06^{*}$ & $389^{*}$ \\
\hline DAB83 42 & 7.87 & 63.6 & $1.5 \mathrm{E}+04$ & $2.8 \mathrm{E}+04$ & $9.1 \mathrm{E}+04$ & 345 \\
\hline DAB86 12-16 & 7.50 & 1785.0 & $4.6 \mathrm{E}+04$ & $3.1 \mathrm{E}+03$ & 14 & $2.1 \mathrm{E}+03$ \\
\hline DCP211/19-20 & 4.89 & 780.0 & & 26 & & $>398$ \\
\hline DCP211/35-36 & 4.69 & 1476.0 & & 5 & & $>462$ \\
\hline DCP168/20-22 & 5.61 & 62.4 & & $>347$ & & $2.3 \mathrm{E}+03$ \\
\hline DCP168/31-33 & 6.31 & 7.6 & & $>59$ & & 742 \\
\hline DCP170/14-16 & 4.59 & 98.1 & & $>14$ & & 26 \\
\hline DCP170/20-22 & 5.83 & 97.5 & & $>92$ & & 68 \\
\hline D-2 & 5.49 & 5.5 & $8.6 \mathrm{E}+03$ & $6.5 \mathrm{E}+03$ & 153 & $8.8 \mathrm{E}+03$ \\
\hline D-4 & 5.94 & 9.5 & $1.3 \mathrm{E}+03$ & $1.7 \mathrm{E}+03$ & 403 & $7.8 \mathrm{E}+03$ \\
\hline G-10 & 6.12 & 72.2 & $4.6 \mathrm{E}+03$ & $2.7 \mathrm{E}+03$ & $1.5 \mathrm{E}+03$ & $6.1 \mathrm{E}+03$ \\
\hline H-5 & 6.02 & 174.5 & $1.3 \mathrm{E}+03$ & 906 & $3.1 \mathrm{E}+03$ & $2.0 \mathrm{E}+04$ \\
\hline$J-6$ & 5.13 & 114.8 & $1.9 \mathrm{E}+03$ & 284 & $3.8 \mathrm{E}+03$ & $2.9 \mathrm{E}+04$ \\
\hline K-4 & 4.52 & 101.5 & $1.1 \mathrm{E}+03$ & 364 & $4.6 \mathrm{E}+03$ & $3.3 \mathrm{E}+04$ \\
\hline
\end{tabular}


Table 39. Correlation Coefficients for $K_{\text {davail, }} \mathbf{p H}$, and Sulfate Values Presented in Table 38

\begin{tabular}{llllll}
\hline \multicolumn{1}{l}{ Upland data only } & \multicolumn{1}{c}{$\mathbf{p H}$} & \multicolumn{1}{c}{ Sulfate } & \multicolumn{1}{c}{ Be $\mathbf{K}_{\mathbf{d}}$} & $\mathbf{N i ~ K}_{\mathbf{d}}$ & $\mathbf{U} \mathbf{K}_{\mathbf{d}}$ \\
Sulfate & -0.374 & & & & \\
$\mathrm{Be} \mathrm{K}$ & $0.648^{* *}$ & 0.007 & & & \\
$\mathrm{Ni} \mathrm{K}_{\mathrm{d}}$ & $0.636^{* *}$ & -0.256 & 0.287 & & \\
$\mathrm{U} \mathrm{K}_{\mathrm{d}}$ & 0.066 & $-0.442^{*}$ & -0.076 & -0.056 & \\
As K & -0.083 & -0.060 & -0.179 & -0.110 & 0.243 \\
\hline
\end{tabular}

* Significant correlation at $\mathrm{p}<0.05$ for 22 degrees of freedom (df) is 0.423

** Significant correlation is significant at $\mathrm{p}<0.01$ for 22 degrees of freedom (df) is 0.537 .

\begin{tabular}{|c|c|c|c|c|c|}
\hline \multicolumn{6}{|c|}{ Wetland data only } \\
\hline & pH & Sulfate & Be $K_{d}$ & $\mathrm{Ni} K_{d}$ & $\mathbf{U} \mathbf{K}_{\mathbf{d}}$ \\
\hline Sulfate & -0.098 & & & & \\
\hline $\mathrm{Be} \mathrm{K}_{\mathrm{d}}$ & 0.166 & -0.566 & & & \\
\hline $\mathrm{Ni} \mathrm{K}$ & 0.261 & -0.677 & $0.960 * *$ & & \\
\hline $\mathrm{U} \mathrm{K}_{\mathrm{d}}$ & -0.643 & $0.795^{*}$ & -0.634 & $-0.777^{*}$ & \\
\hline As $K_{d}$ & $-0.810^{*}$ & 0.631 & -0.558 & -0.672 & $0.941 * *$ \\
\hline
\end{tabular}

* Significant correlation at $\mathrm{p}<0.05$ for 5 degrees of freedom is 0.755 .

** Significant correlation at $\mathrm{p}<0.05$ for 5 degrees of freedom is 0.875 .

Arsenic exhibited a broad range of $\mathrm{K}_{\mathrm{d}}$ values (16 to $3 \mathrm{E}+04 \mathrm{~mL} / \mathrm{g}$; Figure 45 ). Maximum $\mathrm{K}_{\mathrm{d}}$ values observed were in the $\mathrm{pH}$ range between 4 and 6 . This observation is consistent with the sorption of As (III) to metal oxides/hydroxides. A sorption maximum around 7 for As III on hydrous ferric oxide has been reported, whereas As $\mathrm{V}$ has a sorption maximum around $\mathrm{pH}$ 4. As $\mathrm{pH}$ increased above 6 , lower $\mathrm{K}_{\mathrm{d}}$ were observed likely due to desorption of arsenic, an anion, with increasing $\mathrm{pH}$. The highest $\mathrm{K}_{\mathrm{d}}$ values were associated with the wetland samples. The measurement of high $\mathrm{K}_{\mathrm{d}}$ values for wetland samples is consistent both with similar $\mathrm{K}_{\text {davail }}$ values for the ash sample (DAB 86) and also with expectations that the wetlands should favor attenuation of arsenic due to increased biomass and less oxidizing conditions. Arsenic is strongly bound by soil organic matter (Cullen and Reimer, 1989). The lowest $\mathrm{K}_{\mathrm{d}} \mathrm{S}$ values were associated with the lowest $\mathrm{pH}$ locations in the vicinity of the DCPRB plume.

In summary, Be $\mathrm{Ni}$, and $\mathrm{U} \mathrm{K}_{\mathrm{d}}$ values followed well established trends with $\mathrm{pH}$. Because $\mathrm{pH}$ is an easy and routine parameter measured at the SRS, it will provide an excellent ancillary parameter for predicting the $\mathrm{K}_{\mathrm{d}}$ values for these COCs. In the case of $\mathrm{Be}$ and $\mathrm{Ni}, \mathrm{pH}$ across the entire range evaluated, $\mathrm{pH} 3$ to 8, was an excellent predictor of $\mathrm{K}_{\mathrm{d}}$ values. For $\mathrm{U}$, $\mathrm{pH}$ was a good predictor of $\mathrm{K}_{\mathrm{d}}$ values between $\mathrm{pH} 3$ and 5 . These observations are readily interpreted in light of geochemical sorption mechanisms based on expected metal speciation. 


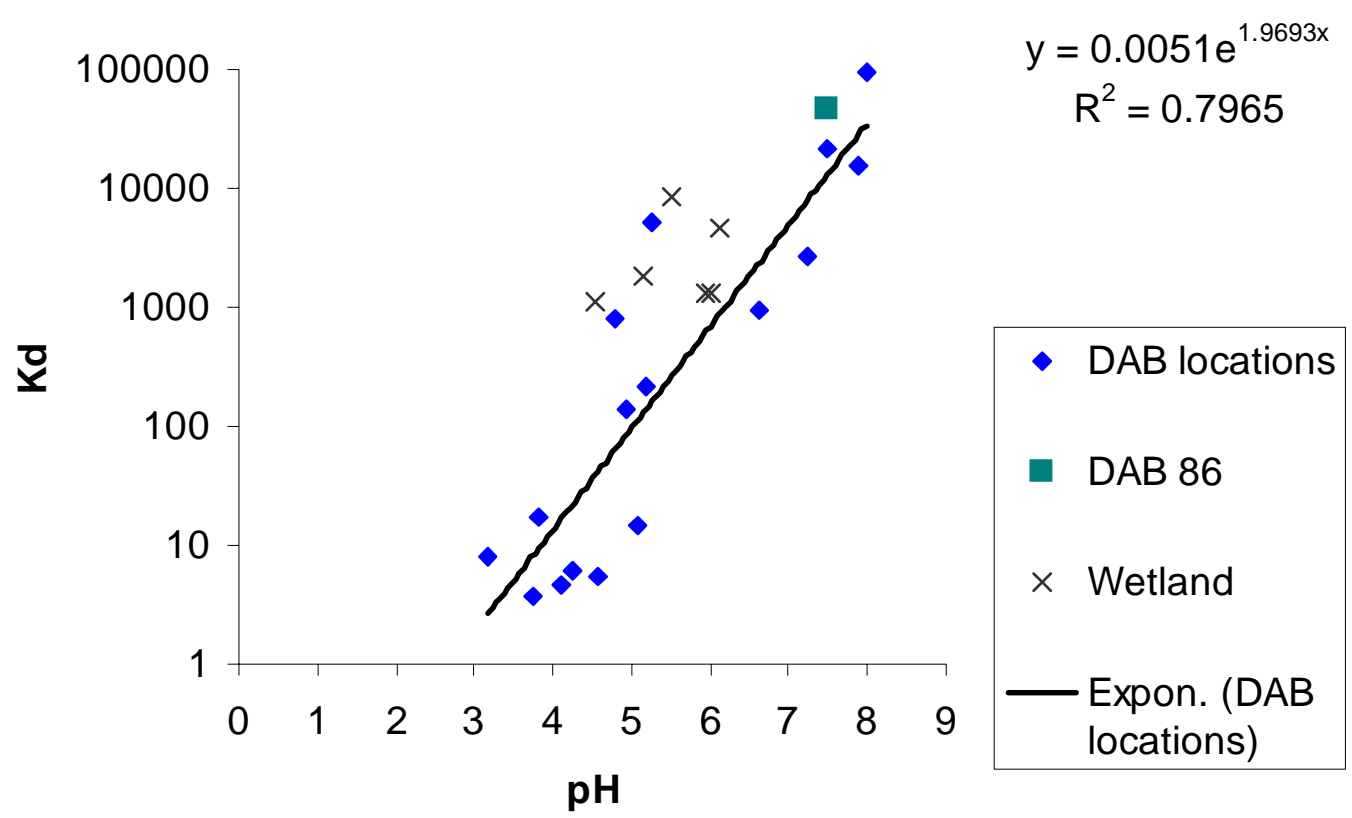

Figure 42. Beryllium Distribution Coefficients $(\mathrm{mL} / \mathrm{g}$; Based on Available Beryllium Sediment Concentrations) versus pH (log scale)

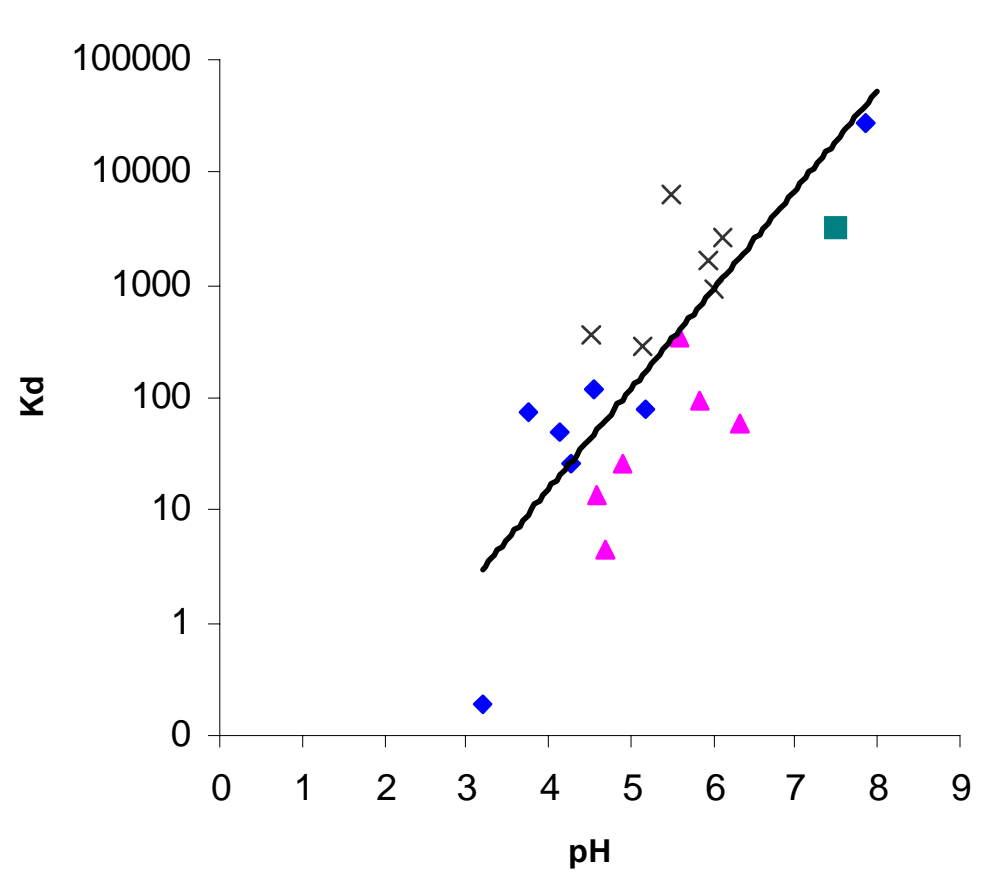

$$
\begin{gathered}
y=0.0045 e^{2.0376 x} \\
R^{2}=0.8072
\end{gathered}
$$

- DAB locations

DAB 86

$\times$ Wetland

$\triangle$ DCP locations

Expon. (DAB locations)

Figure 43. Nickel Distribution Coefficients (mL/g; Based on Available Nickel Sediment Concentrations) versus $\mathrm{pH}(\log$ scale) 
WSRC-TR-2004-00124, REVISION 0

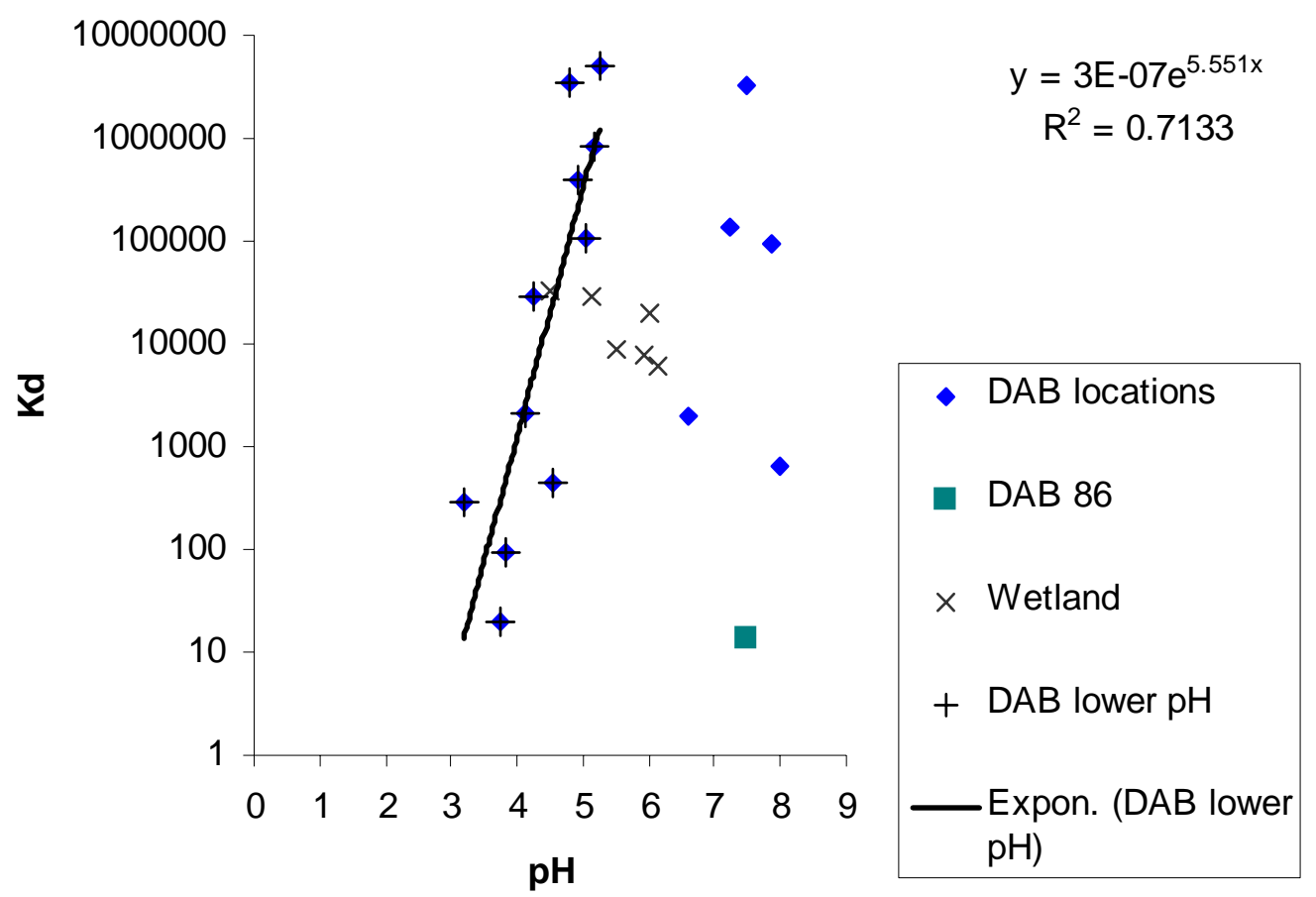

Figure 44. Uranium Distribution Coefficients $(\mathrm{mL} / \mathrm{g}$; Based on Available Uranium Sediment Concentrations) versus pH (log scale)

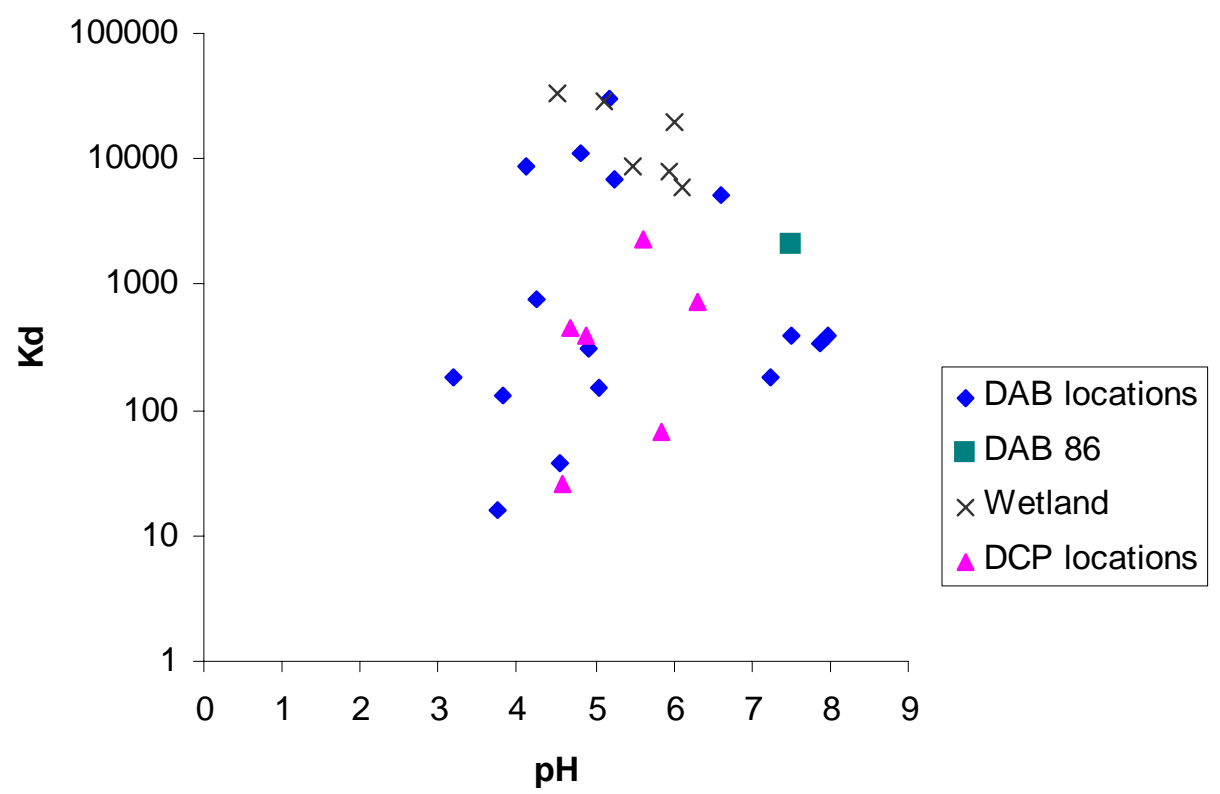

Figure 45. Arsenic Distribution Coefficients ( $\mathrm{mL} / \mathrm{g}$; Based on Available Arsenic Sediment Concentrations) versus pH for all locations (log scale) 


\subsection{MICROBIOLOGY}

Two sections of the contaminant plume were evaluated for biological and geochemical activity related to MNA. One section was under the ash basin, and sediment samples were taken at twelve different sites and depths down to 42 feet (estimated to be in the contaminant plume emanating from the DCPRB). The second section was in the D-Area wetland where shallow sediment cores were taken in four locations that were thought to be part of the DCPRB plume outcrop area, an area north of location H5 (Figure 2). Two additional wetland sites were on the distal fringe of the wetland and were thought to be unimpacted by either the ash discharged from the DAB or the DCPRB plume. Evaluation of the wetland area soil microbiology is complicated by the fact that an undetermined amount of ash was surficially deposited on this site due to past disposal practices. Much of the ash is still present in some wetland locations yielding ash layers of up to $1 \mathrm{~m}$ in depth below a shallow soil covering. Therefore some sections of the wetland are presumed to be impacted both by outcrop of the contaminant plume as well as ash deposited at the surface. The impact of these two contaminant sources was demonstrated through the use of discriminant analysis by region analysis of Biolog ${ }^{\circledR}$ data (Section 5.2). This data indicated that the two sample locations nearest the ash and contaminant plume outcropping area, K-4 and H-5, had bacteria structures more similar to those in impacted upland soils than wetland soils. Comparisons of the two sections, although difficult, were made in this report based on the assumed groundwater connectivity based on site hydrology characterization.

\subsubsection{Microbial densities}

Microbial densities (both total and viable) varied greatly with depth and site (Table 27 and Table 28, Figure 16 and Figure 17). In some sediments, no or very few viable aerobic cultures (plate counts) were detected (DAB 87 38) and yet the total counts were similar to other sites (Table 27). This lack of CFUs could be due to several reasons, including the fact that some bacteria require more specialized media, longer incubation times, or other culture conditions.

Since the media used was specific for aerobic culturable bacteria, few fungal colonies were seen on the culture media. D-Area fungi relative to metal removal could be examined in future studies. Several weeks after the initial sampling and plating, cultures from DAB 92 were replated to see if Stenotrophomonas maltophilia colonies were present in those sediment samples. Again, S. maltophilia is involved in a number of reactions that enhance contaminant sorption to sediments, including metal reduction (Se), production of insoluble metal precipitates, raising sediment $\mathrm{pH}$, and desulfurization (discussed in detail in Section 6.4.3). The DAB 92 plates contained primarily fungal colonies and little $S$. maltophilia was culturable. The reason for these finding could be that fungal spores were present in the porewater but initially repressed in the media. Fungal populations likely are present in these sediments and could be contributing to MNA of the contaminants. This would take specific culture techniques to quantify the fungal relative densities and activity. 
Limited numbers of sulfate reducing bacteria were detected in the Upland samples. Since many sulfate reducing populations are sensitive to oxygen exposure, it is possible that some were not detected because of extensive oxygen exposure during the sampling process. Sulfate reducers can play an important role in the MNA of sites contaminated with metals. An ongoing project (Phifer et al. 2003) in 488-D (the D-Area Ash Basin) shows the rise in sulfate reducers corresponding to the precipitation of metal sulfides in groundwater. These results were the result of biostimulation in the subsurface. The sulfate reducing bacteria use sulfate as an electron acceptor resulting in the production of sulfide and the subsequent in situ precipitation of metal sulfides.

Few acid-producing bacteria were found in the uplands in this study (Table 27). This is most likely due to nutrient limitations as these organisms prefer robust fermentative conditions. These results are promising for MNA in that it is preferred that the $\mathrm{pH}$ at the site go up rather than down for purposes of metal removal.

\subsubsection{Ecofunctional Enzymes}

Limited Biolog ${ }^{\circledR}$ substrate utilization was demonstrated in DAB 8420 feet (located downgradient of 488-D, Figure 1) while none was seen in DAB 8738 feet (located beneath the 488-D). These could be due to strictly anaerobic or viable but non-culturable bacteria at these sites. It may be possible to attribute community-level metabolic diversity to a population that becomes active only under controlled conditions; whereas under field conditions the same population may be stressed and/or inactive.

The Biolog ${ }^{\circledR}$ substrate utilization patterns measured aerobic ecofunctional enzyme activity in D-Area porewater demonstrating that the subsurface communities contained a diverse microbial population. Although significant differences in substrate utilization were measured in sediments tested, only some of the substrate types were significantly different in all of the sites. This suggests that these measured differences may reflect the normal variability inherent from sample to sample, rather than a definite spatial pattern in metabolic potential. For example, the carbon substrate utilization profiles detected a significant difference in metabolic activities with depth in upland sediments (Figure 18). Wetland sediments were taken at all locations at only one depth and showed significant spatial differences (Figure 19).

The principal component analysis of Biolog ${ }^{\circledR}$ data did separate microbial communities based on location within the contaminant plume. Differences between depths of sediment samples make comparisons of uplands vs. wetlands difficult. This indicates that either the range of contaminant concentrations (ppb-low ppm) chosen for this study was too narrow to influence metabolic activity, or that the variability inherent in natural communities over such a heterogeneous physical area is so great that activity towards 95 substrates could not be used to successfully separate the communities. In addition, the usefulness of Biolog ${ }^{\circledR}$ information in microbial ecological studies is further limited by the potential of populations to thrive within a substrate containing well under controlled laboratory conditions. 
WSRC-TR-2004-00124, REVISION 0

If there is an advantage of Biolog ${ }^{\circledR}$ over direct cell enumeration to characterize microbial ecology at the community level, it is the capability of Biolog ${ }^{\circledR}$ to describe the potential rate of metabolic function and activity towards a wide range of substrates (Bochner and Savageau 1977, Garland and Mills 1991, Gordon et al. 1993, Guckert et al., 1996) With the proper controls, this database can potentially describe the activity and function of entire microbial communities, as opposed to merely indicating a 'snap shot' of total cell densities or of a specific cell type. Future MNA studies using the Biolog ${ }^{\circledR}$ community-level analysis should try to measure the percentage of the community that is responsible for a majority of specific activity, as well as addressing the ecological relevance of the substrates to the environment being examined.

\subsubsection{Identification of Cultured Isolates}

Stenotrophomonas maltophilia, the predominant bacterial type isolated from DAB 83 and DAB 84, is a commonly found aerobic environmental gram-negative bacillus.

Stenotrophomonas maltophilia has been isolated from aquatic environments, from soils, and from vegetation (Bollet et al., 1995) and is becoming increasingly prevalent in infections in immuno compromised patients, particularly those with cystic fibrosis (Denton et al. 2000). Stenotrophomonas maltophilia, isolated from uranium mining wastes, has been proven capable of forming uranium complexes by binding processes (Merroun et al., 2002). In addition, Stenotrophomonas maltophilia, isolated from a seleniferous agricultural evaporation pond sediment in California was capable of reducing selenium oxyanions (selenate and selenite) to elemental selenium at oxygen levels less than $0.1 \mathrm{mg} / \mathrm{L}$ and is being investigated for bioremediation purposes to treat seleniferous wastewater (Dungan et al., 2003). There has been evidence of the presence of Stenotrophomonas maltophilia in petroleum contaminated soils containing dibenzothiophene (DBT) and in sulfurous oil contaminated sediments. Gene amplification studies of the genes that encode enzymes involved the desulphurization of these compounds has associated Stenotrophomonas maltophilia with this process (Duarte et al., 2001). Stenotrophomonas maltophilia's potential ability for metal reduction, insoluble metal complex formation, and desulfurization, along with its predominance in these SRS sediment samples, may be significant factors in the monitored natural attenuation of this SRS site. In this study, this bacterium was only identified and found to be predominant in DAB 83 and 84 . Isolated bacteria including Stenotrophomonas maltophilia and Enterobacter have the ability to raise $\mathrm{pH}$ as demonstrated here and can reduce metal availability that can enhance MNA of metals.

Future work would examine specific metal and sulfur biotransformation at this site in relation to Stenotrophomonas maltophilia and Enterobacter sp. In addition, molecular techniques could be applied to determine the distribution and activity of these organisms at the site. 
WSRC-TR-2004-00124, REVISION 0

\subsection{SUMMARY AND CONCLUSIONS}

Low aqueous concentrations of metals and large distribution coefficients $\left(\mathrm{K}_{\mathrm{d}}\right.$ values) are strong indicators that natural attenuation is occurring to a significant degree at D-Area. For the plume emanating from the vicinity of the D-Area Coal Pile (DCP) and D-Area Coal Pile Runoff Basin (DCPRB) significant attenuation of all metal COCs evaluated is occurring in groundwater relative to modeled dilution effects. This conclusion was further supported in a separate task to this project in which it was shown that DCPRB sediment had an extraordinarily high capacity to sorb several contaminants (Kaplan and Knox, 2004). The magnitude and relative contributions to this attenuation from geochemical and biological effects were evaluated in terms of $\mathrm{pH}$, redox, sulfate, porewater COC concentrations, and \% metal in soil available for transport, in situ transport factors, and biological indicators.

Large distribution coefficients demonstrate the high attenuation capacity of the D-Area soil for the four COCs in this study (Be, Ni, U, As). Distribution coefficients for each of the COCs followed well-established geochemical trends for $\mathrm{pH}$ dependent sorption mechanisms. A number of operationally defined methods were evaluated to better define the fraction of COCs likely available for transport in a range of D-Area soils in order to develop a more appropriate definition of the sources of COCs in these soils as well as to better define the distribution coefficients or in situ $\mathrm{K}_{\mathrm{d}}$ values used to model the transport of these sources.

MNA at D-Area can be interpreted and quantified based on geochemical mechanisms. The large buffering capacity of the upland soils in D-Area for the acid emanating from the DCPRB accounts for attenuation of acidity. This buffering capacity is attributed to the metal oxides/hydroxides present in D-Area soils. Attenuation of acidity leads to precipitation of dissolved metal oxides/hydroxides (Al, Fe, Mn) that further increases the sorption capacity (as evidenced by high cation exchange capacities) of these soils for trace metal COCs. This effect is quantified in terms of the $\mathrm{pH}$ dependence of the distribution coefficients $\left(\mathrm{K}_{\mathrm{d}}\right)$.

The microbiological community evaluation revealed the presence of microorganisms at all tested locations including low $\mathrm{pH}$, high sulfate plume regimes as well as in the wetland area (both nonimpacted sites as well as sites impacted by ash sluice). Aerobic functional and structural diversity of microbial communities were identified from most D-Area sediment cores. Microbial diversity and concentration increased with distance from the D-Area Coal Pile and D-Area Coal Pile Runoff Basin.

Both aerobic (Stenotrophomonas maltophilia) and anaerobic sulfate reducing bacteria (SRBs) microbial species capable of desulfurization and metal reduction were found at the site indicating potential contribution of microbial community to natural attenuation. The isolation and predominance of Stenotrophomonas maltophilia from upland locations and its potential for aerobic metal biotransformation and complex formation may be strong indicators of aerobic metal interactions occurring in the upland areas. Sulfate reducers were at low concentration in the uplands soils. 
Microbial evidence also indicates natural contaminant attenuation potential in the wetland/upland interface, but could not be quantified from these studies. This is evidenced by decreasing aqueous sulfate concentrations and increased bacterial counts as the plume moves further into the wetlands. Distinct differences in bacterial counts and structure were measured between the upland and wetland locations. The greater bacterial counts in the wetlands may contribute to natural attenuation through biosorption. Comparison of wetland to upland samples showed a commonality between substrate utilization for the wetland samples closest to the discharge area and upland samples. Those wetland locations most impacted by the contaminants, K-4, J-6, and H-5, had low EFE as compared to those sites further from the source, D-4, D-2, and G-10 (Figure 23).

Because geochemical and microbiological effects on the attenuation of inorganics are necessarily related through numerous relationships such as redox, it is difficult to isolate the individual contribution of each in the natural environment. Based on the lower abundance of organisms in the areas of highest impact (low pH, high sulfate), it is likely that geochemical effects such as sorption and precipitation dominate here. $\mathrm{pH}$ was found to be the most significant predictor of attenuation as evidenced by porewater concentrations, $\%$ availability of COC in soil, and distribution coefficients. As the COC plume approaches higher $\mathrm{pH}$ regimes in the wetland areas the microbial community is more active and likely contributes to a higher degree in the attenuation of COCs. 
WSRC-TR-2004-00124, REVISION 0

\subsection{RECOMMENDATIONS}

Based on the findings in this report, the following recommendations are made.

1. It is recommended that MNA be invoked at the DEXOU. There is a preponderance of evidence documented in this report supporting this approach, including porewater COC concentration trends, soil sorption data, and soil microbial characterization data.

2. To account for many of the natural attenuating processes occurring at the site, it is recommended that future risk/groundwater modeling use the $\mathrm{pH}$-dependent $\mathrm{K}_{\mathrm{d}}$ values reported here. This is consistent with conceptual hydrogeochemical model of $\mathrm{pH}-$ dependent transport factors documented in Brewer and Sechor (2002). These $\mathrm{pH}$ dependent $\mathrm{K}_{\mathrm{d}}$ values should be the site-specific values generated in this study based on COC desorption, the rate-limiting reaction, as compared to (ad)sorption. Furthermore, these values are technically defensible and they greatly reduce the uncertainty associated with literature-derived or theoretically-derived $\mathrm{K}_{\mathrm{d}}$ values. Additionally, $\mathrm{pH}$ is recommended as a "master variable" for determining $\mathrm{K}_{\mathrm{d}}$ values at the site because: 1) it was highly correlated to several groundwater secondary parameters that influence COC sorption in this system (e.g., Eh, sulfate, and cation exchange capacity) and, therefore, these $K_{d}$ values to some degree account for variations in these secondary parameters, 2 ) it is easy to measure, and 3 ) there is a large amount of historical $\mathrm{pH}$ data available for the site. More sophisticated sorption models were evaluated. However, the current state-of-the-art does not permit for a quantitative model for metals attenuation by microbial processes. Therefore, the implementation of a more sophisticated model for either biotic or geochemical processes is not warranted at this time.

3. It is recommended that additional natural attenuation of $\mathrm{COC}$ be accounted for in future modeling by including only the "available fraction" of COC in the source term. By doing so, the mass of COC available for entering into the mobile aqueous phase may be decreased by as much as $90 \%$. The "nonavailable fraction" is that fraction of the total COC pool that is strongly bound by the source material.

4. If MNA were to be implemented, a monitoring network based on existing wells and sampling strategy will need to be developed. It is recommended that this sampling strategy include: $\mathrm{pH}$, Eh, organic carbon content, chemical and biological oxygen demand, aqueous COC concentrations on a relatively frequent basis and, on a less frequent basis available soil concentrations and microbial densities and activities. 
5. Although there is a high degree of certainty for the effectiveness of MNA of inorganics at the D-Area, the following are data gaps that should be considered:

a. Work is currently being conducted on more active source remediation techniques (Phifer et al., 2003). If this approach, or an alternative approach, is implemented, then the effects of the source remediation on the attenuation processes at the site will need to be evaluated.

b. Although the majority of the attenuation of metals is currently going on in the upland areas of the waste site, the wetlands at the D-Area are a large, yet unaccounted for, attenuation capacity. The hydrologic flow through this system, however, is not well known and could be beneficial to the MNA approach, if additional attenuation capacity is necessary. This should include an evaluation of the flow fields in the wetlands under high- and low-water level conditions.

c. Characterization of wetland soils below the ash deposition in the wetland would provide additional validation of geochemical assumptions in previous modeling ( $\mathrm{pH}$ and sorption of COCs).

d. The work completed in this study is represents a "snapshot" in time. The temporal effects (e.g., seasonal changes) should be examined.

e. Transport of arsenic has not been modeled. Given that arsenic exists as anionic species and demonstrates a departure in sorption behavior from previously modeled cations $(\mathrm{Be}, \mathrm{Ni}, \mathrm{U})$. The reversibility of sorption of arsenic near/in the DCPRB should be evaluated as geochemical conditions are expected to change with source control.

6. Microcosm studies with D-Area groundwater could be used for estimations of metal attenuation rates. Experiments with D-Area microbial biomass could be designed to assess metal biosorption in the subsurface. Follow-up microbiological testing of ground water wells and wetlands can be used to validate long term MNA biological potential as well as seasonality of activity. Future work should be designed to characterize the behavior of these metals as related to redox, cationic vs. anionic sp., sediments vs. groundwater, alkaline vs. acidic conditions, and oxidative vs. reducing conditions. 
WSRC-TR-2004-00124, REVISION 0

\subsection{REFERENCES}

Alexander, M., 1994. Bioremediation and Bioremediation. Academic Press. NY.

Amonette, J. E., G. R., Holdren, K. M., Krupa, and C. W. Lindenmeier, 1994. Assessing the Environmental Availability of Uranium in Soils and Sediments. U. S. Nuclear Regulatory Commission Report, NUREG/CR-6232.

Anderson, M. A., Bertsch, P.M. Zelazny, L.W. 1993. "Multicomponent Transport Through Soil Subjected to Coal Pile Runoff Under Steady Saturated Flow" Trace Elements in Coal And Coal Combustion Residues, p. 137-163, Lewis Publishers., Boca Raton, FL.

Balkwill, D. L., 1989. Numbers, Diversity, and Morphological Characteristics of Aerobic Chemoheterotrophic Bacteria in Deep Subsurface Sediments from a Site in South Carolina. Geomicrobiol., J. 7:33-52.

Bollet, C., Davin-Regli, A., and DeMicco, P. 1995. A Simple Method for Selective Isolation of Stenotrophomonas maltophilia from Environmental Samples. Appl. Environ. Microbiol. 61: $1653-1654$.

Bochner, B. R., and M. A. Savageau. 1977. Generalized indicator plate of genetic, metabolic, and taxonomic studies with microorganisms. Appl. Environ. Microbiol.. 33:434-444.

Brewer, K. E., Sochor, C. S. 2002. Flow and Transport Modeling for D-Area Groundwater (U) WSRC-RP-2002-4166.

Cullen, W. R., and D. J. Reimer. 1989. Arsenic Speciation in the Environment. Chem. Rev. 89:713-764.

Denham, M., J. R. Kastner, K. M. Jerome, J. Santo Domingo, B. B. Looney, M. M. Franck. 1999. Effects of Fenton's Reagent on Aquifer Geochemistry and Microbiology at the A/M Area, Savannah River Site. WSRC-TR-99-00428. WSRC, Aiken, SC.

Denton, M, Kerr, KG. 2000. Microbiological and clinical aspects of infection associated with Stenotrophomonas maltophilia. Clin Microbiol Rev. 11: 57-80.

Duarte, G.F., Rosado, A., Seldin, L. deAraujo, W., van Elsas, J. 2001. Analysis of bacterial community structure in sulfurous-oil-containing soil and detection of species carrying dibenzothiophene desulfurization (dsz) genes. Appl. Environ. Microbiol. 67: 1052-1062.

Dungan, R., Yates, S., and Frankenberger, W. 2003. Transformations of selenate and selenite by Stenotrophomonas maltophilia isolated from a seleniferous agricultural drainage pond sediment Environmental Microbiology. 5: 287-295

Dzombak, D. and Morel, F.M.M.. 1990. Surface Complexation Modeling Hydrous Ferric Oxide. Wiley - Intersciences, NY. 
Fan, T.W.M., R. M. Higashi, and A. N. Lane. 2000. Chemical Characterization of a chelatortreated soil humate by solution state multinuclear two-dimension NMR with FITR and pyrolysis-GCMS. Environ. Sci. Technol. 34, 1636-1646,

Findley, M. Characterizing the Environmental Availability of Trace Metals in Soils at the Savannah River Site. MS Thesis, Clemson University (1998).

Fliermans, C. B., M. M. Franck, T. C. Hazen, and R. W. Gorden. 1997. Ecofunctional enzymes of microbial communities in ground water. FEMS Microbiol. Rev. 20:379-389.

Garland, J. L., and A. L. Mills. 1991. Classification and characterization of heterotrophic microbial communities on the basis of patterns of community-level sole-carbon-source utilization. Appl. Environ. Microbiol. 57: 2351-2359.

Gorden, R. W., T. C. Hazen, and C. B. Fliermans. 1993. Rapid screening for bacteria capable of degrading toxic organic compounds. J. Microbiol. Meth. 18:339-347.

Guckert, J.B., Carr, G.J., Johnson, T.D., Hamm, B.G., Davidson, D.H., and Y. Kumagai. 1996. Community analysis by Biolog: Curve integration for statistical analysis of activated sludge microbial habitats. J. Microbiol. Meth. 27:183-197.

Johnson, W. H. Sorption Models for U, Cs, and Cd on Upper Atlantic Coastal Plain Soils. $\mathrm{PhD}$ Thesis, Georgia Institute of Technology (1995).

Kaplan, D. I. 2003. Influence of Surface Charge of an Fe-oxide and an Organic Matter Dominated Soil on Iodide and Pertechnetate Sorption. Radiochim. Acta 91: 173-178.

Kaplan, D. I., and A. S. Knox. 2004. Monitored Natural Attenuation Under Varying Redox Conditions of Inorganic Contaminants from the D-Area Coal Pile Runoff Basin. WSRC, Aiken, SC

Krupka, K. M., D. I. Kaplan, G. Whelan, R. J. Serne, and S. V. Mattigod. 1999. Understanding Variation in Partition Coefficient, Kd, Values. Volume II: Review of Geochemistry and Available Kd Values, for Cadmium, Cesium, Chromium, Lead, Plutonium, Radon, Strontium, Thorium, Tritium (3H), and Uranium. EPA 402-R-99004A. Office of Air and Radiation, Office of Solid Waste and Emergency Response, U.S. Environmental Protection Agency, Washington, DC. (http://www.epa.gov/radiation/cleanup/partition.htm)

Looney, B. B., C. A. Eddy, M. Ramdeen, J. Pickett, V. Rogers, M. T. Scott, and P. A. Shirley. Geochemical and Physical Properties of Soils and Shallow Sediments at the Savannah River Site. WSRC-RP-90-1031. WSRC, Aiken, SC.

Lovely, D. R., and E. J. P. Phillips, Y. A. Gory, E. R. Landa. Uranium Precipitation by Shewanella putrefaciens. Nature 350: 413-416. 
Merroun, M., Henning, C., Rossbery, A., Funke, H., Selensak-Pobell, S., and T. Reich EXAFS investigations of uranium complexes formed by different bacteria isolated from uranium mining wastes. 2002. Biannual Report 2001/2002 Project Group ESRF- Beamline of the Forschungszentrum Rossendorf. 26-29.

Miller, W., D. Martens, L. Zelazny, 1986, "Effect of Sequence in Extraction of Trace Metals from Soils," Journal of the Soil Science Society of America 50:598-601.

Miller, W.P.; Miller, D. M. Commun. In Soil Sci. Plant Anal. 1987, 18(1) p. 1-15.

Odum, H.T. 2000. "Heavy Metals in the Environment: Using Wetlands for their Removal". Lewis Publishers, Boca Raton, FL.

Phifer, M.A., Sappington, F.C., Pemberton, B.E., and Nichols, R.L., 1996. "Interim Report D-Area Interceptor Well, DIW-1 Water Table Aquifer (U)." WSRC-TR-99-00017, September, Revision 0, Savannah River Site, Aiken SC 29808

Phifer, M. A., C. E. Turick, M. R. Millings. 2001. D-Area Coal Pile Runoff Basin Sulfate Reduction Literature Review and Feasibility Report. WSRC-TR-2001-00371, Rev. 0, WSRC, Aiken SC.

Phifer, M.A., C.E. Turick, M.R. Millings, F.C. Sappington, P.C. McKinsey, C.L. Bayer, and J.Ross. 2003. Sulfate reduction remediation of a metals plume through organic injection. Proceedings of the Seventh International In Situ and On-Site Bioremediation Symposium. Orlando, FL

Powell, K. R., Serkiz, S. M., Kaplan, D. I. Evaluation of the D-Area Expanded Operable Unit for Monitored Natural Attenuation of Inorganic Constituents of Concern: Interim Report WSRC-TR-2001-00574; 2001.

RCRA Facility Investigation/Remedial Investigation Work Plan Addendum for the D-area Expanded Operable Unit. USDOE report WSRC-RP-99-4067 Rev 0; 1999.

Rege, M.A., J.N. Petersen, D.L. Johnstone, C.E. Turick, D.R. Yonge, W. A. Apel. 1997. Bacterial reduction of hexavalent chromium by Enterobacter cloacae strain HO1 grown on sucrose. Biotechnol. Lett. 7:691-694.

Sposito, G. 1989. The Chemistry of Soils. Oxford Press, New York.

Stumm, W., and J. J. Morgan. 1969. Aquatic chemistry Chemical Equilibria and Rates in Natural Waters, $3^{\text {rd }}$ Edition, Wiley Intersciences Publishers, NY.

Sumner, M. E.; Miller, W.P. SSSA Book Series: 5. Methods of Soil Analysis, Part 3 Chemical Methods. p.1218-1220, 1996.

U.S. Environmental Protection Agency, Office of Solid Waste and Emergency Response, April 1999,Use of Monitored Natural Attenuation at Superfund, RCRA Corrective Action, and Underground Storage Tank Sites. OSWER Directive 9200.4-17P. 
Wilkie, J. A., and Hering, J. G. 1996. Adsorption of arsenic onto hydrous ferric oxide: Effects of Adsorbate/adsorbent ratios and co-occurring solutes. Colloids and Surfaces: Physiochemical and Engineering Aspects. 107: 97-100.

WSRC, 1991. "RCRA Facility Investigation/Remedial Investigation Work Plan for the 488D Ash Basin (U).” WSRC-RP-91-102, Rev. 0, Westinghouse Savannah River Company, Savannah River Site, Aiken, South Carolina

WSRC, 2000. "RCRA Facility Investigation/Remedial Investigation Work Plan Addendum for the D-Area Expanded Operable Unit (U)." WSRC-RP-99-4067, Rev. 0, Westinghouse Savannah River Company, Savannah River Site, Aiken, South Carolina

WSRC. RFI/RI with BRA for the TNX Outfall Delta. Lower, Discharge Gully and Swamp Operable Unit. WSRC-RP-98-4158, Rev. 0. Westinghouse Savannah River Company, Aiken, SC (1999)

WSRC. Treatability Study Work Plan for Monitored Natural Attenuation of Inorganic Contaminants. WSRC-RP-2002-4039, Rev 0. Westinghouse Savannah River Company, Aiken, SC (2002)

WSRC. Monitoring Work Plan for the D-Area Groundwater. WSRC-RP-2003-4250 Rev. 0. Westinghouse Savannah River Company, Aiken, SC (2003) 


\section{APPENDIX A. SEQUENTIAL EXTRACTION PROCEDURE}

\section{PURPOSE}

This procedure provides a method of identifying the trace metals and contaminates sorbed on to specific soil phases of a sample. Through selective chemistry, 8 different soil phases are identified and removed utilizing a sequential extraction procedure as outlined by Miller (1986). Samples extracted from this procedure can be analyzed by ICP-MS.

\section{REQUIRED EQUIPMENT/REAGENTS}

\section{A. Equipment}

1. 50-ml Oak Ridge centrifuge tubes

2. \#10 (2-mm) soil sieve

3. $0.45-\mu \mathrm{m}$ cellulose acetate or cellulose nitrate syringe filters

4. $0.45-\mu \mathrm{m}$ PTFE syringe filters

a. or \#42 Whatman filter paper and plastic filtering funnels

5. 30-ml syringes

6. 1-liter volumetric flasks

7. 1-liter reagent bottles

8. 125-ml glass reagent bottle

9. 50-ml plastic volumetric flasks

10. 30-ml sample bottles

11. 60-ml sample bottles

12. Hot acid digestion bombs with PTFE inserts

13. Disposable transfer pipettes

14. Test tube racks for 50-ml Oak Ridge tubes

15. Aluminum foil

16. Aluminum drying dishes

17. High-speed centrifuge

18. 25 -ml graduated cylinders

19. 50-ml graduated cylinders 


\section{B. Equipment}

1. Ultra-pure $72 \%$ nitric acid $\left[\mathrm{HNO}_{3}\right]$

2. Ultra-pure $48 \%$ hydrofluoric acid [HF]

3. Ultra-pure $36 \%$ hydrochloric acid $[\mathrm{HCl}]$

4. Hydroxylamine-hydrochloride $\left[\mathrm{NH}_{2} \mathrm{OH} \cdot \mathrm{HCl}\right]$

5. Ammonium oxalate $\left[\left(\mathrm{NH}_{4}\right)_{2} \mathrm{C}_{2} \mathrm{O}_{4} \bullet \mathrm{H}_{2} \mathrm{O}\right]$

6. Calcium nitrate $\left[\mathrm{Ca}\left(\mathrm{NO}_{3}\right)_{2} \bullet 4 \mathrm{H}_{2} \mathrm{O}\right]$

7. $99.5 \%$ Glacial acetic acid $\left[\mathrm{CH}_{3} \mathrm{COOH}\right]$

8. Sodium pyrophosphate $\left[\mathrm{NaP}_{2} \mathrm{O}_{7} \bullet 10 \mathrm{H}_{2} \mathrm{O}\right]$

9. Oxalic acid [C2H2O4] or oxalic acid dihydrate $\left[\mathrm{C} 2 \mathrm{H} 2 \mathrm{O} 4 \cdot 2 \mathrm{H}_{2} \mathrm{O}\right]$

10. Citric acid monohydrate $\left[\mathrm{C}_{6} \mathrm{H}_{8} \mathrm{O}_{7} \cdot \mathrm{H}_{2} \mathrm{O}\right.$ or $\left.\mathrm{HOC}\left(\mathrm{CH}_{2} \mathrm{CO}_{2} \mathrm{H}_{2}\right)_{2} \mathrm{CO}_{2} \mathrm{H}_{\bullet} \cdot \mathrm{H}_{2} \mathrm{O}\right]$

11. Sodium citrate dihydrate $\left[\mathrm{NaC}_{6} \mathrm{H}_{5} \mathrm{O}_{7} \cdot 2 \mathrm{H}_{2} \mathrm{O}\right]$

12. Sodium hydrosulfite or hyposulfite dithionite $\left[\mathrm{Na}_{2} \mathrm{~S}_{2} \mathrm{O}_{4} \bullet \mathrm{H}_{2} \mathrm{O}\right]$

13. Distilled, deionized (DDI) water

\section{PROCEDURE}

\section{A. Preparation of Reagents}

1. Exchangeable Reagent

a. Add $118 \mathrm{~g}$ of calcium nitrate to a 1-liter volumetric flask.

b. Fill the flask about half full with DDI water and swirl to dissolve calcium nitrate

c. Dilute to the mark with DDI water.

2. Acid Soluble Reagent

a. Add $23.6 \mathrm{~g}$ of calcium nitrate and $25.4 \mathrm{ml}$ of glacial acetic acid into a 1liter volumetric flask

b. Dilute up to the mark with DDI water to make a $0.44 \mathrm{M}$ acetic acid $0.1 \mathrm{M}$ calcium nitrate solution.

3. Manganese Oxide Occluded Reagent

a. Add $0.694 \mathrm{~g}$ of hydroxylamine-hydrochloride and $6.3 \mathrm{ml}$ of $72 \%$ nitric acid into a 1-liter volumetric flask.

b. Dilute up to the mark with DDI water to obtain a $0.01 \mathrm{M}$ hydroxylaminehydrochloride/0.1 M nitric acid solution.

4. Organically Bound Reagent

a. Add $44.6 \mathrm{~g}$ of sodium pyrophosphate into a 1-liter volumetric flask.

b. Dilute to the mark with DDI water to make a $0.1 \mathrm{M}$ solution.

5. Amorphous Iron Oxide Reagent:

a. $24.9 \mathrm{~g}$ of ammonium oxalate and $9.00 \mathrm{~g}$ of oxalic acid (or $12.6 \mathrm{~g}$ of oxalic acid dihydrate) into a 1-liter volumetric flask

b. Dilute to the mark with DDI water to make a $0.175 \mathrm{M}$ ammonium oxate/0.1 M oxalic acid solution. 
6. Crystalline Fe Oxide Reagent:

a. Add $44.1 \mathrm{~g}$ of sodium citrate dihydrate and $10.51 \mathrm{~g}$ of citric acid hydrate to a 1-liter volumetric flask.

b. Dilute to the mark with DDI water to make a $0.15 \mathrm{M}$ sodium citrate/ 0.05 $\mathrm{M}$ citric acid solution.

7. Aqua Regia

a. In a fume hood add $20 \mathrm{ml}$ of $72 \%$ nitric acid and $60 \mathrm{ml}$ of $36 \%$ hydrochloric acid in a $125-\mathrm{ml}$ labeled storage bottle.

b. Leave the bottle uncovered overnight to allow gas from reaction to escape.

c. Store in an approved acid storage area.

8. Calcium Nitrate Wash Solution

a. Add $3 \mathrm{~g}$ of calcium nitrate to a 1-liter volumetric flask.

b. Dilute to the mark with DDI water to make a $0.0127 \mathrm{M}$ solution.

\section{B. Sample Preparation}

1. Sieve the air-dried soil sample through a 2-mm sieve.

2. Record the weight of clean, dry, 50-ml Oak Ridge centrifuge tubes. 4 tubes are required for each sample (three repetitions and one blank).

3. Add approximately $0.750 \mathrm{~g}$ of the air-dried, sieved soil into each pre-weighed centrifuge tube (except the blank).

\section{Soluble Fraction}

1. Add $30-\mathrm{ml}$ of DDI water to each tube

2. Record the weight of the tube and added water. Calculate and record the actual volume of water added.

3. Shake for 16 hours on a wrist-action shaker at approximately 90 cycles per minute.

4. Centrifuge at 10,000 RPM for 30 minutes.

NOTE: During this entire procedure, use a transfer pipette to carefully remove the supernate from the tubes and transfer it to the syringe barrel or discard it.

5. Filter supernate from each tube through a $0.45-\mu \mathrm{m}$ cellulose-acetate filter and into a $30-\mathrm{ml}$ sample bottle.

6. Acidify the supernate with $150 \mu 1$ of $72 \%$ nitric acid and save for analysis.

7. Weigh and record the weight of each tube and extract. Record the actual volume of extract removed from each tube.

8. Add $20 \mathrm{ml}$ of DDI water to each tube.

9. Vortex each tube for 5 to 10 seconds to loosen soil from the tube.

10. Centrifuge for 30 minutes at 10,000 rpm.

11. Discard the supernate. 


\section{Easily Exchangeable Fraction}

1. Record the weight of tube and residue.

2. Add $30 \mathrm{ml}$ of exchangeable reagent to each tube.

3. Record the weight of the tube and added reagent. Calculate and record the actual volume of reagent added.

4. Shake for 16 hours on a wrist-action shaker at approximately 90 cycles per minute.

5. Centrifuge for 30 minutes at $10,000 \mathrm{rpm}$.

6. Filter supernate from each tube through a $0.45-\mu \mathrm{m}$ cellulose-acetate filter and into a 30-ml sample bottle.

7. Acidify supernate with $150 \mu \mathrm{l}$ of $72 \%$ nitric acid and save for analysis.

8. Record the weight of tube and residue. Calculate the actual amount of supernate extracted.

9. Add $20 \mathrm{ml}$ of calcium nitrate wash solution to each tube.

10. Vortex each tube for 5 to 10 seconds to loosen soil from the tube.

11. Centrifuge for 30 minutes at $10,000 \mathrm{rpm}$.

12. Discard the supernate.

\section{E. Acid Soluble Fraction}

1. Record the weight of tube and residue.

2. Add $30 \mathrm{ml}$ of the acid soluble reagent to each tube.

3. Record the weight tube and residue. Calculate the amount of reagent added.

4. Shake for 8 hours on a wrist-action shaker at approximately 90 cycles per minute.

5. Centrifuge for 30 minutes at $10,000 \mathrm{rpm}$.

6. Filter supernate from each tube through a $0.45-\mu \mathrm{m}$ cellulose-acetate filter and into a 30-ml sample bottle.

7. Acidify supernate with $150 \mu \mathrm{l}$ of $72 \%$ nitric acid and save for analysis.

8. Record the weight of tube and residue. Calculate the actual amount of supernate extracted.

9. Add $20 \mathrm{ml}$ of calcium nitrate wash solution to each tube.

10. Vortex each tube for 5 to 10 seconds to loosen soil from the tube.

11. Centrifuge for 30 minutes at $10,000 \mathrm{rpm}$.

12. Discard the supernate. 


\section{F. Manganese Oxide}

1. Record the weight of tube and residue.

2. Add $30 \mathrm{ml}$ of the acid soluble reagent to each tube.

3. Record the weight tube and residue. Calculate the amount of reagent added.

4. Shake for 30 minutes on a wrist-action shaker at approximately 90 cycles per minute.

5. Centrifuge for $30 \mathrm{~min}$. at $10,000 \mathrm{rpm}$.

6. Filter the supernate through a $0.45-\mu \mathrm{m}$ cellulose acetate filter and into a $30-\mathrm{ml}$ sample bottle.

7. Acidify supernate with $150 \mu 1$ of $72 \%$ nitric acid and save for analysis.

8. Record the weight of tube and residue. Calculate the actual amount supernate extracted.

9. Add $20 \mathrm{ml}$ of calcium nitrate wash solution to each tube.

10. Vortex each tube for 5 to 10 seconds to loosen soil from the tube.

11. Centrifuge for 3 to minutes at $10,000 \mathrm{rpm}$.

12. Discard the supernate.

\section{G. Organically Bound Fraction}

1. Record the weight of tube and residue.

2. Add $30 \mathrm{ml}$ of the organically bound reagent to each tube.

3. Record the weight tube and reagent. Calculate and record the actual volume of reagent added.

4. Shake for 24 hours on a wrist-action shaker at approximately 90 cycles per minute.

5. Centrifuge for $30 \mathrm{~min}$. at $10,000 \mathrm{rpm}$.

6. Filter the supernate through a $0.45-\mu \mathrm{m}$ cellulose-acetate filter and into a $30-\mathrm{ml}$ sample bottle.

7. Acidify the supernate with $150 \mu 1$ of $72 \%$ nitric acid and save for analysis.

8. Record the weight of each tube and residue. Calculate the actual amount of supernate extracted.

9. Add $20 \mathrm{ml}$ of calcium nitrate wash solution to each tube.

10. Vortex each tube for 5 to 10 seconds to loosen soil from the tube.

11. Centrifuge for 30 minutes at $10,000 \mathrm{rpm}$.

12. Discard the supernate. 


\section{H. Noncystalline Aluminosilcates and Hydrous Oxides}

NOTE: Steps 2 through 10 must be completed in such a manner to prevent ultraviolet light from influencing the sample. Steps 2, 3, and 7, and when loading or unloading tubes from the centrifuge should be performed under red light if possible. The presence of ultra-violet light causes the removal of the crystalline as well as the non-crystalline phases.

1. Record the weight of tube and residue.

2. Label and record the weight of a $15 \mathrm{~cm}$ by $15 \mathrm{~cm}$ sheet of aluminum foil for each tube.

3. Add $30 \mathrm{ml}$ of amorphous iron oxide reagent to each tube and immediately wrap the tube in aluminum foil.

4. Record the weight of each tube, reagent and foil. Calculate and record the actual volume of reagent used.

5. Shake for 4 hours on a wrist-action shaker at approximately 90 cycles per minute.

6. Centrifuge the tubes for 30 minutes at $10,000 \mathrm{rpm}$.

7. Filter the supernate through a $0.45-\mu \mathrm{m}$ cellulose-acetate filter and into a $30-\mathrm{ml}$ sample bottle.

8. Record the weight of the each tube, residue and foil. Calculate the actual volume of supernate extracted.

9. Add $20 \mathrm{ml}$ of calcium nitrate wash solution to each tube.

10. Vortex each tube for 5 to 10 seconds to loosen soil from the tube.

11. Discard the foil and centrifuge each tube for 30 minutes at 10,000 rpm.

12. Discard the supernate.

\section{Crystalline Iron Oxides and Aluminum Oxides}

1. Record the weight of tubes and residue.

2. Add $30 \mathrm{ml}$ of crystalline oxide reagent to each tube.

3. Add $0.75 \mathrm{~g}$ of sodium hydrosulfite to each tube.

4. Record the weight of each tube and reagent. Calculate and record the actual volume of reagent added.

5. Shake for 0.5 hours in a water bath at $50^{\circ} \mathrm{C}$ at approximately 90 cycles per minute.

6. Centrifuge for 30 minutes at $10,000 \mathrm{rpm}$.

7. Filter the supernate through a $0.45-\mu \mathrm{m}$ cellulose-acetate filter and into a $30-\mathrm{ml}$ sample bottle.

8. Acidify the supernate with $150 \mu 1$ of $72 \%$ nitric acid and save for analysis.

9. Record the weight of tube and residue. Calculate the actual volume supernate extracted.

10. Add 20 nil of calcium nitrate wash solution to each tube.

11. Vortex each tube for 5 to 10 seconds to loosen soil from the tube.

12. Centrifuge for 30 minutes at $10,000 \mathrm{rpm}$.

13. Discard the supernate. 


\section{J. Total and Partial Digestions of Samples}

1. Label and weigh an aluminum drying dish for each tube.

2. Spray $\approx 5 \mathrm{ml}$ of DDI water into each tube and vortex the tube long enough to break up the pellet at the bottom.

3. With the aid of a DDI water rinse, transfer the tube's contents to a drying dish.

4. Dry the soil residue at $105^{\circ} \mathrm{C}$ in an oven until a constant weight is reached.

5. Place approximately $200 \mathrm{mg}$ of oven-dried soil residue from each tube into an acid digestion bomb insert.

6. Add approximately $200 \mathrm{mg}$ of original soil which has been air-dried and passed through a \#10 sieve into an acid digestion bomb insert.

\section{DANGER: Steps 7, 11, 12, and 13 must be performed inside a fume hood.}

7. Add to each $1 \mathrm{ml}$ of aqua regia and $10 \mathrm{ml}$ of $48 \% \mathrm{HF}$ to each vessel.

8. Place the bomb inserts into the digestion bomb shells and tighten until just hand tight.

9. Place bombs into a $105^{\circ} \mathrm{C}$ oven for 3 hours.

10. Remove the bombs from the oven and allow to cool for at least 15 minutes.

11. Filter the extract from the bomb inserts flasks through either PTFE syringe filters into a plastic $50-\mathrm{ml}$ volumetric flask.

12. Dilute to $50 \mathrm{ml}$ with DDI water.

13. Transfer to a 60-ml sample bottle for storage and transfer. 
This page intentionally left blank. 


\section{APPENDIX B. SEQUENTIAL EXTRACTION DATA}

Table B- 1. Abbreviations for sequential extraction steps

\begin{tabular}{|l|l|}
\hline \multicolumn{1}{|c|}{ Abbreviation } & \multicolumn{1}{|c|}{ Sequential Extraction Step } \\
\hline DDI & Water Soluble \\
CN & Easily Exchangeable \\
AA & Acid Soluble \\
HH & Easily Reducible \\
HP & Organic Bound \\
AO & Amorphous Oxide Bound \\
SD & Crystalline Oxide Bound \\
PD & Residual \\
\hline
\end{tabular}

Table B- 2. Wetland beryllium in soil (ppm)

\begin{tabular}{|l|r|r|r|r|r|r|r|r|}
\hline $\begin{array}{c}\text { Beryllium } \\
\text { ppm }\end{array}$ & \multicolumn{1}{c|}{ DDI } & \multicolumn{1}{c|}{ CN } & \multicolumn{1}{c|}{ AA } & \multicolumn{1}{c|}{ HH } & \multicolumn{1}{c|}{ HP } & \multicolumn{1}{c|}{ AO } & \multicolumn{1}{l|}{ SD } & \multicolumn{1}{l|}{ PD } \\
\hline D2 1 & 0.00 & 0.04 & 0.34 & 0.06 & 0.29 & 0.04 & 0.02 & 0.69 \\
stdev & 0.00 & 0.00 & 0.10 & 0.00 & 0.07 & 0.01 & 0.00 & 0.09 \\
\hline D4 1 & 0.00 & 0.05 & 0.25 & 0.06 & 0.30 & 0.03 & 0.03 & 1.11 \\
stdev & 0.00 & 0.02 & 0.03 & 0.00 & 0.02 & 0.01 & 0.03 & 0.27 \\
\hline G10 2 & 0.00 & 0.05 & 0.60 & 0.22 & 0.47 & 0.05 & 0.00 & 5.68 \\
stdev & 0.00 & 0.05 & 0.18 & 0.00 & 0.08 & 0.00 & 0.00 & 0.23 \\
\hline H5 1 & 0.00 & 0.03 & 0.69 & 0.24 & 0.39 & 0.04 & 0.00 & 3.15 \\
stdev & 0.00 & 0.01 & 0.12 & 0.01 & 0.08 & 0.00 & 0.00 & 0.57 \\
\hline J6 2 & 0.00 & 0.03 & 0.43 & 0.22 & 0.40 & 0.03 & 0.00 & 4.97 \\
stdev & 0.00 & 0.00 & 0.02 & 0.00 & 0.04 & 0.01 & 0.00 & 0.83 \\
\hline K4 2 & 0.00 & 0.08 & 0.51 & 0.23 & 0.56 & 0.02 & 0.01 & 3.86 \\
stdev & 0.00 & 0.04 & 0.01 & 0.02 & 0.02 & 0.00 & 0.00 & 0.69 \\
\hline
\end{tabular}


WSRC-TR-2004-00124, REVISION 0

Table B- 3. Wetland aluminum in soil (ppm)

\begin{tabular}{|l|r|r|r|r|r|r|r|r|}
\hline $\begin{array}{c}\text { Aluminum } \\
\text { ppm }\end{array}$ & \multicolumn{1}{c|}{ DDI } & \multicolumn{1}{c|}{ CN } & \multicolumn{1}{c|}{ AA } & \multicolumn{1}{c|}{ HH } & HP & \multicolumn{1}{c|}{ AO } & \multicolumn{1}{c|}{ SD } & \multicolumn{1}{c|}{ PD } \\
\hline D2 1 & 4.00 & 34.96 & 5.74 & 0.35 & 0.00 & 0.13 & 15.12 & 51102.09 \\
stdev & 0.83 & 0.42 & 1.50 & 0.01 & 0.02 & 0.18 & 3.75 & 14971.23 \\
\hline D4 1 & 1.62 & 35.71 & 5.74 & 0.50 & 0.00 & 0.10 & 12.64 & 77248.24 \\
stdev & 0.97 & 5.00 & 0.38 & 0.10 & 0.02 & 0.01 & 0.67 & 2331.23 \\
\hline G10 2 & 1.23 & 26.58 & 1.07 & 0.00 & 0.34 & 0.88 & 75.47 & 68006.83 \\
stdev & 0.80 & 0.50 & 1.25 & 0.00 & 0.49 & 0.52 & 3.44 & 6713.22 \\
\hline H5 1 & 1.92 & 20.75 & 2.45 & 0.02 & 0.39 & 1.00 & 46.00 & 44679.49 \\
stdev & 0.01 & 0.42 & 0.07 & 0.03 & 0.02 & 0.13 & 3.35 & 7415.49 \\
\hline J6 2 & 1.21 & 97.21 & 4.83 & 0.00 & 0.96 & 1.39 & 55.51 & 70211.12 \\
stdev & 1.20 & 2.19 & 2.73 & 0.00 & 0.43 & 0.07 & 12.19 & 8584.49 \\
\hline K4 2 & 1.60 & 123.09 & 5.70 & 0.13 & 0.00 & 1.41 & 57.14 & 54220.23 \\
stdev & 0.26 & 9.96 & 1.40 & 0.18 & 0.02 & 0.35 & 11.32 & 6318.70 \\
\hline
\end{tabular}

Table B- 4. Wetland nickel in soil (ppm)

\begin{tabular}{|l|r|r|r|r|r|r|r|r|}
\hline Nickel ppm & \multicolumn{1}{|c|}{ DDI } & \multicolumn{1}{c|}{ CN } & \multicolumn{1}{c|}{ AA } & HH & HP & AO & \multicolumn{1}{c|}{ SD } & \multicolumn{1}{c|}{ PD } \\
\hline D2 1 & 0.01 & 0.63 & 17.41 & 0.36 & 2.01 & 0.18 & 0.51 & 11.70 \\
stdev & 0.00 & 0.19 & 11.28 & 0.04 & 0.52 & 0.03 & 0.08 & 1.42 \\
\hline D4 1 & 0.00 & 0.51 & 1.86 & 0.44 & 1.89 & 0.23 & 0.76 & 18.74 \\
stdev & 0.00 & 0.27 & 2.64 & 0.02 & 0.10 & 0.05 & 0.09 & 0.21 \\
\hline G10 2 & 0.07 & 1.44 & 3.88 & 0.85 & 4.49 & 0.43 & 0.71 & 36.57 \\
stdev & 0.00 & 0.30 & 5.48 & 0.00 & 1.78 & 0.03 & 0.01 & 5.19 \\
\hline H5 1 & 0.02 & 2.06 & 2.75 & 0.93 & 3.19 & 1.77 & 0.99 & 27.88 \\
stdev & 0.00 & 0.26 & 2.82 & 0.03 & 0.70 & 0.12 & 0.12 & 6.77 \\
\hline J6 2 & 0.10 & 1.56 & 4.28 & 0.69 & 2.97 & 0.62 & 0.94 & 35.67 \\
stdev & 0.00 & 0.17 & 2.13 & 0.02 & 0.56 & 0.11 & 0.34 & 3.90 \\
\hline K4 2 & 0.06 & 0.00 & 1.86 & 0.30 & 3.68 & 0.94 & 1.08 & 28.44 \\
stdev & 0.02 & 0.17 & 2.63 & 0.04 & 0.36 & 0.61 & 0.16 & 2.38 \\
\hline
\end{tabular}

Table B- 5. Wetland arsenic in soil (ppm)

\begin{tabular}{|l|r|r|r|r|r|r|r|r|}
\hline Arsenic ppm & \multicolumn{1}{|c|}{ DDI } & \multicolumn{1}{c|}{ CN } & \multicolumn{1}{c|}{ AA } & \multicolumn{1}{c|}{ HH } & \multicolumn{1}{c|}{ HP } & \multicolumn{1}{l|}{ AO } & \multicolumn{1}{l|}{ SD } & \multicolumn{1}{l|}{ PD } \\
\hline D2 1 & 0.01 & 0.23 & 0.58 & 0.08 & 0.69 & 2.03 & 1.90 & 0.84 \\
stdev & 0.00 & 0.05 & 0.16 & 0.02 & 0.17 & 0.23 & 0.56 & 0.32 \\
\hline D4 1 & 0.01 & 0.22 & 0.25 & 0.08 & 0.48 & 2.71 & 2.79 & 1.21 \\
stdev & 0.00 & 0.06 & 0.05 & 0.00 & 0.01 & 0.40 & 0.37 & 0.26 \\
\hline G10 2 & 0.07 & 0.13 & 2.51 & 2.98 & 23.21 & 11.51 & 2.30 & 1.51 \\
stdev & 0.01 & 0.01 & 0.75 & 0.01 & 1.73 & 0.10 & 0.08 & 0.15 \\
\hline H5 1 & 0.16 & 0.06 & 5.26 & 7.08 & 48.77 & 14.44 & 1.05 & 1.12 \\
stdev & 0.02 & 0.04 & 0.10 & 0.24 & 13.48 & 0.80 & 0.05 & 0.18 \\
\hline J6 2 & 0.02 & 0.06 & 2.30 & 3.07 & 28.32 & 3.88 & 0.84 & 2.31 \\
stdev & 0.01 & 0.09 & 0.17 & 0.72 & 4.24 & 0.79 & 0.06 & 0.62 \\
\hline K4 2 & 0.02 & 0.35 & 0.96 & 1.62 & 51.68 & 20.51 & 1.85 & 1.34 \\
stdev & 0.01 & 0.11 & 0.07 & 0.02 & 5.25 & 2.41 & 0.48 & 0.07 \\
\hline
\end{tabular}


WSRC-TR-2004-00124, REVISION 0

Table B- 6. Wetland selenium in soil (ppm)

\begin{tabular}{|l|r|r|r|r|r|r|r|r|}
\hline Selenium ppm & \multicolumn{1}{|c|}{ DDI } & \multicolumn{1}{c|}{ CN } & \multicolumn{1}{c|}{ AA } & \multicolumn{1}{c|}{ HH } & \multicolumn{1}{c|}{ HP } & \multicolumn{1}{l|}{ AO } & \multicolumn{1}{l|}{ SD } & \multicolumn{1}{l|}{ PD } \\
\hline D2 1 & 0.00 & 0.23 & 1.16 & 0.21 & 0.14 & 0.34 & 0.00 & 0.00 \\
stdev & 0.01 & 0.33 & 0.73 & 0.02 & 0.20 & 0.03 & 0.07 & 0.00 \\
\hline D4 1 & 0.00 & 0.46 & 0.90 & 0.15 & 0.00 & 0.42 & 0.00 & 0.00 \\
stdev & 0.00 & 0.34 & 0.25 & 0.01 & 0.03 & 0.10 & 0.07 & 0.00 \\
\hline G10 2 & 0.03 & 0.44 & 0.08 & 0.27 & 5.75 & 0.35 & 0.00 & 0.00 \\
stdev & 0.04 & 0.15 & 0.11 & 0.01 & 1.00 & 0.08 & 0.07 & 0.00 \\
\hline H5 1 & 0.09 & 0.36 & 0.55 & 0.49 & 8.21 & 0.21 & 0.15 & 0.00 \\
stdev & 0.01 & 0.02 & 0.29 & 0.01 & 2.55 & 0.07 & 0.22 & 0.00 \\
\hline J6 2 & 0.01 & 0.55 & 0.51 & 0.32 & 3.63 & 0.03 & 0.27 & 0.00 \\
stdev & 0.02 & 0.13 & 0.68 & 0.13 & 1.11 & 0.01 & 0.39 & 0.00 \\
\hline K4 2 & 0.02 & 0.41 & 0.17 & 0.29 & 3.45 & 0.45 & 0.96 & 0.00 \\
stdev & 0.02 & 0.51 & 0.24 & 0.08 & 0.70 & 0.04 & 0.74 & 0.00 \\
\hline
\end{tabular}

Table B- 7. Wetland uranium in soil (ppm)

\begin{tabular}{|l|r|r|r|r|r|r|r|r|}
\hline Uranium ppm & \multicolumn{1}{|c|}{ DDI } & \multicolumn{1}{c|}{ CN } & \multicolumn{1}{c|}{ AA } & \multicolumn{1}{c|}{ HH } & \multicolumn{1}{c|}{ HP } & \multicolumn{1}{c|}{ AO } & \multicolumn{1}{c|}{ SD } & \multicolumn{1}{l|}{ PD } \\
\hline D2 1 & 0.44 & 0.00 & 0.92 & 0.40 & 0.58 & 0.11 & 0.08 & 1.18 \\
stdev & 0.37 & 0.00 & 0.18 & 0.03 & 0.22 & 0.02 & 0.00 & 0.34 \\
\hline D4 1 & 0.05 & 0.00 & 0.39 & 0.53 & 0.68 & 0.16 & 0.13 & 1.92 \\
stdev & 0.02 & 0.00 & 0.12 & 0.02 & 0.03 & 0.03 & 0.03 & 0.04 \\
\hline G10 2 & 0.02 & 0.00 & 0.25 & 0.89 & 1.35 & 0.30 & 0.05 & 3.08 \\
stdev & 0.00 & 0.00 & 0.03 & 0.04 & 0.48 & 0.00 & 0.02 & 0.32 \\
\hline H5 1 & 0.00 & 0.00 & 0.11 & 0.72 & 1.73 & 0.28 & 0.06 & 2.03 \\
stdev & 0.00 & 0.00 & 0.04 & 0.01 & 0.42 & 0.03 & 0.01 & 0.47 \\
\hline J6 2 & 0.00 & 0.00 & 0.09 & 0.55 & 1.42 & 0.19 & 0.04 & 3.01 \\
stdev & 0.00 & 0.00 & 0.01 & 0.06 & 0.05 & 0.03 & 0.00 & 0.38 \\
\hline K4 2 & 0.00 & 0.00 & 0.14 & 0.68 & 1.04 & 0.18 & 0.02 & 1.92 \\
stdev & 0.00 & 0.00 & 0.00 & 0.04 & 0.12 & 0.02 & 0.00 & 0.16 \\
\hline
\end{tabular}

Table B- 8. Wetland iron in soil (ppm)

\begin{tabular}{|l|l|l|l|l|l|r|r|r|r|}
\hline Iron ppm & DDI & & CN & AA & HH & HP & AO & SD & PD \\
\hline D2 1 & 5.45 & 0.04 & 24.16 & 473.70 & 3998.59 & 3794.47 & 8664.89 & 10763.12 \\
stdev & 1.99 & 0.00 & 1.84 & 10.67 & 76.26 & 311.89 & 1180.09 & 3744.15 \\
\hline D4 1 & 1.54 & 0.04 & 47.87 & 626.25 & 3762.71 & 5828.59 & 13769.93 & 13991.04 \\
stdev & 0.72 & 0.00 & 0.46 & 25.17 & 170.68 & 439.54 & 1865.29 & 2201.74 \\
\hline G10 2 & 0.90 & 0.04 & 147.25 & 624.80 & 2596.34 & 830.41 & 808.93 & 13340.80 \\
stdev & 0.26 & 0.01 & 5.47 & 7.82 & 8.74 & 43.25 & 124.21 & 1203.49 \\
\hline H5 1 & 2.50 & 0.06 & 40.97 & 662.36 & 3597.65 & 4363.48 & 699.65 & 17035.68 \\
stdev & 1.41 & 0.03 & 0.48 & 5.32 & 148.21 & 1055.36 & 32.09 & 2103.53 \\
\hline J6 2 & 0.05 & 0.48 & 64.63 & 451.21 & 2125.83 & 1099.91 & 531.53 & 20458.00 \\
stdev & 0.05 & 0.08 & 1.22 & 11.99 & 211.30 & 91.66 & 38.64 & 2446.35 \\
\hline K4 2 & 0.21 & 0.51 & 100.46 & 526.18 & 3683.34 & 2298.70 & 593.34 & 13231.93 \\
stdev & 0.00 & 0.13 & 0.28 & 6.84 & 34.24 & 1178.27 & 47.93 & 1634.30 \\
\hline
\end{tabular}


WSRC-TR-2004-00124, REVISION 0

Table B- 9. Wetland vanadium in soil (ppm)

\begin{tabular}{|l|r|r|r|r|r|r|r|r|}
\hline \multicolumn{1}{|c|}{$\begin{array}{l}\text { Vanadium } \\
\text { ppm }\end{array}$} & \multicolumn{1}{c|}{ DDI } & \multicolumn{1}{c|}{ CN } & \multicolumn{1}{c|}{ AA } & HH & \multicolumn{1}{c|}{ HP } & \multicolumn{1}{c|}{ AO } & \multicolumn{1}{c|}{ SD } & \multicolumn{1}{c|}{ PD } \\
\hline D2 1 & 0.99 & 0.96 & 0.04 & 1.51 & 12.64 & 5.69 & 19.58 & 29.51 \\
stdev & 1.33 & 0.91 & 0.05 & 0.03 & 0.49 & 0.73 & 2.84 & 8.61 \\
\hline D4 1 & 0.04 & 0.10 & 0.19 & 1.96 & 13.09 & 12.14 & 31.61 & 41.49 \\
stdev & 0.00 & 0.09 & 0.09 & 0.12 & 0.97 & 0.45 & 4.40 & 5.93 \\
\hline G10 2 & 0.41 & 0.04 & 2.34 & 9.77 & 27.86 & 0.25 & 2.28 & 84.04 \\
stdev & 0.02 & 0.01 & 0.04 & 0.10 & 0.18 & 0.31 & 0.43 & 3.46 \\
\hline H5 1 & 0.52 & 0.11 & 1.42 & 10.83 & 31.85 & 0.26 & 0.92 & 56.88 \\
stdev & 0.08 & 0.10 & 0.16 & 0.22 & 1.25 & 0.32 & 0.09 & 8.24 \\
\hline J6 2 & 0.08 & 0.03 & 1.11 & 4.99 & 19.74 & 0.04 & 0.74 & 92.63 \\
stdev & 0.04 & 0.01 & 0.27 & 0.15 & 1.97 & 0.05 & 0.02 & 13.66 \\
\hline K4 2 & 0.02 & 0.04 & 0.69 & 4.28 & 27.12 & 3.84 & 1.09 & 69.90 \\
stdev & 0.02 & 0.01 & 0.04 & 0.07 & 0.33 & 0.24 & 0.11 & 5.04 \\
\hline
\end{tabular}


WSRC-TR-2004-00124, REVISION 0

Table B- 10. Upland beryllium in soil (ppm)

\begin{tabular}{|c|c|c|c|c|c|c|c|c|}
\hline $\begin{array}{l}\text { Beryllium } \\
\text { ppm }\end{array}$ & DDI & $\mathrm{CN}$ & $\mathbf{A A}$ & HH & HP & AO & SD & PD \\
\hline $168 / 1.5$ & 0.00 & 0.59 & 0.18 & 0.03 & 0.02 & 0.02 & 0.01 & 1.19 \\
\hline stdev & 0.00 & 0.12 & 0.12 & 0.00 & 0.00 & 0.01 & 0.01 & 0.18 \\
\hline $168 / 20$ & 2.24 & 2.07 & 0.36 & 0.04 & 0.06 & 0.01 & 0.00 & 0.42 \\
\hline stdev & 0.13 & 0.24 & 0.02 & 0.00 & 0.00 & 0.00 & 0.00 & 0.13 \\
\hline $168 / 31$ & 1.05 & 0.58 & 0.03 & 0.00 & 0.02 & 0.00 & 0.00 & 0.18 \\
\hline stdev & 0.02 & 0.22 & 0.04 & 0.00 & 0.00 & 0.00 & 0.00 & 0.09 \\
\hline $170 / 1$ & 0.00 & 0.04 & 0.01 & 0.00 & 0.00 & 0.01 & 0.00 & 0.25 \\
\hline stdev & 0.00 & 0.04 & 0.01 & 0.00 & 0.00 & 0.00 & 0.00 & 0.15 \\
\hline $170 / 14$ & 0.01 & 0.02 & 0.00 & 0.00 & 0.02 & 0.01 & 0.00 & 0.22 \\
\hline stdev & 0.00 & 0.00 & 0.00 & 0.00 & 0.00 & 0.00 & 0.00 & 0.01 \\
\hline $170 / 20$ & 0.16 & 0.00 & 0.01 & 0.01 & 0.00 & 0.02 & 0.00 & 0.64 \\
\hline stdev & 0.04 & 0.00 & 0.01 & 0.00 & 0.00 & 0.00 & 0.00 & 0.05 \\
\hline $211 / 2$ & 0.00 & 0.00 & 0.02 & 0.00 & 0.00 & 0.00 & 0.00 & 0.19 \\
\hline stdev & 0.00 & 0.00 & 0.01 & 0.00 & 0.00 & 0.00 & 0.00 & 0.05 \\
\hline $211 / 9$ & 0.00 & 0.01 & 0.00 & 0.00 & 0.00 & 0.00 & 0.01 & 0.57 \\
\hline stdev & 0.00 & 0.00 & 0.00 & 0.00 & 0.00 & 0.00 & 0.01 & 0.08 \\
\hline $211 / 19$ & 0.01 & 0.17 & 0.10 & 0.03 & 0.16 & 0.09 & 0.67 & 1.40 \\
\hline stdev & 0.00 & 0.01 & 0.00 & 0.00 & 0.01 & 0.02 & 0.07 & 0.18 \\
\hline $211 / 35$ & 0.06 & 0.09 & 0.03 & 0.01 & \begin{tabular}{|l|}
0.06 \\
\end{tabular} & 0.00 & 0.58 & 0.00 \\
\hline stdev & 0.00 & 0.03 & 0.01 & 0.01 & 0.00 & 0.00 & 0.02 & na \\
\hline $92 / 5$ & 0.02 & 0.16 & 0.00 & 0.04 & 0.02 & 0.01 & 0.00 & 0.94 \\
\hline st dev & 0.01 & 0.18 & 0.00 & 0.04 & 0.02 & 0.00 & 0.00 & na \\
\hline $92 / 21$ & 0.05 & 0.01 & 0.00 & 0.00 & 0.00 & 0.00 & 0.00 & 0.45 \\
\hline st dev & 0.01 & 0.01 & 0.00 & 0.00 & 0.01 & 0.00 & 0.00 & 0.03 \\
\hline $85 / 32$ & 0.00 & 0.02 & 0.06 & 0.03 & 0.11 & 0.04 & 0.01 & 1.23 \\
\hline st dev & 0.00 & 0.01 & 0.01 & 0.00 & 0.05 & 0.01 & 0.01 & 0.27 \\
\hline $81 / 45$ & \begin{tabular}{l|l|}
0.02 \\
\end{tabular} & 0.04 & 0.08 & 0.02 & 0.10 & 0.07 & 0.09 & 0.56 \\
\hline st dev & 0.01 & 0.01 & 0.05 & 0.01 & 0.05 & 0.04 & 0.04 & 0.28 \\
\hline $87 / 38$ & 0.01 & 0.01 & 0.01 & 0.00 & 0.02 & 0.01 & 0.00 & 0.39 \\
\hline st dev & 0.00 & 0.01 & 0.00 & 0.00 & 0.00 & 0.00 & 0.01 & 0.02 \\
\hline $84 / 28$ & 0.00 & 0.02 & 0.02 & 0.01 & 0.02 & 0.01 & 0.03 & 0.53 \\
\hline st dev & 0.00 & 0.00 & 0.00 & 0.00 & 0.01 & 0.00 & 0.01 & 0.11 \\
\hline $83 / 42$ & 0.00 & 0.00 & 0.81 & 2.51 & 0.13 & 0.02 & 0.30 & 0.46 \\
\hline st dev & 0.00 & 0.00 & 0.03 & 0.06 & 0.01 & 0.00 & 0.09 & 0.08 \\
\hline $86 / 12$ & 0.00 & 0.14 & 0.85 & 0.24 & 0.29 & 0.16 & 0.12 & 7.01 \\
\hline st dev & 0.00 & 0.19 & 0.03 & 0.00 & 0.05 & 0.00 & 0.01 & 0.66 \\
\hline
\end{tabular}


WSRC-TR-2004-00124, REVISION 0

Table B- 11. Upland aluminum in soil (ppm)

\begin{tabular}{|c|c|c|c|c|c|c|c|c|}
\hline $\begin{array}{c}\text { Aluminum } \\
\text { ppm }\end{array}$ & DDI & $\mathbf{C N}$ & $\mathbf{A A}$ & HH & HP & AO & SD & PD \\
\hline $\begin{array}{l}168 / 1.5 \\
\text { stdev }\end{array}$ & \begin{tabular}{l|}
0.00 \\
0.00
\end{tabular} & $\begin{array}{r}365.77 \\
17.32\end{array}$ & $\begin{array}{r}228.42 \\
0.22\end{array}$ & $\begin{array}{r}27.24 \\
0.40\end{array}$ & $\begin{array}{r}76.20 \\
4.96\end{array}$ & $\begin{array}{r}307.56 \\
3.58\end{array}$ & $\begin{array}{r}211.68 \\
1.11\end{array}$ & $\begin{array}{r}10443.83 \\
1468.21\end{array}$ \\
\hline $\begin{array}{l}168 / 20 \\
\text { stdev }\end{array}$ & $\begin{array}{r}27.35 \\
2.60\end{array}$ & $\begin{array}{r}275.65 \\
8.08\end{array}$ & $\begin{array}{r}56.43 \\
0.08\end{array}$ & $\begin{array}{l}7.55 \\
0.01\end{array}$ & \begin{tabular}{l|}
10.75 \\
15.20
\end{tabular} & \begin{tabular}{r|}
25.13 \\
2.09 \\
\end{tabular} & \begin{tabular}{r|}
19.21 \\
2.11
\end{tabular} & $\begin{array}{l}4582.42 \\
1231.14\end{array}$ \\
\hline $\begin{array}{l}168 / 31 \\
\text { stdev }\end{array}$ & \begin{tabular}{l|}
2.59 \\
0.21
\end{tabular} & $\begin{array}{r}116.37 \\
2.78\end{array}$ & $\begin{array}{r}30.45 \\
1.30\end{array}$ & $\begin{array}{l}2.65 \\
0.76\end{array}$ & \begin{tabular}{l|}
3.35 \\
3.53
\end{tabular} & $\begin{array}{l}4.96 \\
0.56\end{array}$ & \begin{tabular}{l|}
4.58 \\
0.05
\end{tabular} & $\begin{array}{r}1630.39 \\
456.42\end{array}$ \\
\hline $\begin{array}{l}170 / 1 \\
\text { stdev }\end{array}$ & \begin{tabular}{l|}
1.81 \\
0.00
\end{tabular} & $\begin{array}{r}272.57 \\
8.17\end{array}$ & $\begin{array}{r}135.28 \\
1.32\end{array}$ & $\begin{array}{l}6.34 \\
0.42\end{array}$ & \begin{tabular}{|l|}
60.73 \\
10.17
\end{tabular} & \begin{tabular}{r|}
18.99 \\
0.92
\end{tabular} & $\begin{array}{r}304.88 \\
0.85\end{array}$ & $\begin{array}{r}11367.99 \\
830.88\end{array}$ \\
\hline \begin{tabular}{|l|}
$170 / 14$ \\
stdev
\end{tabular} & \begin{tabular}{l|}
5.14 \\
0.39
\end{tabular} & $\begin{array}{r}95.15 \\
0.96 \\
\end{array}$ & $\begin{array}{r}150.25 \\
1.86\end{array}$ & $\begin{array}{r}12.55 \\
0.58\end{array}$ & $\begin{array}{r}52.90 \\
2.54 \\
\end{array}$ & \begin{tabular}{r|}
24.02 \\
0.89
\end{tabular} & \begin{tabular}{r|}
18.51 \\
1.29 \\
\end{tabular} & $\begin{array}{r}10987.93 \\
426.78\end{array}$ \\
\hline \begin{tabular}{|l|}
$170 / 20$ \\
stdev
\end{tabular} & \begin{tabular}{l|}
1.72 \\
0.30
\end{tabular} & $\begin{array}{l}0.50 \\
0.35\end{array}$ & $\begin{array}{l}6.62 \\
0.19\end{array}$ & $\begin{array}{l}0.71 \\
0.31\end{array}$ & \begin{tabular}{r|}
10.41 \\
0.97 \\
\end{tabular} & $\begin{array}{r}39.19 \\
0.05 \\
\end{array}$ & \begin{tabular}{r|}
15.27 \\
1.83 \\
\end{tabular} & $\begin{array}{r}10801.55 \\
168.36 \\
\end{array}$ \\
\hline $\begin{array}{l}211 / 2 \\
\text { stdev }\end{array}$ & $\begin{array}{l}0.00 \\
0.00\end{array}$ & $\begin{array}{r}21.38 \\
1.88 \\
\end{array}$ & $\begin{array}{l}0.00 \\
0.00\end{array}$ & $\begin{array}{l}1.10 \\
0.05\end{array}$ & $\begin{array}{l}6.69 \\
0.30\end{array}$ & $\begin{array}{l}0.00 \\
0.00\end{array}$ & \begin{tabular}{r|}
13.72 \\
4.15 \\
\end{tabular} & $\begin{array}{r}7661.35 \\
616.79 \\
\end{array}$ \\
\hline $\begin{array}{l}211 / 9 \\
\text { stdev }\end{array}$ & \begin{tabular}{l|}
0.22 \\
0.00
\end{tabular} & \begin{tabular}{|r|}
36.83 \\
7.02
\end{tabular} & $\begin{array}{l}0.00 \\
0.00\end{array}$ & $\begin{array}{l}1.36 \\
0.20\end{array}$ & \begin{tabular}{l|}
5.12 \\
0.85
\end{tabular} & \begin{tabular}{l|}
0.00 \\
0.00
\end{tabular} & $\begin{array}{l}8.32 \\
0.20\end{array}$ & $\begin{array}{r}10991.43 \\
88.65\end{array}$ \\
\hline $\begin{array}{l}211 / 19 \\
\text { stdev }\end{array}$ & $\begin{array}{l}0.56 \\
0.12\end{array}$ & $\begin{array}{r}25.63 \\
6.09 \\
\end{array}$ & $\begin{array}{l}0.00 \\
0.00\end{array}$ & $\begin{array}{l}1.11 \\
0.01\end{array}$ & $\begin{array}{l}5.28 \\
1.76 \\
\end{array}$ & $\begin{array}{l}0.00 \\
0.00\end{array}$ & $\begin{array}{l}4.22 \\
2.97\end{array}$ & $\begin{array}{r}10922.64 \\
166.40 \\
\end{array}$ \\
\hline $\begin{array}{l}211 / 35 \\
\text { stdev }\end{array}$ & \begin{tabular}{l|}
4.12 \\
0.22
\end{tabular} & $\begin{array}{r}255.01 \\
1.85\end{array}$ & $\begin{array}{l}0.00 \\
0.00\end{array}$ & $\begin{array}{l}2.44 \\
0.38\end{array}$ & \begin{tabular}{r|}
58.71 \\
7.94 \\
\end{tabular} & \begin{tabular}{l|}
0.00 \\
0.00
\end{tabular} & $\begin{array}{r}112.53 \\
1.25\end{array}$ & $\begin{array}{r}540.13 \\
\text { na }\end{array}$ \\
\hline $\begin{array}{l}92 / 5 \\
\text { st dev }\end{array}$ & \begin{tabular}{l|}
1.40 \\
0.64
\end{tabular} & $\begin{array}{r}135.90 \\
17.39\end{array}$ & $\begin{array}{r}26.06 \\
6.47\end{array}$ & $\begin{array}{r}17.08 \\
2.63\end{array}$ & \begin{tabular}{r|}
16.81 \\
3.13
\end{tabular} & \begin{tabular}{r|}
122.86 \\
33.46
\end{tabular} & $\begin{array}{r}136.68 \\
6.34\end{array}$ & \\
\hline $\begin{array}{l}92 / 21 \\
\text { st dev } \\
\end{array}$ & \begin{tabular}{l|}
0.97 \\
0.12 \\
\end{tabular} & \begin{tabular}{|l|}
3.93 \\
2.44
\end{tabular} & $\begin{array}{r}58.28 \\
7.01\end{array}$ & $\begin{array}{r}18.01 \\
2.86\end{array}$ & $\begin{array}{r}59.48 \\
1.46\end{array}$ & $\begin{array}{r}45.27 \\
5.91\end{array}$ & \begin{tabular}{r|}
13.82 \\
3.68
\end{tabular} & $\begin{array}{l}\mathrm{nd} \\
\mathrm{nd}\end{array}$ \\
\hline $\begin{array}{l}85 / 32 \\
\text { st dev }\end{array}$ & \begin{tabular}{l|}
0.01 \\
0.01
\end{tabular} & $\begin{array}{l}4.07 \\
0.13\end{array}$ & $\begin{array}{l}7.98 \\
1.57\end{array}$ & $\begin{array}{l}7.77 \\
0.40\end{array}$ & \begin{tabular}{l|}
2.28 \\
0.13
\end{tabular} & \begin{tabular}{l|}
0.95 \\
0.27
\end{tabular} & $\begin{array}{r}20.92 \\
0.16\end{array}$ & $\begin{array}{r}18997.15 \\
219.65\end{array}$ \\
\hline $\begin{array}{l}81 / 45 \\
\text { st dev }\end{array}$ & $\begin{array}{l}0.17 \\
0.11\end{array}$ & $\begin{array}{l}5.71 \\
0.83 \\
\end{array}$ & $\begin{array}{r}17.74 \\
0.58\end{array}$ & $\begin{array}{l}6.62 \\
1.51\end{array}$ & $\begin{array}{l}8.76 \\
4.12\end{array}$ & \begin{tabular}{|l|}
3.95 \\
3.43 \\
\end{tabular} & \begin{tabular}{|l|}
55.90 \\
21.75
\end{tabular} & $\begin{array}{r}15173.14 \\
9329.46\end{array}$ \\
\hline $\begin{array}{l}87 / 38 \\
\text { st dev }\end{array}$ & \begin{tabular}{l|}
1.01 \\
0.73
\end{tabular} & $\begin{array}{r}15.56 \\
1.84\end{array}$ & $\begin{array}{r}16.12 \\
0.65\end{array}$ & $\begin{array}{l}8.23 \\
0.89\end{array}$ & \begin{tabular}{l|}
2.83 \\
0.06
\end{tabular} & \begin{tabular}{l|}
1.27 \\
0.31
\end{tabular} & $\begin{array}{r}43.53 \\
0.40\end{array}$ & $\begin{array}{r}18899.00 \\
166.01\end{array}$ \\
\hline \begin{tabular}{|l}
$84 / 28$ \\
st dev
\end{tabular} & $\begin{array}{l}0.00 \\
0.00\end{array}$ & $\begin{array}{l}4.03 \\
0.43\end{array}$ & $\begin{array}{r}19.43 \\
3.21\end{array}$ & $\begin{array}{l}7.39 \\
0.56\end{array}$ & \begin{tabular}{|l|}
6.23 \\
1.28
\end{tabular} & $\begin{array}{l}3.69 \\
1.26 \\
\end{array}$ & $\begin{array}{r}22.45 \\
2.71\end{array}$ & $\begin{array}{r}13238.01 \\
6756.92 \\
\end{array}$ \\
\hline $\begin{array}{l}83 / 42 \\
\text { st dev }\end{array}$ & \begin{tabular}{l|}
0.06 \\
0.05
\end{tabular} & $\begin{array}{l}0.08 \\
0.01\end{array}$ & $\begin{array}{r}19.88 \\
1.62\end{array}$ & $\begin{array}{l}0.00 \\
0.05\end{array}$ & $\begin{array}{l}7.59 \\
1.90\end{array}$ & \begin{tabular}{l|}
5.47 \\
0.65
\end{tabular} & \begin{tabular}{r|}
58.31 \\
9.93
\end{tabular} & $\begin{array}{r}3094.68 \\
832.75\end{array}$ \\
\hline $\begin{array}{l}86 / 12 \\
\text { st dev }\end{array}$ & \begin{tabular}{l|}
5.44 \\
1.03
\end{tabular} & $\begin{array}{l}8.80 \\
5.28\end{array}$ & $\begin{array}{l}0.02 \\
0.05\end{array}$ & $\begin{array}{l}0.00 \\
0.05\end{array}$ & \begin{tabular}{l|}
0.00 \\
0.00
\end{tabular} & \begin{tabular}{l|}
0.00 \\
0.00
\end{tabular} & $\begin{array}{l}98.82 \\
31.80\end{array}$ & $\begin{array}{l}\mathrm{nd} \\
\mathrm{nd}\end{array}$ \\
\hline
\end{tabular}


Table B- 12. Upland nickel in soil (ppm)

\begin{tabular}{|c|c|c|c|c|c|c|c|c|}
\hline Nickel ppm & DDI & $\mathrm{CN}$ & AA & HH & HP & AO & SD & PD \\
\hline $\begin{array}{l}168 / 1.5 \\
\text { stdev }\end{array}$ & $\begin{array}{l}0.00 \\
0.00 \\
\end{array}$ & $\begin{array}{l}0.56 \\
0.14 \\
\end{array}$ & $\begin{array}{l}0.05 \\
0.08 \\
\end{array}$ & $\begin{array}{l}0.02 \\
0.01 \\
\end{array}$ & $\begin{array}{l}0.09 \\
0.07 \\
\end{array}$ & $\begin{array}{l}0.08 \\
0.00 \\
\end{array}$ & $\begin{array}{l}0.92 \\
0.10 \\
\end{array}$ & $\begin{array}{l}43.11 \\
42.58 \\
\end{array}$ \\
\hline $\begin{array}{l}168 \text { / } 20 \\
\text { stdev }\end{array}$ & $\begin{array}{r}15.43 \\
0.62\end{array}$ & \begin{tabular}{l|}
4.16 \\
0.40
\end{tabular} & $\begin{array}{l}0.09 \\
0.08\end{array}$ & $\begin{array}{l}0.05 \\
0.01\end{array}$ & \begin{tabular}{l|}
1.46 \\
0.05
\end{tabular} & $\begin{array}{l}0.31 \\
0.02\end{array}$ & $\begin{array}{l}1.01 \\
0.28\end{array}$ & $\begin{array}{l}13.62 \\
12.57\end{array}$ \\
\hline \begin{tabular}{|l}
168 / 31 \\
stdev
\end{tabular} & $\begin{array}{l}1.69 \\
0.03 \\
\end{array}$ & $\begin{array}{l}0.75 \\
0.26 \\
\end{array}$ & $\begin{array}{l}0.43 \\
0.07\end{array}$ & $\begin{array}{l}0.09 \\
0.02 \\
\end{array}$ & $\begin{array}{l}0.69 \\
0.09 \\
\end{array}$ & $\begin{array}{l}0.03 \\
0.00 \\
\end{array}$ & $\begin{array}{l}0.70 \\
0.09 \\
\end{array}$ & $\begin{array}{l}12.99 \\
10.91 \\
\end{array}$ \\
\hline $\begin{array}{l}170 / 1 \\
\text { stdev }\end{array}$ & $\begin{array}{l}0.04 \\
0.06\end{array}$ & $\begin{array}{l}0.28 \\
0.02\end{array}$ & $\begin{array}{l}0.09 \\
0.12\end{array}$ & $\begin{array}{l}0.02 \\
0.03\end{array}$ & $\begin{array}{l}0.14 \\
0.11\end{array}$ & $\begin{array}{l}0.01 \\
0.01\end{array}$ & $\begin{array}{l}1.01 \\
0.20\end{array}$ & $\begin{array}{l}24.62 \\
10.76\end{array}$ \\
\hline \begin{tabular}{|l|}
$\begin{array}{l}170 / 14 \\
\text { stdev }\end{array}$ \\
\end{tabular} & $\begin{array}{l}0.00 \\
0.00 \\
\end{array}$ & $\begin{array}{l}0.55 \\
0.12 \\
\end{array}$ & $\begin{array}{l}0.02 \\
0.03 \\
\end{array}$ & $\begin{array}{l}0.00 \\
0.00 \\
\end{array}$ & $\begin{array}{l}0.20 \\
0.19 \\
\end{array}$ & $\begin{array}{l}0.09 \\
0.03 \\
\end{array}$ & $\begin{array}{l}0.81 \\
0.27 \\
\end{array}$ & $\begin{array}{l}7.46 \\
0.08 \\
\end{array}$ \\
\hline $\begin{array}{l}170 \text { / } 20 \\
\text { stdev }\end{array}$ & $\begin{array}{l}2.72 \\
0.20\end{array}$ & $\begin{array}{l}0.00 \\
0.00\end{array}$ & $\begin{array}{l}2.33 \\
0.15\end{array}$ & $\begin{array}{l}0.00 \\
0.00\end{array}$ & $\begin{array}{l}0.55 \\
0.26\end{array}$ & $\begin{array}{l}0.09 \\
0.02\end{array}$ & $\begin{array}{l}0.58 \\
0.02\end{array}$ & $\begin{array}{r}12.08 \\
3.40\end{array}$ \\
\hline $\begin{array}{l}211 / 2 \\
\text { stdev }\end{array}$ & $\begin{array}{l}0.01 \\
0.02\end{array}$ & $\begin{array}{l}0.15 \\
0.21\end{array}$ & $\begin{array}{l}3.27 \\
2.85\end{array}$ & $\begin{array}{l}0.10 \\
0.06\end{array}$ & $\begin{array}{l}0.61 \\
0.22\end{array}$ & $\begin{array}{l}0.04 \\
0.00\end{array}$ & $\begin{array}{l}0.10 \\
0.10\end{array}$ & $\begin{array}{r}10.54 \\
4.22\end{array}$ \\
\hline $\begin{array}{l}211 / 9 \\
\text { stdev }\end{array}$ & $\begin{array}{l}0.01 \\
0.00\end{array}$ & $\begin{array}{l}0.00 \\
0.00\end{array}$ & $\begin{array}{l}1.80 \\
0.37\end{array}$ & $\begin{array}{l}0.09 \\
0.00\end{array}$ & $\begin{array}{l}0.58 \\
0.01\end{array}$ & $\begin{array}{l}0.03 \\
0.01\end{array}$ & $\begin{array}{l}0.00 \\
0.00\end{array}$ & $\begin{array}{r}13.34 \\
2.55\end{array}$ \\
\hline $\begin{array}{l}211 / 19 \\
\text { stdev }\end{array}$ & $\begin{array}{l}0.13 \\
0.01\end{array}$ & \begin{tabular}{l|}
1.17 \\
1.04
\end{tabular} & $\begin{array}{l}3.46 \\
1.33\end{array}$ & $\begin{array}{l}0.16 \\
0.03\end{array}$ & $\begin{array}{l}0.90 \\
0.13\end{array}$ & $\begin{array}{l}0.06 \\
0.00\end{array}$ & $\begin{array}{l}0.58 \\
0.06\end{array}$ & $\begin{array}{r}17.97 \\
2.73\end{array}$ \\
\hline $\begin{array}{l}211 / 35 \\
\text { stdev }\end{array}$ & $\begin{array}{l}0.38 \\
0.00 \\
\end{array}$ & $\begin{array}{l}0.15 \\
0.22 \\
\end{array}$ & $\begin{array}{l}6.17 \\
1.21 \\
\end{array}$ & $\begin{array}{l}0.07 \\
0.01 \\
\end{array}$ & $\begin{array}{l}0.35 \\
0.04 \\
\end{array}$ & $\begin{array}{l}0.01 \\
0.00 \\
\end{array}$ & $\begin{array}{l}0.58 \\
0.17 \\
\end{array}$ & $\begin{array}{r}5.72 \\
\mathrm{na} \\
\end{array}$ \\
\hline $\begin{array}{l}92 / 5 \\
\text { st dev }\end{array}$ & $\begin{array}{l}0.25 \\
0.04\end{array}$ & $\begin{array}{l}0.00 \\
0.00\end{array}$ & $\begin{array}{l}0.00 \\
0.00\end{array}$ & $\begin{array}{l}0.07 \\
0.01\end{array}$ & $\begin{array}{l}0.00 \\
0.00\end{array}$ & $\begin{array}{l}0.01 \\
0.01\end{array}$ & $\begin{array}{l}0.25 \\
0.18\end{array}$ & $\begin{array}{r}11.92 \\
\text { na }\end{array}$ \\
\hline $\begin{array}{l}92 / 21 \\
\text { st dev }\end{array}$ & $\begin{array}{l}0.06 \\
0.03\end{array}$ & $\begin{array}{l}0.18 \\
0.25\end{array}$ & $\begin{array}{l}0.72 \\
1.01\end{array}$ & $\begin{array}{l}0.72 \\
0.32\end{array}$ & $\begin{array}{l}0.00 \\
0.00\end{array}$ & $\begin{array}{l}0.00 \\
0.00\end{array}$ & $\begin{array}{l}0.11 \\
0.04\end{array}$ & $\begin{array}{l}\text { nd } \\
\text { nd }\end{array}$ \\
\hline $\begin{array}{l}85 / 32 \\
\text { st dev }\end{array}$ & $\begin{array}{l}0.02 \\
0.01\end{array}$ & $\begin{array}{r}24.98 \\
5.48\end{array}$ & $\begin{array}{l}1.43 \\
0.88\end{array}$ & $\begin{array}{l}0.04 \\
0.01\end{array}$ & $\begin{array}{l}0.14 \\
0.06\end{array}$ & $\begin{array}{l}0.03 \\
0.01\end{array}$ & $\begin{array}{l}0.05 \\
0.07\end{array}$ & $\begin{array}{r}11.55 \\
3.99\end{array}$ \\
\hline $\begin{array}{l}81 / 45 \\
\text { st dev }\end{array}$ & $\begin{array}{l}0.03 \\
0.00\end{array}$ & $\begin{array}{r}17.58 \\
1.29\end{array}$ & $\begin{array}{l}0.65 \\
0.92\end{array}$ & $\begin{array}{l}0.01 \\
0.00\end{array}$ & $\begin{array}{l}0.03 \\
0.01\end{array}$ & $\begin{array}{l}0.01 \\
0.02\end{array}$ & $\begin{array}{l}0.92 \\
0.20\end{array}$ & $\begin{array}{l}1.76 \\
2.23\end{array}$ \\
\hline $\begin{array}{l}87 \text { / } 38 \\
\text { st dev }\end{array}$ & $\begin{array}{l}0.03 \\
0.02\end{array}$ & $\begin{array}{r}23.16 \\
7.06\end{array}$ & $\begin{array}{l}8.63 \\
2.92\end{array}$ & $\begin{array}{l}0.03 \\
0.01\end{array}$ & $\begin{array}{l}0.04 \\
0.01\end{array}$ & $\begin{array}{l}0.01 \\
0.02\end{array}$ & $\begin{array}{l}0.02 \\
0.03\end{array}$ & $\begin{array}{l}8.40 \\
2.95\end{array}$ \\
\hline $\begin{array}{l}84 / 28 \\
\text { st dev }\end{array}$ & $\begin{array}{l}0.01 \\
0.01\end{array}$ & $\begin{array}{r}21.68 \\
0.14\end{array}$ & $\begin{array}{l}1.07 \\
0.40\end{array}$ & $\begin{array}{l}0.01 \\
0.00\end{array}$ & $\begin{array}{l}0.04 \\
0.04\end{array}$ & $\begin{array}{l}0.01 \\
0.00\end{array}$ & $\begin{array}{l}0.06 \\
0.04\end{array}$ & $\begin{array}{l}2.87 \\
0.25\end{array}$ \\
\hline $\begin{array}{l}83 / 42 \\
\text { st dev }\end{array}$ & $\begin{array}{l}0.10 \\
0.04\end{array}$ & $\begin{array}{r}17.49 \\
1.20\end{array}$ & $\begin{array}{r}32.07 \\
1.27\end{array}$ & $\begin{array}{l}1.97 \\
0.25\end{array}$ & $\begin{array}{l}1.95 \\
0.17\end{array}$ & $\begin{array}{l}0.53 \\
0.10\end{array}$ & $\begin{array}{l}0.81 \\
0.08\end{array}$ & $\begin{array}{l}1.57 \\
0.17\end{array}$ \\
\hline $\begin{array}{l}86 / 12 \\
\text { st dev }\end{array}$ & $\begin{array}{l}0.05 \\
0.00\end{array}$ & $\begin{array}{l}1.50 \\
2.02\end{array}$ & $\begin{array}{l}8.24 \\
1.55\end{array}$ & $\begin{array}{l}1.91 \\
0.04\end{array}$ & $\begin{array}{l}1.32 \\
0.22\end{array}$ & $\begin{array}{l}0.87 \\
0.05\end{array}$ & $\begin{array}{l}1.59 \\
0.02\end{array}$ & $\begin{array}{r}44.92 \\
3.60\end{array}$ \\
\hline
\end{tabular}


WSRC-TR-2004-00124, REVISION 0

Table B- 13. Upland arsenic in soil (ppm)

\begin{tabular}{|c|c|c|c|c|c|c|c|c|}
\hline Arsenic ppm & DDI & $\mathbf{C N}$ & $\mathbf{A A}$ & HH & HP & AO & SD & PD \\
\hline $\begin{array}{l}168 / 1.5 \\
\text { stdev }\end{array}$ & \begin{tabular}{l|}
0.01 \\
0.00
\end{tabular} & $\begin{array}{l}0.01 \\
0.00\end{array}$ & $\begin{array}{l}0.07 \\
0.03\end{array}$ & $\begin{array}{l}0.02 \\
0.00\end{array}$ & $\begin{array}{l}0.30 \\
0.00\end{array}$ & $\begin{array}{l}0.24 \\
0.01\end{array}$ & \begin{tabular}{l|l}
0.39 \\
0.16
\end{tabular} & $\begin{array}{l}2.07 \\
0.47\end{array}$ \\
\hline $\begin{array}{l}168 / 20 \\
\text { stdev }\end{array}$ & \begin{tabular}{l|}
0.38 \\
0.03
\end{tabular} & $\begin{array}{l}0.09 \\
0.04\end{array}$ & $\begin{array}{l}0.48 \\
0.02\end{array}$ & $\begin{array}{l}4.00 \\
0.04\end{array}$ & \begin{tabular}{l|l|}
5.54 \\
0.19
\end{tabular} & $\begin{array}{l}0.89 \\
0.01\end{array}$ & \begin{tabular}{l|}
1.26 \\
0.98
\end{tabular} & $\begin{array}{l}3.23 \\
1.39\end{array}$ \\
\hline $\begin{array}{l}168 / 31 \\
\text { stdev }\end{array}$ & \begin{tabular}{l|}
0.11 \\
0.01
\end{tabular} & $\begin{array}{l}0.02 \\
0.00\end{array}$ & $\begin{array}{l}0.48 \\
0.09\end{array}$ & $\begin{array}{l}1.24 \\
0.14\end{array}$ & $\begin{array}{l}1.67 \\
0.06\end{array}$ & $\begin{array}{l}0.20 \\
0.01\end{array}$ & \begin{tabular}{l|}
0.63 \\
0.31
\end{tabular} & $\begin{array}{l}3.02 \\
0.25\end{array}$ \\
\hline $\begin{array}{l}170 / 1 \\
\text { stdev }\end{array}$ & $\begin{array}{l}0.00 \\
0.00\end{array}$ & $\begin{array}{l}0.00 \\
0.00\end{array}$ & $\begin{array}{l}0.01 \\
0.01\end{array}$ & $\begin{array}{l}0.01 \\
0.00\end{array}$ & $\begin{array}{l}0.42 \\
0.03\end{array}$ & $\begin{array}{l}0.44 \\
0.02\end{array}$ & \begin{tabular}{l|}
1.86 \\
0.23
\end{tabular} & $\begin{array}{l}0.27 \\
0.25\end{array}$ \\
\hline \begin{tabular}{|l|}
$170 / 14$ \\
stdev
\end{tabular} & \begin{tabular}{l|}
0.00 \\
0.00
\end{tabular} & $\begin{array}{l}0.00 \\
0.00\end{array}$ & $\begin{array}{l}0.03 \\
0.02\end{array}$ & $\begin{array}{l}0.04 \\
0.00\end{array}$ & \begin{tabular}{l|}
0.05 \\
0.04
\end{tabular} & $\begin{array}{l}0.01 \\
0.00\end{array}$ & \begin{tabular}{l|}
0.05 \\
0.00
\end{tabular} & $\begin{array}{l}0.12 \\
0.13\end{array}$ \\
\hline \begin{tabular}{|l|}
$170 / 20$ \\
stdev
\end{tabular} & \begin{tabular}{l|}
0.01 \\
0.00
\end{tabular} & $\begin{array}{l}0.00 \\
0.00\end{array}$ & $\begin{array}{l}0.02 \\
0.00\end{array}$ & $\begin{array}{l}0.02 \\
0.00\end{array}$ & \begin{tabular}{l|}
0.21 \\
0.03
\end{tabular} & $\begin{array}{l}0.09 \\
0.00\end{array}$ & \begin{tabular}{l|}
0.05 \\
0.03
\end{tabular} & $\begin{array}{l}0.36 \\
0.08\end{array}$ \\
\hline $\begin{array}{l}211 / 2 \\
\text { stdev }\end{array}$ & \begin{tabular}{l|}
0.00 \\
0.00
\end{tabular} & \begin{tabular}{l|}
0.72 \\
0.20
\end{tabular} & $\begin{array}{l}0.03 \\
0.02\end{array}$ & $\begin{array}{l}0.01 \\
0.01\end{array}$ & $\begin{array}{l}0.07 \\
0.02\end{array}$ & $\begin{array}{l}0.38 \\
0.05\end{array}$ & \begin{tabular}{l|}
0.40 \\
0.01
\end{tabular} & $\begin{array}{l}1.16 \\
0.03\end{array}$ \\
\hline $\begin{array}{l}211 / 9 \\
\text { stdev }\end{array}$ & $\begin{array}{l}0.00 \\
0.00\end{array}$ & $\begin{array}{l}0.86 \\
0.05\end{array}$ & $\begin{array}{l}0.03 \\
0.01\end{array}$ & $\begin{array}{l}0.01 \\
0.00\end{array}$ & $\begin{array}{l}0.05 \\
0.01\end{array}$ & $\begin{array}{l}0.38 \\
0.01\end{array}$ & \begin{tabular}{l|}
0.94 \\
0.05
\end{tabular} & $\begin{array}{l}1.03 \\
0.22\end{array}$ \\
\hline \begin{tabular}{|l|}
$211 / 19$ \\
stdev
\end{tabular} & $\begin{array}{l}0.00 \\
0.00 \\
\end{array}$ & $\begin{array}{l}1.31 \\
0.53 \\
\end{array}$ & $\begin{array}{l}0.05 \\
0.01\end{array}$ & $\begin{array}{l}0.02 \\
0.00\end{array}$ & $\begin{array}{l}0.09 \\
0.01\end{array}$ & $\begin{array}{l}0.51 \\
0.09\end{array}$ & $\begin{array}{l}1.27 \\
0.15 \\
\end{array}$ & $\begin{array}{l}1.72 \\
0.20\end{array}$ \\
\hline $\begin{array}{l}211 / 35 \\
\text { stdev }\end{array}$ & \begin{tabular}{l|}
0.00 \\
0.00
\end{tabular} & \begin{tabular}{l|}
2.22 \\
0.50
\end{tabular} & $\begin{array}{l}0.06 \\
0.03\end{array}$ & $\begin{array}{l}0.01 \\
0.01\end{array}$ & \begin{tabular}{l|}
0.01 \\
0.00
\end{tabular} & $\begin{array}{l}0.01 \\
0.00\end{array}$ & \begin{tabular}{l|}
0.38 \\
0.10
\end{tabular} & $\begin{array}{r}0.11 \\
\text { na }\end{array}$ \\
\hline $\begin{array}{l}92 / 5 \\
\text { st dev }\end{array}$ & $\begin{array}{l}0.02 \\
0.01\end{array}$ & $\begin{array}{l}0.00 \\
0.00\end{array}$ & $\begin{array}{l}0.00 \\
0.00\end{array}$ & $\begin{array}{l}0.00 \\
0.00\end{array}$ & $\begin{array}{l}0.00 \\
0.00\end{array}$ & $\begin{array}{l}0.14 \\
0.00\end{array}$ & \begin{tabular}{l|}
0.59 \\
0.05
\end{tabular} & $\begin{array}{l}1.49 \\
0.00\end{array}$ \\
\hline $\begin{array}{l}92 / 21 \\
\text { st dev }\end{array}$ & \begin{tabular}{l|}
0.01 \\
0.00
\end{tabular} & $\begin{array}{l}0.00 \\
0.00\end{array}$ & $\begin{array}{l}1.07 \\
0.42\end{array}$ & $\begin{array}{l}0.02 \\
0.00\end{array}$ & $\begin{array}{l}0.02 \\
0.01\end{array}$ & $\begin{array}{l}0.00 \\
0.00\end{array}$ & \begin{tabular}{l|}
0.08 \\
0.12
\end{tabular} & $\begin{array}{l}0.36 \\
0.20\end{array}$ \\
\hline $\begin{array}{l}85 / 32 \\
\text { st dev }\end{array}$ & \begin{tabular}{l|}
0.00 \\
0.00
\end{tabular} & $\begin{array}{l}0.00 \\
0.01\end{array}$ & $\begin{array}{l}0.00 \\
0.00\end{array}$ & $\begin{array}{l}0.01 \\
0.00\end{array}$ & $\begin{array}{l}0.09 \\
0.03\end{array}$ & $\begin{array}{l}1.81 \\
0.49\end{array}$ & \begin{tabular}{l|}
0.33 \\
0.05
\end{tabular} & $\begin{array}{l}3.37 \\
4.77\end{array}$ \\
\hline \begin{tabular}{|l|}
$81 / 45$ \\
st dev
\end{tabular} & $\begin{array}{l}0.00 \\
0.00\end{array}$ & $\begin{array}{l}0.00 \\
0.01\end{array}$ & $\begin{array}{l}0.00 \\
0.00\end{array}$ & $\begin{array}{l}0.00 \\
0.00\end{array}$ & $\begin{array}{l}0.01 \\
0.00\end{array}$ & $\begin{array}{l}0.10 \\
0.04\end{array}$ & \begin{tabular}{l|}
0.11 \\
0.10
\end{tabular} & $\begin{array}{l}0.35 \\
0.50\end{array}$ \\
\hline $\begin{array}{l}87 \text { / } 38 \\
\text { st dev }\end{array}$ & \begin{tabular}{l|}
0.00 \\
0.00
\end{tabular} & $\begin{array}{l}0.00 \\
0.01\end{array}$ & $\begin{array}{l}0.00 \\
0.00\end{array}$ & $\begin{array}{l}0.00 \\
0.00\end{array}$ & $\begin{array}{l}0.01 \\
0.00\end{array}$ & $\begin{array}{l}0.03 \\
0.00\end{array}$ & \begin{tabular}{l|}
0.05 \\
0.02
\end{tabular} & $\begin{array}{l}0.61 \\
0.01\end{array}$ \\
\hline $\begin{array}{l}84 / 28 \\
\text { st dev }\end{array}$ & $\begin{array}{l}0.00 \\
0.00\end{array}$ & $\begin{array}{l}0.00 \\
0.01\end{array}$ & $\begin{array}{l}0.00 \\
0.00\end{array}$ & $\begin{array}{l}0.01 \\
0.00\end{array}$ & $\begin{array}{l}0.01 \\
0.00\end{array}$ & $\begin{array}{l}0.02 \\
0.00\end{array}$ & $\begin{array}{l}0.03 \\
0.01\end{array}$ & $\begin{array}{l}0.05 \\
0.07\end{array}$ \\
\hline $\begin{array}{l}83 / 42 \\
\text { st dev }\end{array}$ & \begin{tabular}{l|}
0.00 \\
0.00
\end{tabular} & $\begin{array}{l}0.00 \\
0.01\end{array}$ & $\begin{array}{l}0.00 \\
0.00\end{array}$ & $\begin{array}{l}0.37 \\
0.03\end{array}$ & $\begin{array}{l}0.22 \\
0.02\end{array}$ & $\begin{array}{l}1.23 \\
0.05\end{array}$ & \begin{tabular}{l|}
0.69 \\
0.09
\end{tabular} & $\begin{array}{l}0.66 \\
0.08\end{array}$ \\
\hline $\begin{array}{l}86 / 12 \\
\text { st dev }\end{array}$ & \begin{tabular}{l|}
1.68 \\
0.12
\end{tabular} & \begin{tabular}{|l|}
1.33 \\
1.20
\end{tabular} & $\begin{array}{r}11.56 \\
0.06\end{array}$ & $\begin{array}{r}17.43 \\
0.19\end{array}$ & $\begin{array}{l}1.55 \\
0.02\end{array}$ & $\begin{array}{l}8.04 \\
0.07\end{array}$ & \begin{tabular}{l|}
0.58 \\
0.09
\end{tabular} & $\begin{array}{l}1.56 \\
0.03\end{array}$ \\
\hline
\end{tabular}


WSRC-TR-2004-00124, REVISION 0

Table B- 14. Upland uranium in soil (ppm)

\begin{tabular}{|c|c|c|c|c|c|c|c|c|}
\hline Uranium ppm & DDI & $\mathbf{C N}$ & $\mathbf{A A}$ & HH & HP & AO & SD & PD \\
\hline $\begin{array}{l}168 / 1.5 \\
\text { stdev }\end{array}$ & $\begin{array}{l}\mathrm{nd} \\
\mathrm{nd}\end{array}$ & $\begin{array}{l}0.03 \\
0.01\end{array}$ & $\begin{array}{l}0.24 \\
0.04\end{array}$ & $\begin{array}{l}\mathrm{nd} \\
\mathrm{nd}\end{array}$ & $\begin{array}{ll}\mathrm{nd} \\
\mathrm{nd}\end{array}$ & \begin{tabular}{l|}
0.09 \\
0.01
\end{tabular} & \begin{tabular}{l|}
0.05 \\
0.03
\end{tabular} & $\begin{array}{l}2.32 \\
0.10\end{array}$ \\
\hline $\begin{array}{l}168 / 20 \\
\text { stdev }\end{array}$ & $\begin{array}{l}\mathrm{nd} \\
\mathrm{nd}\end{array}$ & $\begin{array}{ll}0.31 \\
0.01\end{array}$ & $\begin{array}{l}1.21 \\
0.05\end{array}$ & $\begin{array}{l}\mathrm{nd} \\
\mathrm{nd}\end{array}$ & $\begin{array}{ll}\mathrm{nd} \\
\mathrm{nd}\end{array}$ & \begin{tabular}{l|}
0.41 \\
0.02
\end{tabular} & \begin{tabular}{l|}
0.15 \\
0.00
\end{tabular} & $\begin{array}{l}2.82 \\
0.74\end{array}$ \\
\hline $\begin{array}{l}168 / 31 \\
\text { stdev }\end{array}$ & \begin{tabular}{l|}
1.08 \\
0.33
\end{tabular} & $\begin{array}{l}0.08 \\
0.03\end{array}$ & $\begin{array}{l}0.28 \\
0.03\end{array}$ & $\begin{array}{l}0.07 \\
0.01\end{array}$ & \begin{tabular}{l|}
0.13 \\
0.11
\end{tabular} & $\begin{array}{l}0.09 \\
0.01\end{array}$ & \begin{tabular}{l|}
0.08 \\
0.03
\end{tabular} & $\begin{array}{l}1.30 \\
0.23\end{array}$ \\
\hline $\begin{array}{l}170 / 1 \\
\text { stdev }\end{array}$ & \begin{tabular}{l|}
0.00 \\
0.00
\end{tabular} & $\begin{array}{l}0.01 \\
0.01\end{array}$ & $\begin{array}{l}0.18 \\
0.03\end{array}$ & \begin{tabular}{l|}
0.03 \\
0.01
\end{tabular} & \begin{tabular}{l|}
0.15 \\
0.02
\end{tabular} & $\begin{array}{l}0.07 \\
0.00\end{array}$ & \begin{tabular}{l|}
0.06 \\
0.01
\end{tabular} & $\begin{array}{l}0.54 \\
0.20\end{array}$ \\
\hline $\begin{array}{l}170 / 14 \\
\text { stdev }\end{array}$ & \begin{tabular}{l|}
0.00 \\
0.00
\end{tabular} & $\begin{array}{l}0.00 \\
0.00\end{array}$ & $\begin{array}{l}0.11 \\
0.01\end{array}$ & \begin{tabular}{l|}
0.00 \\
0.00
\end{tabular} & \begin{tabular}{l|}
0.00 \\
0.00
\end{tabular} & \begin{tabular}{l|}
0.00 \\
0.00
\end{tabular} & \begin{tabular}{l|}
0.00 \\
0.00
\end{tabular} & $\begin{array}{l}0.33 \\
0.08\end{array}$ \\
\hline \begin{tabular}{|l|}
$170 / 20$ \\
stdev
\end{tabular} & $\begin{array}{l}0.00 \\
0.00\end{array}$ & $\begin{array}{l}0.00 \\
0.00\end{array}$ & $\begin{array}{l}0.00 \\
0.00\end{array}$ & \begin{tabular}{l|}
0.00 \\
0.00
\end{tabular} & \begin{tabular}{l|}
0.00 \\
0.00
\end{tabular} & \begin{tabular}{l|}
0.02 \\
0.00
\end{tabular} & \begin{tabular}{l|}
0.02 \\
0.01
\end{tabular} & $\begin{array}{l}0.89 \\
0.07\end{array}$ \\
\hline $\begin{array}{l}211 / 2 \\
\text { stdev }\end{array}$ & \begin{tabular}{l|}
0.00 \\
0.00
\end{tabular} & $\begin{array}{l}0.04 \\
0.01\end{array}$ & $\begin{array}{l}0.04 \\
0.01\end{array}$ & \begin{tabular}{l|}
0.03 \\
0.00
\end{tabular} & \begin{tabular}{l|}
0.29 \\
0.05
\end{tabular} & \begin{tabular}{l|}
0.01 \\
0.00
\end{tabular} & \begin{tabular}{l|}
0.00 \\
0.00
\end{tabular} & $\begin{array}{l}0.42 \\
0.00\end{array}$ \\
\hline $\begin{array}{l}211 / 9 \\
\text { stdev }\end{array}$ & $\begin{array}{l}0.00 \\
0.00\end{array}$ & $\begin{array}{l}0.07 \\
0.02\end{array}$ & $\begin{array}{l}0.00 \\
0.00\end{array}$ & \begin{tabular}{l|}
0.04 \\
0.00
\end{tabular} & \begin{tabular}{l|}
0.65 \\
0.07
\end{tabular} & \begin{tabular}{l|}
0.03 \\
0.00
\end{tabular} & \begin{tabular}{l|}
0.03 \\
0.00
\end{tabular} & $\begin{array}{l}0.51 \\
0.22\end{array}$ \\
\hline \begin{tabular}{|l|}
$211 / 19$ \\
stdev
\end{tabular} & \begin{tabular}{l|}
0.00 \\
0.00
\end{tabular} & $\begin{array}{l}0.04 \\
0.00\end{array}$ & $\begin{array}{l}0.01 \\
0.00\end{array}$ & $\begin{array}{l}0.09 \\
0.02\end{array}$ & $\begin{array}{l}0.58 \\
0.02 \\
\end{array}$ & $\begin{array}{l}0.31 \\
0.02 \\
\end{array}$ & $\begin{array}{l}0.34 \\
0.07\end{array}$ & $\begin{array}{l}0.72 \\
0.14\end{array}$ \\
\hline $\begin{array}{l}211 / 35 \\
\text { stdev }\end{array}$ & \begin{tabular}{l|}
0.00 \\
0.00
\end{tabular} & $\begin{array}{l}0.03 \\
0.01\end{array}$ & $\begin{array}{l}0.00 \\
0.00\end{array}$ & \begin{tabular}{l|}
0.01 \\
0.01
\end{tabular} & \begin{tabular}{l|}
0.12 \\
0.04
\end{tabular} & $\begin{array}{l}0.00 \\
0.00\end{array}$ & \begin{tabular}{l|}
0.00 \\
0.00
\end{tabular} & $\begin{array}{r}0.07 \\
\mathrm{na}\end{array}$ \\
\hline $\begin{array}{l}92 / 5 \\
\text { st dev }\end{array}$ & $\begin{array}{l}2.13 \\
1.34\end{array}$ & $\begin{array}{l}0.01 \\
0.01\end{array}$ & $\begin{array}{l}3.29 \\
1.15\end{array}$ & \begin{tabular}{l|}
0.01 \\
0.00
\end{tabular} & \begin{tabular}{l|}
0.10 \\
0.02
\end{tabular} & \begin{tabular}{l|}
0.01 \\
0.00
\end{tabular} & \begin{tabular}{l|}
0.00 \\
0.00
\end{tabular} & $\begin{array}{l}1.41 \\
0.00\end{array}$ \\
\hline $\begin{array}{l}92 / 21 \\
\text { st dev }\end{array}$ & \begin{tabular}{l|}
0.39 \\
0.21
\end{tabular} & $\begin{array}{l}0.00 \\
0.00\end{array}$ & $\begin{array}{l}0.74 \\
0.54\end{array}$ & $\begin{array}{l}0.00 \\
0.00\end{array}$ & \begin{tabular}{l|}
0.05 \\
0.02
\end{tabular} & \begin{tabular}{l|}
0.01 \\
0.00
\end{tabular} & \begin{tabular}{l|}
0.01 \\
0.02
\end{tabular} & $\begin{array}{l}0.01 \\
0.00\end{array}$ \\
\hline $\begin{array}{l}85 / 32 \\
\text { st dev }\end{array}$ & \begin{tabular}{l|}
0.00 \\
0.00
\end{tabular} & \begin{tabular}{l|}
0.32 \\
0.10
\end{tabular} & $\begin{array}{l}0.00 \\
0.01\end{array}$ & $\begin{array}{l}0.00 \\
0.01\end{array}$ & \begin{tabular}{l|}
0.04 \\
0.05
\end{tabular} & \begin{tabular}{l|}
0.05 \\
0.02
\end{tabular} & \begin{tabular}{l|}
0.00 \\
0.00
\end{tabular} & $\begin{array}{l}0.38 \\
0.02\end{array}$ \\
\hline \begin{tabular}{|l|}
$81 / 45$ \\
st dev
\end{tabular} & \begin{tabular}{l|}
0.00 \\
0.00
\end{tabular} & $\begin{array}{l}3.61 \\
1.14 \\
\end{array}$ & $\begin{array}{l}0.00 \\
0.01\end{array}$ & $\begin{array}{l}0.00 \\
0.01\end{array}$ & $\begin{array}{l}0.00 \\
0.00\end{array}$ & $\begin{array}{l}0.05 \\
0.00\end{array}$ & $\begin{array}{l}0.00 \\
0.00\end{array}$ & $\begin{array}{l}1.29 \\
1.52\end{array}$ \\
\hline $\begin{array}{l}87 \text { / } 38 \\
\text { st dev }\end{array}$ & $\begin{array}{l}0.00 \\
0.00\end{array}$ & $\begin{array}{l}0.14 \\
0.05\end{array}$ & $\begin{array}{l}0.00 \\
0.01\end{array}$ & \begin{tabular}{l|}
0.00 \\
0.01
\end{tabular} & \begin{tabular}{l|}
0.09 \\
0.01
\end{tabular} & \begin{tabular}{l|}
0.05 \\
0.00
\end{tabular} & \begin{tabular}{l|}
0.00 \\
0.00
\end{tabular} & $\begin{array}{l}0.84 \\
0.49\end{array}$ \\
\hline $\begin{array}{l}84 / 28 \\
\text { st dev }\end{array}$ & \begin{tabular}{l|}
0.00 \\
0.00
\end{tabular} & $\begin{array}{l}0.68 \\
0.14\end{array}$ & $\begin{array}{l}0.00 \\
0.01\end{array}$ & $\begin{array}{l}0.00 \\
0.01\end{array}$ & $\begin{array}{l}0.07 \\
0.04\end{array}$ & $\begin{array}{l}0.03 \\
0.01\end{array}$ & $\begin{array}{l}0.00 \\
0.00\end{array}$ & $\begin{array}{l}0.81 \\
0.05\end{array}$ \\
\hline $\begin{array}{l}83 / 42 \\
\text { st dev }\end{array}$ & \begin{tabular}{l|}
0.00 \\
0.00
\end{tabular} & $\begin{array}{l}1.42 \\
0.54\end{array}$ & $\begin{array}{l}0.08 \\
0.03\end{array}$ & \begin{tabular}{l|}
0.90 \\
0.11
\end{tabular} & \begin{tabular}{l|}
0.03 \\
0.01
\end{tabular} & \begin{tabular}{l|}
0.01 \\
0.00
\end{tabular} & \begin{tabular}{l|}
0.00 \\
0.00
\end{tabular} & $\begin{array}{l}0.07 \\
0.02\end{array}$ \\
\hline $\begin{array}{l}86 / 12 \\
\text { st dev }\end{array}$ & \begin{tabular}{l|}
0.07 \\
0.02
\end{tabular} & $\begin{array}{l}0.16 \\
0.06\end{array}$ & $\begin{array}{l}0.47 \\
0.10\end{array}$ & \begin{tabular}{l|}
0.91 \\
0.14
\end{tabular} & \begin{tabular}{l|}
0.55 \\
0.13
\end{tabular} & \begin{tabular}{l|}
0.98 \\
0.75
\end{tabular} & $\begin{array}{l}5.94 \\
2.71\end{array}$ & $\begin{array}{l}4.17 \\
0.18\end{array}$ \\
\hline
\end{tabular}


WSRC-TR-2004-00124, REVISION 0

Table B- 15. Upland iron in soil (ppm)

\begin{tabular}{|c|c|c|c|c|c|c|c|c|}
\hline Iron ppm & DDI & $\mathrm{CN}$ & $\mathbf{A A}$ & HH & HP & AO & SD & PD \\
\hline $\begin{array}{l}168 / 1.5 \\
\text { stdev }\end{array}$ & $\begin{array}{l}0.61 \\
0.75 \\
\end{array}$ & $\begin{array}{r}28.85 \\
0.03 \\
\end{array}$ & $\begin{array}{r}348.84 \\
1.40 \\
\end{array}$ & $\begin{array}{r}46.45 \\
0.33 \\
\end{array}$ & $\begin{array}{r}144.25 \\
6.54 \\
\end{array}$ & $\begin{array}{r}430.80 \\
20.66 \\
\end{array}$ & $\begin{array}{r}1612.26 \\
11.03 \\
\end{array}$ & $\begin{array}{r}14908.57 \\
1940.99 \\
\end{array}$ \\
\hline $\begin{array}{l}168 / 20 \\
\text { stdev }\end{array}$ & \begin{tabular}{r|}
1297.42 \\
29.61
\end{tabular} & $\begin{array}{r}527.64 \\
21.25\end{array}$ & $\begin{array}{r}372.86 \\
3.83\end{array}$ & $\begin{array}{r}146.39 \\
1.32\end{array}$ & \begin{tabular}{r|}
1363.02 \\
130.35
\end{tabular} & $\begin{array}{r}267.19 \\
33.49\end{array}$ & $\begin{array}{l}376.41 \\
180.99\end{array}$ & $\begin{array}{r}10149.62 \\
2114.74\end{array}$ \\
\hline $\begin{array}{l}168 / 31 \\
\text { stdev }\end{array}$ & $\begin{array}{l}290.62 \\
408.38\end{array}$ & $\begin{array}{r}269.58 \\
17.76\end{array}$ & $\begin{array}{r}186.56 \\
9.13\end{array}$ & $\begin{array}{r}30.20 \\
1.82\end{array}$ & $\begin{array}{r}893.16 \\
77.03\end{array}$ & $\begin{array}{r}87.05 \\
4.66\end{array}$ & $\begin{array}{l}265.93 \\
170.92\end{array}$ & $\begin{array}{l}4917.91 \\
2268.35\end{array}$ \\
\hline $\begin{array}{l}170 / 1 \\
\text { stdev }\end{array}$ & \begin{tabular}{l|}
2.93 \\
0.19
\end{tabular} & $\begin{array}{l}2.64 \\
0.92\end{array}$ & $\begin{array}{r}15.45 \\
1.04\end{array}$ & $\begin{array}{r}25.52 \\
2.59\end{array}$ & \begin{tabular}{l|}
46.17 \\
14.25
\end{tabular} & $\begin{array}{r}453.70 \\
1.96\end{array}$ & $\begin{array}{r}2896.75 \\
26.19\end{array}$ & $\begin{array}{l}3090.42 \\
1008.09\end{array}$ \\
\hline $\begin{array}{l}170 / 14 \\
\text { stdev }\end{array}$ & \begin{tabular}{l|}
4.21 \\
2.91
\end{tabular} & $\begin{array}{l}1.60 \\
0.13\end{array}$ & $\begin{array}{l}2.54 \\
0.06\end{array}$ & $\begin{array}{r}36.20 \\
0.28\end{array}$ & $\begin{array}{r}10.96 \\
0.09\end{array}$ & $\begin{array}{l}3.18 \\
0.26\end{array}$ & $\begin{array}{r}121.80 \\
0.77\end{array}$ & $\begin{array}{r}1971.96 \\
165.47\end{array}$ \\
\hline $\begin{array}{l}170 / 20 \\
\text { stdev }\end{array}$ & $\begin{array}{r}424.30 \\
45.58\end{array}$ & $\begin{array}{r}52.60 \\
1.93\end{array}$ & $\begin{array}{r}136.91 \\
10.49\end{array}$ & $\begin{array}{l}4.26 \\
0.40\end{array}$ & $\begin{array}{r}587.75 \\
20.77\end{array}$ & $\begin{array}{r}88.92 \\
5.00\end{array}$ & $\begin{array}{l}237.61 \\
119.05\end{array}$ & $\begin{array}{l}9344.83 \\
1073.76\end{array}$ \\
\hline $\begin{array}{l}211 / 2 \\
\text { stdev }\end{array}$ & \begin{tabular}{l|}
0.02 \\
0.03
\end{tabular} & $\begin{array}{l}1.28 \\
1.03\end{array}$ & $\begin{array}{r}16.90 \\
3.42\end{array}$ & $\begin{array}{r}24.37 \\
0.31\end{array}$ & \begin{tabular}{r|}
75.51 \\
1.01
\end{tabular} & $\begin{array}{r}400.57 \\
88.55\end{array}$ & $\begin{array}{r}1912.85 \\
66.53 \\
\end{array}$ & $\begin{array}{r}1819.22 \\
135.37\end{array}$ \\
\hline $\begin{array}{l}211 / 9 \\
\text { stdev }\end{array}$ & $\begin{array}{l}0.04 \\
0.00\end{array}$ & $\begin{array}{l}3.09 \\
1.23\end{array}$ & $\begin{array}{l}7.95 \\
0.47\end{array}$ & $\begin{array}{l}8.09 \\
0.10\end{array}$ & $\begin{array}{r}47.94 \\
0.75\end{array}$ & $\begin{array}{r}338.38 \\
10.80\end{array}$ & $\begin{array}{r}5310.57 \\
37.21\end{array}$ & $\begin{array}{r}3160.31 \\
863.50\end{array}$ \\
\hline $\begin{array}{l}211 / 19 \\
\text { stdev }\end{array}$ & $\begin{array}{r}10.07 \\
0.50\end{array}$ & $\begin{array}{r}71.42 \\
1.61\end{array}$ & $\begin{array}{r}56.93 \\
1.37\end{array}$ & $\begin{array}{r}170.80 \\
9.19\end{array}$ & $\begin{array}{r}552.19 \\
29.84\end{array}$ & $\begin{array}{r}5290.34 \\
552.74\end{array}$ & $\begin{array}{r}12941.90 \\
1004.44\end{array}$ & $\begin{array}{r}11588.75 \\
993.32\end{array}$ \\
\hline $\begin{array}{l}211 / 35 \\
\text { stdev }\end{array}$ & $\begin{array}{r}44.23 \\
0.91\end{array}$ & $\begin{array}{r}13.49 \\
0.28\end{array}$ & $\begin{array}{r}36.78 \\
0.49\end{array}$ & $\begin{array}{r}66.98 \\
4.14\end{array}$ & \begin{tabular}{r|}
87.51 \\
1.71
\end{tabular} & $\begin{array}{r}212.99 \\
14.59\end{array}$ & $\begin{array}{r}2805.41 \\
9.84\end{array}$ & $\begin{array}{r}280.70 \\
\text { na }\end{array}$ \\
\hline $\begin{array}{l}92 / 5 \\
\text { st dev }\end{array}$ & $\begin{array}{r}386.97 \\
50.47\end{array}$ & $\begin{array}{l}9.08 \\
2.10\end{array}$ & $\begin{array}{r}53.74 \\
0.37\end{array}$ & $\begin{array}{r}25.67 \\
4.98\end{array}$ & $\begin{array}{r}205.57 \\
2.80\end{array}$ & $\begin{array}{r}653.42 \\
15.39\end{array}$ & $\begin{array}{r}2533.96 \\
101.15\end{array}$ & $\begin{array}{l}\mathrm{nd} \\
\mathrm{nd}\end{array}$ \\
\hline $\begin{array}{l}92 / 21 \\
\text { st dev }\end{array}$ & $\begin{array}{r}271.98 \\
2.78\end{array}$ & $\begin{array}{l}10.26 \\
14.45\end{array}$ & $\begin{array}{r}17.16 \\
4.58\end{array}$ & $\begin{array}{r}16.99 \\
1.34\end{array}$ & $\begin{array}{r}161.59 \\
2.38\end{array}$ & $\begin{array}{r}138.73 \\
15.71\end{array}$ & $\begin{array}{r}93.91 \\
5.69\end{array}$ & $\begin{array}{l}\mathrm{nd} \\
\mathrm{nd}\end{array}$ \\
\hline $\begin{array}{l}85 / 32 \\
\text { st dev }\end{array}$ & \begin{tabular}{l|}
0.04 \\
0.00
\end{tabular} & $\begin{array}{l}0.04 \\
0.01\end{array}$ & $\begin{array}{r}28.90 \\
6.02\end{array}$ & $\begin{array}{r}17.57 \\
0.21\end{array}$ & $\begin{array}{r}124.36 \\
8.55\end{array}$ & $\begin{array}{l}623.71 \\
107.56\end{array}$ & $\begin{array}{r}130.34 \\
21.22\end{array}$ & $\begin{array}{r}1307.46 \\
160.54\end{array}$ \\
\hline $\begin{array}{l}81 / 45 \\
\text { st dev }\end{array}$ & \begin{tabular}{l|}
0.19 \\
0.12
\end{tabular} & $\begin{array}{l}0.04 \\
0.01\end{array}$ & $\begin{array}{r}21.08 \\
6.06\end{array}$ & $\begin{array}{r}14.21 \\
7.26\end{array}$ & $\begin{array}{l}67.47 \\
20.64\end{array}$ & $\begin{array}{l}209.17 \\
118.76\end{array}$ & $\begin{array}{l}604.75 \\
257.75\end{array}$ & $\begin{array}{l}10811.46 \\
12057.36\end{array}$ \\
\hline $\begin{array}{l}87 / 38 \\
\text { st dev }\end{array}$ & \begin{tabular}{l|}
0.75 \\
0.15
\end{tabular} & $\begin{array}{l}0.04 \\
0.01\end{array}$ & $\begin{array}{r}20.58 \\
0.66\end{array}$ & $\begin{array}{l}9.90 \\
0.40\end{array}$ & \begin{tabular}{r|}
59.10 \\
0.57
\end{tabular} & $\begin{array}{r}187.84 \\
13.32\end{array}$ & $\begin{array}{r}602.02 \\
88.38\end{array}$ & $\begin{array}{r}1626.48 \\
92.70\end{array}$ \\
\hline $\begin{array}{l}84 / 28 \\
\text { st dev }\end{array}$ & \begin{tabular}{l|}
0.04 \\
0.00
\end{tabular} & $\begin{array}{l}0.04 \\
0.01\end{array}$ & $\begin{array}{r}12.15 \\
4.93\end{array}$ & $\begin{array}{r}13.98 \\
4.76\end{array}$ & $\begin{array}{l}60.25 \\
17.53\end{array}$ & $\begin{array}{l}71.37 \\
18.70\end{array}$ & $\begin{array}{r}291.23 \\
70.16\end{array}$ & $\begin{array}{r}3272.46 \\
437.36\end{array}$ \\
\hline $\begin{array}{l}83 / 42 \\
\text { st dev }\end{array}$ & \begin{tabular}{l|}
0.20 \\
0.14
\end{tabular} & $\begin{array}{l}0.04 \\
0.01\end{array}$ & $\begin{array}{l}5.97 \\
0.97\end{array}$ & $\begin{array}{r}1158.84 \\
60.11\end{array}$ & $\begin{array}{r}2855.64 \\
360.58\end{array}$ & $\begin{array}{r}1034.61 \\
169.37\end{array}$ & $\begin{array}{r}3018.38 \\
360.42\end{array}$ & $\begin{array}{r}4708.95 \\
856.34\end{array}$ \\
\hline $\begin{array}{l}86 / 12 \\
\text { st dev }\end{array}$ & $\begin{array}{l}0.04 \\
0.00\end{array}$ & $\begin{array}{l}269.56 \\
381.16\end{array}$ & $\begin{array}{r}455.16 \\
7.42\end{array}$ & $\begin{array}{r}582.32 \\
13.91\end{array}$ & $\begin{array}{r}390.79 \\
39.93\end{array}$ & $\begin{array}{r}1762.35 \\
110.64\end{array}$ & $\begin{array}{r}2098.45 \\
19.14\end{array}$ & nd \\
\hline
\end{tabular}


WSRC-TR-2004-00124, REVISION 0

APPENDIX C.

AMORPHOUS OXIDE SINGLE STEP EXTRACTION RESULTS (ppm)

\begin{tabular}{|c|c|c|c|c|c|c|}
\hline $\begin{array}{c}\text { AO SS } \\
\text { ppm }\end{array}$ & Beryllium & Aluminum & Nickel & Arsenic & Uranium & Iron \\
\hline $92 / 5$ & 0.068 & 4.949 & 0.749 & 0.130 & 0.126 & 513.370 \\
\hline $92 / 21$ & 0.177 & 2.686 & 0.339 & 0.013 & 0.116 & 707.078 \\
\hline $85 / 32$ & 0.295 & 3.771 & 0.382 & 1.518 & 0.433 & 219.226 \\
\hline $85 / 45$ & 0.109 & 13.476 & 0.514 & 0.088 & 0.070 & 485.368 \\
\hline $81 / 30$ & 0.565 & 3.225 & 0.567 & 0.311 & 1.702 & 262.031 \\
\hline $81 / 45$ & 0.481 & 4.359 & 0.274 & 0.116 & 0.139 & 7697.497 \\
\hline $81 / 50$ & 7.015 & 1.101 & 2.282 & 0.811 & 1.274 & 327.920 \\
\hline $87 / 33$ & 0.144 & 4.075 & 0.267 & 0.323 & 0.934 & 249.183 \\
\hline $87 / 38$ & 0.064 & 4.826 & 0.183 & 0.049 & 0.512 & 208.165 \\
\hline $87 / 53$ & 0.889 & 6.549 & 0.177 & 0.074 & 0.394 & 3.905 \\
\hline $84 / 20$ & 0.019 & 10.409 & 0.170 & 0.012 & 0.053 & 19.667 \\
\hline $84 / 28$ & 0.064 & 7.266 & 0.169 & 0.030 & 0.237 & 68.129 \\
\hline $84 / 38$ & 2.602 & 3.302 & 0.578 & 0.381 & 2.598 & 1400.714 \\
\hline $83 / 32$ & 2.415 & 2.783 & 0.507 & 0.092 & 3.970 & 685.128 \\
\hline $83 / 38$ & 1.418 & 3.400 & 2.167 & 0.404 & 1.645 & 449.420 \\
\hline $83 / 42$ & 3.775 & 3.641 & 4.830 & 0.851 & 2.074 & 2028.944 \\
\hline 86 & 1.814 & 0.986 & 4.829 & 36.767 & 3.907 & 0 \\
\hline
\end{tabular}


This page intentionally left blank. 


\section{APPENDIX D. NOTES ON DISCRIMINANT ANALYSIS BY REGION ON THE BASIS OF BIOLOG ${ }^{\circledR}$ TESTING OF SOIL SLURRIES}

\section{Part 1 of 3, Discriminant Analysis by Region}

\section{Carbon Source Means by Region}

\begin{tabular}{|c|c|c|c|}
\hline $\begin{array}{l}\text { Area } \\
\text { Number of Sampling Locations }\end{array}$ & $\frac{\text { Upland }}{15}$ & $\frac{\text { Wetland }}{6}$ & $\frac{\text { All }}{21}$ \\
\hline \multicolumn{4}{|l|}{$\%$ for Carbon Source } \\
\hline Polymers & 12 & 27 & 16 \\
\hline Carbohydrates & 12 & 38 & 20 \\
\hline Esters & 20 & 25 & 21 \\
\hline Carboxylic Acids & 17 & 29 & 20 \\
\hline Amides & 13 & 6 & 11 \\
\hline Amino Acids & 14 & 36 & 20 \\
\hline Aromatic Chemicals & 3 & 42 & 14 \\
\hline Amines & 7 & 28 & 13 \\
\hline Alcohols & 17 & 25 & 19 \\
\hline Phosphorylated Chemicals & 7 & 39 & 16 \\
\hline
\end{tabular}

Canonical Plot of Sampling Locations for the First 2 Discriminant Factors

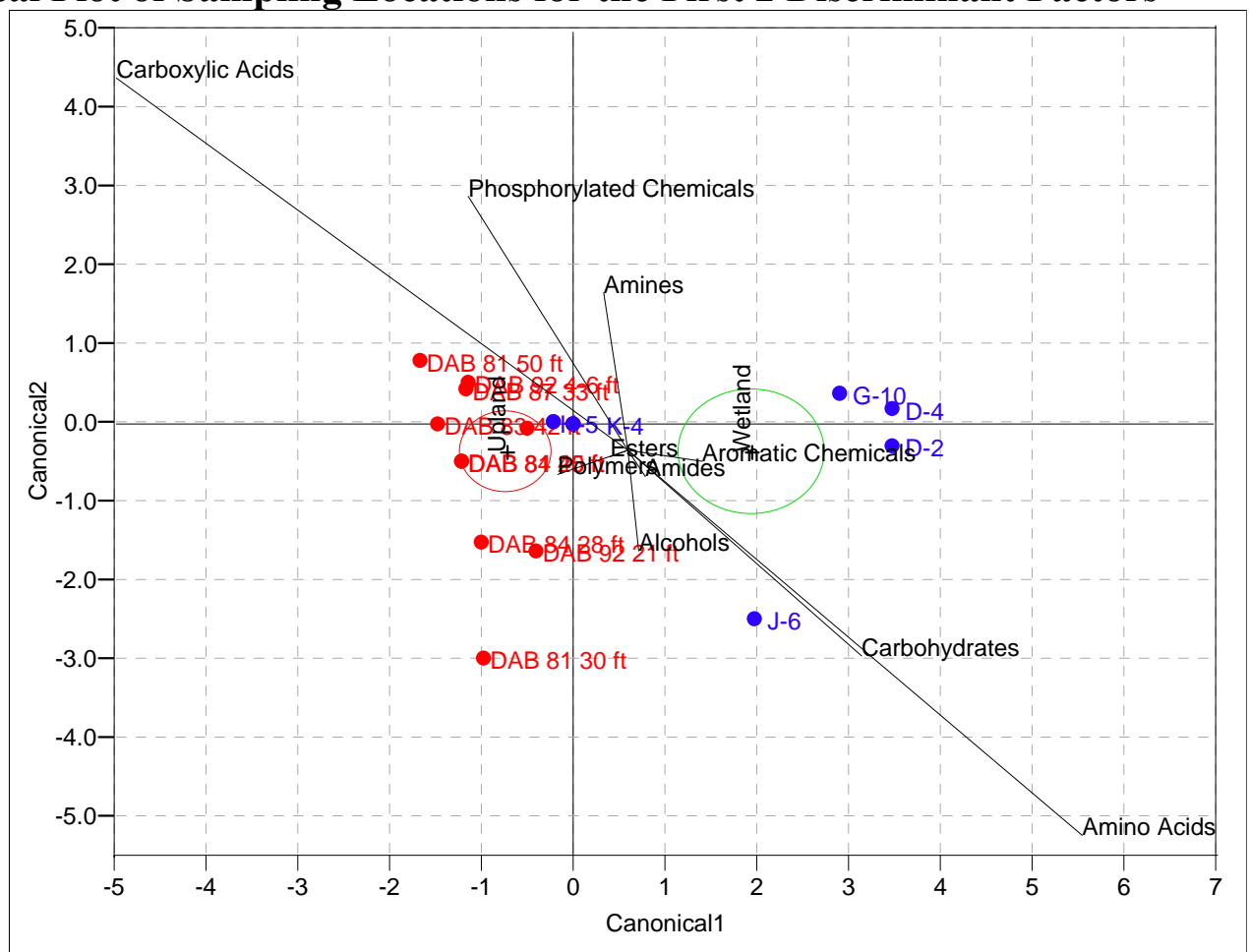




Discriminant Scores
\begin{tabular}{|lc|}
\hline Number Misclassified & 2 \\
Percent Misclassified & 9.524 \\
-2LogLikelihood & 5.12 \\
\hline & \multicolumn{1}{|c|}{ Coefficient } \\
\hline Eigenvectors & $\underline{\text { Scores }}$ \\
\hline Polymers & -0.0303 \\
Carbohydrates & 0.1072 \\
Esters & -0.0060 \\
Carboxylic Acids & -0.2368 \\
Amides & 0.0086 \\
Amino Acids & 0.1797 \\
Aromatic Chemicals & 0.0363 \\
Amines & -0.0118 \\
Alcohols & 0.0035 \\
Phosphorylated & \\
Chemicals & -0.0519 \\
\hline
\end{tabular}

This discriminant analysis between upland \& wetland groups assumes that the wetland \& upland wells were correctly classified. However, the results indicate that 2 wetland wells appear to be consistent with upland the biolog structure. Since there are 2 populations, upland \& wetland, there is only one linear discriminant function used to separate the populations. The coefficient scores for this discrimant function are given in the table just above. A good discrimant function should have an interpretation that makes sense to the scientist. This function weights carbohydrates, carbolic acids, \& amino acids most heavily. This is pictured in the canonical plot on the left. These canonical plots are created to depict the 2 most important discrimant functions, one on the horizontal axis \& two on the vertical axis. Since only 1 discrimant function is used here, the distances along the $\mathrm{x}$-axis are meaningful; the distances on the y-axis are not. 
WSRC-TR-2004-00124, REVISION 0

\begin{tabular}{|c|c|c|c|c|c|c|c|}
\hline $\begin{array}{l}\text { Sample ID and } \\
\text { Depth of Sample }\end{array}$ & Actual & $\underline{\text { SRS East }}$ & $\underline{\text { SRS North }}$ & $\frac{\text { Dist(Actua }}{\underline{1})}$ & $\frac{\text { Prob(Actua }}{1)}$ & Plot Log(Prob) & Predicted \\
\hline DAB $924-6 \mathrm{ft}$ & Upland & 19717.73 & 63907.03 & 66.12819 & 0.9908 & & Upland \\
\hline DAB $9221 \mathrm{ft}$ & Upland & 19717.73 & 63907.03 & 63.66330 & 0.9363 & & Upland \\
\hline DAB $9223 \mathrm{ft}$ & Upland & 19717.73 & 63907.03 & 53.27497 & 0.8970 & & Upland \\
\hline DAB $8130 \mathrm{ft}$ & Upland & 18608.53 & 64335.39 & 67.18845 & 0.9854 & & Upland \\
\hline DAB $8145 \mathrm{ft}$ & Upland & 18608.53 & 64335.39 & 56.77335 & 0.9924 & & Upland \\
\hline DAB $8150 \mathrm{ft}$ & Upland & 18608.53 & 64335.39 & 66.89187 & 0.9976 & & Upland \\
\hline DAB $8332 \mathrm{ft}$ & Upland & 17252.27 & 64790.61 & 52.34673 & 0.8372 & & Upland \\
\hline DAB $8338 \mathrm{ft}$ & Upland & 17252.27 & 64790.61 & 52.34673 & 0.8372 & & Upland \\
\hline DAB $8342 \mathrm{ft}$ & Upland & 17252.27 & 64790.61 & 67.37177 & 0.9962 & & Upland \\
\hline DAB $8420 \mathrm{ft}$ & Upland & 17211 & 64389.99 & 56.77335 & 0.9924 & & Upland \\
\hline DAB $8428 \mathrm{ft}$ & Upland & 17211 & 64389.99 & 66.33681 & 0.9861 & & Upland \\
\hline DAB $8438 \mathrm{ft}$ & Upland & 17211 & 6438 & 61.83614 & 0.9511 & & Upland \\
\hline DAB $8733 \mathrm{ft}$ & Upland & 17670.53 & 64309.34 & 53.76716 & 0.9910 & & Upland \\
\hline DAB $8738 \mathrm{ft}$ & Upland & 17670.53 & 64309.34 & 52.34673 & 0.8372 & & Upland \\
\hline DAB $8753 \mathrm{ft}$ & Upland & 17670.53 & 64309.34 & 52.34673 & 0.8372 & & Upland \\
\hline G-10 & Wetland & 14808.48 & 63010.24 & 60.42786 & 0.9980 & & Wetland \\
\hline D-2 & Wetland & 14683.87 & 65824.63 & 63.09266 & 0.9995 & & Wetland \\
\hline D-4 & Wetland & 14477.71 & 65189.11 & 63.42609 & 0.9996 & & Wetland \\
\hline H-5 & Wetland & 15631.71 & 64483.6 & 57.60270 & 0.1030 & & Upland \\
\hline $\mathrm{J}-6$ & Wetland & 16162.52 & 63966.16 & 59.14601 & 0.9750 & & Wetland \\
\hline $\mathrm{K}-4$ & Wetland & 16676 & 64485.06 & 55.62161 & 0.1628 & & Upland \\
\hline
\end{tabular}

'*' indicates misclassified

\begin{tabular}{|lcc|}
\hline Counts: Actual Rows by Predicted & Upland & Wetland \\
\hline Columns & 15 & 0 \\
Upland & 2 & 4 \\
Wetland & 2 & 4 \\
\hline
\end{tabular}

Part 2 of 3, Discriminant Analysis by Region, Excluding Sampling Locations H-5 and K-4 from the Training Set

\section{Carbon Source Means by Region}

\begin{tabular}{|c|c|c|c|}
\hline Area & Upland & Wetland & $\underline{\text { All }}$ \\
\hline Number of Sampling Locations & 15 & 4 & 19 \\
\hline \multicolumn{4}{|l|}{$\%$ for Carbon Source } \\
\hline Polymers & 12 & 40 & 18 \\
\hline Carbohydrates & 12 & 55 & 21 \\
\hline Esters & 20 & 38 & 24 \\
\hline Carboxylic Acids & 17 & 43 & 22 \\
\hline Amides & 13 & 8 & 12 \\
\hline Amino Acids & 14 & 54 & 22 \\
\hline Aromatic Chemicals & 3 & 63 & 16 \\
\hline Amines & 7 & 42 & 14 \\
\hline Alcohols & 17 & 38 & 21 \\
\hline Phosphorylated Chemicals & 7 & 58 & 18 \\
\hline
\end{tabular}




\section{Canonical Plot of Sampling Locations for the First 2 Discriminant Factors}

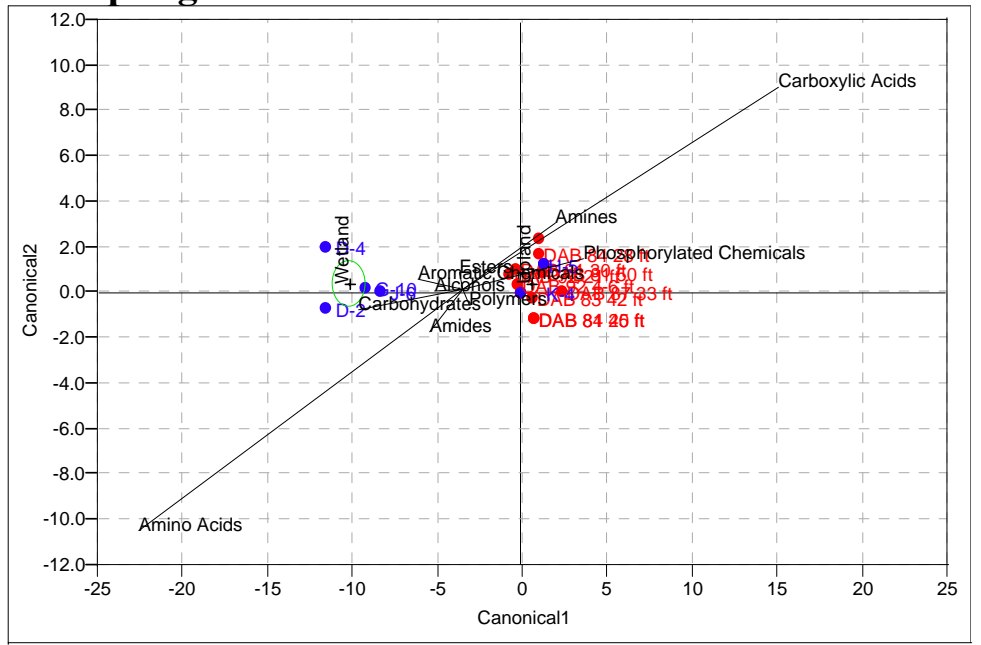

\section{Discriminant Scores}

\begin{tabular}{|ll|}
\hline Number Missclassified & 0 \\
Percent Misclassified & 0 \\
-2 LogLikelihood & 0 \\
\hline
\end{tabular}

\begin{tabular}{|lr|}
\hline & \multicolumn{2}{c|}{ Coefficient } \\
Eigenvectors & \multicolumn{1}{l|}{ Scores } \\
Polymers & 0.0175 \\
Carbohydrates & -0.2994 \\
Esters & -0.0046 \\
Carboxylic Acids & 0.8432 \\
Amides & -0.0808 \\
Amino Acids & -0.7675 \\
Aromatic Chemicals & -0.1632 \\
Amines & 0.2540 \\
Alcohols & -0.0481 \\
Phosphorylated & \\
Chemicals & 0.2259 \\
\hline
\end{tabular}

This discriminant analysis takes the 2 wetland groups that were classified as upland areas $\&$ removes them from the basis data set that creates the discrimant function. The discriminant function coefficients are given in the table above. Note that the carbolic acis $\&$ amino acids are still predominant. The weighting of the carbohydrates has fallen (relative two these other two predictors) nearly down to the level of mines \& phosphorylated chemicals. The canonical plot on the left show this. Remember that only the horizontal component is interpretable. Predictions are made for the 2 wetland wells $(\mathrm{H}-5$ \& K-4) that are not in the basis set used to create the discriminant function. Both still classify as upland wells 
WSRC-TR-2004-00124, REVISION 0

\begin{tabular}{|c|c|c|c|c|c|c|c|}
\hline $\begin{array}{l}\text { Sample ID and Depth of } \\
\text { Sample }\end{array}$ & $\underline{\text { Actual }}$ & $\underline{\text { SRS East }}$ & $\underline{\text { SRS North }}$ & $\frac{\text { Dist(Actua }}{\underline{1})}$ & $\frac{\operatorname{Prob}(\text { Actua }}{\underline{1)}}$ & $\underline{\text { Plot } \log (\text { Prob })}$ & $\underline{\text { Predicted }}$ \\
\hline DAB $924-6 \mathrm{ft}$ & Upland & 19717.73 & 63907.03 & 64.02570 & 1.0000 & & Upland \\
\hline DAB $9221 \mathrm{ft}$ & Upland & 19717.73 & 63907.03 & 62.34307 & 1.0000 & & Upland \\
\hline DAB $9223 \mathrm{ft}$ & Upland & 19717.73 & 63907.03 & 52.57484 & 1.0000 & & Upland \\
\hline DAB $8130 \mathrm{ft}$ & Upland & 18608.53 & 64335.39 & 64.93167 & 1.0000 & & Upland \\
\hline DAB $8145 \mathrm{ft}$ & Upland & 18608.53 & 64335.39 & 54.96029 & 1.0000 & & Upland \\
\hline DAB $8150 \mathrm{ft}$ & Upland & 18608.53 & 64335.39 & 64.13137 & 1.0000 & & Upland \\
\hline DAB $8332 \mathrm{ft}$ & Upland & 17252.27 & 64790.61 & 51.0 & 1.0000 & & Upland \\
\hline DAB $8338 \mathrm{ft}$ & Upland & 17252.27 & 64790.61 & 51.01007 & 1.0000 & & Upland \\
\hline DAB $8342 \mathrm{ft}$ & Upland & 17252.27 & 64790.61 & 64.33398 & 1.0000 & & Upland \\
\hline DAB $8420 \mathrm{ft}$ & Upland & 17211 & 64389.99 & 54.96029 & 1.0000 & & Upland \\
\hline DAB $8428 \mathrm{ft}$ & Upland & 17211 & 64389.99 & 63.83888 & 1.0000 & & Upland \\
\hline DAB $8438 \mathrm{ft}$ & Upland & 17211 & 64389.99 & 59.85359 & 1.0000 & & Upland \\
\hline DAB $8733 \mathrm{ft}$ & Upland & 17670.53 & 64309.34 & 55.37184 & 1.0000 & & Upland \\
\hline DAB $8738 \mathrm{ft}$ & Upland & 17670.53 & 64309.34 & $51 .($ & 1.0000 & & Upland \\
\hline DAB $8753 \mathrm{ft}$ & Upland & 17670.53 & 64309.34 & 51.0 & 1.0000 & & Upland \\
\hline G-10 & Wetland & 14808.48 & 63010.24 & 58.48613 & 1.0000 & & Wetland \\
\hline D-2 & Wetland & 14683.87 & 65824.63 & 60.00650 & 1.0000 & & Wetland \\
\hline D-4 & Wetland & 14477.71 & 65189.11 & 60.33676 & 1.0000 & & Wetland \\
\hline H-5 & Wetland & 15631.71 & 64483.6 & & & & Upland \\
\hline J-6 & Wetland & 16162.52 & 63966.16 & 59.59683 & 1.0000 & & Wetland \\
\hline $\mathrm{K}-4$ & Wetland & 16676 & 64485.06 & & & & Upland \\
\hline
\end{tabular}

'*' indicates misclassified

\begin{tabular}{|lcc|}
\hline Counts: Actual Rows by Predicted & Upland & Wetland \\
\hline Columns & 15 & 0 \\
Upland & 0 & 4 \\
Wetland & & \\
\hline
\end{tabular}

Part 3 of 3, Discriminant Analysis by Region, Reassigning Sampling Locations H-5 and K-4 to the Wetlands Region

Carbon Source Means by Region

\begin{tabular}{|c|c|c|c|}
\hline $\begin{array}{l}\text { Area } \\
\text { Number of Sampling Locations }\end{array}$ & $\frac{\text { Upland }}{17}$ & $\frac{\text { Wetland }}{4}$ & $\frac{\text { All }}{21}$ \\
\hline \multicolumn{4}{|l|}{$\%$ for Carbon Source } \\
\hline Polymers & 10.59 & 40.00 & 16.19 \\
\hline Carbohydrates & 11.29 & 55.25 & 19.67 \\
\hline Esters & 17.65 & 37.50 & 21.43 \\
\hline Carboxylic Acids & 14.94 & 42.75 & 20.24 \\
\hline Amides & 11.76 & 8.25 & 11.10 \\
\hline Amino Acids & 12.35 & 53.75 & 20.24 \\
\hline Aromatic Chemicals & 2.94 & 62.50 & 14.29 \\
\hline Amines & 5.88 & 41.75 & 12.71 \\
\hline Alcohols & 14.71 & 37.50 & 19.05 \\
\hline Phosphorylated Chemicals & 5.88 & 58.25 & 15.86 \\
\hline
\end{tabular}




\section{Canonical Plot of Sampling Locations for the First 2 Discriminant Factors}

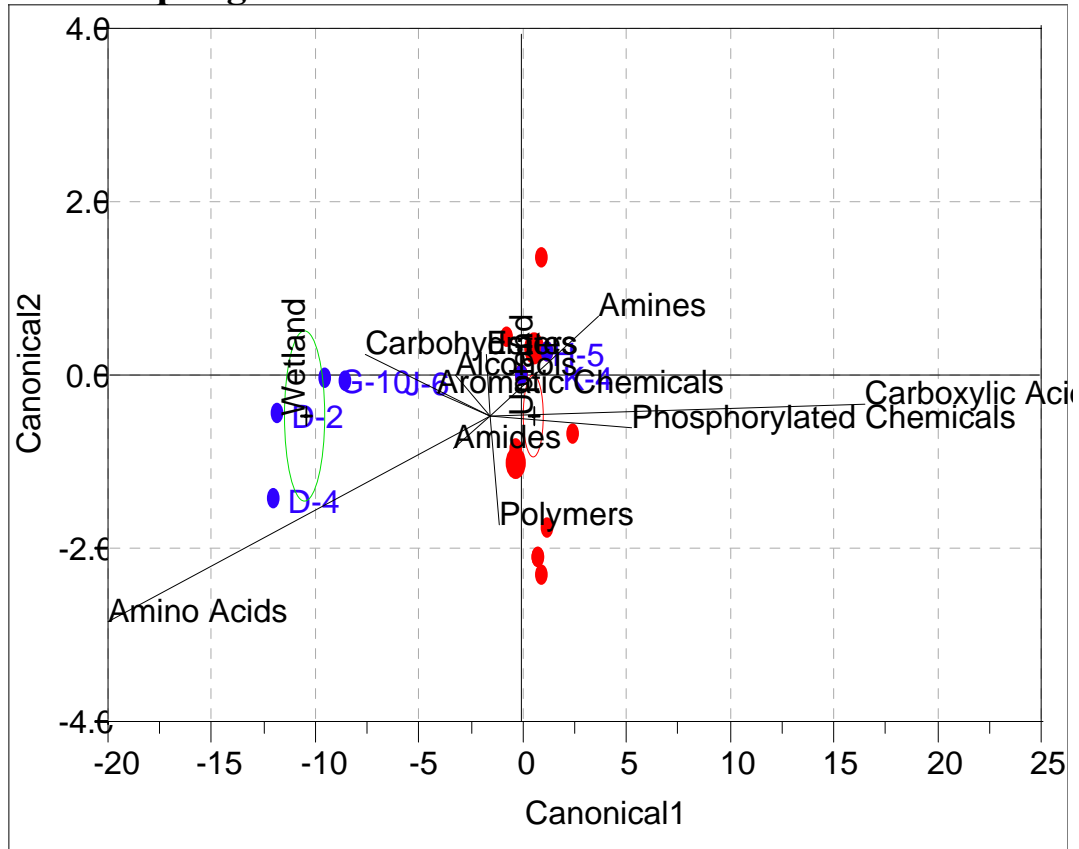

\section{Discriminant Scores}

\begin{tabular}{|ll|}
\hline Number Missclassified & 0 \\
Percent Misclassified & 0 \\
-2LogLikelihood & 0 \\
\hline
\end{tabular}

\begin{tabular}{|lc|}
\hline & Coefficient \\
Eigenvectors & $\underline{\underline{\text { Scores }}}$ \\
Polymers & 0.0198038 \\
Carbohydrates & -0.306494 \\
Esters & -0.005201 \\
Carboxylic Acids & 0.8490139 \\
Amides & -0.079055 \\
Amino Acids & -0.770392 \\
Aromatic Chemicals & -0.169592 \\
Amines & 0.2553354 \\
Alcohols & -0.049207 \\
Phosphorylated & \\
Chemicals & 0.2302248 \\
\hline
\end{tabular}

As a check, the 2 wetland wells (H-5 \& K-4) were reassigned as upland wells and a new discriminant function was created. The coefficient scores above show that carbolic acids \& amino acids are the most heavily weighted Biolog constituents. Carbohydrates, amines, \& aromatic chemicals are secondary 
WSRC-TR-2004-00124, REVISION 0

\begin{tabular}{|c|c|c|c|c|c|c|c|}
\hline $\begin{array}{l}\text { Sample ID and Depth of } \\
\text { Sample }\end{array}$ & Actual & $\underline{\text { SRS East }}$ & $\underline{\text { SRS North }}$ & $\frac{\operatorname{Dist}(\text { Actuc }}{1)}$ & $\frac{\operatorname{rob}(\text { Actua }}{1)}$ & Plot Log(Prob) & Predicted \\
\hline DAB $924-6 \mathrm{ft}$ & Upland & 19717.73 & 63907.03 & 64.99638 & 1.0000 & & Upland \\
\hline DAB $9221 \mathrm{ft}$ & Upland & 19717.73 & 63907.03 & 63.10531 & 1.0000 & & Upland \\
\hline DAB $9223 \mathrm{ft}$ & Upland & 19717.73 & 63907.03 & 51.05847 & 1.0000 & & Upland \\
\hline DAB $8130 \mathrm{ft}$ & Upland & 18608.53 & 64335.39 & 66.04712 & 1.0000 & & Upland \\
\hline DAB $8145 \mathrm{ft}$ & Upland & 18608.53 & 64335.39 & 54.83253 & 1.0000 & & Upland \\
\hline DAB $8150 \mathrm{ft}$ & Upland & 18608.53 & 64335.39 & 65.15841 & 1.0000 & & Upland \\
\hline DAB $8332 \mathrm{ft}$ & Upland & 17252.27 & 64790.61 & 49.87498 & 1.0000 & & Upland \\
\hline DAB $8338 \mathrm{ft}$ & Upland & 17252.27 & 64790.61 & 49.87498 & 1.0000 & & Upland \\
\hline DAB $8342 \mathrm{ft}$ & Upland & 17252.27 & 64790.61 & 65.35979 & 1.0000 & & Upland \\
\hline DAB $8420 \mathrm{ft}$ & Upland & 17211 & 64389.99 & 54.83253 & 1.0000 & & Upland \\
\hline DAB $8428 \mathrm{ft}$ & Upland & 17211 & 64389.99 & 64.46536 & 1.0000 & & Upland \\
\hline DAB $8438 \mathrm{ft}$ & Upland & 17211 & 64389.99 & 59.69228 & 1.0000 & & Upland \\
\hline DAB $8733 \mathrm{ft}$ & Upland & 17670.53 & 64309.34 & 54.89232 & 1.0000 & & Upland \\
\hline DAB $8738 \mathrm{ft}$ & Upland & 17670.53 & 64309.34 & 49.87498 & 1.0000 & & Upland \\
\hline DAB $8753 \mathrm{ft}$ & Upland & 17670.53 & 64309.34 & 49.87498 & 1.0000 & & Upland \\
\hline G-10 & Wetland & 14808.48 & 63010.24 & 58.61693 & 1.0000 & & Wetland \\
\hline D-2 & Wetland & 14683.87 & 65824.63 & 60.14682 & 1.0000 & & Wetland \\
\hline D-4 & Wetland & 14477.71 & 65189.11 & 60.80149 & 1.0000 & & Wetland \\
\hline H-5 & Upland & 15631.71 & 64483.6 & 51.05847 & 1.0000 & & Upland \\
\hline $\mathrm{J}-6$ & Wetland & 16162.52 & 63966.16 & 59.86155 & 1.0000 & & Wetland \\
\hline K-4 & Upland & 16676 & 64485.06 & 49.87498 & 1.0000 & & Upland \\
\hline & & & & & & & \\
\hline $\begin{array}{l}\text { Counts: Actual Row } \\
\text { Columns }\end{array}$ & & & land & etla & & & \\
\hline Upland & & & 17 & 0 & & & \\
\hline Wetland & & & 0 & 4 & & & \\
\hline
\end{tabular}

Contour Plots of the Posterior Probability that the Sampling Location is in the Upland Region

(a) Based on a Training Set of the Original Upland and Wetland Sampling Locations

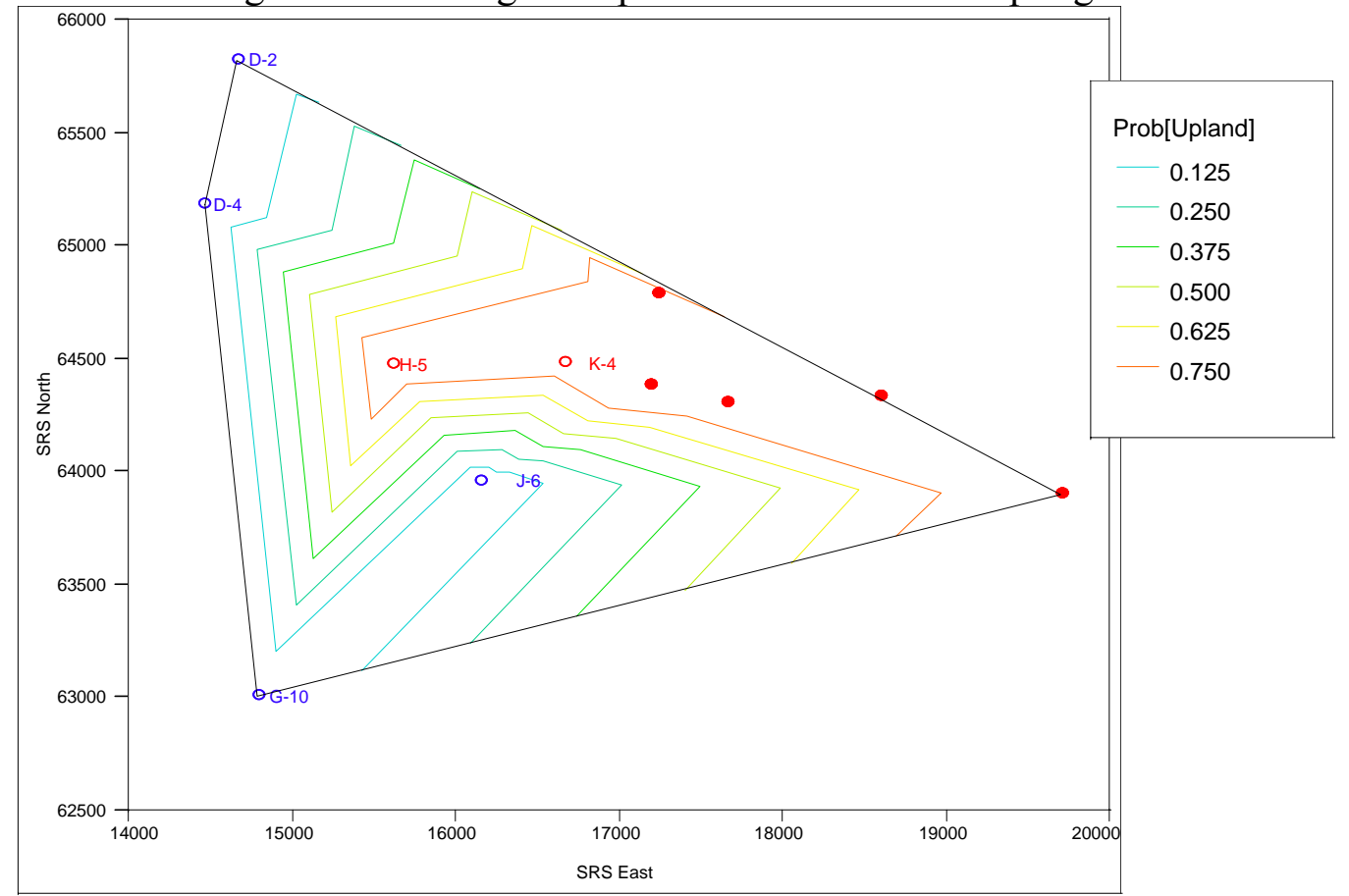


(b) Based on a Training Set that Excludes Sampling Locations H-5 and K-4 from the

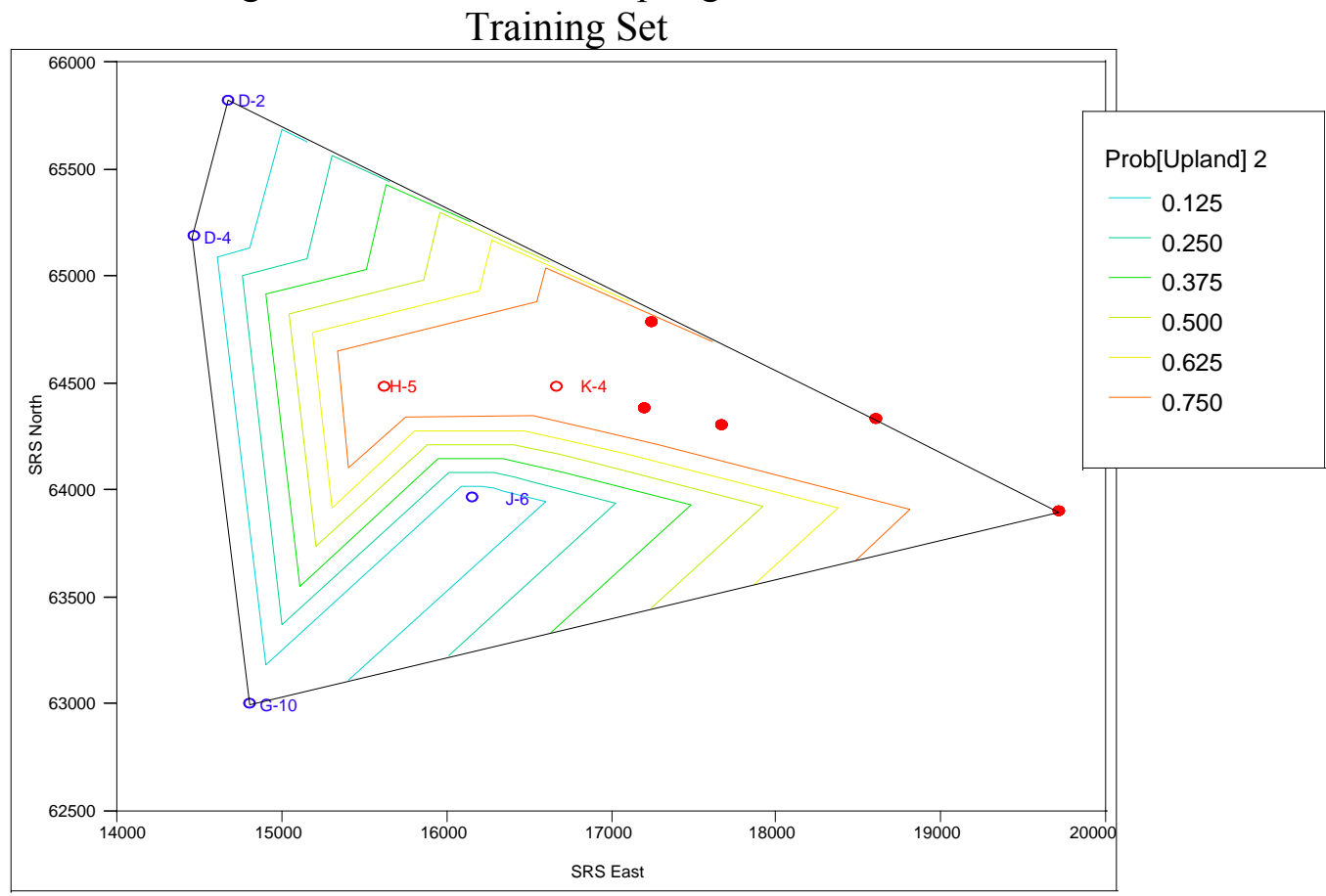

(c) Based on a Training Set that Reassigns Sampling Locations H-5 and K-4 to the Uplands

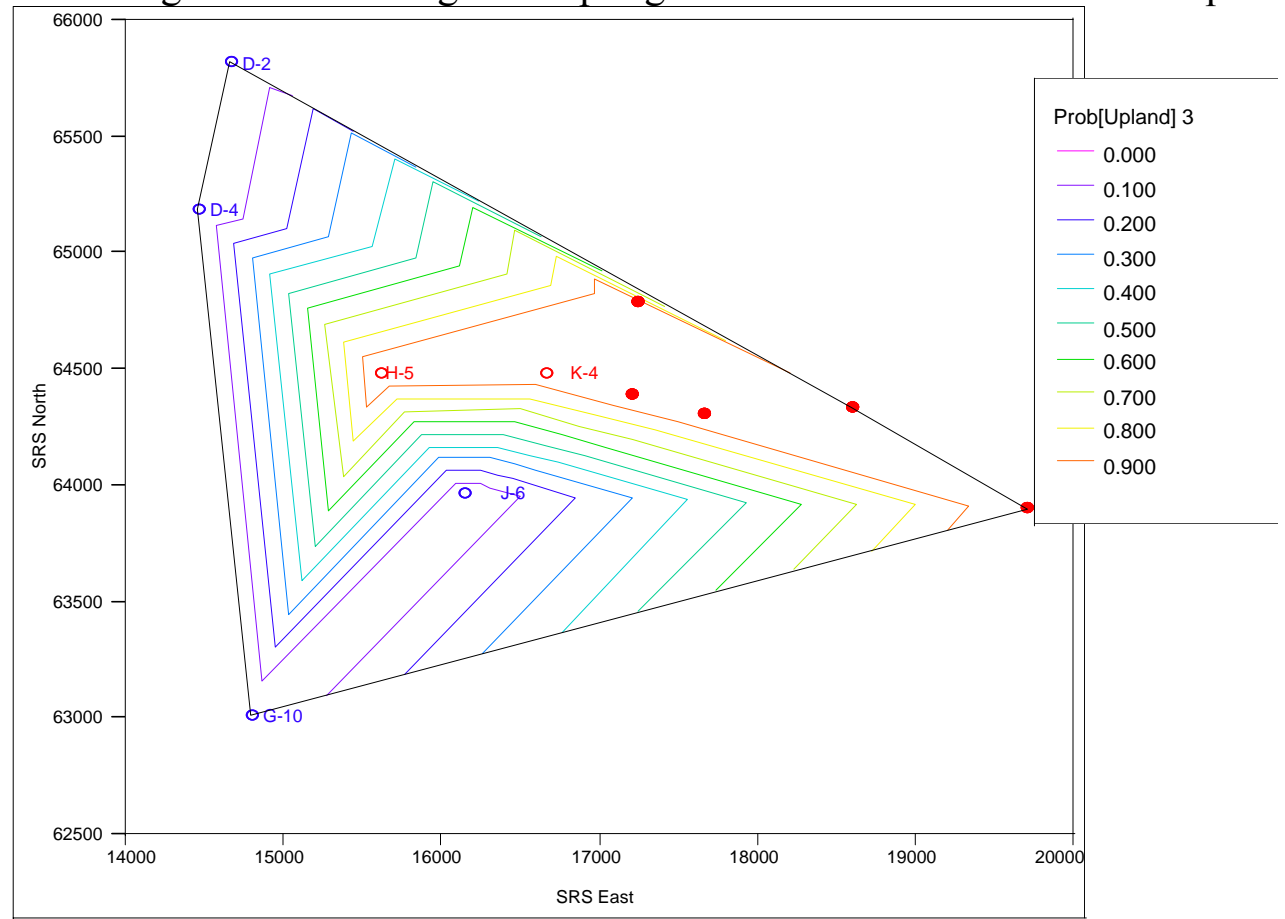


WSRC-TR-2004-00124, REVISION 0

Contour Plots of \% from Carbon Sources
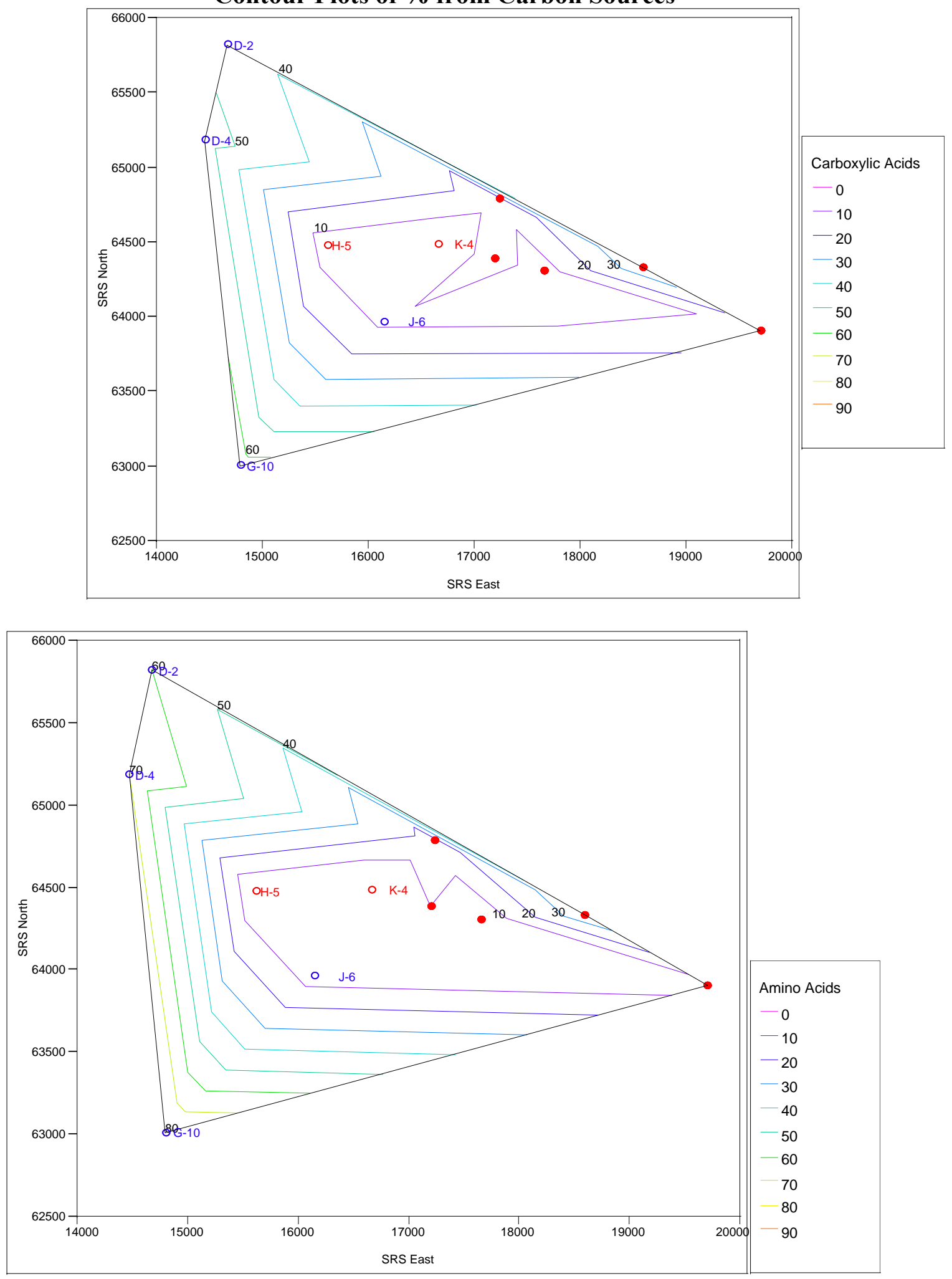
WSRC-TR-2004-00124, REVISION 0

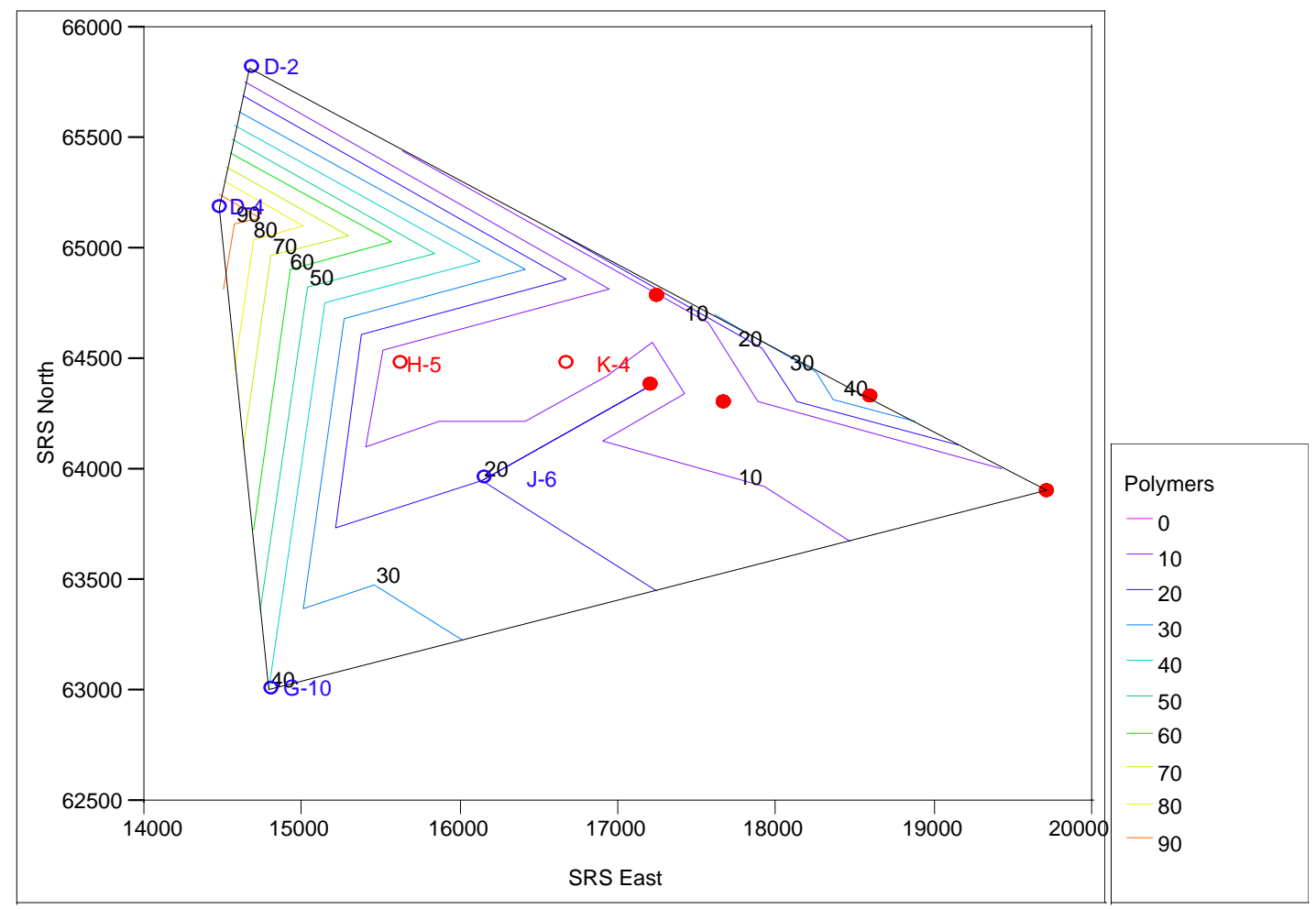


WSRC-TR-2004-00124, REVISION 0

\section{Contour Plots of \% from Carbon Sources}
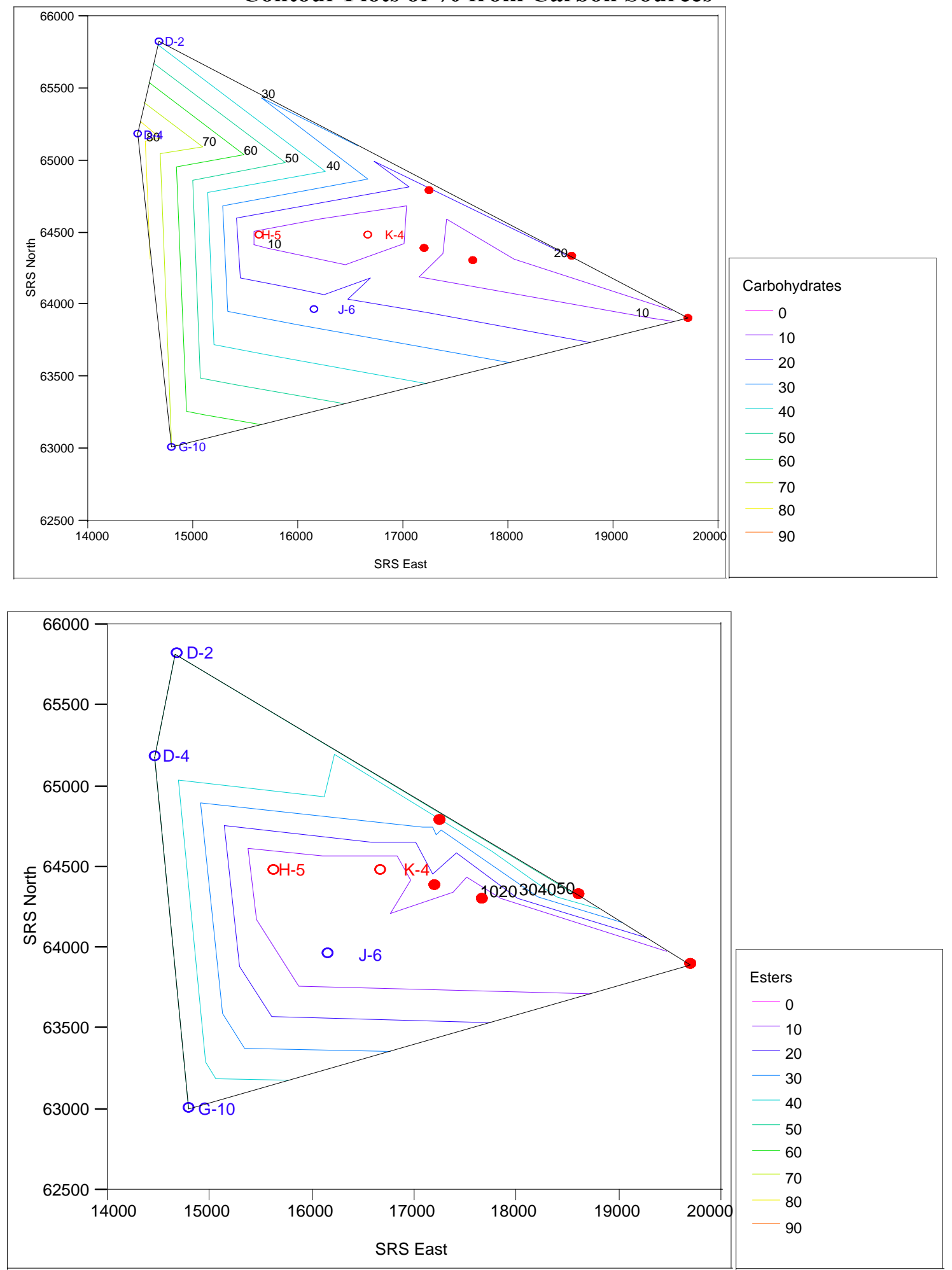
WSRC-TR-2004-00124, REVISION 0

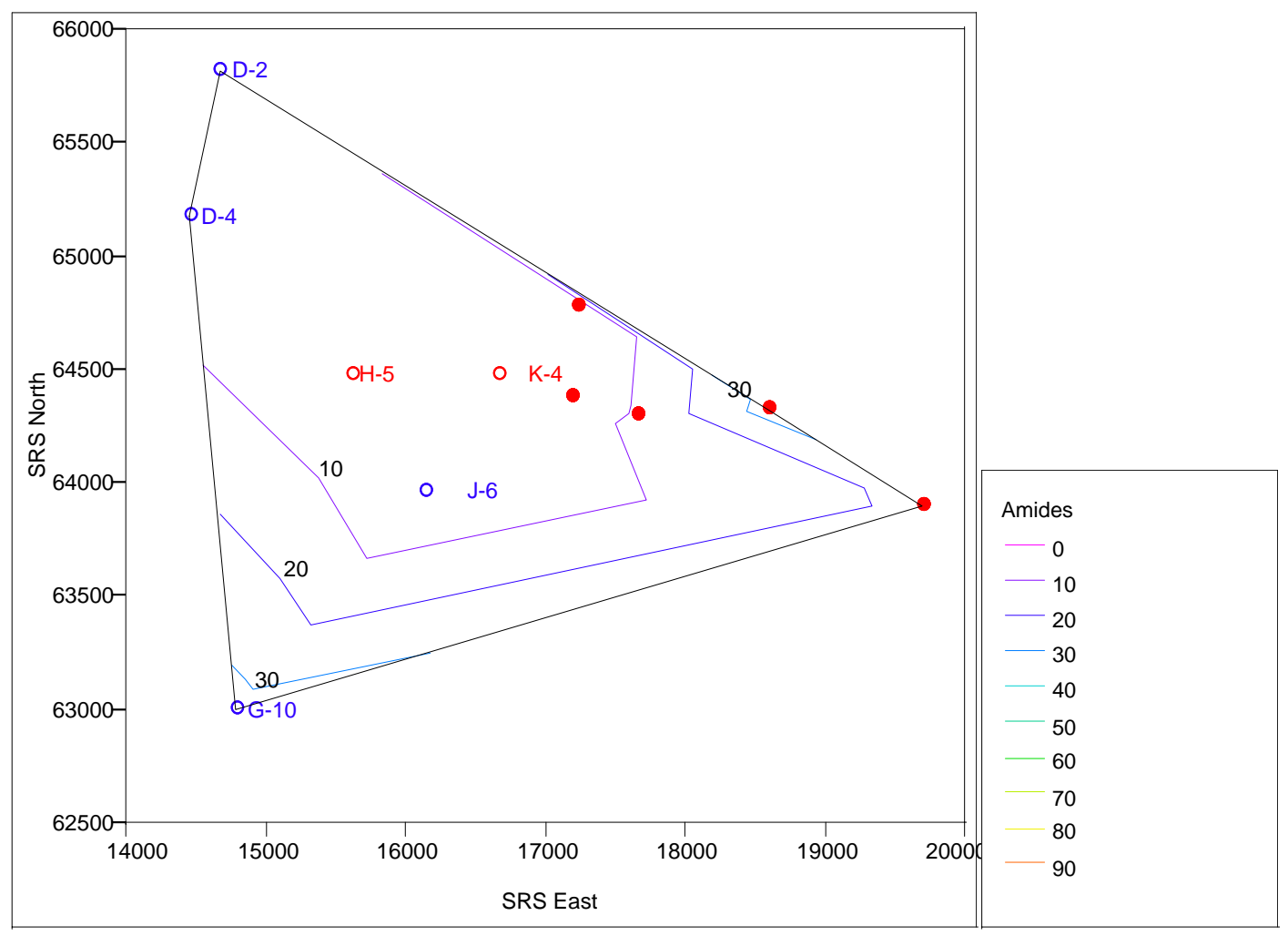

\section{Contour Plots of \% from Carbon Sources}

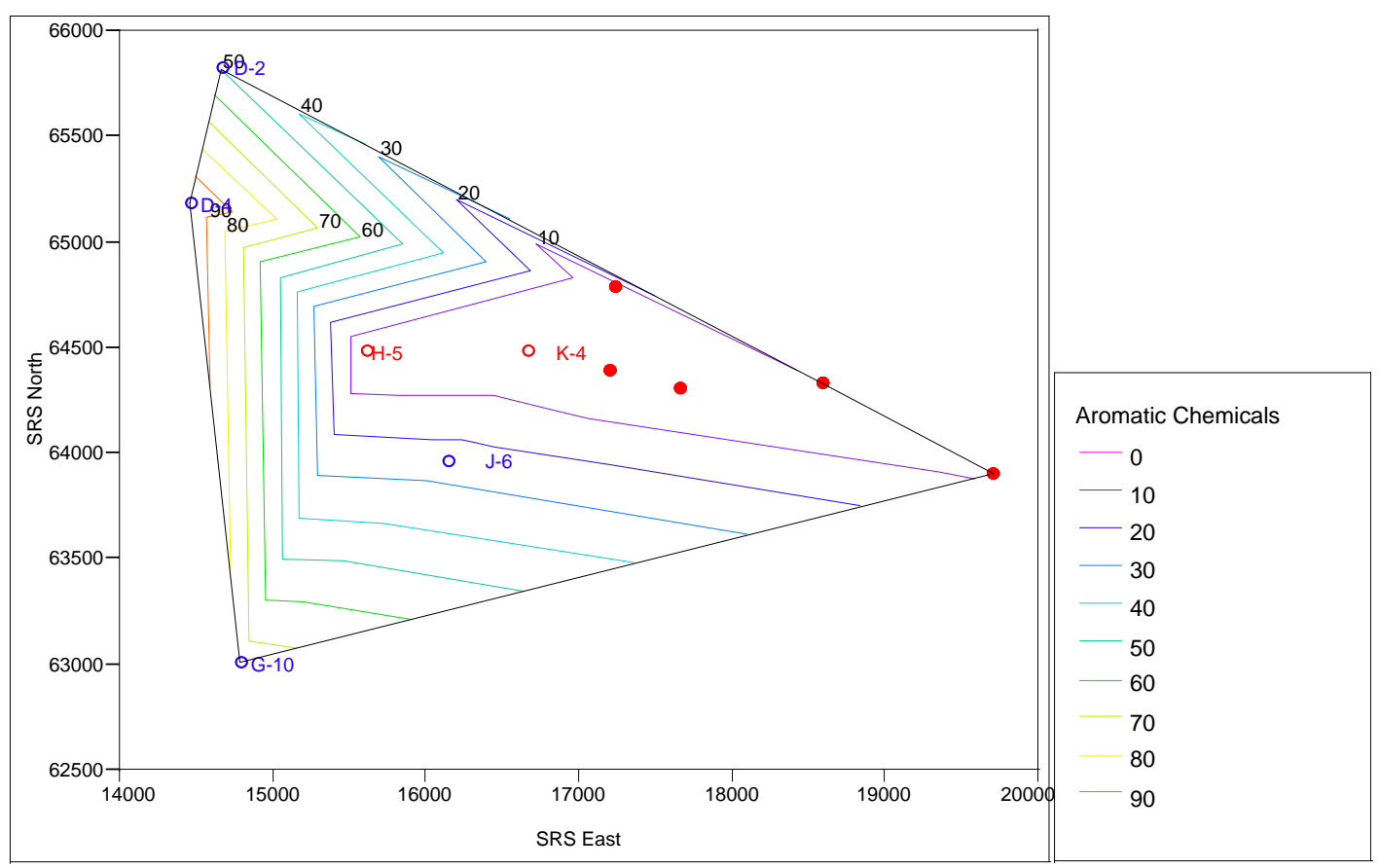


WSRC-TR-2004-00124, REVISION 0
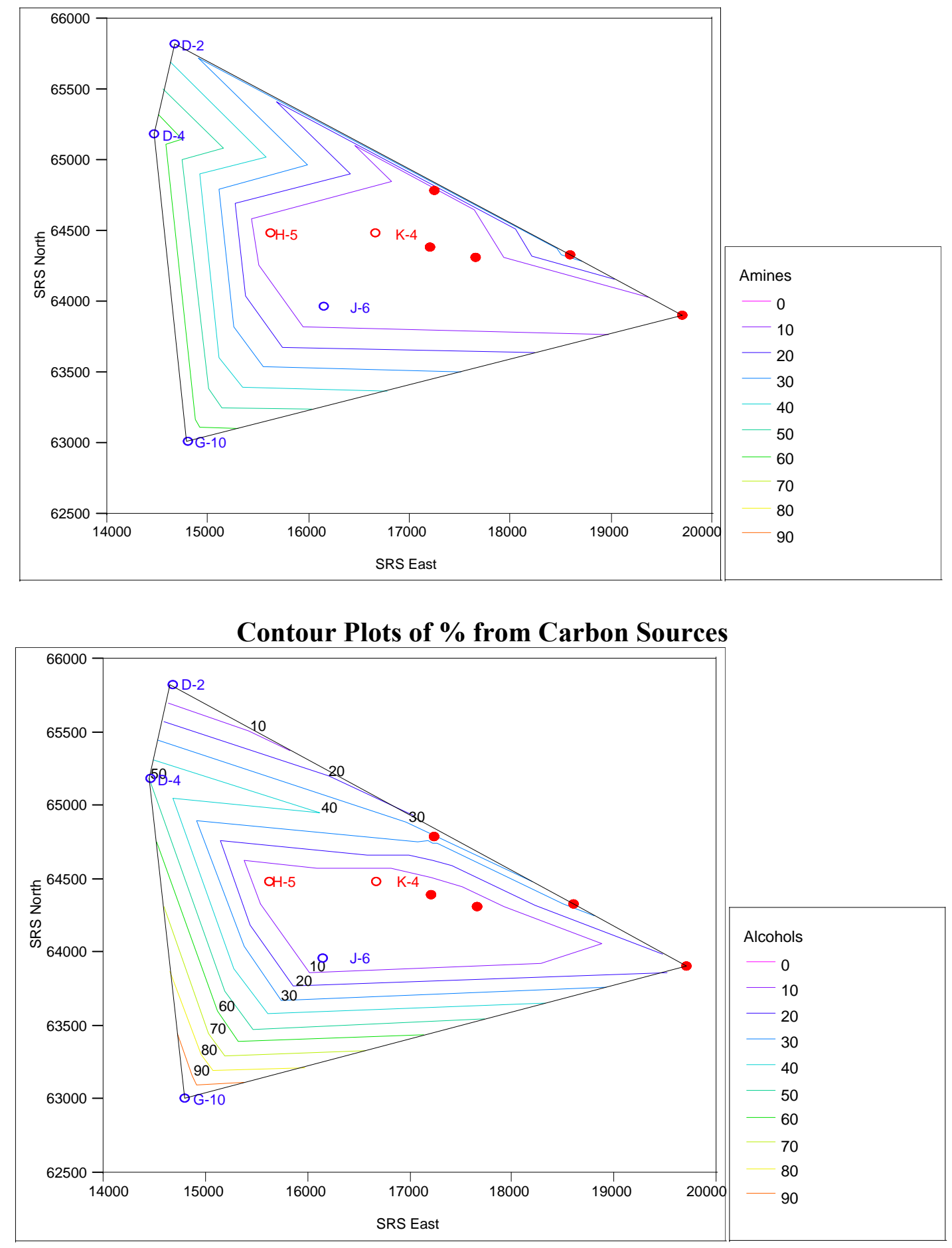
WSRC-TR-2004-00124, REVISION 0

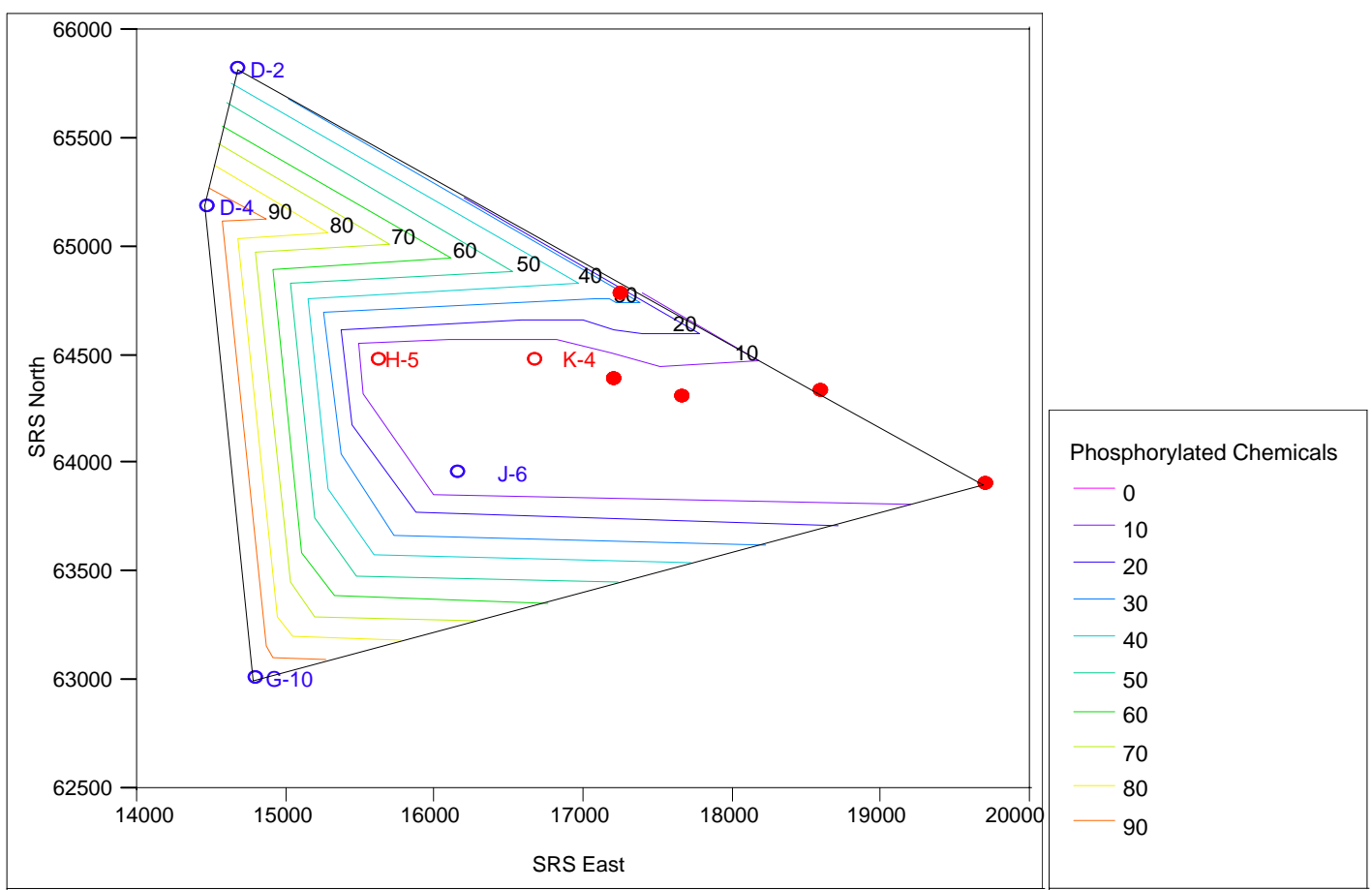




\section{APPENDIX E. D-AREA TREATABILITY STUDY WORK PLAN CROSSWALK}

\begin{tabular}{|c|c|c|c|}
\hline & $\begin{array}{l}\text { Treatability Study Work } \\
\text { Plan Objective }\end{array}$ & $\begin{array}{c}\text { DEXOU } \\
\text { MNA Report } \\
\text { Section }\end{array}$ & Comment \\
\hline 1 & Overall Objectives & & \\
\hline $\mathrm{a}$ & $\begin{array}{l}\text { Provide a technically } \\
\text { defensible definition of the } \\
\text { contaminant sources (heavy } \\
\text { metal and acidity) present at } \\
\text { D-Area by the following: } \\
\text { - Collecting samples in the } \\
\text { upland and wetland areas } \\
\text { impacted by coal plant } \\
\text { operations to evaluate the } \\
\text { quantity of metal } \\
\text { contaminants, redox } \\
\text { potential, and acidity } \\
\text { - Characterizing the } \\
\text { availability of inorganic } \\
\text { COCs using operationally } \\
\text { defined sequential } \\
\text { extraction techniques }\end{array}$ & $\begin{array}{l}2.2 \\
3.3 .1 \\
4.1 \\
4.2 \\
5.1 \\
6.2\end{array}$ & $\begin{array}{l}\text { The tendency of the sediments in the } \\
\text { operable unit to sorb Be, Ni, and U } \\
\text { followed well established geochemical } \\
\text { trends. Sediment sorption for U was } \\
\text { greater than for Ni, which in turn was } \\
\text { greater than for Be. Four methods } \\
\text { were used to measure COC } \\
\text { concentrations in soils including; an } \\
8 \text {-step sequential extraction (SE) } \\
\text { procedure, a single step extraction } \\
\text { corresponding to the amorphous iron } \\
\text { oxide step }\left(6^{\text {th }} \mathrm{SE} \text { step), EPA method }\right. \\
3050 \mathrm{~b} \text {, and total digestion. In general, } \\
\text { data from the single step extraction and } \\
\text { SE steps } 1-6 \text { were comparable, as was } \\
\text { total digestion and SE steps } 1-8 \text {. The } \\
\text { EPA method is aggressive and may } \\
\text { overestimate the metal fraction } \\
\text { available for transport. }\end{array}$ \\
\hline
\end{tabular}


WSRC-TR-2004-00124, REVISION 0

\begin{tabular}{|c|c|c|}
\hline $\begin{array}{l}\text { Treatability Study Work } \\
\text { Plan Objective }\end{array}$ & $\begin{array}{c}\text { DEXOU } \\
\text { MNA Report } \\
\text { Section }\end{array}$ & Comment \\
\hline $\begin{array}{l}\text { b Provide data that can be used } \\
\text { to model the attenuation } \\
\text { capacity of the aquifer system } \\
\text { at D-Area for metal } \\
\text { contaminants and acidity. } \\
\text { This part of the study will be } \\
\text { designed to collect data to } \\
\text { quantify the relative } \\
\text { contributions of geochemical } \\
\text { and microbial processes (as } \\
\text { well as the interactions } \\
\text { between these two processes) } \\
\text { in the attenuation observed at } \\
\text { D-Area. The overall } \\
\text { objective of this portion of the } \\
\text { Treatability Study is to } \\
\text { determine the predominant } \\
\text { mechanisms, both abiotic and } \\
\text { biotic, controlling the } \\
\text { attenuation of inorganic } \\
\text { COCs at D-Area. }\end{array}$ & $\begin{array}{l}2.2 \\
3.3 .2 \\
3.4 \\
5.1 \\
6.0\end{array}$ & $\begin{array}{l}\text { Significant MNA is occurring at the } \\
\text { study site. This was directly observed } \\
\text { by significant decreases in the COC } \\
\text { (Be, Ni, U, and As) concentrations as a } \\
\text { function of distance from the respective } \\
\text { point sources in the operable unit. } \\
\text { Sediments were found to have a large } \\
\text { tendency to sorb all four COCs, i.e., } \\
\text { they had large distribution coefficients, } \\
\text { Kd values. COC sorption was strongly } \\
\text { pH dependent. Importantly, because } \\
\text { the sediments appear to have a high } \\
\text { buffering capacity for the acid } \\
\text { emanating from the D-Area Coal Pile } \\
\text { Runoff Basin, much of the site has } \\
\text { quite high Kd values. Increasing } \\
\text { microbial densities evident in the } \\
\text { wetlands can be correlated to greater } \\
\text { biomass and diversity. The more } \\
\text { biomass present in a system the higher } \\
\text { metal sorption and biotransfor-mation } \\
\text { that occurs. Attenuation of pH and } \\
\text { sulfate was also demonstrated in the } \\
\text { wetlands. In the wetlands there are two } \\
\text { potential sources of contaminants, from } \\
\text { surface deposition as well as emerging } \\
\text { plumes from the coal piles. }\end{array}$ \\
\hline \multicolumn{3}{|l|}{2 Geochemical Processes } \\
\hline $\begin{array}{l}\text { a Identify the controlling } \\
\text { geochemical attenuation } \\
\text { mechanisms in the distal } \\
\text { portion of the plume. }\end{array}$ & $\begin{array}{l}2.2 \\
6.0\end{array}$ & $\begin{array}{l}\text { A large capacity for geochemical } \\
\text { attenuation exists near source areas for } \\
\text { As, U, Ni, and Be. With the exception } \\
\text { of Be all COCs are below MCLs before } \\
\text { reaching the wetland. More biological } \\
\text { activity in the wetlands may indicate a } \\
\text { departure from geochemical dominated } \\
\text { behavior. Elucidating geochemical } \\
\text { attenuation mechanisms in the wetlands } \\
\text { is complicated by ash dumped into the } \\
\text { wetlands which represents another } \\
\text { source distinct from the groundwater } \\
\text { plume. However, the wetlands exhibit } \\
\text { a high capacity for attenuation as } \\
\text { evidenced by high Kds for the COCs. }\end{array}$ \\
\hline
\end{tabular}


WSRC-TR-2004-00124, REVISION 0

\begin{tabular}{|c|c|c|}
\hline $\begin{array}{l}\text { Treatability Study Work } \\
\text { Plan Objective }\end{array}$ & $\begin{array}{l}\text { DEXOU } \\
\text { MNA Report } \\
\text { Section }\end{array}$ & Comment \\
\hline $\begin{array}{l}\text { b Collect data (e.g., } \\
\text { groundwater } \mathrm{pH}, \mathrm{E}_{\mathrm{h}} \text {, metals } \\
\text { concentrations) to develop an } \\
\text { understanding of the changes } \\
\text { in geochemical attenuation } \\
\text { along the groundwater flow } \\
\text { path. }\end{array}$ & $\begin{array}{l}4.2 \\
5.1 \\
6.2 .1 \\
6.2 .2 \\
6.2 .3\end{array}$ & $\begin{array}{l}\text { Geochemical parameters follow } \\
\text { expected trends for attenuation, i.,e., } \\
\text { increasing } \mathrm{pH} \text {, decreasing Eh and } \\
\text { decreasing pore water concentrations of } \\
\text { COCs with increasing distance from } \\
\text { the source and depth. }\end{array}$ \\
\hline $\begin{array}{l}\text { c From field data, develop site- } \\
\text { specific transport factors } \\
\text { (sorption coefficients) along } \\
\text { the groundwater flow path. }\end{array}$ & 6.3 & $\begin{array}{l}\text { The tendency of the sediments in the } \\
\text { operable unit to sorb Be, Ni, and U } \\
\text { followed well established geochemical } \\
\text { trends. Sediment sorption for U was } \\
\text { greater than for Ni, which in turn was } \\
\text { greater than for Be. Furthermore, over } \\
\text { the range of pH } 3 \text { to } 8 \text {, there was a } \\
\text { significant logarithmic trend with in } \\
\text { situ Kd values (for U the pH range was } \\
3 \text { to 5.5). Arsenic, an anion, sorbed } \\
\text { exceptionally strongly to wetland } \\
\text { sediments (Kd values }>10,000 \text { mL/g). } \\
\text { This is important because the wetland } \\
\text { sediments may act as an As-sorbing } \\
\text { zone. Arsenic also sorbed strongly to } \\
\text { aquifer sediments, albeit less strongly } \\
\text { than the wetland sediment. Based on } \\
\text { selective extraction procedures, it is } \\
\text { postulated that the numerous Fe } \\
\text { minerals in these sediments are } \\
\text { responsible for much of the sorption } \\
\text { capacity for the COCs. Arsenic may be } \\
\text { bound to the sediment's natural organic } \\
\text { matter and Fe phases (perhaps as solid } \\
\text { solutions, i.e., poorly defined Fe } \\
\text { precipitates). }\end{array}$ \\
\hline $\begin{array}{l}\text { d Characterize the soil } \\
\text { geochemistry (e.g., sorption } \\
\text { capacity and mineralogy) at } \\
\text { the site and the manner in } \\
\text { which these properties relate } \\
\text { to sorption processes for } \\
\text { COCs. }\end{array}$ & 5.1 .2 & $\begin{array}{l}\text { Soil mineralogy and its relation to } \\
\text { sorption processes was characterized } \\
\text { by the measurement of COCs } \\
\text { associated with each phase defined by a } \\
\text { sequential extraction procedure as } \\
\text { described in } 3 \mathrm{c} \text { above. } \\
\text { Characterization of soil texture, cation } \\
\text { and anion exchange capacity, and } \\
\text { extractable } \mathrm{Al} \text {, Fe was also performed. }\end{array}$ \\
\hline
\end{tabular}


WSRC-TR-2004-00124, REVISION 0

\begin{tabular}{|c|c|c|}
\hline $\begin{array}{l}\text { Treatability Study Work } \\
\text { Plan Objective }\end{array}$ & $\begin{array}{l}\text { DEXOU } \\
\text { MNA Report } \\
\text { Section }\end{array}$ & Comment \\
\hline $\begin{array}{l}\text { evaluate the metal availability } \\
\text { of the source contamination } \\
\text { for its transport from upland } \\
\text { and wetland sediments into } \\
\text { groundwater or surface water } \\
\text { systems. }\end{array}$ & $\begin{array}{l}3.3 \\
5.1 .3 \\
6.2 \\
6.3\end{array}$ & $\begin{array}{l}\text { Section } 6.2 \text { is a discussion of COC } \\
\text { concentrations and their availability. } \\
\text { Section } 6.3 \text { summarizes Kds for COCs } \\
\text { based on available metal fraction in } \\
\text { soil. Figures } 42-45 \text { plot COC Kds vs } \\
\text { pH based on the available fraction. }\end{array}$ \\
\hline $\begin{array}{l}\text { f In conjunction with the } \\
\text { microbial processes portion of } \\
\text { this Treatability Study, } \\
\text { develop an understanding of } \\
\text { the manner in which } \\
\text { geochemical conditions affect } \\
\text { microbial communities and } \\
\text { the manner in which } \\
\text { microbial processes impact } \\
\text { the site geochemistry with } \\
\text { respect to site-specific } \\
\text { transport factors. }\end{array}$ & $\begin{array}{l}5.2 \\
5.3 \\
6.4\end{array}$ & $\begin{array}{l}\text { The contaminants at this site are not at } \\
\text { concentrations particularly toxic to } \\
\text { bacteria. In fact bacteria were found at } \\
\text { all locations in relatively high numbers. } \\
\text { Just as the BIOLOG plates were found } \\
\text { to buffer pH, biomass and associated } \\
\text { proteins and carbohydrate production } \\
\text { buffer groundwater. }\end{array}$ \\
\hline 3 Microbial Processes & & \\
\hline $\begin{array}{l}\text { a Determine whether direct } \\
\text { monitoring of highly selected } \\
\text { microbiological parameters } \\
\text { can serve as a surrogate for } \\
\text { defining the capacity of } \\
\text { natural attenuation. }\end{array}$ & $\begin{array}{l}4.3 \\
5.2 \\
5.3 \\
6.4\end{array}$ & $\begin{array}{l}\text { Ecofunctional enzyme activity and } \\
\text { limited microbial isolations did show } \\
\text { correlation of select microbial activity } \\
\text { with location in the plume. }\end{array}$ \\
\hline $\begin{array}{l}\text { b Evaluate the contribution of } \\
\text { naturally occurring } \\
\text { microorganisms to the } \\
\text { attenuation of metals } \\
\text { concentrations and the low- } \\
\text { pH groundwater at D-Area } \\
\text { groundwater and surface } \\
\text { water plumes. }\end{array}$ & $\begin{array}{l}4.3 \\
5.2 \\
5.3 \\
6.4\end{array}$ & $\begin{array}{l}\text { Indirect evidence indicates density } \\
\text { shifts and different microbial } \\
\text { populations along contaminant } \\
\text { gradients. }\end{array}$ \\
\hline $\begin{array}{l}\text { c Determine the concentration } \\
\text { of the bacterial components of } \\
\text { the community present in D- } \\
\text { Area groundwater plume and } \\
\text { determine if the bacterial } \\
\text { communities are associated } \\
\text { with the porewater, } \\
\text { sediments, or wetland } \\
\text { habitats. }\end{array}$ & $\begin{array}{l}4.3 \\
5.2\end{array}$ & $\begin{array}{l}\text { Microbial concentrations were } \\
\text { determined in only sediment porewater } \\
\text { for this project. }\end{array}$ \\
\hline
\end{tabular}


WSRC-TR-2004-00124, REVISION 0

\begin{tabular}{|c|c|c|c|}
\hline & $\begin{array}{l}\text { Treatability Study Work } \\
\text { Plan Objective }\end{array}$ & $\begin{array}{l}\text { DEXOU } \\
\text { MNA Report } \\
\text { Section }\end{array}$ & Comment \\
\hline $\mathrm{d}$ & $\begin{array}{l}\text { Characterize bacterial } \\
\text { populations present and assess } \\
\text { their activity with respect to } \\
\text { D-Area plume. }\end{array}$ & $\begin{array}{l}4.3 \\
5.2 \\
5.3 \\
6.4\end{array}$ & $\begin{array}{l}\text { Microbial activity was closely linked to } \\
\text { location and geochemistry. } \\
\text { Heterogeneity of microbial and } \\
\text { geochemistry in subsurface sediments } \\
\text { in upland as compared to wetland was } \\
\text { evident. Greater diversity with } \\
\text { distance from source. }\end{array}$ \\
\hline $\mathrm{e}$ & $\begin{array}{l}\text { Investigate the correlation } \\
\text { between presence, density and } \\
\text { activity of identified bacteria } \\
\text { and natural attenuation of D- } \\
\text { Area plume using selected } \\
\text { immunoprobes. }\end{array}$ & & $\begin{array}{l}\text { No microbes isolated that probes were } \\
\text { available for. }\end{array}$ \\
\hline$f$ & $\begin{array}{l}\text { Determine the activity of } \\
\text { selected naturally occurring } \\
\text { microorganisms to reduce } \\
\text { heavy metal concentrations, } \\
\text { reduce sulfate concentrations, } \\
\text { and increase pH values using } \\
\text { selected sequential extraction } \\
\text { techniques. }\end{array}$ & & $\begin{array}{l}\text { Specific reduction tests not done with } \\
\text { extractions do to extra labor involved. }\end{array}$ \\
\hline $\mathrm{g}$ & $\begin{array}{l}\text { Evaluate the effects of } \\
\text { naturally occurring } \\
\text { microorganisms on the } \\
\text { sequestration or removal of } \\
\text { metal contaminants (thus the } \\
\text { naturally occurring } \mathrm{K}_{\mathrm{d}} \mathrm{s} \text { ) } \\
\text { following modification of the } \\
\text { mineral phases in the soil by } \\
\text { sequential extraction. }\end{array}$ & & $\begin{array}{l}\text { Specific metal removal tests not done } \\
\text { with extractions do to extra labor } \\
\text { involved. }\end{array}$ \\
\hline
\end{tabular}


This page intentionally left blank. 


\section{DISTRIBUTION}

J. C. Black

R. F. Blundy

R. L. Brigmon

B. T. Butcher

K. P. Crapse

M. A. Heitkamp

D. I. Kaplan

A. S. Knox

P. C. McKinsey

A. L. Pishko

W. J. Rice

J. A. Ross

S. M. Serkiz

E. P. Shine

R. P. Socha, 4 copies

W. E. Stevens

R. S. Vanpelt

G. R. Wein

STI, 4 copies

WPT File
$735 \mathrm{~A}$

$730-2 \mathrm{~B}$

999-W

773-43A

773-43A

999-W

773-43A

773-42A

999-W

735-11A

730-2B

$730-2 \mathrm{~B}$

$773 \mathrm{~A}$

773-42A

$730-2 \mathrm{~B}$

$773 \mathrm{~A}$

730-2B

730-2B

703-43A

773-43A 